\title{
FEMINISMO/S 24
}

Género y humor en

discursos de mujeres y hombres

G. Angela Mura

y Leonor Ruiz Gurillo (editoras)

La mujer tiene un gran sentido del humor, pero evita reírse porque le salen
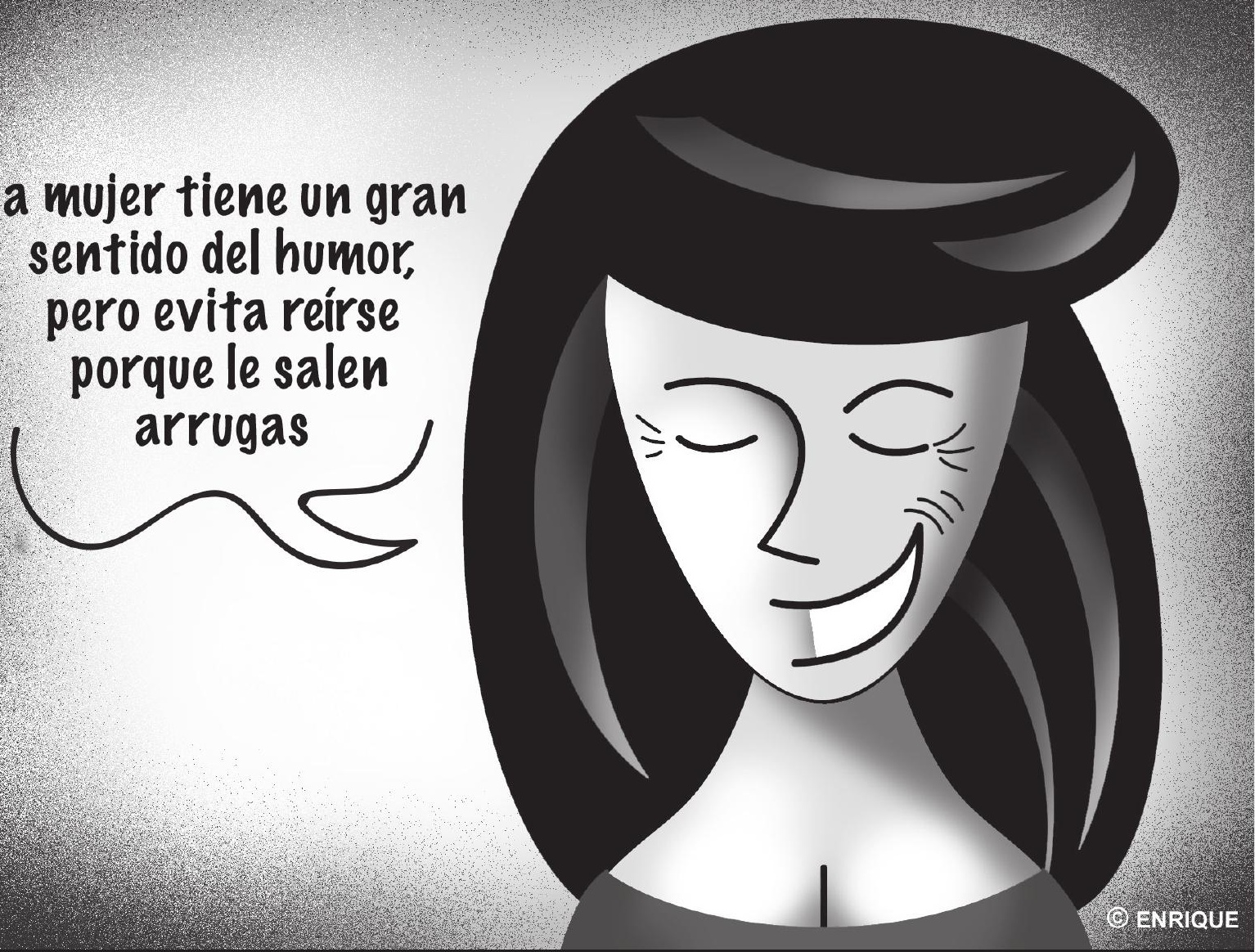



\title{
FEMINISMO/S
}

Revista del Instituto Universitario de Estudios de Género de la Universidad de Alicante Número 24, diciembre de 2014

\section{Género y humor en discursos de mujeres y hombres}

\author{
G. Angela Mura y Leonor Ruiz Gurillo (editoras)
}





\title{
FEMINISMO/S \\ Revista del Instituto Universitario de Estudios de Género de la Universidad de Alicante
}

\author{
Revista Semestral \\ Editada por el Instituto Universitario de Estudios de Género de la Universidad de Alicante \\ con la colaboración del Vicerrectorado de Cultura, Deporte y Política Lingüística
}

Número 24, diciembre de 2014

Directora: Helena EstABLIER PÉREZ (Universidad de Alicante)

Secretaria: Maribel PeÑAlVER ViCEA (Universidad de Alicante)

\section{CONSEJO DE REDACCIÓN}

Mónica Moreno SeCo (Universidad de Alicante)

Nieves MONTESINOS SÁNCHEZ (Universidad de Alicante)

Mar ESQUEMBRE VALDÉS (Universidad de Alicante)

$\mathrm{M}^{\mathrm{a}}$ Teresa RuIz CANTERo (Universidad de Alicante)

Carmen MAÑas Viejo (Universidad de Alicante)

Purificación Heras GONZÁLEz (Universidad Miguel Hernández)

Carmen Olaria DE GUSI (Universitat Jaume I)

$\mathrm{M}^{a}$ Dolores Ramos (Universidad de Málaga)

\section{CONSEJO ASESOR}

Nieves BARANDA LETURIO (UNED)

Mabel Burín (Universidad de Buenos Aires)

Silvia CAPORALE Bizzini (Universidad de Alicante)

Angels CARABí (Universidad de Barcelona)

Pilar CUder Domínguez (Universidad de Huelva)

Joaquín DE JUAN (Universidad de Alicante)

$\mathrm{M}^{\mathrm{a}}$ José FraU (Universidad de Alicante)

Eddy GIL DE MEjÍA (Fachhochschule Oldenburg)

$\mathrm{M}^{\mathrm{a}}$ Victoria GoRDiLlo (Universidad Complutense de Madrid)

Albert GRAS (Universidad de Alicante)

Marina MAYORAL (Universidad Complutense de Madrid)

Montserrat PALAU (Universitat Rovira i Virgil)

$\mathrm{M}^{\mathrm{a}}$ Dolores Reventós (Universidad de Murcia)

Carmen RiERA (Universidad de Barcelona)

Ana SÁNCHEZ TORRES (Universidad de Valencia)

Begoña SAN Miguel DEL Hoyo (Universidad de Alicante)

Marta SegarRa (Universidad de Barcelona)

Cristina Segura (Universidad Complutense de Madrid)

Julia Sevilla (Universidad de Valencia)

$\mathrm{M}^{\mathrm{a}}$ Carmen SIMÓN (CSIC)

Ruth TeubÁl (Universidad de Buenos Aires)

Meri TORRAS (Universidad de Barcelona) 


\title{
REDACCIÓN
}

Instituto Universitario de Estudios de Género de la Universidad de Alicante

Campus de Sant Vicent del Raspeig

Apdo. 99 E-03080 Alicante

Tel. 965909415 - Fax 965909658

e-mail: revistafeminismos@ua.es; iuieg@ua.es - web: http://ieg.ua.es

\section{SUSCRIPCIÓN}

Instituto Universitario de Estudios de Género de la Universidad de Alicante Campus de Sant Vicent del Raspeig Apdo. 99 E-03080 Alicante

Tel. 965909415 - Fax 965909658

e-mail: iuieg@ua.es -web: http://ieg.ua.es

Precio de cada ejemplar: $12 €$

\author{
Publicaciones de la Universidad de Alicante \\ Campus de San Vicente s/n \\ 03690 San Vicente del Raspeig \\ publicaciones@ua.es \\ http://publicaciones.ua.es \\ Teléfono: 965903480
}

\section{Edita:}

Instituto Universitario de Estudios de Género de la Universidad de Alicante con la colaboración del Vicerrectorado de Cultura, Deporte y Política Lingüística Cuenta con una Ayuda para la Publicación de Revistas Científicas del Vicerrectorado de Investigación, Desarrollo e Innovación

\section{ISSN: $1696-8166$}

DOI: $10.14198 / \mathrm{fem} .2014 .24$

Depósito legal: A-910-2003

Diseño de cubierta: candela ink

Ilustración de cubierta: Enrique Pérez, Gabinete de Imagen y Comunicación Gráfica de la Universidad de Alicante Maquetación: Marten Kwinkelenberg Impresión: Guada Impresores

Feminismo/s no se identifica necesariamente con los contenidos de los artículos firmados. Prohibida la reproducción total o parcial de los artículos sin la autorización previa.

Feminismo/s se encuentra indexada en las bases de datos de ERIH, ISOC-CINDOC y LATINDEX. También se encuentra recogida en DICE, In-RECS y MLA. 


\section{INDEX /ÍNDICE}

G. Angela Mura y Leonor Ruiz Gurillo

Introducción.

9

Introduction

\section{LA INTERACCIÓN CONVERSACIONAL}

M. Belén Alvarado Ortega

Humor y género: análisis de conversaciones entre mujeres

Humor and gender: conversation's analysis between women

\section{Magdalena Romera}

Humor, género y relación social. El humor como estrategia interaccional ... 41 Humor, gender and social relationships. Humor as an interactional strategy

Virginia Acuña Ferreira

Las funciones competitivas del humor en los cotilleos de jóvenes

veinteañeras.

The competitive functions of humours in young women's gossip

Meritxell Maza

El gènere i l'humor en interaccions didàctiques d'alumnes de secundària ... 95 Gender and humor in high school didactic interactions

\section{LOS MEDIOS DE COMUNICACIÓN SOCIAL}

José Joaquín Martínez Egido

El humor en el artículo de opinión

Humor in op-ed articles

Amaia Álvarez Uria, Raquel (Lucas) Platero Méndez, María Rosón Villena

El «estilo de la carne» en Maikrux y Falete: feminidad, humor y agencia.. 143

The 'corporeal style' in Maikrux and Falete: feminity, humour and agency 
Ana Mancera Rueda

El sexismo como blanco del humor en las redes sociales

163

Sexism as a target of humor in social networks

\section{LA COMPETENCIA HUMORÍSTICA}

Larissa Timofeeva Timofeev

El humor verbal en niños de educación primaria: desarrollo

de la conciencia metapragmática.

Verbal humour in primary school children: Development of metapragmatic awareness

Laura María Aliaga Aguza

Evolución del humor en la mujer: desde primaria a la universidad

Humor evolution in women: From primary school to college

\section{LITERATURA Y CULTURA}

\section{Mohamed El-Madkouri Maataoui}

Aspectos culturales de la traducción del humor sobre la mujer

Cultural aspects of the translation of humor about women

Francisco José Cortés Vieco

'Girls wanna have fun'?: El verso suelto humorístico de la poesía de Dorothy Parker en los 'alegres' años veinte

'Girls wanna have fun'?: The Comical free Verse in Dorothy Parker's Poetry during the Roaring Twenties

Normas editoriales de Feminismo/s 


\title{
INTRODUCCIÓN
}

\author{
G. Angela Mura y LEONOR Ruiz Gurillo \\ Universidad de Alicante. Grupo GRIALE
}

El humor es un hecho pragmático que afecta a diversas ramas de la ciencia, como la psicología, la sociología, la medicina o la lingüística, y que se refleja en procedimientos tan diversos como la edad de los hablantes, su nivel sociocultural, sus capacidades cognitivas o afectivas o su género. Este monográfico va dedicado precisamente a la relación del humor con el género, entendido como variable social que determina la identidad de los hablantes. Aunque las investigaciones han avanzado mucho en los últimos años, todavía se alude a diversas consideraciones acerca del hecho de que las mujeres no usan humor o que no tienen sentido del humor. Fue Robin Lakoff la que en 1973 y, más tarde, con su libro de $1975^{1}$, inició las investigaciones acerca cómo usan las mujeres el lenguaje. Su trabajo levantó ampollas, pues estaba lleno de tópicos sin comprobación empírica que situaban el lenguaje de las mujeres como pobre o trivial frente al de los hombres. Sin embargo, estos primeros trabajos evidenciaron, entre otros hechos, la necesidad de apoyarse en corpus y de entender el género (masculino, femenino o cualquier otro) como «a set of practices through which people construct and claim identities» (Eckert y McConnell-Ginet ${ }^{2}$ ).

Por lo que afecta al humor, algunos de los trabajos basados en la diferencia entre los géneros y en el dominio del sexo masculino sobre el femenino (Lakoff

1. Lakoff, Robin: Language and Woman's place. New York, Harper and Row, 1975.

2. Eckert, Penelope and Sally McConnell-Ginet: Language and Gender. Cambridge, Cambridge University Press, 2013, p. 47. 
19753; Cox et alii 19904; Goodman 19925), determinaron que las mujeres no eran capaces de usar humor ni de interpretarlo. Como se ha demostrado posteriormente (Jenkins $1985^{6}$ ), tal atribución encierra en sí misma un prejuicio: el hecho de mirar la realidad desde ojos masculinos y, en consecuencia, defender que este es el único modelo de comunicación. En los ochenta empiezan a elaborarse investigaciones que inciden en que la mujer sí usa el humor; se observa que ya no vale el modelo simplista del hombre activo que hace chistes y de la mujer que receptivamente sonríe (Kotthoff 2006a: $4^{7}$ ). Por lo común, tales planteamientos simplistas no se fundamentan en la comprobación empírica de las hipótesis, sino únicamente en los estereotipos heredados o las ideas preconcebidas de los investigadores. Cuando los investigadores se apoyan en corpus y analizan, por ejemplo, el humor en interacción (entre otros Rossen-Knill y Henry, $1997^{8}$, Hay 2000, Attardo 2001b, Schegloff $2001^{9}$, Everts, $2003^{10}$, Norrick $2003^{11}$, Kotthoff 2006a y 2006b ${ }^{12}$, Holmes $2006^{13}$, Lampert y Ervin-Tripp 2006 ${ }^{14}$, Davies 2003 y $2006^{15}$, Norrick y Chiaro 2009 ${ }^{16}$, etc.)

3. Op. cit.

4. Cox, Joe A., Read, L. Raymond y Van Auken, Philip M.: «Male-female differences in communicating job-related humor: An exploratory study». Humor 3(1990), pp. 287-295.

5. Goodman, Lizbeth: «Gender and humour». En Frances Bonner et al. (dirs), Imagining women: Cultural representations and gender, Cambridge: Polity, 1992, pp. 296-300.

6. Jenkins, Mercilee. «What's so funny?: Joking among women». En Sue Bremner, Noelle Caskey y Birch Moonwomon (dirs), Proceedings of the first Berkeley Women and Language Conference, Berkeley, CA, Women and Language Group, 1985, pp. 135-151.

7. Kotthoff, Helga: «Gender and humor: The state of the art». En Journal of Pragmatics, 38, 2006a, pp. 4-25.

8. Rossen-Knill, D.F. y R. Henry: «The pragmatics of verbal parody», Journal of Pragmatics, 27, 1997, pp.. 719-752.

9. Schegloff, E.A.: «Getting serious: Joke $\rightarrow$ serious 'no'», Journal of Pragmatics, 33, 2001, pp. 1947-1955.

10. Everts, E.: «Identifying a particular family humor style: A sociolinguistic discourse analysis», Humor s 2003,16-4, pp. 369-412.

11. Norrick, Neal: «Issues in conversational joking». Journal of Pragmatics 35, 2003, pp. 1333-1359.

12. Kotthoff, Helga, op. cit. Kotthoff, Helga: «Pragmatics of performance and the analysis of conversational humor», Humor, 19-3, 2006b, pp. 271-304.

13. Hay, Jennifer: «The pragmatics of humor support», Humor 14-1, 2001, pp. 55-82.

14. Lampert, M. D. y S. M. Ervin-Tripp: «Risky laughter: Teasing and self-directed joking among male y female friends», Journal of Pragmatics, 38, 2006, pp. 51-72.

15. Davies C. E.: «Gendered sense of humor as expressed through aesthetic typifications», Journal of Pragmatics, 38, 2003, pp. 96-113.

Davies C. E.: «Gendered sense of humor as expressed through aesthetic typifications», Journal of Pragmatics, 38, 2006, pp. 96-113.

16. Norrick, Neal and Delia Chiaro: Humor in interaction. Amsterdam/Philadelphia, John Benjamins, 2009. 
manifiestan que ambos géneros usan humor, si bien es cierto que lo emplean con finalidades diferenciadas y que los efectos y las estrategias discursivas que persiguen las diversas identidades no coinciden.

Así pues, desde una perspectiva discursiva del género es posible llevar a cabo análisis empíricos y comprobaciones más amplias sobre el uso del humor que las meramente intuitivas e impresionistas. El trabajo que hoy presentamos plantea como hipótesis general el hecho de que las mujeres usan humor en sus discursos, aunque es probable que lo hagan de un modo diferente a como lo hacen los hombres. Para corroborar esta hipótesis y desmentir definitivamente las ideas preconcebidas, las investigaciones que aquí se exponen se apoyan en corpus reales. Dichos corpus exponen usos diferenciados del hecho pragmático del humor en situaciones cotidianas como la interacción conversacional o los medios de comunicación social. Asimismo, el empleo de un corpus determinado permite proponer ciertos parámetros en la evolución de la competencia humorística desde la infancia a la madurez. No se olvida la influencia de los aspectos culturales en formatos como los chistes o la poesía.

A partir de estos presupuestos, las contribuciones que componen este número se articulan en cuatro bloques temáticos que observan el hecho pragmático del humor en el discurso desde diferentes perspectivas y en contextos de enunciación distintos. El primer bloque estudia este fenómeno a través del prisma de La interacción conversacional y se abre con el trabajo de M. Belén Alvarado Ortega (Humor y género: análisis de conversaciones entre mujeres), dedicado a un análisis pormenorizado de enunciados conversacionales que contienen humor producido por mujeres, con particular atención a las estrategias que utilizan las hablantes para salvaguardar la imagen, tanto en el caso de humor continuado como en las situaciones de humor fallido. En esta misma línea, en su artículo Humor, género y relación social. El humor como estrategia interaccional, Magdalena Romera indaga en el empleo de las expresiones lingüísticas humorísticas como herramienta interaccional en la conversación y lo hace teniendo en cuenta la variable género de los participantes y la relación social que existe entre ellos. En la contribución de Virginia Acuña Ferreira se observan Las funciones competitivas del humor en los cotilleos de jóvenes veinteañeras, pues la autora emplea un corpus de conversaciones entre jóvenes universitarias gallegas para poner de manifiesto la competitividad que subyace en el humor ligado al cotilleo entre mujeres. El artículo de Meritxell Maza, titulado El gènere i l'humor en interaccions didàctiques d'alumnes de secundària, se encarga de cerrar este primer bloque. A través de una investigación en didáctica de la lengua, la autora estudia el uso del humor por parte 
de adolescentes desde una perspectiva de género para llegar a determinar sus funciones tanto competitivas como cooperativas.

En el segundo bloque de artículos se observa la presencia y repercusión de este fenómeno pragmático en Los medios de comunicación social, en concreto, la prensa escrita, la televisión y las redes sociales. De la prensa escrita se ocupa la investigación de José Joaquín Martínez Egido (El humor en el artículo de opinión), que se apoya en un corpus de género periodístico -constituido por artículos de opinión publicados en la prensa española- en el que el autor observa las ocurrencias humorísticas que aparecen con el objeto de delinear las diferencias en el uso y en el tratamiento del humor por parte de los autores y autoras examinados. El corpus empleado por Amaia Álvarez Uria, Raquel (Lucas) Platero Méndez y María Rosón Villena en el artículo El «estilo de la carne» en Maikrux y Falete: feminidad, humor y agencia procede de la televisión. En este trabajo se contemplan las manifestaciones humorísticas de dos exponentes transgresores de los medios de comunicación español y vasco, Maikrux y Falete, que encarnan feminidades fuertes muy presentes en nuestra cultura popular y que han tenido un gran éxito mediático. Con el trabajo El sexismo como blanco del humor en las redes sociales, Ana Manera Rueda analiza las marcas e indicadores del humor en las redes sociales. La autora se basa en un corpus de mensajes de denuncia del contenido sexista de las declaraciones de algunos políticos españoles publicados en la red social Twitter.

El tercer bloque de investigaciones trata de La competencia humorística y se abre con un artículo de Larissa Timofeeva Timofeev titulado El humor verbal en niños de educación primaria: desarrollo de la conciencia metapragmática, donde se aborda el tema innovador del humor infantil desde la perspectiva lingüística. Esta investigación se fundamenta en los estudios de psicología evolutiva pero va más allá y, tomando como punto de partida los postulados del grupo GRIALE y un corpus de narraciones humorísticas infantiles elaborado por el mismo grupo de investigación, indaga en los rasgos lingüísticos específicos del humor verbal en niños y niñas. El mismo corpus es el que ha empleado Laura María Aliaga Aguza para llevar a cabo su investigación Evolución del humor en la mujer: desde primaria a la universidad. En este caso, la autora analiza la evolución del humor en la mujer desde la etapa escolar (concretamente $4 .^{\circ}$ de primaria) hasta el primer año universitario. Para ello, amplía el corpus arriba mencionado con un segundo corpus de redacciones humorísticas escritas por jóvenes universitarias y recogido, asimismo, por el grupo GRIALE.

El cuarto y último bloque del volumen lleva por título Literatura y cultura y contiene dos contribuciones que analizan el hecho pragmático del humor 
en dos géneros textuales distintos: el chiste y la poesía, respectivamente. Mohamed El-Madkouri Maataoui reflexiona acerca de los Aspectos culturales de la traducción del humor sobre la mujer y lo hace a partir de un corpus de chistes sobre la mujer en español peninsular y en árabe. Desde una perspectiva traductológica, el autor se propone mostrar las radicales diferencias entre dichas culturas a la hora de emitir enunciados humorísticos centrados en la figura femenina. El corpus empleado por Francisco José Cortés Vieco en su artículo 'Girls wanna have fun'?: El verso suelto humorístico de la poesía de Dorothy Parker en los 'alegres' años Veinte se enmarca en otro escenario y en otra época (Nueva York durante los años Veinte) y está constituido por la obra poética de la autora estadounidense Dorothy Parker. Con este marco de fondo, el autor explora las convergencias y las divergencias entre el universo lírico y el cómico en la obra de esta triste «mujer-chiste».

La variedad de enfoques y perspectivas presentes en los artículos de los que se compone este volumen, así como la amplia gama de corpus empleados para afianzar y corroborar las investigaciones presentadas, ponen de manifiesto la pluralidad de variables que condicionan el hecho pragmático del humor. Entre ellas, destaca la variable social del género que, como apreciaremos a lo largo de estas páginas, permite observar este fenómeno desde una perspectiva discursiva innovadora y de gran interés.

Este monográfico ha sido posible gracias a los proyectos de investigación FFI2012-30941: «Innovaciones lingüísticas del humor: géneros textuales, identidad y enseñanza del español», y GRE 12-01 «Lengua y Sexo: Uso del humor en hombres y mujeres». Para más datos sobre el grupo de investigación GRIALE, promotor de este volumen, puede consultarse su web: http:// dfelg.ua.es/griale/. Deseamos dar las gracias a las personas que han participado en este volumen, así como a quienes han evaluado los artículos con el fin de garantizar la calidad de este trabajo.

\section{Bibliografía}

ATTARDO, Salvatore. «Humor and Irony in Interaction: From Mode Adoption to Failure of Detection». In L. Anolli, R. Ciceri and G. Riva (eds.): Say not Say: New perspectives on miscommunication. Amsterdam, IOS Press, 2001, pp. 165-185.

Cox, Joe A., Read, L. Raymond and Philip M. Van Auken. «Male-female differences in communicating job-related humor: An exploratory study». Humor, 3 , 1990, pp. 287-295.

DAVIES, C. E. «Gendered sense of humor as expressed through aesthetic typifications», Journal of Pragmatics, 38, 2003, pp. 96-113. 
ECKert, Penelope and Sally MCCONnEll-Ginet. Language and Gender. Cambridge, Cambridge University Press, 2013.

EVERTS, E. «Identifying a particular family humor style: A sociolinguistic discourse analysis», Humor s 16-4, 2003, pp. 369-412.

GoOdmAN, Lizbeth. «Gender and humour». In Frances Bonner et alii (dirs.): Imagining women: Cultural representations and gender, Cambridge: Polity, 1992, pp. 296-300.

HAY, Jennifer. «The pragmatics of humor support», Humor 14-1, 2001, pp. 55-82.

Holmes, Janet. «Sharing a laugh: Pragmatic aspects of humor and gender in the work-place», Journal of Pragmatics, 38, 2006, pp. 26-50.

JENKINS, Mercilee. «What's so funny?: Joking among women». In Sue Bremner, Noelle Caskey and Birch Moonwomon (dirs.), Proceedings of the first Berkeley Women and Language Conference. Berkeley, CA, Women and Language Group, 1985, pp. 135-151.

KotthofF, Helga. "Gender and humor: The state of the art», Journal of Pragmatics, 38, 2006a, pp. 4-25.

KotтhofF, Helga. «Pragmatics of performance and the analysis of conversational humor», Humor, 19-3, 2006b, pp. 271-304.

LAKOFF, Robin. «Language and woman's place», Language and Society, 2, 197g3, pp. $45-80$.

LAKOFF, Robin. Language and Woman's place. New York, Harper and Row, 1975.

LAMPERT, M. D. and S. M. ERVIN-TRIPP. «Risky laughter: Teasing and self-directed joking among male and female friends», Journal of Pragmatics, 38, 2006, pp. 51-72.

NORRICK, Neal. «Issues in conversational joking». Journal of Pragmatics 35, 2003 , pp. 1333-1359.

NORRICK, Neal and Delia Chiaro. Humor in interaction. Amsterdam/Philadelphia, John Benjamins, 2009.

RosSEN-KNILL, D.F. and R. HENRY. «The pragmatics of verbal parody», Journal of Pragmatics, 27, 1997, pp. 719-752.

SCHEGLOFF, E.A. «Getting serious: serious 'no'», Journal of Pragmatics, 33, 2001, pp. 1947-1955. 
LA INTERACCIÓN CONVERSACIONAL 



\title{
HUMOR Y GÉNERO: ANÁLISIS DE CONVERSACIONES ENTRE MUJERES ${ }^{1}$
}

\author{
M. BelÉn Alvarado OrTEgA \\ Universidad de Alicante. Grupo GRIALE
}

Recibido: $15 / 09 / 2014$

Aceptado: 24/11/2014

\section{Resumen}

El trabajo que presentamos pretende analizar enunciados conversacionales que contienen humor producidos por mujeres, que, pueden continuar o no el modo humorístico. Este hecho da lugar a diversas estrategias conversacionales que dependen del sexo y del contexto situacional, marcados por el carácter del corpus recogido y por la identidad de género. Para llevar a cabo nuestro objetivo utilizamos el corpus Corpus de conversaciones coloquiales en proceso de digitalización de Briz y el grupo Val.Es.Co. En el análisis observamos que, cuando aparece el humor, las estrategias que utilizan las mujeres para salvaguardar la imagen son diferentes si el humor es continuado o fallido.

Palabras clave: cortesía, humor continuado, humor fallido, estrategias conversacionales.

\section{Abstract}

The article presents an analysis of conversational humoristic utterances in Spanish produced by women. Humor can appear in conversation as a conversational strategy to identify groups that depend on gender identity and situation. In a specific conversational corpus (Corpus de conversaciones coloquiales, Briz and Val.Es.Co. Group), a particular kind of humor made by women, shown by marks and indicators, will be

1. Este trabajo cuenta con la ayuda del proyecto GRE 12-01 «Lengua y Sexo: Uso del humor en hombres y mujeres» y del proyecto FFI2012-30941: «Innovaciones lingüísticas del humor: géneros textuales, identidad y enseñanza del español».

Feminismo/s 24, diciembre 2014, pp. 17-39

DOI: $10.14198 / \mathrm{fem} .2014 .24 .02$ 
discussed. I present an analysis in order to show different strategies used by women to protect their public face, when they use humor, continued or failed.

Keywords: politeness, continued humor, failed humor, conversational strategies.

Feminismo/s 24, diciembre 2014, pp. 17-39 


\section{Introducción}

El propósito de este trabajo es analizar las estrategias de humor verbal que utilizan las mujeres en la conversación para comprobar que su comportamiento difiere según sea humor continuado o humor fallido. La base teórica que sustenta el trabajo es la Teoría General del Humor Verbal (TGHV) propuesta por Attardo y Raskin ${ }^{2}$, y Attardo ${ }^{3}$, y su aplicación al estudio del español que realizan Ruiz Gurillo y Alvarado ${ }^{4}$. Sobre la identidad de género nos basamos en los trabajos de $\mathrm{Hay}^{5}$, que muestra algunas funciones y fases del humor en la conversación; Santaemilla ${ }^{6}$, que recoge las ideas más importantes sobre género, dominio y conversación; Mills ${ }^{7}$, que relaciona género y descortesía; Kotthoff ${ }^{8}$, que muestra la unión entre género y humor; Bell ${ }^{9}$, evalúa las respuestas de humor fallido; $y$, finalmente, Suderland y Litosseliti ${ }^{10}$, que desarrollan la identidad de género en el análisis del discurso.

2. Attardo, Salvatore y Victor Raskin: «Script theory revis(it)ed: Joke similarity and joke representation model». HUMOR: International Journal of Humor Research, 4, 1999, pp. 293-347.

3. Attardo, Salvatore: «A primer for the linguistics of humor». In Raskin, V. (ed.): The primer of humor research. Berlin: Mouton de Gruyter. 2008.

4. Ruiz Gurillo Leonor y Belén Alvarado Ortega (eds.).: Irony and Humor: From Pragmatics to Discourse. Amsterdam. John Benjamins.2013.

5. Hay, Jennifer: «Functions of humor in the conversation of men and women». In Journal of Pragmatics, 32. 2000, pp. 709-742.

Hay, Jennifer: «The pragmatics of humor support». Humor, 14-1, 2001, pp. 55-82.

6. Santaemilia, José: «Towards a pragmatics of gendered conversation: a few general considerations». En Quaderns de Filología, vol. VII, 2002, pp. 93-113.

7. Mills, Sarah: «Gender and impoliteness». Journal of Politeness Research 1, 2005, pp. 263-280.

8. Kotthoff, Helga: «Gender and humor: The state of the art». Journal of Pragmatics, 38. 2006, pp. 4-25.

9. Bell, Nancy: «Responses to failed humor». Journal of Pragmatics 41, 2009a, pp. 18251836.

Bell, Nancy: «Impolite responses to failed humor». In Humor in interaction, Neal Norrick and Chiaro (eds.), Amsterdan/Philadelphia. John Benjamins, 2009b, pp. 143-163.

10. Suderland Jane y Lia Litosseliti (eds.): Gender identity and discourse analysis. Amsterdan. John Benjamins, 2002. 
El análisis de las estrategias conversacionales de la mujer y el humor se mostrará con ejemplos de humor extraídos del Corpus de conversaciones coloquiales en proceso de digitalización ${ }^{11}$ de Briz y el grupo Val.Es.Co. en los que únicamente ha participado el género femenino. En nuestro corpus hemos analizado 77 minutos de 6 conversaciones coloquiales diferentes, entre mujeres de 18 a 25 años, con algún grado de familiaridad y amistad, y en las que hemos encontrado ocurrencias de humor continuado y de humor fallido.

Por tanto, explicaremos cómo se puede apreciar el humor en la conversación tanto si es continuado como si es fallido (epígrafe 2), lo que nos llevará a establecer diferentes fases. Además, observaremos qué estrategias conversacionales pueden aparecer (epígrafe 3); cómo actúa la mujer en la conversación (epígrafe 4); qué tipo de humor produce (epígrafe 5) y el análisis de ejemplos (epígrafe 6); y, por último, llegaremos a una serie de conclusiones sobre el uso del humor en las conversaciones de mujeres (epígrafe 7).

\section{Humor y conversación: claves para su interpretación}

El humor aparece en la conversación cotidiana de forma espontánea entre familiares y amigos para estrechar lazos entre ellos o bien para atacar la imagen del otro, entre otras razones. Por eso, el humor presenta diferentes funciones en la conversación que han sido consideradas por autores como Attardo, entre otros. De esta manera, cuando utilizamos el humor en la conversación, queremos unirnos a un grupo social, pretendemos mostrar sofisticación, cortesía o, incluso, podemos convencer de algo. Por tanto, el humor presenta en la conversación unas funciones sociales que nos llevan a afirmar que, cuando lo utilizamos, tenemos una intención comunicativa concreta. Esta idea ha sido tratada en Alvarado ${ }^{12}$, trabajo en el que demostramos que el humor sirve, junto con la ironía, para estrechar lazos entre hablante y oyente.

Para saber cómo funciona el humor en la conversación, debemos establecer las dos etapas que menciona Attardo ${ }^{13}$ : por un lado, la capacidad para entender el humor, es decir, la capacidad humorística (humor competence) y, por otro, la actuación del humor (humor performance). La primera fase es la capacidad que tiene el hablante y el oyente de hacer y reconocer el humor en un contexto determinado, mientras que la segunda tiene que ver con el deseo

11. Este corpus se encuentra en proceso de digitalización, y nos gustaría agradecer a A. Briz y al grupo Val.Es.Co. que nos hayan permitido acceder a él.

12. Alvarado, M. Belén: «Una propuesta de estudio para el humor en la conversación coloquial». ELUA, 26, 2012, pp. 7-28.

13. Attardo, Salvatore: Humorous Texts: A semantic and pragmatic analysis. Berlin. Mouton De Gruyter, 2001a, p. 167. 
y la disposición de apreciarlo. De esta manera, hablante y oyente participan activamente en el intercambio comunicativo, a partir de una serie de mecanismos lingüísticos en el enunciado que ayudan al interlocutor a la correcta interpretación del mismo. Esta idea es la que une la TGHV de Attardo con la propuesta del grupo GRIALE que afirmaba que todo intercambio comunicativo humorístico tiene a disposición del oyente indicadores o marcas, es decir, mecanismos lingüísticos bajo la terminología de Attardo, que sirven de pista para interpretar el enunciado de ese modo, en términos irónico-humorísticos. En este trabajo consideramos que tanto hablante como oyente tienen capacidad para apreciar el humor, es decir, la primera fase de humor.

Por tanto, en todos los casos de humor es fundamental observar dónde aparecen los elementos lingüísticos y cuáles son las pistas para que el oyente interprete el enunciado correctamente. Dichas pistas son denominadas por Attardo jab lines o ganchos ${ }^{14}$, si aparecen en la trama, o punch lines o remates, si aparecen al final del texto. Semánticamente son elementos iguales, y la única diferencia que presentan es su posición textual y su función pragmática. De este modo, si aparecen en el centro de la conversación sirven para dar pistas al oyente sobre su intención humorística, es decir, se utilizan como gancho, mientras que si se dan al final se utilizan como remate humorístico. Además, debido al carácter de nuestro corpus, la aparición de las risas ${ }^{15}$ es uno de los fenómenos que vamos a utilizar para el reconocimiento del humor en los enunciados conversacionales, ya que es la consecuencia directa del humor y, por tanto, la manera más precisa de observar que se produce humor en la conversación.

Para comenzar nuestro estudio sobre el humor en las conversaciones de mujeres, partiremos primeramente de la presentación de las fases por las que pasa un enunciado humorístico para producir humor, idea que ha sido tratada por Hay ${ }^{16} y$, posteriormente, por Attardo. Para estos autores dichas fases son: reconocimiento, entendimiento, apreciación y acuerdo, y están estrechamente relacionadas con la capacidad para entender el humor (humor competence) y la actuación del humor (humor performance).

14. Ibíd., p. 82.

15. Sobre este fenómeno numerosos autores han manifestado su opinión al respecto, como Coser (1960), Raskin (1985), Attardo (1993), Hay (2001) o Kotthoff (2003), que han explicado los chistes y las bromas a partir de las risas, y han desarrollado teorías sobre el humor; no obstante, preferimos asumir las ideas de Norrick (1993) sobre las risas, puesto que considera que este signo explícito es el más apropiado para respaldar un corpus de humor como el nuestro.

16. Hay, Jennifer: «The pragmatics of humor support», op. cit., p. 67.

Feminismo/s 24, diciembre 2014, pp. 17-39 
El reconocimiento del enunciado en términos humorísticos es la fase inicial en la que los interlocutores deben interpretar el humor. Esta fase inicial tiene que ver con humor competence, es decir, con la capacidad que tiene el interlocutor de reconocer que en un enunciado hay humor.

La fase de entendimiento está estrechamente relacionada con la anterior, ya que el oyente previamente ha reconocido el enunciado humorístico y, en esta fase, además, lo ha comprendido.

La apreciación es la primera fase que tiene que ver con la actuación del humor, ya que los interlocutores pueden compartir la intención humorística de partida del hablante porque lo han reconocido, lo han entendido y lo han apreciado como tal. En esta fase se decide si se da el humor compartido y continuado o, por el contrario, aparece el humor fallido.

La última fase de un enunciado humorístico es el acuerdo que pueden mostrar tanto oyente como hablante a la hora de producir e interpretar humor. En esta fase de actuación del humor, los interlocutores han decidido continuarlo en la conversación.

No obstante, cabe tener presente que todas estas fases aparecen en la conversación cuando tanto hablante como oyente participan y aceptan el enunciado en términos humorísticos, esto es, se produce un mode adoption por parte de los interlocutores. Según Attardo ${ }^{17}$, mode adoption existe cuando el oyente reacciona al humor con humor, y se dan diferentes intervenciones humorísticas, concepto que también recogen Eisterhold et alii ${ }^{18}$.

Veamos la figura 1 para ilustrar las fases por las que pasa un enunciado humorístico en nuestro corpus. Si observamos la figura, vemos que la competencia para entender el humor envuelve al resto de elementos, puesto que, como hemos dicho anteriormente, para recopilar nuestro corpus partimos de la idea de que todos los interlocutores poseen esa capacidad humorística. De este modo, tras un enunciado humorístico que presente marcas o indicadores (jab lines), es decir, pistas para el interlocutor, el oyente debe ser capaz de interpretarlo de esa manera. Así, estaríamos en la fase de reconocimiento y entendimiento del humor. Tras estas dos primeras fases, encontramos la fase de apreciación que se sitúa a medio camino de la actuación del humor. Esto se debe a que el oyente en este momento es cuando debe decidir si continúa con

17. Attardo, Salvatore: «Humor and irony in interaction: from mode adoption to failure of detection». In L. Anolli, R. Ciceri \& G. Riva (eds.): Say not to say: new perspectives on miscommunication. 2001b, pp. 166-186.

18. Eisterhold, Jodi, Attardo, Salvatore and Boxer, Diana. 2006. «Reactions to irony in discourse: evidence fo the least disruption principle». Journal of Pragmatics 38, 2006, p. 1240 . 


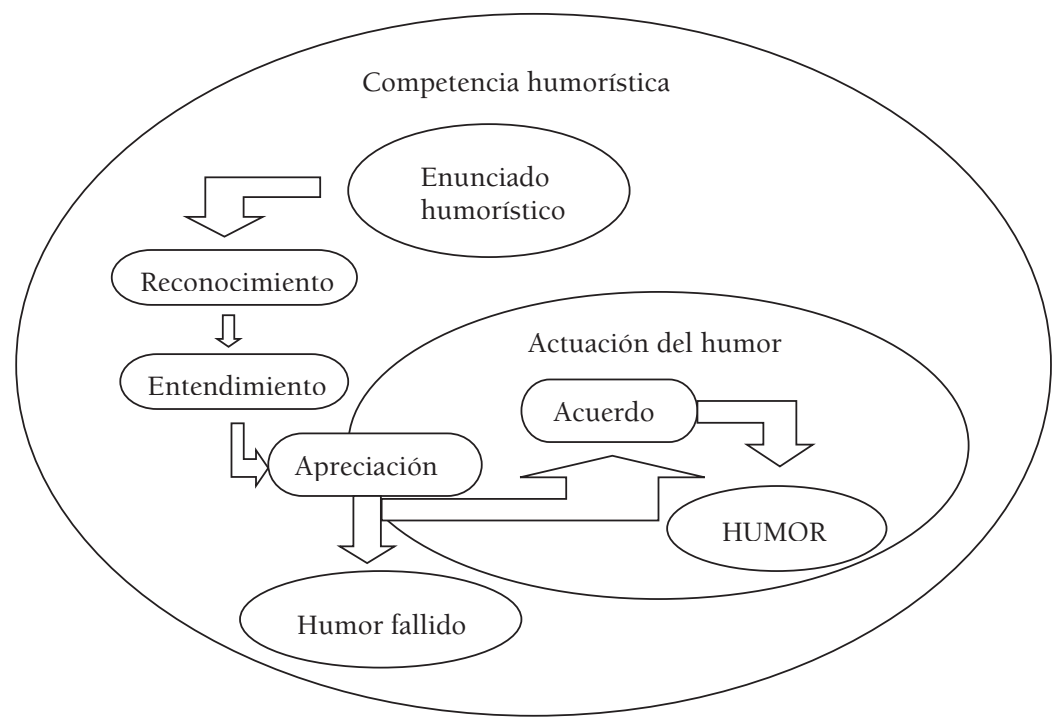

Figura 1. Fases del enunciado humorístico

el modo humorístico (mode adoption) y, por tanto, pasa a la fase de acuerdo y produce o acepta el humor, o, por el contrario, rechaza el humor y no lo continúa. En este caso, estaríamos ante un caso de humor fallido ${ }^{19}$.

Por tanto, la figura 1 sirve, en nuestro trabajo, para ilustrar los casos de humor continuado y humor fallido en la conversación. El humor continuado aparece en las ocurrencias cuando los interlocutores tienen competencia humorística, es decir, reconocen, entienden y aprecian el humor, a partir de los ganchos que les muestra el hablante; y, además, lo comparten, aceptan y continúan con los remates, como pueden mostrar las risas. Mientras que el humor fallido se da cuando los dos interlocutores poseen la capacidad humorística, pero uno de ellos reconoce o entiende un falso gancho y desprecia el humor, sin que haya presencia de remate humorístico. Para entender los conceptos que hemos presentado observemos el ejemplo (1).

En (1) tres amigas conversan sobre el examen práctico del coche que ha aprobado una de ellas, C:

19. Alvarado, M. Belén: «Failed humor in conversational utterances in Spanish: a matter of (im)politeness». En Ruiz Gurillo, L. y Alvarado Ortega, B.: Irony and Humor: From Pragmatics to Discourse. Amsterdam. John Benjamins, 2013. 
(1)

C: pero ¿qué le iba a decir, Mari? //

A: seguro que llega a mi madre ${ }^{20}$ y le dice que diu la xica no sé què d'un cotxe $e^{21}$

C: (risas)

A: quee /s’ha trobat un cot-22 yo qué sé qué historia le montará $\downarrow$ no se entera $\uparrow$ la pobre mujer

C: pero si llamaas/ preguntas por la- / y no le dices algo a ellaa/§

A:

$\S[$ que se ] n'ha anat

en $\operatorname{cootxee} e^{23} \S$

C: $\quad \S[i$ [sabes? Pues]

A:= yo qué sé $\downarrow$ mi madre ¿en coche?

$\mathrm{C}$ : y es cuando le dices [mira $(())]$

B:

[noo pero] se lo pensará/ si le dice algo del

coche $=$

C: [noo]

$\mathrm{B}:=[$ se lo] pensará

(Corpus Val.Es.Co., digital [146.A.:21-32])

En (1) A y C, que son hermanas, crean humor a partir del hecho de que su abuela no reproduce correctamente lo que le cuentan, en este caso, que C ha aprobado el carné de coche. La primera intervención de A da el primer indicador de humor para el oyente, ya que reproduce de forma humorística y con estilo directo las palabras que podría haber dicho la abuela, por tanto, estamos ante el primer gancho; así C reconoce, entiende, aprecia y está de acuerdo con el humor de A, como muestran las risas en su intervención posterior, que actúan como remate. Sin embargo, B no está participando en este momento del humor, puesto que se trata de la abuela de A y C. En su caso, reconoce, entiende y aprecia el humor, pero no lo comparte, como muestra en su intervención, volviendo al tema serio, por lo que B sería un caso de humor fallido.

\section{Estrategias conversacionales y humor}

Parece coherente pensar que la mayoría de las estrategias conversacionales que se utilizan en los casos de humor y de humor fallido están directamente relacionadas con la cortesía y con la imagen de los interlocutores. La cortesía es una estrategia conversacional que se utiliza para evitar conflictos y mantener buenas relaciones entre los individuos de una sociedad, mientras que el humor hace peligrar esa relación cuando se ataca a la imagen de los

20. A y $\mathrm{C}$ son hermanas

21. Val. 'que dice la chica que no sé qué de un coche'

22. Val. 'que se ha encontrado un co (che)'

23. Val. 'que se ha ido en coche'

Feminismo/s 24, diciembre 2014, pp. 17-39 
interlocutores. Brown y Levinson ${ }^{24}$, señalan que el hablante tiene una imagen que debe proteger sin que esto signifique un daño a la imagen de sus interlocutores. En los casos de humor la imagen tanto del hablante como del oyente pueden verse atacadas cuando se convierten en la meta del humor, por lo que es fundamental conocer qué estrategias aplican para defenderse.

Diferentes investigadores enumeran las estrategias que se utilizan en el humor como Culpeper ${ }^{25}$, Hay ${ }^{26}$, entre otros. Tales estrategias están relacionadas con la cortesía y con la descortesía que producen en el intercambio conversacional, como, por ejemplo, la gestión social, la afiliación al grupo conversacional, la sofisticación, la evaluación, la persuasión, la cortesía, la apariencia, la simpatía, la contradicción, el auto-humor, la superposición o simplemente por el mero hecho de contribuir al humor.

Todas estas estrategias probablemente serán diferentes en el uso de hombres y de mujeres y del papel que desempeñan en la conversación. Como el caso que nos ocupa es estudiar el humor en las conversaciones de mujeres, nos centraremos únicamente en las que aparecen documentadas en el corpus analizado $^{27}$. De ahí que, a partir de los datos obtenidos, distingamos para su estudio, como hemos dicho anteriormente, entre el humor que produce la mujer, tanto si es continuado como si es fallido, y concretar qué estrategias se utilizan.

\section{La mujer en la conversación}

La búsqueda de las características del lenguaje femenino ha sido una cuestión que ya interesaba a R. Lakoff, ideas que recoge de sus antecesores ${ }^{28}$. Para estos autores, influenciados por el contexto sociocultural que les rodeaba, la mujer no tiene sentido del humor porque no entiende el remate humorístico de las bromas. Estas ideas, propias del momento en el que se escribe la obra, se deben al papel que tenía la mujer en la sociedad, ya que se situaba en un

24. Brown, Penelope y Stephen Levinson: Politeness: Some universals in language usage. New Cork. Cambridge University Press, 1987, p. 13.

25. Culpeper, Jonathan: «Towards an anatomy of impoliteness». Journal of Pragmatics 25, 1996, p. 355.

26. Hay, Jennifer: «The pragmatics of humor support», op. cit., p. 60.

27. Recordemos que nuestro corpus está extraído de Briz y grupo Val.Es.Co. (corpus digital) del que hemos analizado 77 minutos de 6 conversaciones coloquiales diferentes, en los que las interlocutoras de cada una de las conversaciones son mujeres de entre 18 a 25 años, y en las que hemos encontrado ocurrencias de humor continuado y de humor fallido.

28. Jespersen (1922), Labov (1972), Trudgill (1972), entre otros

Feminismo/s 24, diciembre 2014, pp. 17-39 
segundo plano, dedicada al hogar y a la crianza de sus hijos, y su lenguaje debía ser más decoroso y cuidado que el de los hombres ${ }^{29}$.

Siguiendo esta idea sobre la mujer, Santaemilia ${ }^{30}$ enumera tres factores que influyen en el género y la conversación: el déficit, que tiene que ver con la falta de autoridad que tiene la mujer en la conversación con respecto al hombre; el dominio, que es un privilegio del hombre para poder interrumpir el discurso de la mujer; y la diferencia, que tiene que ver con la visión distinta del mundo que tienen estos dos géneros. Sin embargo, habría que comprobar que estos factores siguen vigentes en la actualidad, ya que parece que estos parámetros no son totalmente válidos, puesto que la mujer está integrada en el mundo laboral, ha adoptado las normas del discurso masculino y las ha hecho propias (interrupciones, lenguaje directo, bromas, etc.). Al tiempo, han evolucionado las teorías sobre el humor en las mujeres, como Suderland y Litosseliti (2002) que desarrollan la identidad de género en el análisis del discurso y en la construcción de papeles sociales caracterizados por la condición social.

En esta misma línea, Kotthoff ${ }^{31}$ muestra la unión entre género y humor, y lo relaciona con el nivel sociocultural. Afirma que las mujeres con nivel sociocultural bajo realizan humor como los hombres, mientras que los hombres con nivel sociocultural alto crean humor como las mujeres. Habría que hacer un estudio contrastivo para comprobar que es así en la conversación, ya que nuestro corpus está basado únicamente en conversaciones en las que solo participan interlocutoras de género femenino con un nivel cultural medio-alto.

Si retomamos la idea de que las mujeres han adoptado el lenguaje de los hombres para hacer humor con un estilo más directo y más agresivo, veremos que se relaciona con la descortesía, ya que su intervención humorística puede afectar a la imagen de los interlocutores. A este respecto, Bell ${ }^{32}$ afirma que algunas bromas pueden actuar sobre la imagen del interlocutor si se utilizan para interrumpir la conversación, puesto que este hecho puede alterar el comportamiento esperado por él. Por eso, para producir humor es necesario empatizar con nuestro interlocutor y saber cómo va a reaccionar ante el enunciado humorístico. Por tanto, cuanto mayor sea el rasgo de familiaridad y cercanía de los interlocutores, mayor será la probabilidad de que aparezca el humor en las conversaciones, ya que los interlocutores que se encuentran en

29. Para un repaso bibliográfico sobre el tema, véase Santaemilia (2002).

30. Santaemilia, J., op. cit., p. 104.

31. Kotthoff, Helga, op. cit., p. 21.

32. Bell, Nancy: «Impolite responses to failed humor», op. cit., p. 158. 
un ambiente distendido se sienten más seguros para producir y recibir humor, tal y como sucede en nuestro corpus.

Observaremos, a continuación, en los ejemplos extraídos de nuestro corpus de mujeres con alto grado de familiaridad y con un nivel de estudios medios y superiores, cómo actúan ante enunciados humorísticos conversacionales. Por eso dedicaremos un epígrafe a mostrar ocurrencias de humor continuado en la conversación, y otro a los ejemplos de humor fallido.

\section{El humor continuado en la conversación de mujeres}

Como hemos dicho, a pesar de que en las investigaciones clásicas del humor predominaba la idea de que las mujeres tenían menos sentido del humor que los hombres ${ }^{33}$, mostraremos, en este epígrafe, que en nuestro corpus las mujeres utilizan el humor continuado de forma frecuente con unas funciones determinadas, ya que se encuentran en un ambiente distendido y familiar. Recordamos que el humor continuado se da cuando se reconoce, se entiende, se aprecia y, además, se comparte y se continúa; es decir, se presenta en los interlocutores la competencia humorística y la actuación del humor, tal y como hemos visto en la figura 1.

Observemos el ejemplo (2), que comparte el mismo contexto que el ejemplo (1). A y C son hermanas y dialogan sobre el hecho de que su abuela no comprenda bien las cosas:

(2)

C: ya pero b- quedamos que- que si llamaba era para- $\mathrm{p}$ (or)- /aprobado

A: mi abuela no se entera tía/ cuando vinieron Jose y todos estos al chalet/ eixos amiguets teus són molt simpàtic ${ }^{34}$, eh? / yo digo ni se le ocurra a nadie decir nada, tía, que s- que lo trabuca todo y no se entera de nada§

C:

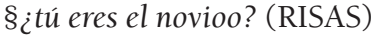

A: (RISAS) además de verdad $\downarrow$ tía

C: y Jose ¿eh?ieh?

A: tu eres el d'Alacant $\downarrow$ el que anaves a casar-te en ella? ? $^{35}$

C: (RISAS) bueno tía $\rightarrow$ se- se lo tengo que decir también al primo Santi// ¿y Jesús cómo ha quedao [yo es que antes no los he visto]

(Corpus Val.Es.Co., digital [146.A.:37-46])

En (2) se producen varias intervenciones humorísticas porque A reproduce a través del estilo directo las palabras que dijo su abuela sobre un amigo (eixos amiguets teus són molt simpàtics) y C continúa con la reproducción (¿itú eres el

33. Hay, Jennifer, op. cit., p. 712.

34. Val. 'esos amiguitos tuyos son muy simpáticos'

35. Val. '¿tú eres el de Alicante, el que ibas a casarte con ella?

Feminismo/s 24, diciembre 2014, pp. 17-39 
novioo?) provocando las risas de ambas interlocutoras. Si observamos el ejemplo, el humor continúa varias intervenciones más, que actúan como gancho humorístico, ya que la meta del humor es la abuela de ambas, que se encuentra ausente en la conversación, por lo que A y C están afianzando sus lazos en el grupo conversacional. Además, como se trata de la abuela de ambas, se encuentran con autoridad y poder suficientes para poder continuar el humor, hecho que contrasta con $\mathrm{B}$, ya que a pesar de que se está presente en la misma conversación, entiende el humor pero no participa del mismo para no atacar la imagen de la abuela de A y C, tal y como hemos visto en (1).

Sin embargo, cuando el humor no se produce hacia la abuela de A y C, B sí que participa del mismo. Veamos (3):

C: $\quad$ Seh- ese- ese que te he dicho yo que ha suspendido que se lo han dicho seguro $\downarrow$ et- ee- era de teleco $\downarrow$ típico PAVITO/ de estos§

A:

$\S$ mari como [el ingenier ${ }^{36}$ ]

C: $\quad[$ de $(())]$ como el INGENIER

A: $\left[\left(\left(\right.\right.\right.$ Beniferrii/ Beniferrii $\left.\left.\left.{ }^{37}\right)\right)\right]$

C: [con una cara de- de pa-/ de PAVO $\rightarrow$ y nada

A: (RISAS) (María Josés8) ¿te acuerdas cuando fuimos a- a-? ¿eras tú la que viniste(s) conmigo? [eeh (RISAS)]

B: [sí sí si] que no se enteraba

(Corpus Val.Es.Co., digital [146.A.:90-99])

En este caso, la meta del humor es una persona ausente en la conversación, que no tiene que ver con ningún familiar de las interlocutoras, el ingenier de Beniferri, por lo que las tres interlocutoras se sienten con confianza y seguridad para poder hacer humor continuado de una persona ausente, incluso atacando su imagen con varios ganchos (con una cara de pavo// ite acuerdas cuando fuimos a...?). Por eso, B continua también con una intervención que actúa de remate humorístico y apoya el humor que ha realizado C (sí, sí, sí, que no se enteraba) para mostrar la identidad de grupo. La estrategia conversacional que se ha utilizado sigue siendo la afiliación al grupo conversacional.

En (4) dos compañeras de trabajo dialogan sobre el hecho de que un alumno de A le había contado que en Noruega había un alto índice de infidelidad:

36. Vulg. por el cat. enginyer 'ingeniero'.

37. Barrio de Valencia. Aluden a una anécdota relacionada con el ingenier.

38. Nombre de B 
(4)

A: quería decir $\downarrow$ bueno $\downarrow$ del centro de Noruega al NORTE $\uparrow$ el norte de Noruega $\uparrow$ que por lo visto $\uparrow$ sí quee es verdad que en general era maayor la infidelidad $\downarrow$

B: (gracias) ${ }^{39}$

A: la infidelidad de los hombres que de las mujeres $\uparrow$ pero quee deel-

?: [((ial revés $(()) ?))]$

A: [el norte] de Noruega $\uparrow$ que era [al revés $\left.\downarrow^{40}\right]$

$\mathrm{B}$ :

[(RISAS)]

A: = y yo $\uparrow /$ digo bueno $\downarrow$ iy CON QUIÉN?§
$\mathrm{B}$ :
A:
$\S(($ y a que $))[(())]$
[¿y con quién] allí?!

porque pensaba el norte de Noruega ijoder! ee- [más arriba=]

$\mathrm{B}$ :

A: = del Círculo Polar Ártico§

$\mathrm{B}$ :

[con más armarios $\uparrow$ ]

$\S$ el norte de Noruega con los esquimales///

(Corpus Val.Es.Co., digital [218.A.1.:83-96])

En (4) A y B continúan el humor porque A atenta contra una situación, el hecho de que los hombres en Noruega sean infieles cuando hay poca densidad de población. Para ello, A aporta diferentes ganchos (y yo digo bueno iy con quién?// ¿y con quién allí?) que B entiende y acepta como humorísticos, tal y como muestran sus risas, que serían el remate humorístico. En este caso, B continúa el humor (con más armarios) y, de este modo, se afianza la identidad de grupo conversacional.

En ocasiones, el humor atenta contra la imagen de una de las interlocutoras, como observamos en (5), en donde A y B son amigas y están hablando sobre anécdotas conjuntas:

A: el sábado ¿te vienes? me voy yo al pueblo/// a pasarlo bomba

B: uic $^{41} /$ de maravillaa ${ }^{42} \S$

A:

§oh pos no te quejarás guapaa§

B:

$\S$ no yo no me quejo§

A:

te vi en to (da) la noche

B: (RISAS) ¿yo a ti sí hermosa?

A: yo estaba hablaando

B: que tú te fuiste primera ¡eh!

39. Alguien le da algo B y lo agradece.

40. Entre risas.

41. Expresión de incredulidad.

42. Entre risas.

Feminismo/s 24, diciembre 2014, pp. 17-39 
A: yo estuve hablaando§

B:

§algo tenía que hacer§

A:

$\S$ yo soy muy buena

B: ssí claro claro// eso está claro

B: no que no m'apeteix ${ }^{43} \xi$

A:

Suna que es irresistiblee (RISAS)

B: $\mathrm{ss}^{44} /$ a mí me pasa lo mismoo $\downarrow \S$

A:

§que va hombre es broma ¿eh?/ to- todo

esto es bromaa ${ }^{45}$

$$
\text { (Corpus Val.Es.Co., digital [235.A:87-104]) }
$$

En (5) A invita a su amiga B al pueblo donde parece que en el pasado B se lo pasó muy bien, ya que conoció a un chico y dejó a su amiga sola toda la noche. La intervención de A (no te vi en toda la noche) atenta contra la imagen de $\mathrm{B}$, que se lo toma de forma humorística, puesto que se trata de un gancho, pero a la vez B se defiende con otro gancho que ataca a A (¿yo a ti sí hermosa?), de donde se infiere que también ligó esa noche. Como vemos, A no esperaba esta intervención, por lo que, a partir de ahí, A y B continúan con una serie de alternancias de turnos irónicos que actúan como ganchos, siguen el modo humorístico y atentan contra la imagen de ambas (yo soy muy buena// sí claro, claro), hasta que B decide parar el modo humorístico volviendo al tema serio (no que no m'apeteix). Sin embargo, A no continúa esa intervención y vuelve a la ironía y al humor (una que es irresistible), por lo que B está obligada a continuarlo para defender la imagen (a mí me pasa lo mismo). Finalmente, A decide que debe parar el juego y afirma que todo lo que está diciendo es broma para salvaguardar la imagen y la relación de ambas. En este caso, la estrategia conversacional evoluciona desde salvaguardar la imagen negativa de cada interlocutora, para que sea respetada por la otra, hasta la última intervención, en la que se intenta estrechar lazos entre ambas.

En (6) las mismas amigas que aparecen en la ocurrencia anterior, siguen dialogando sobre si se van al pueblo o no:

(6)

B:

A: ${ }^{46}$

Spero si van el miércoles ¿tú vas a ir?

B: ¡¿no por qué?!

43. Val. 'No que no me apetece'.

44. Expresión afirmativa e irónica.

45. Entre risas.

46. Chasquido con función de negación.

Feminismo/s 24, diciembre 2014, pp. 17-39 
A: ¿a qué? ((allí no tengo nada)) ((no)) tía y luego ver allí a la gente $e^{47} \rightarrow / / /$ además no tengo quéstudiar

B: ¿no quieres ver a la gentee ${ }^{48}$

A: no (RISAS)/ es que salgo de mi casa y ya lo veo $\downarrow$ (RISAS)

B: ¡vaya! ¿a quién? ${ }^{49}$

A: no sé

B: tú sabrás

A: al vecino de arriba NO TE DIGO /// (2») no además no/ quiero dedicarme a estudiar $\rightarrow / /$ les estoy convenciendo para ir -el sábado (( )) ¿ivale?

(Corpus Val.Es.Co., digital [235.A:114-126])

En (6) B pregunta a su amiga A si va a ir al pueblo con sus padres, pero A no quiere ir para no ver a un exnovio. Tanto A como B saben a quién se están refiriendo y ambas continúan el modo humorístico; sin embargo, B intenta atacar la imagen de A y le hace preguntas que actúan como ganchos humorísticos para incomodarla (¿no quieres ver a la gente?), a las que A responde irónicamente para defender su imagen (al vecino de arriba no te digo). Es A la que realiza la última intervención en modo humorístico como remate para volver al modo serio, ya que ve peligrar su imagen (quiero dedicarme a estudiar...). En este caso, al igual que en (5), la estrategia conversacional que se utiliza con el humor es salvaguardar la imagen negativa de las interlocutoras.

En algunos casos aparecidos en nuestro corpus, el hablante realiza autohumor para salvaguardar la imagen de un ataque inminente. En (7) las mismas amigas que los ejemplos anteriores dialogan sobre un trabajo de carrera que tienen que terminar:

(7)

A: pesadísimo no además/ luego pasarlo y todo// ((tío)) a mí me cuesta más ((que te den-dejeme)) un trocho- un tocho- ay un trocho

B: (RISAS) UN TRocho (RISAS)

A: hablo de categoría ${ }^{50}$ ya $\downarrow$

B: se t'ha pegao de mí

A: síi (RISAS)/ tanto estudio y luego na de na/// (2») me voy a tumbar aquí un poco porque ya// estoy cansá del todo ¿eh?

(Corpus Val.Es.Co., digital [235.A:147-153])

En (7) el humor se produce cuando A no pronuncia bien la palabra tocho para hacer referencia a la cantidad de papeles que deben escribir. B retoma

47. Risa tímida.

48. Entre risas.

49. Entre risas.

50. Ironía.

Feminismo/s 24, diciembre 2014, pp. 17-39 
las palabras que ha reproducido A como un falso gancho para realizar ironía y humor; sin embargo, A siente que se ataca a su imagen negativa, como muestran las risas de $\mathrm{B}$, e intenta defenderse continuando el humor a través de una intervención irónica que actúa como remate (hablo de categoría). Esta intervención produce humor continuado que decide acabar A con la introducción de un tema serio (me voy a tumbar aquí un poco...). En este caso el humor continuado y el auto-humor sirven como estrategia conversacional de protección de imagen.

Así, en la mayoría de los casos encontrados, el humor se continúa para estrechar lazos entre los interlocutores o para proteger la imagen negativa de los ataques del hablante, en menor medida. En las ocurrencias hemos visto que, cuando los temas no tienen que ver directamente con los interlocutores, hay más posibilidades de que se produzca el modo humorístico y continuado, y, por consiguiente, la afiliación al grupo conversacional; mientras que cuando los temas son referentes a alguno de los interlocutores, el humor continuado se produce para proteger la imagen pública. Sin embargo, esta última estrategia conversacional se multiplica en los casos de humor fallido, puesto que lo más habitual en la conversación es que cuando se ataque a la imagen de un interlocutor, no se acepte ni aprecie el modo humorístico, como veremos seguidamente.

\section{El humor fallido en la conversación de mujeres}

En las ocurrencias de humor fallido en la conversación, los interlocutores interpretan de manera errónea una intervención como un falso gancho, es decir, aparece una intervención con posible indicador o marca de humor, cuando en realidad no lo es. Veamos el ejemplo (8) en el que dos amigas conversan sobre el abuelo de A que quiere vivir solo en Valencia:

(8)

A: él $\downarrow$ solo/ a vivir solo $\downarrow / /$ y entonces $\uparrow[h e m o s$ busca(d)o]

B: $\quad$ [chulito $\uparrow]$ como toda la familia ¿no $?^{51}$

(RISAS)

A: y hemos busca(d)o una- (bueno la buscamos $\downarrow$ el el-)

B: el lunes empezó la mujer ¿no?

A: para que $\uparrow$ - por ejemplo mi madre como se va a trabajar por las mañanas $\uparrow \S$

B:

(Corpus Val.Es.Co., digital [173.B:20-27])

51. Entre risas.

Feminismo/s 24, diciembre 2014, pp. 17-39 
En (8) B interpreta la primera intervención de A (él solo, a vivir solo) como un posible gancho, a partir del cual se siente con confianza para crear humor (chulito, como toda la familia, ¿no?). En este caso, la intervención de B no ha sido continuada por A, ya que el enunciado humorístico ataca a la imagen pública de su abuelo y se produce humor fallido en el hablante, que ha intentado crear humor sobre el abuelo de A. A partir de esa intervención de humor fallido se continúa el tema serio ( $y$ hemos buscado una) para proteger la imagen de una persona ausente y familiar del hablante. Por tanto, el humor se reconoce y se entiende, pero no se acepta ni se comparte.

En otras ocasiones, el humor fallido se produce en el oyente cuando es este el que interpreta un elemento lingüístico o varios como ganchos, y no lo son porque el hablante los ignora y continúa con la conversación en modo serio, como vemos en (9). En este ejemplo, varias interlocutoras dialogan sobre una plaga de pulgas que A tenía en su piso:

(9)

B: [ pero/ ¿para] qué limpiaste tanto $\uparrow$ ?

A: tía/ porque estaba empara[noyá (per)día $\uparrow=$ ]

C:

[(RISAS)]

$\mathrm{A}:=[$ quee $\rightarrow]$

C: [ por los piojos] chica§

A: $\quad$ \& yo soy mogo- mogollón de propensa/ a que me pique todo/ o sea / yo / / me depilo las piernas $\uparrow / y$ tengo unos picoreh que me muero/me baño en la playa $\uparrow / y$ me pican las piernas/muy propensa ¿no $\uparrow ? /$ y un día $\rightarrow$ estamos en el $\rightarrow /$ en el $\rightarrow /$ en el bar $\uparrow$ y me dice Carmen/ tienes una cosa

(Corpus Val.Es.Co., digital [151.B.:11-22])

En (9) A, B y C dialogan sobre la manía que tiene una de ellas a los insectos, sobre todo, a las pulgas y a los piojos. La intervención que produce $\mathrm{A}$ (tia/ porque estaba emparanoyá perdía) es interpretada por $C$ como un gancho humorístico por la interpretación literal que hace $C$ del enunciado, cuando en realidad no es una intervención humorística, porque están teniendo una conversación seria sobre la limpieza de una plaga de pulgas que había en su piso. Por tanto, este falso jab line o gancho hace que $\mathrm{C}$ se tome con humor un enunciado, que no es humorístico, y pone su imagen en peligro con respecto al grupo conversacional, que reconoce y entiende el humor pero no lo comparte ni aprecia. De ahí que $C$ no continúe el humor y opte por el tema serio como modo de reparar su imagen hacia los demás.

El silencio también aparece en nuestro corpus como forma de respuesta ante enunciados potencialmente humorísticos. Este fenómeno ha sido 
estudiado por autores como $\mathrm{Hay}^{52}$, Norrick ${ }^{53}$ o Priego Valverde ${ }^{54}$ que afirman que el silencio se interpreta como falta de acuerdo con el enunciado. Sin embargo, todos advierten de la posibilidad de que el silencio pueda deberse también a la falta de entendimiento del enunciado humorístico, es decir, aparece en los casos en los que no se ha reconocido el humor. Recordemos que tomamos como humor fallido aquellos enunciados que se dan en la conversación coloquial y que han superado las tres primeras fases de humor, reconocimiento, entendimiento y apreciación; por tanto, entendemos que los interlocutores son capaces de distinguir el humor, pero no lo han continuado, tal y como vimos en la figura 1. Así, no tenemos en cuenta los silencios que se dan en las intervenciones humorísticas en las que el oyente no ha entendido el enunciado, hecho que sí sucede en los trabajos de Priego Valverde, entre otros. Observemos el siguiente ejemplo que se produce en la misma conversación que la ocurrencia anterior, en la que varias amigas dialogan sobre la plaga de pulgas que A tuvo en su piso:

A: = superemparanoyada con eso/ pero mogollón/ hasta lo de abajo $\uparrow / /$ paraa/ lo- d'ese todo// después voy/me ca-me pongo el otro pijama que tenía limpio/ me lo pongo/ me acuesto/después/me tocó $\uparrow /$ me pon- y aquí/ yo $\uparrow$ hasta $\rightarrow$ / fíjate tú [lo que hace la psicología=]

C: [(RISAS)]

$\mathrm{A}:$ : que yo/ hasta me notaba erupciones/o sea/ yo me notaba ya/ el bultito de que me habían picaoł/y por la mañana no tenía nada/ y yo me tocaba aquí y tenía/ me tocaba aquí que me rascaba/ y tenía también/ me tocaba aquí/ y también tenía/ mira/ hasta las seis de la ma-tía iqué no dormí! $\uparrow /$ (es) que ¡NO DORMí! ¿eh? $\uparrow /$ no podía dormir $\uparrow /$ en la cama $\rightarrow$ / a punto de llorar/ digo la despierto\$ y hacemos aquí la limpieza a las seis de la mañana// y ya desde ese día/ pues emparanoyá/ mañana limpio la habitación

(Corpus Val.Es.Co., digital [151.B.:11-22])

En (10) A cuenta que sigue obsesionada con la plaga de pulgas que tuvo en su piso y que no le deja hacer su vida normal. C interpreta la primera intervención de A como un falso gancho del hablante (superemparanoyada...); sin embargo, nadie continúa el modo humorístico, porque lo que A está contando es un tema serio, por lo que $\mathrm{C}$ opta por el silencio en el resto de intervenciones

52. Hay, Jennifer, op. cit.

53. Norrick, Neal: «Issues in conversational joking». Journal of Pragmatics 35, 2003, pp. 1333-1359.

54. Priego Valverde, Beatrice: «Failed humor in conversation: A double voicing analysis». In Norrick, Neal and Delia Chiaro. 2009. Humor in interaction, Amsterdam/Philadelphia. John Benjamins, pp. 165-186. 
de A, al igual que el resto de interlocutoras. De este modo, no peligra la imagen pública de ninguna de ellas y se afianza el grupo conversacional. Por ello, el silencio se utiliza como una estrategia conversacional relacionada directamente con la cortesía, puesto que sirve para salvaguardar la imagen del interlocutor, que se ha visto dañada por la emisión o la interpretación de un falso enunciado humorístico como un gancho erróneo, como observamos en (10).

Pero, además del silencio y de la continuación del tema serio, existen otras estrategias conversacionales que se utilizan para salvaguardar la imagen del interlocutor como, por ejemplo, el cambio de tópico conversacional. Veamos (11) en el que las mismas interlocutoras de las ocurrencias anteriores siguen dialogando sobre los planes del próximo verano:

C:

[yo me voy ] a pegar un verano que te cagas $\uparrow$ el invierno va a ser una mierda lo que este verano me voy pegar un viaje por toda Europa que se va a cagar la perra (RISAS) ((ellaa))/ quiero hacer el Interrail ${ }^{55}$ [ con]

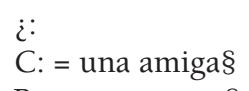

(Corpus Val.Es.Co., digital [151.B.:424-430])

En (11) C habla sobre los planes de verano que se ha propuesto al acabar el curso. Mientras cuenta sus intenciones, utiliza la expresión coloquial se va a cagar la perra como gancho humorístico, que le produce risas a ella misma, pero no a sus interlocutoras, que están más preocupadas de aprobar todas las asignaturas que en pensar en el verano. En este caso, también se produce humor fallido en el hablante, ya que ha introducido un gancho que sus oyentes no han interpretado como tal y no han compartido, porque no consideran la situación humorística. Así, deciden cambiar el tópico conversacional, tal y como muestra la intervención de B (pero ipiensas sacarlo todo en junio?) para que no peligre la imagen negativa de $C$.

En los casos de humor fallido, el oyente interpreta un falso gancho o el hablante introduce ganchos en su intervención que producen incongruencias. Estas pistas, que deja al oyente para que las interprete y continúe el modo humorístico con algún remate o resuelva esa incongruencia con otro gancho, fracasan porque no se aceptan como enunciados humorísticos. Los temas en los ejemplos que hemos analizado de humor fallido tienen que ver con las

55. Se trata de un billete de tren único que te permite viajar por Europa durante un tiempo determinado. Es muy popular entre los jóvenes.

Feminismo/s 24, diciembre 2014, pp. 17-39 
vivencias de las interlocutoras, de ahí que decidan no continuar el humor para proteger su imagen pública.

\section{Conclusiones}

Este trabajo se ha centrado específicamente en analizar los enunciados conversacionales producidos por mujeres en los que aparece el modo humorístico continuado y fallido. Si se percibe el modo humorístico y se comparte se darían las cuatro fases del humor, vistas en la figura 1 , y, por tanto, el humor continuado en el enunciado, mientras que si no se continúa el modo humorístico, porque no hay acuerdo, se dan solo tres fases (reconocimiento, entendimiento y apreciación) y aparecen los casos de humor fallido.

En los casos en los que el grado de familiaridad o cercanía es menor entre las interlocutoras, se producen más casos de humor continuado en mujeres. Este hecho se debe a que se afianzan los lazos con el grupo conversacional y permite proteger la imagen pública de las interlocutoras. Sucede, sobre todo, en los casos en los que se realiza humor con temas relacionados con situaciones o con personas ausentes, como hemos visto en (2), (3), (4), (5), (6) y (7).

El humor fallido en conversaciones de mujeres se produce, en la mayoría de los casos, para proteger la imagen de las interlocutoras, ya que el grado de familiaridad y cercanía favorece la aparición de la ironía y el humor que atenta sobre los participantes del acto comunicativo. Se produce, sobre todo, con temas relacionados con su vida cotidiana. Las estrategias conversacionales que se han utilizado en los casos analizados son: la continuación del tema serio, como hemos visto en (8) y (9), los silencios (10) y el cambio de tópico conversacional (11).

En general, podemos afirmar que las mujeres en la conversación cotidiana realizan humor continuado para afianzar los lazos del grupo conversacional y lo rechazan para salvaguardar su imagen pública. En futuros trabajos observaremos qué sucede cuando son hombres los que realizan el humor.

\section{Referencias}

Corpus

BRIZ, Antonio y Grupo Val.Es.Co.: Corpus de conversaciones coloquiales (digital), 2002.

Bibliografía

Alvarado, M. Belén: «Las marcas de la ironía». In Interlingüística, 16, Online, 2006. 
Alvarado, M. Belén: «Ironía y cortesía». En Ruiz Gurillo L. \& X. Padilla (eds.). Dime cómo ironizas y te diré quién eres: una aproximación pragmática a la ironía. Frankfurt, Peter Lang. 2009, pp. 333-345.

Alvarado, M. Belén: Las fórmulas rutinarias del español: teoría y aplicaciones. Frankfurt, Peter Lang, 2010.

AlvarAdo, M. Belén: «Una propuesta de estudio para el humor en la conversación coloquial». ELUA, 26, 2012, pp. 7-28.

AlvarAdo, M. Belén: «Failed humor in conversational utterances in Spanish: a matter of (im)politeness». En Ruiz Gurillo, L. y Alvarado Ortega, B.: Irony and Humor: From Pragmatics to Discourse. Amsterdam. John Benjamins, 2013.

AtTARDO, Salvatore: Humorous Texts: A semantic and pragmatic analysis. Berlin. Mouton De Gruyter, 2001a.

ATTARDO, Salvatore: «Humor and irony in interaction: from mode adoption to failure of detection». En L. Anolli, R. Ciceri \& G. Riva (eds.): Say not to say: new perspectives on miscommunication, 2001b, pp. 166-186.

ATtARDO, Salvatore: «Multimodal markers of irony and sarcasm», en Humor: International Journal of Humor Research, 16:2, 2003, pp. 243-260.

ATtARDO, Salvatore: «A primer for the linguistics of humor». En Raskin, V. (ed.): The primer of humor research. Berlin, Mouton de Gruyter, 2008.

ATTARDO, Salvatore y Victor RASKIN: «Script theory revis(it)ed: Joke similarity and joke representation model». En HUMOR: International Journal of Humor Research, 4, 1991, pp. 293-347.

BELL, Nancy: «Responses to failed humor», Journal of Pragmatics 41, 2009a, pp. 1825-1836.

BELL, Nancy: «Impolite responses to failed humor». En Humor in interaction, Neal Norrick and Chiaro (eds.), Amsterdan/Philadelphia. John Benjamins, 2009b, pp. 143-163.

BROWn, Penelope y Stephen LeVInSON: Politeness: Some universals in language usage. New Cork. Cambridge University Press, [1978] 1987.

COSER, Rose: «Laughter among colleagues: A study of the social functions of humor among the staff of a mental hospital», Psychiatry 23, 1960, pp. 83-91.

CUlPEPER, Jonathan: «Towards an anatomy of impoliteness», Journal of Pragmatics 25, 1996, pp. 349-367.

EISTERHOlD, Jodi, ATTARDO, Salvatore and BOXER, Diana: «Reactions to irony in discourse: evidence fo the least disruption principle», Journal of Pragmatics 38, 2006, pp. 1239-1256.

HAVERKATE, Henk: «La ironía verbal: análisis pragmalingüístico». En Revista Española de Lingüística, 15, 2, 1985, pp. 343-391.

HAVERKATE, Henk: La cortesía verbal. Estudio pragmalingüístico. Madrid, Gredos, 1994.

Feminismo/s 24, diciembre 2014, pp. 17-39 
HAY, Jennifer: «Functions of humor in the conversation of men and women». En Journal of Pragmatics, 32, 2000, pp. 709-742.

HAY, Jennifer: «The pragmatics of humor support», Humor 14-1, 2001, pp. 55-82.

HolmeS, Janet: «Sharing a laugh: Pragmatic aspects of humor and gender in the work-place». En Journal of Pragmatics, 38, 2006, pp. 26-50.

Holmes, Janet y Meredith MARRA: «Having a laugh at work: how humour contributes to workplace culture». En Journal of Pragmatics, 34, 2002, pp. 1683-1710.

JESPERSEN, Otto: Language: Its nature, development and origins. London. Allen and Unwin, 1922.

KotThoff, Helga: «Gender and joking: on the complexities of women's image politics in humorous narratives». En Journal of Pragmatics, 32, 2000 pp. 55-80.

Kotтhoff, Helga: «Responding to irony in different contexts: on cognition in conversation». Journal of Pragmatics, 35, 2003, pp. 1387-1411.

Kotthoff, Helga: «Gender and humor: The state of the art». En Journal of Pragmatics, 38, 2006, pp. 4-25.

LABOV, William: «The social stratification of $\mathrm{r}$ in New York City Department Stores». En Coupland y Jaworski (eds.): Sociolinguistics: A reader and Coursebook. New York. Martin`s Press, 1997, pp. 168-178.

LAKOFF, Robin: Language and Woman's place. New York, Harper and Row, 1975.

MiLls, Sarah: «Gender and impoliteness». Journal of Politeness Research 1, 2005, pp. 263-280.

NORRICK, Neal: «Issues in conversational joking». Journal of Pragmatics 35, 2003, pp. 1333-1359.

NORRICK, Neal and Delia Chiaro: Humor in interaction. Amsterdam/Philadelphia, John Benjamins, 2009.

PRIEGO VAlVERDE, Beatrice: «Failed humor in conversation: A double voicing analysis». En Norrick, Neal and Delia Chiaro: Humor in interaction. Amsterdam/Philadelphia. John Benjamins, 2009, pp. 165-186.

RASKIN, Victor: Semantic Mechanisms of Humor. Dordrecht, D. Reidel, 1985.

RUIz GuRILlo, Leonor: «¿Cómo se gestiona la ironía en la conversación?» En Rilce, 25.2, 2009, pp. 363-377.

RUIZ GURILLO, Leonor: «Para una aproximación neogriceana a la ironía en español». En RFE, 40, 2, 2010, pp. 95-124.

Ruiz GuRILlo, Leonor: La lingüística del humor en español. Madrid, Arco Libros, 2012.

RuIz GuRILlo, Leonor y Xose Padilla (eds.): Dime cómo ironizas y te diré quién eres: una aproximación pragmática a la ironía. Frankfurt, Peter Lang, 2009.

Ruiz Gurillo, Leonor y Belén Alvarado Ortega (eds.): Irony and Humor: From Pragmatics to Discourse. Amsterdam. John Benjamins, 2013. 
SANTAEMILIA, José: «Towards a pragmatics of gendered conversation: a few general considerations». En Quaderns de Filología, vol. VII, 2002, pp. 93-113.

SudERlAnd, Jane y Lia Litosseliti (eds.): Gender identity and discourse analysis. Amsterdan. John Benjamins, 2002.

SPENCER-OATEY, Helen: (Im)Politeness, face an perceptions of rapport: un packaging their bases an interrelationships». Journal of Politeness Research 1, 2005 pp. 95-119.

TRUdGILL, Peter: The social differentiation of English in Norwich. Cambridge. Cambridge University Press, 1972.

ZAJDMAN, Anat: «Humorous face-threatening acts: Humor as strategy». Journal of Pragmatics 23, 1995, pp. 325-339. 



\title{
HUMOR, GÉNERO Y RELACIÓN SOCIAL. EL HUMOR COMO ESTRATEGIA INTERACCIONAL
}

\author{
Magdalena Romera \\ Universidad Pública de Navarra-Universitat de les Illes Balears
}

Recibido: 15/09/2014

Aceptado: 24/11/2014

\section{Resumen}

Este trabajo explora el uso de las expresiones lingüísticas de humor como herramienta interaccional en la conversación, en relación al género de los participantes y la relación social que los une. Mientras que hace algún tiempo se aludía a la falta de sentido del humor por parte de las mujeres, hoy está claro que las mujeres, al igual que los hombres, usan el humor como estrategia fundamental en la interacción. Desde este punto de vista interaccional, se ha aludido además a la importancia de factores sociales y contextuales en la producción e interpretación del humor. En este trabajo nos centramos en la relación social que mantienen los hablantes como elemento que condiciona su conducta discursiva y que por lo tanto puede afectar al uso de las expresiones de humor. A partir de los datos de conversaciones semidirigidas, mantenidas por dos parejas de mujeres, dos parejas de hombres, una pareja mixta y dos grupos de hombres y mujeres, a los que les unen distintas relaciones, analizamos el humor como estrategia discursiva. Teniendo en cuenta que el recurso al humor presenta variaciones individuales, vemos cómo tanto mujeres como hombres lo utilizan fundamentalmente como herramienta para el fortalecimiento de la relación social. Asimismo el grado de fortaleza de los vínculos entre ellos permite un mayor o menor despliegue del modo humorístico de interacción.

Palabras clave: Género; expresión del humor; relación social; interacción discursiva; afiliativo; informacional.

\begin{abstract}
This paper explores the use of linguistic expressions of humor as an interactional tool in conversation, according to the gender of the participants and the social relationship
\end{abstract}


held between them. While early studies argued that women lacked a sense of humor, it is now clear that both women and men use humor as a key strategy in interaction. Besides gender, from an interactional perspective, other social and contextual factors have been claimed to play an important role in the use of humor. In this paper we focus on the social relationship held between speakers as an element that determines their linguistic behavior and which can therefore affect their use of humor in interaction. From semi-structured conversations maintained by two pairs of women, two pairs of men, a couple and two mixed groups of men and women, we analyze the use of humorous expressions as an interactional strategy. Bearing in mind that the use of humor is highly constrained by individual variation, we see how both women and men use humorous expressions primarily as a way of strengthening their social relationships. Also the strength of the bonds holding between them allows them to use a more humorous or a more serious mode of communication.

Keywords: Gender; expression of humor; social relationship; discourse interaction; affiational; informational. 


\section{Introducción}

Este trabajo explora el uso de las expresiones lingüísticas de humor como herramienta interaccional en la conversación, en relación a dos variables concretas, el género de los participantes y la relación social que los une.

Los estudios sobre las expresiones de humor señalan las diferencias en su uso con respecto al género de los hablantes. Mientras que en los primeros estudios se aludía a la falta de sentido del humor en las mujeres, hoy en día se sabe que las diferencias entre ambos no están tanto en su uso, puesto que ambos utilizan el humor como estrategia fundamental en sus interacciones, sino en las distintas funciones con que cada uno las emplea ${ }^{1}$. Dentro de los estudios hispánicos, el grupo GRIALE es quien más detalladamente ha analizado el humor en discursos espontáneos ${ }^{234}$. Sus trabajos han arrojado luz sobre el uso de las expresiones humorísticas, especialmente sobre el recurso a la ironía en la conversación. En esta línea, parece necesario profundizar en aspectos relacionados con las variables sociales que condicionan el uso del humor. En este trabajo queremos ocuparnos de este aspecto, en concreto de comprobar qué uso se hace del humor como estrategia interaccional teniendo en cuenta el género de los hablantes. Además de esto, debido precisamente a la perspectiva interaccional que adoptamos, nos parece necesario contar con otras variables que juegan un papel esencial en la interacción. Aunque la mayoría de los estudios sobre el humor hace referencia a la importancia de los factores sociales y contextuales en

1. KотткоFF, Helga. «Gender and humor: The state of the art». Journal of Pragmatics 38 (2006), pp. 4-25.

2. Ruíz Gurillo, Leonor y Padilla García, Xosé. A. (dirs.). Dime cómo ironizas y te diré quién eres. Una aproximación pragmática a la ironía, Frankfurt, Peter Lang, 2009.

3. Ruíz GuRILlo, Leonor. La lingüística del humor en español, Madrid, Arco/Libros, 2012.

4. Alvarado Ortega, M. Belén. «An Approach to Verbal Humor in Interaction», ProcediaSocial and Behavioral Sciences 95 C, (2013), pp. 594-603. 
la producción e interpretación del mismo ${ }^{5789}$, hasta el momento no se ha explorado la relevancia de la 'relación social' entre los hablantes como factor condicionante. Todo hecho discursivo presenta funciones relacionadas con su propósito comunicativo, así como otras cuyo objetivo es el mantenimiento de la relación social en buenas condiciones ${ }^{10}$. Entendemos por relación social el resultado de los vínculos entre participantes que crean un contexto particular para los interlocutores, en el que el plano colectivo no es la suma de las circunstancias individuales, sino el resultado de la historia conjunta de ambos ${ }^{11}$. De este modo, la relación social crea reglas de conducta particulares, un código relacional propio ${ }^{12}$, que condiciona el uso de las expresiones lingüísticas entre los miembros.

Para explorar estos aspectos nos centramos en el análisis de datos extraídos de cinco conversaciones semidirigidas entre hablantes repartidos en función del género y la relación social que los une. Analizaremos los datos de las conversaciones mantenidas entre dos parejas de mujeres, dos parejas de hombres, una pareja mixta y dos grupos de hombres y mujeres en las que se les pide que discutan sus opiniones acerca de varios temas. Comprobaremos hasta qué punto los factores género y tipo de relación se muestran como condicionantes en el uso de las expresiones de humor.

5. Attardo, Salvatore. Humorous Texts: A Semantic and Pragmatic Analysis, Nueva York, Mouton de Gruyter, 2001.

6. ATtARDO, Salvatore. «A primer for the linguistics of humor.» En Victor Raskin (dir.). The primer of humor research, Berlin, Mouton de Gruyter, 2008.

7. Kerbrat-OreCChiOni, Catherine. «Lhumour au quotidien». En Philip Merlo (dir.) L'humour hispanique, Grimh-LCE-Grimia, Université Lumière Lyon 2, 2004.

8. KotThofF, Helga, 2006, op. cit.

9. Ruíz GURILlO, Leonor, 2012, op. cit.

10. Watzlawick, Paul, Beavin, Janet y Jackson, Don. The Pragmatics of Human Communication. Nueva York, W.W. Norton and Company, 1967.

11. ARUNDAlE, Robert. «Relating», En Miriam Locher y George Sage (dirs.): Interpersonal pragmatics, Berlin, Mouton de Gruyter, (2010), pp. 137-165.

12. Burleson, Brant, MetTS, Sandra y KirCH, Michael W. «Communication in close relationships». En Clyde Hendrick y Susan S. Hendrick (dirs.), Close relationships: A sourcebook, Thousand Oaks, CA, Sage, 2000, pp. 244-258. 


\section{2, Humor y género en la interacción discursiva}

Diversos autores han señalado que el humor es una forma de interacción social ${ }^{13} 14151617$. El modo de interacción humorístico permite interpretar los aspectos de la realidad desde una perspectiva diferente, proporciona un marco compartido en el que tienen cabida las contradicciones, incongruencias y ambigüedades inherentes a toda relación social, y permite por tanto negociar transacciones de otro modo difíciles ${ }^{18}$.

Las funciones principales de las expresiones de humor en la interacción generalizables a diferentes culturas han sido definidas en torno a tres tipos. El destinado a reforzar el vínculo entre interlocutores, también llamado de solidaridad; el relativo a la gestión del poder en la interacción; y el encaminado a servir funciones psicológicas, tales como proteger la imagen propia o gestionar problemas propios o aspectos difíciles 19202122232425 .

La función solidaria parece ser la más frecuente en todos los estudios sobre el humor y está estrechamente ligada al mantenimiento de la interacción y de la propia relación entre los hablantes. En este sentido se ha apelado al principio de la búsqueda del acuerdo ${ }^{26}$. Como señala Pullin $(2010)^{27}$, el consenso

13. RASKIN,Victor. Semantic Mechanisms of Humor. Dordrecht, D. Reidel, 1985.

14. MulKaY, Michael. «On Humour», Cambridge, Polity Press, 1988.

15. ATTARDO, Salvatore, 2001, op. cit.

16. KотTHOFF, Helga, 2001, op. cit.

17. MARTIN, Rod A. The psychology of humor. An integrated approach, Amsterdam, Elsevier, 2007.

18. MARTIN, Rod A., op. cit., p. 115.

19. AlBERTS, Janet. «The use of humor in managing couples' conflict interactions». En Cahn, Dudley D. (dir.). Intimates in conflict. A communicative prespective, Hillsdade, Lawrence Erlbaum, 1990, pp. 105-120.

20. ERVIN-TRIPP, Susan M., LAMPERT, Martin D. «Gender differences in the construction of humorous talk». En Kira Hall, Mary Buchholtz y Birch Moonwomon (dirs.), Locating Power: Proceedings of the Second Berkeley Women and Language Conference. Berkeley, University of California, 1992, pp. 108-117.

21. HAY, Jennifer. «Functions of humor in the conversations of men and women». Journal of Pragmatics 32 (2000), pp. 709-742.

22. KotTHOFF, Helga, 2001, op. cit.

23. HOLMES, Janet. «Sharing a laugh: pragmatic aspects of humor and gender in the workplace». Journal of Pragmatics 38 (2006), pp. 26-50.

24. Ruíz GuRILlo, Leonor, 2012, op. cit.

25. Alvarado Ortega, M. Belén, 2013, op. cit.

26. GRICE, H. Paul. «Logic and conversation». En Peter Cole y Jerry Morgan (dirs.), Syntax and Semantics 3: Speech acts, Nueva York, Academic Press, 1975, pp. 41-58.

27. PUllin, Patricia. "Small talk, rapport, and international communicative competence: Lessons to learn from BELF». Journal of Business Communication, 47 (4) (2010), pp. 455-476.

Feminismo/s 24, diciembre 2014, pp. 41-66 
y la búsqueda de puntos en común refuerzan la solidaridad entre los actantes, revitalizando al mismo tiempo la buena relación entre ellos y suavizando los posibles conflictos anteriores o futuros. Lo interesante es que consenso y solidaridad se retroalimentan. A mayor cercanía y solidaridad establecida y asentada en la relación, mayor es la tolerancia al desacuerdo y la disposición a la resolución del mismo, sin que esto afecte a las partes. El humor es también una estrategia discursiva que permite la gestión del poder en la interacción. Martineau $(1972)^{28}$, Hay $(2000)^{29}$ o Kotthoff $(2006)^{30}$ se refieren a la indexicalización del estatus o la provocación del conflicto en la interacción. En este sentido, el uso de expresiones de humor para la expresión del desacuerdo o incluso para la propia agresión puede estar reservada a aquellos que ostentan el poder en la relación, tanto para aumentar las diferencias como para reducir la asimetría ${ }^{31}{ }^{32}$. El humor también denota poder cuando se emplea para mantener el control de la situación, del comportamiento del otro o de las reglas interaccionales. Finalmente, las funciones psicológicas del humor se centran en el uso del humor para la expresión de aspectos delicados, de los que de otro modo resultaría difícil hablar o que pondrían en peligro la imagen de la persona.

Como vemos, la actividad humorística es una actividad dialógica y sensible a los elementos contextuales. Los factores situacionales, la relación entre los interlocutores, las características de los mismos, edad, sexo, estatus y su disposición y personalidad, harán que el humor obtenga distintas interpretaciones y cumpla funciones diversas.

Entre estos factores se han destacado las diferencias existentes en torno al género como variable transversal que cruza todas las interacciones. Los primeros trabajos en el ámbito anglosajón proponían una incapacidad de la mujer tanto para el uso como para la interpretación del humor ${ }^{33} 34$. Sin embargo, los estudios posteriores han mostrado que esta visión tomaba como

28. MartineAU, William. «A model of the social functions of humor». En Jeffrey Goldstein y Paul McGhee (dirs.), The psychology of humor, Nueva York, Academic Press, 1972, pp. 101-125.

29. HAY, Jennifer, 2000, op. cit.

30. KotTHOFF, Helga, 2006, op. cit.

31. COSER, Rose L. «Laughter among colleagues». Psychiatry 23 (1960), pp. 81-95.

32. KotTHOFF, Helga, 2006, op. cit.

33. LAKOFF, Robin. Language and Woman's Place. NuevaYork, Harper y Row, 1975.

34. Cox, Joe A., Read, L. Raymond y Van Auken, Philip M., «Male-female differences in communicating job-related humor: An exploratory study». Humor 3(1990), pp. 287-295.

35. Goodman, Lizbeth. «Gender and humour». En Frances Bonner et al. (dirs), Imagining women: Cultural representations and gender, Cambridge: Polity, 1992, pp. 296-300. 
referencia un modelo simplista de comunicación, basado únicamente en una perspectiva masculina ${ }^{36}$. Los trabajos más recientes indican que hombres y mujeres utilizan el humor en la interacción, aunque pueden variar las funciones con que cada uno lo emplea.

Una de las características que habitualmente se menciona como típicamente femenina es la orientación más solidaria de la mujer ${ }^{37}$. Los primeros estudios indicaban que las mujeres utilizaban el humor de modo menos agresivo que los hombres ${ }^{38}$. Por el contrario, trabajos más recientes muestran que el humor juega papeles parecidos en ambos, haciendo prevalecer el establecimiento de la solidaridad tanto entre mujeres, como entre hombres, como en grupos mixtos ${ }^{39}{ }^{40}$. A pesar de esto, las estrategias utilizadas pueden ser diferentes, Hay $(2000)^{41}$, Kotthoff $(2000)^{42}$ o Ruíz Gurillo (2012) ${ }^{43}$ coinciden en reportar que las mujeres emplean más alusiones a experiencias propias para crear afinidad con su interlocutor, mientras que los hombres recurren al recuento de experiencias compartidas o alusiones sarcásticas a miembros presentes. Al mismo tiempo la relación social se muestra como un elemento de gran relevancia en las funciones solidarias del humor, prevaleciendo sobre el género de los actantes, de modo que el ataque o la provocación del conflicto mediante el humor solo se permiten cuando la relación está bien establecida ${ }^{44}$. La ironía o la burla aunque sea humorística, siempre pueden resultar amenazadoras y por tanto peligrosas para el mantenimiento de la relación ${ }^{45}{ }^{46}$.

Las diferencias en la indexicalización del poder en la interacción también se muestran asociadas al género. La mayoría de los estudios sugiere que son los hombres los que utilizan el humor para hacer prevalecer su estatus sobre

36. JENKINS, Mercilee. «What's so funny?: Joking among women». En Sue Bremner, Noelle Caskey y Birch Moonwomon (dirs), Proceedings of the first Berkeley Women and Language Conference, Berkeley, CA, Women and Language Group, 1985, pp. 135-151.

37. Deaux, Kay, «Sex and Gender». Annual Review of Psychology 36 (1995), pp. 49-82.

38. Mitchell, J. Clyde. «Network procedures». En Dieter Frick (dir.), The Quality of Urban Life, Berlin, Mouton de Gruyter, 1986, pp. 73-92.

39. HAY, Jennifer, 2000, op. cit.

40. Ruíz GuRILlo, Leonor, 2012, op. cit.

41. HAY, Jennifer, 2000, op. cit.

42. KotTHOFF, Helga, 2006, op. cit.

43. Ruíz GuRILlo, Leonor, 2012, op. cit.

44. HOLMES, Janet. «Sharing a laugh: pragmatic aspects of humor and gender in the workplace». Journal of Pragmatics 38 (2006), pp. 26-50.

45. Kotthoff, Helga, 2006, op. cit.

46. Ruíz GuRILlo, Leonor, 2012, op. cit.

Feminismo/s 24, diciembre 2014, pp. 41-66 
los otros interlocutores y en muchas ocasiones sobre las mujeres ${ }^{47}{ }^{48}$. Las mujeres, sin embargo, raramente utilizan el humor para menospreciar al otro y marcar su propio estatus. De todas formas, el ataque al otro mediante el comentario humorístico también se da tanto en hombres como en mujeres, aunque siempre teniendo en cuenta la relación social y los factores contextuales. Las mujeres mayores muestran más permisividad hacia el humor agresivo sobre el otro, y las adolescentes usan el humor y la burla en sus conversaciones sobre $\operatorname{chicos}^{49} 50$.

Por último, las funciones psicológicas del humor también se podrían asociar a un rasgo tradicionalmente atribuido a las mujeres, puesto que su uso implica un estilo comunicativo más indirecto y probablemente más cortés, generalmente asociado a lo femenino ${ }^{51}$. Sin embargo, tanto hombres como mujeres utilizan el humor para minimizar el impacto de temas difíciles o manejar conflictos y contribuciones problemáticas en la interacción. Hay $(2000)^{52}$ encuentra que las mujeres recurren al humor de manera más general en todos los aspectos potencialmente problemáticos del discurso, mientras que los hombres lo hacen solo para aquellos casos surgidos durante la interacción.

\section{Relación social}

La segunda variable que vamos a considerar en este estudio es la relación social. El concepto de relación social no es nuevo en los estudios del discurso, sin embargo como indicábamos en la introducción, a pesar de constatarse su importancia en el uso de las expresiones lingüísticas, hasta el momento solo ha recibido una relativa atención.

Dentro de la sociolingüística se conoce desde hace tiempo la interacción entre los vínculos que unen a los hablantes y el uso de distintas expresiones

47. BENDIX, John y BENDIX, Regina. «Politics and gender in humor and satire: the cases of Elisabeth Kopp and Geraldine Ferraro.» Schweizer Zeitschrift für Soziologie, 2, (1992), pp. 441-460.

48. BARON, Bettina, y KotTHOFF, Helga (dirs.). Gender in Interaction: Perspectives on Femininity and Masculinity in Ethnography and Discourse, Amsterdam, John Benjamins, 2001.

49. EDER, Donna. "Go get ya a French!": romantic and sexual teasing among adolescent girls». En Deborah Tannen (dir), Gender and Conversational Interaction, Oxford, University Press, 1993, pp. 17-30.

50. KotTHOFF, Helga, 2006, op. cit.

51. Cameron, Deborah. The Myth of Mars and Venus: Do Men and Women Really Speak Different Languages? Oxford, University Press, 2007.

52. HAY, Jennifer, 2000, op. cit. 
lingüísticas. Por ejemplo, la conocida teoría de las redes sociales ${ }^{53}$ se sustenta en la idea de que el cambio lingüístico se produce en función de las relaciones interpersonales de los miembros de una comunidad. Otras corrientes que también han centrado su atención en la relación social se encuentran dentro de la Pragmática. La nueva corriente denominada Pragmática Interpersonal ${ }^{54}$ estudia 'la forma en la que los actantes usan el lenguaje para dar cuerpo y formar relaciones 'in situ' 55 . Tomando como base los postulados de la Comunicación Interpersonal, definen las relaciones interpersonales como «conexiones sociales mutuas entre individuos mediadas por la interacción, incluyendo el poder, la confianza, los roles, los derechos y las obligaciones $»^{56} 57$. Las relaciones pueden entenderse en su versión débil o fuerte ${ }^{58}$. La primera entiende la relación como la suma de las circunstancias de cada uno de los actantes, a partir de los objetivos y demandas de cada uno de ellos. La segunda la entiende como el resultado de la relación que une a los participantes y que se construye y modifica con cada una de las interacciones. La relación en este caso es dinámica y en continuo cambio y condiciona cada una de las interacciones futuras de esos individuos. La visión sin embargo más radical de la pragmática basada en las relaciones sociales es la defendida por Einfiel $(2009 ; 2013)^{59} 60$ en su teoría 'Relationship thinking' ${ }^{61}$. Desde una perspectiva cognitivo antropológica, Einfeld considera que el individuo se define prioritariamente en términos de sus relaciones sociales. Siguiendo las teorías clásicas de la comunicación, afirma que el ser humano al comunicarse debe sujetarse a dos imperativos pragmáticos básicos, el informacional y el afiliativo. El imperativo informacional persigue que aquello que se dice sea interpretado de acuerdo a nuestra intención comunicativa, mientras que el afiliativo nos hace asegurarnos de que manejamos adecuadamente las consecuencias socia-

53. Milroy, Lesley. Language and Social Networks, Blackwell, Oxford, 1987.

54. LOCHER, Miriam y GRAHAM, Sage L. «Introduction to interpersonal pragmatics». En Miriam Locher (dir.). Interpersonal Pragmatics. Berlin, Mouton de Gruyter, 2010, pp. $1-13$.

55. LOCHER, Miriam y GrahAm, Sage L., op. cit., p. 1.

56. HAUGH Michael, KÀDÀr Dániel Z. y Mills, Sara. «Interpersonal pragmatics. Issues and debates». Journal of Pragmatics 58 (2013), p. 4.

57. Traducción propia.

58. ARUNDALE, Robert, 2010, op. cit.

59. ENFIELD, Nick J. «Relationship thinking and human pragmatics». Journal of Pragmatics, 41 (2009), pp. 60-78.

60. ENFIELD, Nick J. Relationship thinking: Agency, enchrony, and human sociality. Oxford, University Press, 2013.

61. Hasta el momento no existe traducción para este término. Una aproximación sería «Pensamiento basado en las relaciones».

Feminismo/s 24, diciembre 2014, pp. 41-66 
les en nuestras interacciones ${ }^{62}$. Y es concretamente este último el que conduce al individuo a construir de forma particular su discurso, puesto que como seres sociales estamos obligados a mantener nuestras relaciones con los otros. Esto nos lleva a la configuración de una estructura social propia para la que poseemos restricciones cognitivas específicas; asimismo nos obliga a emplear tiempo y esfuerzo en pos de su mantenimiento.

Dentro de las corrientes hispánicas del discurso no existen trabajos que incorporen específicamente la variable «relación social», a excepción de algunas propuestas realizadas por Grupo Val.Es.Co. Briz (1998) ${ }^{63}$ en su caracterización del registro coloquial, propone contar con la llamada 'relación vivencial de proximidad' que engloba el «conocimiento mutuo, saber y experiencia compartidos (presuposiciones comunes) ${ }^{64}$. Como vemos, este rasgo podría considerarse cercano a la relación social entre los hablantes, puesto que alude a las características que estos comparten en función de su experiencia compartida, lo que tiene capacidad de condicionar la producción e interpretación del discurso. Estos autores, sin embargo, no desarrollan esta variable o especifican las condiciones para que se dé esta relación o las implicaciones de los distintos tipos de proximidad.

De cualquier modo, es evidente que existe una clara relación entre el tipo de vínculo que se crea entre los hablantes y las condiciones de la interacción, y esto tiene reflejo necesariamente en el uso de las expresiones lingüísticas. En este artículo defendemos la idea de que el ser humano es esencialmente un ser social que configura su propia identidad a partir de la pertenencia al grupo $^{65}$, las actividades y la imagen individuales existen por contraposición a las sociales ${ }^{66}{ }^{67}$. Por tanto las relaciones sociales se crean, existen y deben preservarse para la propia supervivencia. Entendemos la relación social en su versión 'fuerte', como el vínculo que se construye de manera dinámica entre los actantes a partir de cada interacción y de las experiencias compartidas. Al mismo tiempo vamos más allá en la estructura de las relaciones del indi-

62. ENFIELD, Nick J., 2009, op. cit., p. 72.

63. BRIZ GÓMEZ, Antonio. El español coloquial en la conversación: esbozo de pragmalingüística, Barcelona, Ariel, 1998.

64. BRIZ GÓMEZ, Antonio, 1998, op. cit, p. 41.

65. TAYLOR, Charles. Sources of the Self: The Making of the Modern Identity, Cambridge, University Press, 1989.

66. GofFMAn, Erving. Interaction Ritual. Essays on Face-to-face Behavior, Nueva York, Pantheon Books, 1967.

67. HeRITAGE, John y RAYMOND, Geoff. «The terms of agreement: indexing epistemic authority and subordination in talk-in-interaction». Social Psychology Quarterly 68 (2005), pp. 15-38. 
viduo y creemos que no solo se crean condiciones cognitivas específicas de cada relación ${ }^{68}$ para la producción e interpretación del discurso en interacción, sino que el tipo de vínculo conlleva la creación de normas lingüísticas y comportamentales, un código relacional propio para cada diada que permite gestionar adecuadamente la relación con el otro ${ }^{69}$.

La relación social se crea a partir de los elementos históricos que condicionan el vínculo entre los individuos, la forma de creación de la relación, su duración en el tiempo, y el grado de confianza o profundidad de la misma. La mayoría de las relaciones son establecidas de antemano, 'ancladas externamente ${ }^{70}$ tales como las relaciones familiares, vecinales o profesionales. En todos estos casos las reglas de interacción están preestablecidas de acuerdo al consenso de la comunidad en la que surgen. Sin embargo, la historia compartida es primordial para caracterizar cada relación. La extensión en el tiempo, el grado de confianza y la frecuencia e intensidad de las experiencias vividas en común determinan esa historia ${ }^{71}{ }^{72}$. El hecho de compartir experiencias afianza la relación y ayuda a crear un compromiso recíproco. Cuanto más cercana sea la relación, más esperable es que ambos interlocutores se comporten de manera recíproca en cuanto a derechos y obligaciones en la relación. Esto condiciona un comportamiento social y lingüístico, en el que determinadas actuaciones son esperables o admisibles en función del grado de compromiso con el otro.

Los factores relacionados con la jerarquización social de los hablantes condicionan igualmente la constitución de las reglas de intercambio. La distancia social configurada a través del estatus y el poder de los miembros ${ }^{73}$ modifican la manera de relacionarse de dos personas a partir de la posición que se marca para cada uno de ellos, dentro de su comunidad y dentro de la propia relación. Los aspectos situacionales (escenario, tema, propósito de la

68. ENFIELD, Nick J., 2009, op. cit.

69. Burleson, Brant, MeTTS, Sandra y KirCH, Michael W., 2000, op. cit.

70. ENFIELD, Nick J., 2009, op. cit.

71. FERRAND, Alexis. «Redes heterogéneas de discusión y pluralismo cognitivo». REDES. Revista hispana para el análisis de redes sociales. Vol.10, 2 (2006). http://revista-redes. rediris.es/pdf-vol10/vol10_2.pdf. Consultado el 19-03-2014.

72. BOURDON, Sylvain. «Relaciones sociales y trayectorias biográficas: hacia un enfoque comprensivo de los modos de influencia». REDES. Revista hispana para el análisis de redes sociales. 16, 6/2009. http://revista-redes.rediris.es/pdf-vol16/vol16_6.pdf. Consultado el 13-03-2014.

73. Brown, Penélope y Gillman, Albert. «Pronouns of power and solidarity». En Thomas Albert Sebeok (dir.), Style in Language. Cambridge, Mass.: MIT Press, 1960, pp. 253-276.

Feminismo/s 24, diciembre 2014, pp. 41-66 
interacción y características de los participantes, edad, sexo y nivel de instrucción) marcarán asimismo su comportamiento interaccional.

Finalmente, del mismo modo, la individualidad de los actantes tiene un gran peso. A pesar de compartir edad, sexo o nivel de instrucción, ninguno de nosotros actuamos de igual manera. Cada persona se comporta socialmente en sus propios términos. Esta individualidad se refleja en un modo personal de comportamiento condicionado por la personalidad y el temperamento: el estilo del individuo.

A medida que se produce el conocimiento mutuo y una historia común compartida, se irán estableciendo reglas de intercambio por las que se rijan los actantes. Las reglas de intercambio no son sin embargo estáticas, las interacciones diarias y el número de experiencias compartidas en distintos contextos, producen cambios que van determinando la naturaleza de la relación, y clasificando en cada momento determinados comportamientos como admisibles o inadmisibles «para esa relación».

Como señalamos en Romera y Campos Prats $(2014)^{74}$, a pesar de la aparente particularidad de estas reglas existe un rango de comportamientos determinados por los patrones culturales y las normas propias de la comunidad de práctica que marcan límites que los actantes no pueden sobrepasar (Fig. 1). Estos patrones actúan como marco bajo el que se establecen las reglas particulares de intercambio en una relación, más flexibles y variables.

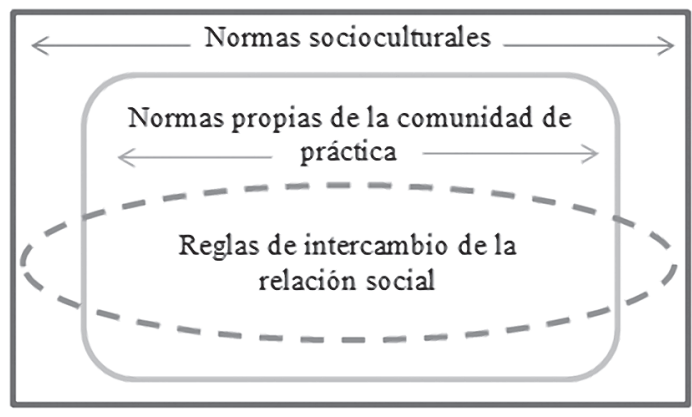

Figura 1. Reglas de intercambio

74. ROMERA, Magdalena y CAMPOS PRATS, Mar. Social relationships and discourse interaction: the case of disagreement in conversation. Enviado a Journal of Pragmatics. 2014. 
Como señala Einfield (2009) $)^{75}$, en toda relación participan además fuerzas negativas y positivas que marcan la interacción. En las relaciones no solo se promueve la confianza, o la identidad común, sino que también existe competencia, autoafirmación o diferenciación. Está claro que las características individuales de cada sujeto juegan aquí un papel importante. Debido al equilibrio de estas fuerzas, en cada interacción es habitual que se produzcan conflictos, especialmente amenazadores cuando afectan al futuro común de los relacionados. Cuando se produce una disonancia entre los individuos que crea tensión o conflicto entre ellos, los actantes pueden optar por la preservación de la relación o bien por asumir el riesgo del resquebrajamiento de la misma.

\section{Estudio empírico}

Los datos de este estudio están extraídos de conversaciones semidirigidas recopiladas entre hablantes de nivel de instrucción superior y edades comprendidas entre los 20 y los 55 años de la ciudad de Palma. Las grabaciones entre parejas se recogieron para la realización de un estudio que tenía como objetivo el análisis de las estrategias de cortesía lingüística en relación al género de los hablantes (Campos Prats, en preparación) ${ }^{76}$. El corpus cuenta con aproximadamente 7 horas de grabación y está compuesto por muestras de 14 hablantes adultos de distinto estatus, a los que se organizó e hizo interactuar por parejas dependiendo de los factores sociales género y tipo de relación. De estas, se tomaron 4 parejas. Además de estos datos, se recogieron grabaciones de otra pareja de amigos y de dos grupos de discusión mixtos, entre 18 y 25 años, todos ellos estudiantes o graduados universitarios. El primer grupo constaba de 3 mujeres y 1 hombre, y el segundo de 2 mujeres y 3 hombres. Tanto a las parejas como a los grupos se les pidió que discutieran sobre temas relacionados con los estereotipos de género.

La relación más o menos estrecha que mantenían los hablantes entre sí se determinó a partir de las siguientes variables:

1. Distancia social. Indica el grado de simetría que se establece en cuanto al estatus y el poder en la relación.

75. ENFIELD, Nick J., 2009, op. cit.

76. CAMPOS PRATS, Mar. Uso e impacto de las expresiones de des/acuerdo e identidad de género. Tesis doctoral. En preparación. 
2. Tipo de relación. Se tomaron tres tipos de relaciones de acuerdo a la división propuesta por Milardo (1988) ${ }^{77}$ y Milroy $(2008)^{78}$. Relación de intercambio en la que los hablantes mantienen una relación estrecha, interaccionan regularmente y además se prestan ayuda directa, consejo, crítica y apoyo. Relación transaccional en la que los hablantes interactúan quizá durante largos periodos de tiempo, pero no son fuente de apoyo material ni simbólico. Y relación pasiva, en la que los hablantes pueden no mantener interacción regularmente, pero sí constituyen ayuda y apoyo moral en los momentos en los que se necesita.

3. Grado de confianza. Tomado como el grado de intimidad y familiaridad entre los miembros de esa relación.

4. Calidad de la relación. Medida en función de lo bien o mal que se llevan los miembros (Alberts 1990) $)^{79}$.

5. Estilo de la pareja. Condicionado por las características de personalidad y temperamento de los miembros que resultará en la prevalencia de una de las dos fuerzas opuestas de confianza o diferenciación.

Todas las variables se ponderaron sobre el rango de 1 a 4 , donde 1 supone el valor de mayor distancia entre los interlocutores y 4 el valor de mayor cercanía entre los mismos. La ponderación dio lugar a la clasificación de hablantes y relaciones más o menos estrechas entre ellos, tal y como se muestra en la Tabla 1 a continuación.

Como vemos, las relaciones se sitúan en una escala de mayor o menor cercanía y fortaleza. Así las que se encuentran entre 1 y 2 son relaciones poco cercanas, entre 2 y 3 relativamente cercanas y entre 3 y 4 las más cercanas. En nuestros datos vemos que entre todos nuestros participantes hay relaciones que oscilan entre 2 y 4 , relativamente cercanas o muy cercanas, sin embargo se pueden establecer diferencias entre ellos. Entre cada pareja del mismo sexo una de ellas presenta mayor cercanía que la otra y lo mismo ocurre con los grupos, de modo que se puedan establecer diferencias con respecto a los resultados.

Las grabaciones fueron realizadas por un entrevistador o entrevistadora en cada caso, por lo que se trata de conversaciones semidirigidas en las que

77. MILARDO, Robert. «Families and social networks: an overview of theory and methodology». En Robert Milardo (dir.), Families and Social Networks, Newbury Park, California, Sage, 1988, pp. 13-47.

78. Milroy, Lesley. Social networks. En Jack. K. Chambers, Peter Trudgill y Natalie Schilling-Estes. The handbook of language variation and change. Oxford. Blackwell. 2008.

79. AlBERTS, Janet, 1990, op. cit. 
Tabla 1. Tipología de hablantes entrevistados y escala de relaciones entre los mismos

\begin{tabular}{|l|c|c|c|c|c|c|c|c|c|}
\hline Hablantes & Sexo & Edad & Vínculo & $\begin{array}{c}\text { Distancia } \\
\text { social }\end{array}$ & $\begin{array}{c}\text { Clase } \\
\text { de } \\
\text { relación }\end{array}$ & $\begin{array}{c}\text { Calidad } \\
\text { relación }\end{array}$ & $\begin{array}{c}\text { Grado de } \\
\text { confianza }\end{array}$ & $\begin{array}{c}\text { Estilo } \\
\text { pareja }\end{array}$ & $\begin{array}{c}\text { Relación } \\
\text { resultante }\end{array}$ \\
\hline Parejal & $\begin{array}{c}\text { Hombre } \\
\text { Mujer }\end{array}$ & $25-30$ & Pareja & 4 & 4 & 4 & 4 & 3 & 3,8 \\
\hline Pareja 2 & $\begin{array}{c}\text { Mujer } \\
\text { Mujer }\end{array}$ & $25-30$ & Amigas & 4 & 4 & 4 & 4 & 3 & 3,8 \\
\hline Pareja 3 & $\begin{array}{c}\text { Mujer } \\
\text { Mujer }\end{array}$ & $30-55$ & Madre-Hija & 3 & 4 & 4 & 3 & 3 & 3,4 \\
\hline Pareja 4 & $\begin{array}{l}\text { Hombre } \\
\text { Hombre }\end{array}$ & $18-25$ & Primos & 4 & 2 & 2 & 2 & 2 & 2,4 \\
\hline Pareja 5 & $\begin{array}{l}\text { Hombre } \\
\text { Hombre }\end{array}$ & $25-30$ & Amigos & 4 & 4 & 4 & 4 & 4 & 4 \\
\hline Grupo 1 & Mixto & $18-25$ & Compañeros & 4 & 2 & 2 & 2 & 2 & 2,4 \\
\hline Grupo 2 & Mixto & $25-30$ & Amigos & 4 & 4 & 3 & 3 & 3 & 3,4 \\
\hline
\end{tabular}

siempre se encontraba presente un miembro adicional al grupo o a la pareja. Sin embargo, es necesario señalar que en todos los casos este miembro pertenecía a la misma comunidad de habla que los participantes y mantenía con todos ellos una relación muy cercana que podría clasificarse del tipo 3-4 en nuestra escala de cercanía.

De las grabaciones se extrajeron todos aquellos fragmentos que contenían recursos al humor. Como criterio se tomó que hubieran producido una reacción de reconocimiento del humor entre los interlocutores, bien por risa o bien por reconocimiento explícito. Cada fragmento se codificó de acuerdo a las variables de los interlocutores, las variables contextuales, la estructura lingüística utilizada y sus funciones en el discurso. Las funciones se determinaron a partir de los tres tipos mencionados en la Sección 2, solidaridad, control y psicológico. Aunque ninguna de las funciones es excluyente y una misma expresión puede cumplir varias de ellas al mismo tiempo, se codificó la más prominente.

\section{5. resultados}

Lo primero que cabe destacar es que el recurso al humor presenta variaciones individuales importantes. Algunos sujetos recurren al mismo en numerosas ocasiones, es decir, forma parte de su modo personal de interacción, mientras que otros solo lo usan esporádicamente. Esto no se correlaciona con el 
género del individuo, en concreto 4 de nuestros participantes, 2 mujeres y 2 hombres, mostraron especial tendencia al modo humorístico de interacción, al menos en el contexto en el que se realizaron las grabaciones ${ }^{80}$. Esto nos ha ofrecido frecuencias de uso de expresiones humorísticas dispares, como se muestra en la Tabla 2.

Tabla 2. Frecuencia de uso de expresiones humorísticas en cada hablante

\begin{tabular}{|c|c|c|c|}
\hline Sexo & Pareja/Grupo & $\mathbf{n}$ & $\%$ \\
\hline H & P1 & 32 & 17,1 \\
\hline M & P2 & 27 & 14,4 \\
\hline H & P5 & 26 & 13,9 \\
\hline M & P2 & 17 & 9,1 \\
\hline H & P5 & 13 & 7,0 \\
\hline H & G1 & 13 & 7,0 \\
\hline M & P3 & 12 & 6,4 \\
\hline M & P3 & 11 & 5,9 \\
\hline H & P4 & 5 & 2,7 \\
\hline H & P4 & 5 & 2,7 \\
\hline M & G1 & 5 & 2,7 \\
\hline M & P1 & 4 & 2,1 \\
\hline H & G2 & 4 & 2,1 \\
\hline H & G2 & 4 & 2,1 \\
\hline M & G1 & 3 & 1,6 \\
\hline M & G1 & 3 & 1,6 \\
\hline M & G2 & 1 &, 5 \\
\hline M & G2 & 1 &, 5 \\
\hline H & G2 & 1 &, 5 \\
\hline & Total & 187 & 100,0 \\
\hline
\end{tabular}

El resto de los resultados confirman de igual manera la frecuencia de uso similar en mujeres y hombres; varían sin embargo las funciones con las que

80. Estamos de acuerdo con Kotthoff (2006), op. cit. en que la expresión del humor es extremadamente sensible al estado de ánimo y a las circunstancias concretas que atraviesa el individuo en cada momento. Por ello, consideramos que los resultados que ofrecemos pueden no ser extensibles a otros contextos. 
unas y otros las emplean. Las siguientes tablas 3 y 4 presentan los resultados obtenidos en los contextos de pareja y grupal.

Tabla 3. Funciones de la expresión de humor en mujeres y hombres en el contexto de parejas.

\begin{tabular}{|c|c|c|c|c|c|c|c|c|}
\hline & $\begin{array}{c}\text { Crear } \\
\text { consenso }\end{array}$ & $\begin{array}{c}\text { Expresar } \\
\text { desacuerdo }\end{array}$ & $\begin{array}{c}\text { Provocar } \\
\text { conflicto }\end{array}$ & $\begin{array}{c}\text { Manejar el } \\
\text { desacuerdo }\end{array}$ & $\begin{array}{c}\text { Crear } \\
\text { lazo } \\
\text { social }\end{array}$ & $\begin{array}{c}\text { Control } \\
\text { de las } \\
\text { normas }\end{array}$ & $\begin{array}{c}\text { Defensa/ } \\
\text { justificación }\end{array}$ & TOTAL \\
\hline MUJER & $32,4 \%$ & $4,2 \%$ & $2,8 \%$ & & $36,6 \%$ & $22,5 \%$ & $1,4 \%$ & $\begin{array}{c}100 \% \\
\mathrm{~N}=71\end{array}$ \\
\hline HOMBRE & $9,5 \%$ & $2,4 \%$ & $2,4 \%$ & $9,6 \%$ & $26,1 \%$ & $23,8 \%$ & $26,2 \%$ & $\begin{array}{c}100 \% \\
\mathrm{~N}=42\end{array}$ \\
\hline
\end{tabular}

Tabla 4. Funciones de la expresión de humor en mujeres y hombres en el contexto de grupo

\begin{tabular}{|c|c|c|c|c|c|c|c|c|}
\hline & $\begin{array}{c}\text { Crear } \\
\text { consenso }\end{array}$ & $\begin{array}{c}\text { Expresar } \\
\text { desacuerdo }\end{array}$ & $\begin{array}{c}\text { Provocar } \\
\text { conflicto }\end{array}$ & $\begin{array}{c}\text { Manejar el } \\
\text { desacuerdo }\end{array}$ & $\begin{array}{c}\text { Crear } \\
\text { lazo } \\
\text { social }\end{array}$ & $\begin{array}{c}\text { Control } \\
\text { de las } \\
\text { normas }\end{array}$ & $\begin{array}{c}\text { Defensa/ } \\
\text { justificación }\end{array}$ & TOTAL \\
\hline MUJER & $42,9 \%$ & $14,3 \%$ & & & $21,4 \%$ & $14,3 \%$ & $7,1 \%$ & $\begin{array}{c}100 \% \\
\mathrm{~N}=14\end{array}$ \\
\hline HOMBRE & $35,3 \%$ & $8,8 \%$ & $2,9 \%$ & $2,9 \%$ & $41,2 \%$ & $5,9 \%$ & $2,9 \%$ & $\begin{array}{c}100 \% \\
\mathrm{~N}=34\end{array}$ \\
\hline
\end{tabular}

Como vemos en la Tabla 3, en el contexto de pareja las mujeres utilizan el humor sobre todo en sus funciones sociales, para fortalecer el lazo social, y crear consenso, pero también para reforzar el control de las reglas de la interacción. Los hombres también refuerzan el vínculo social, pero prescinden del consenso y usan más el humor para el control y la justificación en aspectos problemáticos, como por ejemplo al cometer una equivocación en la conversación, como se muestra en el ejemplo (1).

$(1)^{81} \mathrm{~J}$ : Sí, aparte, creo que la mujer también lo hace, o sea creo que en esa situación estamos igual, tanto los chicos como las chicas salen de marcha.

81. En la transcripción de los ejemplos se han seguido las convenciones propuestas en DuBois et al. (1992). Estos son los símbolos básicos usados:

.. pausa breve

... pausa normal (cerca de un segundo)

... silencio

$=\quad$ alargamiento

@ risas

Feminismo/s 24, diciembre 2014, pp. 41-66 
P: [A ver, un momento, no, no lo hacen más, no lo hacen más. Lo hacen igual.

$\mathrm{J}: \quad$ [Yo he dicho igual]

P: Vale, a ver. Comunicación. Error (con voz robótica). Yo pensaba que no, yo pensaba que...

En el contexto grupal (Cf. Tabla 4 arriba), tanto hombres como mujeres utilizan el humor fundamentalmente para fortalecer los lazos sociales y crear consenso, aunque las mujeres también lo emplean para expresar el desacuerdo y mantener el control en la interacción. Parece entonces que a pesar de las diferencias, la función primordial del humor en todos los casos es reforzar los vínculos entre hablantes.

Al tener en cuenta la relación social que une a los hablantes observamos que los parámetros que más pesan son la cercanía de la relación y el poder en la pareja, como se muestra en la Tabla 5 a continuación.

Tabla 5. Funciones del humor entre las parejas de mujeres

\begin{tabular}{|c|c|c|c|c|c|c|c|}
\hline & & $\begin{array}{c}\text { Crear } \\
\text { consenso }\end{array}$ & $\begin{array}{c}\text { Crear } \\
\text { desacuerdo }\end{array}$ & $\begin{array}{l}\text { Provocar } \\
\text { conflicto }\end{array}$ & $\begin{array}{l}\text { Control de } \\
\text { las normas }\end{array}$ & $\begin{array}{c}\text { Crear lazo } \\
\text { social }\end{array}$ & $\mathbf{n}$ \\
\hline \multirow{2}{*}{ PAREJA 2} & AMIGAl & $\begin{array}{c}5 \\
29,4 \%\end{array}$ & & & & $\begin{array}{c}12 \\
70,6 \%\end{array}$ & 17 \\
\hline & AMIGA2 & $\begin{array}{c}11 \\
40,7 \%\end{array}$ & $\begin{array}{c}2 \\
7,4 \%\end{array}$ & & $\begin{array}{c}6 \\
22,2 \%\end{array}$ & $\begin{array}{c}8 \\
29,6 \%\end{array}$ & 27 \\
\hline \multirow{2}{*}{ PAREJA 3} & MADRE & $\begin{array}{c}2 \\
18,2 \%\end{array}$ & & $\begin{array}{c}2 \\
18,2 \%\end{array}$ & $\begin{array}{c}2 \\
18,2 \%\end{array}$ & $\begin{array}{c}5 \\
45,5 \%\end{array}$ & 11 \\
\hline & HIJA & $\begin{array}{c}5 \\
41,7 \%\end{array}$ & & & $\begin{array}{c}6 \\
50,0 \%\end{array}$ & $\begin{array}{c}1 \\
8,3 \%\end{array}$ & 12 \\
\hline
\end{tabular}

Como vemos, cuanto más cercana es la relación más expresiones de humor encontramos. Las dos parejas de mujeres obtienen resultados altos puesto que ambas mantienen relaciones muy cercanas. Ambas utilizan el humor de modo recurrente fundamentalmente para fortalecer su relación. Sin embargo, son las amigas las que más recurren a este modo de interacción. De las dos, A es quien lo utiliza más profusamente y presenta su uso en casi todas las funciones; A expresa acuerdo y desacuerdo, refuerza el lazo social y controla la interacción como se ve en (2), cuando interrumpe a M para introducir su intervención humorística:

negrita énfasis

[ ] segmento del discurso simultáneo con otro segmento dicho por otro hablante

/ truncamiento 
(2) M: (hablando de su novio) tiene= / tiene un interés súper extraño por la ropa y por la moda y por la elegancia; o sea, para él (.) venir elegante es/

A: $\quad$ iél no es italiano no?

En:@@@

M: No, no

A: $\quad$ entonces es gay

En:@@@

La pareja madre-hija también opta claramente por el fortalecimiento de la relación, aunque observamos que es la madre quien se permite el humor en la provocación del conflicto, debido a la asimetría existente, mientras que la hija lo usa para el refuerzo de su estatus mediante el control de las normas de la interacción. En (3) vemos como la madre se burla de la falta de delicadeza y atenciones del marido hacia la hija.

(3) M.: Bueno, un día] te regaló una piedra [@@@

En:_iiuna piedra?!] [@@@

V.: ¡Qué graciosa!]. [Era

M.: se fue] de excu[rsió=n@y le trajo una piedra@@

V.: $\quad \mathrm{No}==$ ], era una rosa del desierto que le habían traído [en un viaje.

M.: $\quad$ sí==!! ] ay, mira porque le había traído una piedra en vez de una rosa, de verdad!@@

V.: $\quad$ Es un hombre muy rudo, muy rural.

En:@@@

En el caso de los hombres las diferencias entre las dos parejas son más acusadas, en correlación con la distinta relación que los une (Cf. Tabla 6 a continuación).

Tabla 6. Funciones del humor entre las parejas de hombres

\begin{tabular}{|c|c|c|c|c|c|c|c|}
\hline & & $\begin{array}{c}\text { Crear } \\
\text { consenso }\end{array}$ & Desacuerdo & $\begin{array}{c}\text { Control } \\
\text { de las } \\
\text { normas }\end{array}$ & $\begin{array}{c}\text { Crear lazo } \\
\text { social }\end{array}$ & Justificación & $\mathbf{n}$ \\
\hline \multirow{2}{*}{ PAREJA 4} & PRIMOI & $\begin{array}{c}2 \\
40,0 \%\end{array}$ & & & & $\begin{array}{c}3 \\
60,0 \%\end{array}$ & 5 \\
\hline & PRIMO2 & $\begin{array}{c}1 \\
20,0 \%\end{array}$ & $\begin{array}{c}1 \\
20,0 \%\end{array}$ & & $\begin{array}{c}1 \\
20,0 \%\end{array}$ & $\begin{array}{c}2 \\
40,0 \%\end{array}$ & 5 \\
\hline \multirow{2}{*}{ PAREJA 5} & AMIGOl & & $\begin{array}{c}3 \\
23,1 \%\end{array}$ & $\begin{array}{c}4 \\
30,8 \%\end{array}$ & $\begin{array}{c}6 \\
46,2 \%\end{array}$ & & 13 \\
\hline & AMIGO2 & $\begin{array}{c}4 \\
30,8 \%\end{array}$ & $\begin{array}{c}1 \\
7,7 \%\end{array}$ & $\begin{array}{c}1 \\
7,7 \%\end{array}$ & $\begin{array}{c}6 \\
46,2 \%\end{array}$ & $\begin{array}{c}1 \\
7,7 \%\end{array}$ & 13 \\
\hline
\end{tabular}


Mientras que la pareja de amigos presenta el grado más alto de cercanía (4), los primos presentan el grado más bajo entre nuestras parejas $(2,4)$. Esta distancia es fundamental y explica los resultados en el uso del humor. La pareja 5 presenta un modo humorístico de relación en ambos miembros, y este modo de interacción es el que prevalece en todo momento. Se expresa el desacuerdo mediante el humor por ambos miembros, y prácticamente las expresiones humorísticas cumplen todas las funciones. Por el contrario la distancia entre los primos hace que las expresiones de humor sean más escasas y se usen en funciones de refuerzo social o de justificación, como se muestra en (4), donde C y D usan el humor ante una opinión que puede resultar difícil.

(4) C: (lee el tema del que se les pide que hablen)

«En todas las culturas las mujeres tienen menos interés en el atractivo visual del hombre que en el monetario»

C: Joer

D:@@@

C:1@@

D: $\quad$ Pfff. Está complicao este

Todos: @@@

Desde un punto de vista cualitativo, un aspecto interesante en el que la relación tiene un peso importante es en el uso del humor para la provocación del conflicto. Los casos que se han reseñado en otros estudios lo encuentran entre las parejas sentimentales (Alberts 1990). En nuestros datos, aparece efectivamente en la pareja hombre-mujer, pero también entre madre e hija. Las ocasiones en que esto ocurre no son muchas, 1 caso entre la pareja y 2 entre madre e hija. En este segundo caso, como se ha mostrado más arriba en (3), es la madre quien se burla de la hija en varias ocasiones a propósito de lo poco atento que es su yerno. El estatus asimétrico de la relación permite a la madre utilizar la burla con su hija, sabiendo no obstante que esto no pone en peligro la relación.

En caso de la pareja sentimental, es el hombre quien utiliza el humor para recriminar a la mujer su opinión acerca de ciertas mujeres. La recriminación provoca el conflicto conversacional durante numerosos turnos en los que ninguno de los dos da su brazo a torcer y es la entrevistadora quien finalmente zanja la discusión proponiendo una nueva pregunta.

$(5)^{82} \mathrm{~J}$ : A ver, siempre, en todas las sociedades se busca el ascenso social, una forma es casarte con un ricachón, digamos ino? @@ [...]

82. Debido a la longitud de la conversación se han mantenido los signos de transcripción más básicos y solo se ha reproducido la parte más pertinente del ejemplo. 
P: [Es que me estás contando una regla de, [@@] voy a hablar con tópicos ¿vale? porque = sí, porque me cuesta creer que en todas las sociedades lo que se lleva es ser «zorrón implacable». [@@]. O sea el zorrón implacable que se fija en el Ferrari antes que en el tal, cuando se dice que la mujer es emotiva y que busca la belleza en el interior. En el interior de la billetera. O sea que no.

Finalmente, la relación social se muestra relevante asimismo en la expresión del humor en el contexto grupal, como se ve en las Tablas 7 y 8 respectivamente.

Tabla 7. Funciones de la expresión de humor en mujeres y hombres en el grupo 1 con relación fuerte

\begin{tabular}{|c|c|c|c|c|c|c|c|c|}
\hline & $\begin{array}{c}\text { Crear } \\
\text { consenso }\end{array}$ & $\begin{array}{c}\text { Expresar } \\
\text { desacuerdo }\end{array}$ & $\begin{array}{c}\text { Provocar } \\
\text { conflicto }\end{array}$ & $\begin{array}{c}\text { Manejar el } \\
\text { desacuerdo }\end{array}$ & $\begin{array}{c}\text { Crear } \\
\text { lazo } \\
\text { social }\end{array}$ & $\begin{array}{c}\text { Control } \\
\text { de las } \\
\text { normas }\end{array}$ & $\begin{array}{c}\text { Defensa/ } \\
\text { justificación }\end{array}$ & TOTAL \\
\hline MUJER & $45,5 \%$ & $18,2 \%$ & & & $9,1 \%$ & $18,2 \%$ & $9,1 \%$ & $\begin{array}{c}100 \% \\
\mathrm{~N}=11\end{array}$ \\
\hline HOMBRE & $42,3 \%$ & $11,5 \%$ & $3,8 \%$ & $3,8 \%$ & $30,8 \%$ & $3,8 \%$ & $3,8 \%$ & $\begin{array}{c}100 \% \\
\mathrm{~N}=26\end{array}$ \\
\hline
\end{tabular}

Tabla 8. Funciones de la expresión de humor en mujeres y hombres en el grupo 2 con relación débil

\begin{tabular}{|c|c|c|c|c|c|c|c|c|}
\hline & $\begin{array}{c}\text { Crear } \\
\text { consenso }\end{array}$ & $\begin{array}{c}\text { Expresar } \\
\text { desacuerdo }\end{array}$ & $\begin{array}{c}\text { Provocar } \\
\text { conflicto }\end{array}$ & $\begin{array}{c}\text { Manejar el } \\
\text { desacuerdo }\end{array}$ & $\begin{array}{c}\text { Crear } \\
\text { lazo } \\
\text { social }\end{array}$ & $\begin{array}{c}\text { Control } \\
\text { de las } \\
\text { normas }\end{array}$ & $\begin{array}{c}\text { Defensa/ } \\
\text { justificación }\end{array}$ & TOTAL \\
\hline MUJER & $33,3 \%$ & & & & $66.7 \%$ & & & $\begin{array}{l}100 \% \\
\mathrm{~N}=3\end{array}$ \\
\hline HOMBRE & $12,5 \%$ & & & & $75 \%$ & $12,5 \%$ & & $\begin{array}{l}100 \% \\
\mathrm{~N}=8\end{array}$ \\
\hline
\end{tabular}

De nuevo, cuanto más cercana es la relación en el grupo, mayor número de expresiones de humor se usan y con un mayor rango de funciones. Como vemos, las diferencias entre ambos grupos son sustanciales. En el grupo con una relación fuerte, tanto mujeres como hombres refuerzan el vínculo con los otros a través del humor, pero se permite también la expresión del desacuerdo de modo humorístico y el control de las normas. Cuando la relación entre los hablantes del grupo es débil las funciones del humor son exclusivamente solidarias. 


\section{Conclusiones}

Parece, pues, que las expresiones humorísticas no están condicionadas por el género de los hablantes. Tanto hombres como mujeres emplean el modo humorístico de relación en sus interacciones y ambos las utilizan con frecuencia parecida. Lo que parece condicionar en mayor medida su uso es la relación social que mantienen los hablantes. Cuanto más cercana es la relación entre ellos, mayor es el recurso al humor en todas sus funciones. Nuestros datos muestran que la función primordial del humor es el refuerzo del lazo social que une a los hablantes, de modo que en relaciones menos cercanas se usa fundamentalmente para establecer y reforzar ese vínculo. Sin embargo, cuando la relación es estrecha, el abanico de funciones del humor se amplía y se emplea para la expresión del desacuerdo e incluso la provocación del conflicto tanto en hombres como en mujeres.

El contexto pareja/grupo actúa como regulador de las reglas de intercambio y diferenciador de las funciones con las que mujeres y hombres usan las expresiones humorísticas. En pareja, la mujer fundamentalmente crea consenso mediante el humor y refuerza la relación social, y cuanto más cercana es la relación más uso hace del humor para el resto de funciones, incluido el control de las reglas de la interacción y la expresión del desacuerdo. Asimismo en relaciones muy cercanas, la mujer puede provocar el conflicto pero midiendo el impacto de los actos lingüísticos, sin transgresión de los límites de la relación y siempre a sabiendas de que se llegará al consenso. El hombre también utiliza el humor como refuerzo del lazo social y expresión del desacuerdo en relaciones estrechas, pero también usa el humor como medio de autojustificación ante la expresión de aspectos problemáticos en relaciones menos cercanas. Esta última función, que en principio podría parecer perteneciente al estilo más indirecto, relacionado generalmente con el estilo femenino, en nuestros datos solo aparece usada por los hombres. En grupo pesa de nuevo la fuerza de la relación. En el grupo con relación estrecha, las mujeres crean consenso, expresan desacuerdo y realizan el control de las normas de interacción, mientras que los hombres expresan el consenso y refuerzan los lazos sociales. Si la relación es débil, tanto mujeres como hombres usan el humor únicamente en su función primaria de refuerzo de la relación.

\section{Referencias bibliográficas}

AlBERTS, Janet. «The use of humor in managing couples' conflict interactions».

En Cahn, Dudley D. (dir.). Intimates in conflict. A communicative prespective, Hillsdade, Lawrence Erlbaum, 1990, pp. 105-120. 
Alvarado Ortega, M. Belén. «An Approach to Verbal Humor in Interaction», Procedia-Social and Behavioral Sciences 95 C, (2013), pp. 594-603.

ARUndale, Robert. «Relating», En Miriam Locher y George Sage (dirs.): Interpersonal pragmatics, Berlin, Mouton de Gruyter, (2010), pp. 137-165

AtTARDo, Salvatore. Humorous Texts: A Semantic and Pragmatic Analysis, Nueva York, Mouton de Gruyter, 2001.

ATtARDO, Salvatore. "A primer for the linguistics of humor.» En Victor Raskin (dir.). The primer of humor research, Berlin, Mouton de Gruyter, 2008.

BARON, Bettina, y KotTHOFF, Helga (dirs.). Gender in Interaction: Perspectives on Femininity and Masculinity in Ethnography and Discourse, Amsterdam, John Benjamins, 2001.

BENDIX, John y BENDIX, Regina. «Politics and gender in humor and satire: the cases of Elisabeth Kopp and Geraldine Ferraro.» Schweizer Zeitschrift für Soziologie, 2, (1992), pp. 441-460.

BOURDON, Sylvain. «Relaciones sociales y trayectorias biográficas: hacia un enfoque comprensivo de los modos de influencia». REDES. Revista hispana para el análisis de redes sociales. 16, 6/2009. http://revista-redes.rediris.es/pdf-vol16/ vol16_6.pdf consultado el 13-03-2014.

BRIZ GÓMEZ, Antonio. El español coloquial en la conversación: esbozo de pragmalingüística, Barcelona, Ariel, 1998.

Brown, Penélope y GiLlman, Albert. «Pronouns of power and solidarity». En Thomas Albert Sebeok (dir.), Style in Language. Cambridge, Mass.: MIT Press, 1960, pp. 253-276

Burleson, Brant, MetTs, Sandra y KirCH, Michael W. "Communication in close relationships». En Clyde Hendrick y Susan S. Hendrick (dirs.), Close relationships: A sourcebook, Thousand Oaks, CA, Sage, 2000, pp. 244-258.

CAmeron, Deborah. The Myth of Mars and Venus: Do Men and Women Really Speak Different Languages? Oxford, University Press, 2007.

CAMPos PRATS, Mar. Uso e impacto de las expresiones de des/acuerdo e identidad de género. Tesis doctoral. En preparación.

COSER, Rose L. «Laughter among colleagues». Psychiatry 23 (1960), pp. 81-95.

Cox, Joe, A. ReAd, L. Raymond y VAn Auken, Philip M., «Male-female differences in communicating job-related humor: An exploratory study». Humor 3(1990), pp. 287-295.

DEAUX, Kay, «Sex and Gender». Annual Review of Psychology 36 (1995), pp. 49-82.

DEGENNE Alain y FORSE, Michel. Les réseaux sociaux, une analyse structurale en sociologie, París, Armand Colin, 2004.

Dubois, John, Schuetze-Coburn, Stephan, Cumming, Susanne y Paolino, Danae: «Outline of Discourse Transcription». En Jane Edwards y Martin Lampert, 
(dirs.): Talking Data. Transcription and Coding in Discourse Research. Hillsdale, Erlbaum, 1992, 45-89.

EDER, Donna. «"Go get ya a French!”: romantic and sexual teasing among adolescent girls». En Deborah Tannen (dir), Gender and Conversational Interaction, Oxford, University Press, 1993, pp. 17-30.

ENFIELD, Nick J. «Relationship thinking and human pragmatics». Journal of Pragmatics, 41 (2009), pp. 60-78.

ENFIELD, Nick J. Relationship thinking: Agency, enchrony, and human sociality. Oxford, University Press, 2013.

ERVIN-TripP, Susan M., LAMPERT, Martin D. «Gender differences in the construction of humorous talk». En Kira Hall, Mary Buchholtz y Birch Moonwomon (dirs.), Locating Power: Proceedings of the Second Berkeley Women and Language Conference. Berkeley, University of California, 1992, pp. 108-117.

FERRAND, Alexis. «Redes heterogéneas de discusión y pluralismo cognitivo». REDES. Revista hispana para el análisis de redes sociales. Vol.10, 2 (2006). http:// revista-redes.rediris.es/pdf-vol10/vol10_2.pdf consultado el 19-03-2014.

FINCH, Janet y MASON, Jennifer. Negotiating Family Responsibilities, Londres, Routledge, 1993.

GofFMAn, Erving. Interaction Ritual. Essays on Face-to-face Behavior, Nueva York, Pantheon Books, 1967.

GOODMAN, Lizbeth. «Gender and humour». En Frances Bonner et al. (dirs), Imagining women: Cultural representations and gender, Cambridge: Polity, 1992, pp. 296-300.

Grice, H. Paul. «Logic and conversation». En Peter Cole y Jerry Morgan (dirs.), Syntax and Semantics 3: Speech acts, Nueva York, Academic Press, 1975, pp. 41-58.

GrossetTI, Michel. «Where do social relations come from?: A study of personal networks in the Toulouse area of France». Social Networks 27 (2005), pp. 289-300.

HAUGH Michael, KÀDÀr Dániel Z. y MiLlS, Sara. «Interpersonal pragmatics. Issues and debates». Journal of Pragmatics 58 (2013), pp. 1-11.

HAY, Jennifer. «Functions of humor in the conversations of men and women». Journal of Pragmatics 32 (2000), pp. 709-742.

HERITAGE, John y RAYMOND, Geoff. «The terms of agreement: indexing epistemic authority and subordination in talk-in-interaction». Social Psychology Quarterly 68 (2005), pp. 15-38.

HOLMES, Janet. «Sharing a laugh: pragmatic aspects of humor and gender in the workplace». Journal of Pragmatics 38 (2006), pp. 26-50.

JENKINS, Mercilee. «What's so funny?: Joking among women». En Sue Bremner, Noelle Caskey y Birch Moonwomon (dirs), Proceedings of the first Berkeley 
Women and Language Conference, Berkeley, CA, Women and Language Group, 1985, pp. 135-151.

Kerbrat-Orecchioni, Catherine. «L'humour au quotidien». En Philip Merlo (dir.) L'humour hispanique, Grimh-LCE-Grimia, Université Lumière Lyon 2, 2004.

KotThoff, Helga. «Gender and joking. On the complexities of women's image politics in humorous narratives». Journal of Pragmatics 32 (2000), pp. 55-80.

KotTKOFF, Helga. «Gender and humor: The state of the art». Journal of Pragmatics 38 (2006), pp. 4-25.

LAKOFF, Robin. Language and Woman's Place. NuevaYork, Harper y Row, 1975.

LOCHER, Miriam y GRAHAM, Sage L. «Introduction to interpersonal pragmatics». En Miriam Locher (dir.). Interpersonal Pragmatics. Berlin, Mouton de Gruyter, 2010, pp. 1-13.

MARTIN, Rod A. The psychology of humor. An integrated approach, Amsterdam, Elsevier, 2007.

MARTINEAU, William. «A model of the social functions of humor». En Jeffrey Goldstein y Paul McGhee (dirs.), The psychology of humor,. Nueva York, Academic Press, 1972, pp. 101-125.

MILARDO, Robert. «Families and social networks: an overview of theory and methodology». En Robert Milardo (dir.), Families and Social Networks, Newbury Park, California, Sage, 1988, pp. 13-47.

Milroy, Lesley. Language and Social Networks, Blackwell, Oxford, 1987.

Milroy, Lesley. Social networks. En Jack. K. Chambers, Peter Trudgill y Natalie Schilling-Estes. The handbook of language variation and change. Oxford. Blackwell. 2008.

MitCHell, J. Clyde. «Network procedures». En Dieter Frick (dir.), The Quality of Urban Life, Berlin, Mouton de Gruyter, 1986, pp. 73-92.

Mulkay, Michael. «On Humour», Cambridge, Polity Press, 1988.

PULLIN, Patricia. «Small talk, rapport, and international communicative competence: Lessons to learn from BELF». Journal of Business Communication, 47 (4) (2010), pp. 455-476.

RASKIN,Victor. Semantic Mechanisms of Humor. Dordrecht, D. Reidel, 1985.

ROMERA, Magdalena y CAMPOS PRATS, Mar Social relationships and discourse interaction: the case of disagreement in conversation. Enviado a Journal of Pragmatics. 2014.

Ruíz GuRILlo, Leonor. La lingüística del humor en español, Madrid, Arco/Libros, 2012.

Ruíz Gurillo, Leonor y Padilla García, Xosé. A. (dirs.). Dime cómo ironizas y te diré quién eres. Una aproximación pragmática a la ironía, Frankfurt, Peter Lang, 2009. 
TAYLOR, Charles. Sources of the Self: The Making of the Modern Identity, Cambridge, University Press, 1989.

Watzlawick, Paul, Beavin, Janet y Jackson, Don. The Pragmatics of Human Communication. Nueva York, W.W. Norton and Company, 1967. 


\title{
LAS FUNCIONES COMPETITIVAS DEL HUMOR EN LOS COTILLEOS DE JÓVENES VEINTEAÑERAS
}

\author{
VIRGINIA ACUÑA FERREIRA \\ Universidad de Vigo
}

Recibido: $15 / 09 / 2014$

Aceptado: 24/11/2014

\section{Resumen}

Las investigaciones sobre género y humor en la conversación espontánea señalan que las prácticas humorísticas de las mujeres en este tipo de contextos se caracterizan por sus rasgos cooperativos y su funcionalidad principalmente orientada al refuerzo de la solidaridad y/o a la subversión de normas y estereotipos de género. El objetivo de este artículo es resaltar las características formales y funcionales del humor que se produce dentro de la práctica de cotilleo, analizando fragmentos de dos conversaciones espontáneas entre estudiantes universitarias gallegas de poco más de veinte años. En contraste con la caracterización general del humor conversacional de las mujeres en la bibliografía, en este análisis se ponen de relieve las funciones competitivas que subyacen en este tipo de discurso y su papel en el mantenimiento y refuerzo de formas de capital simbólico femenino como la apariencia física y las relaciones sexuales/ románticas con los hombres.

Palabras clave: conversación, humor, cotilleo, estudiantes universitarias, funciones competitivas, capital social femenino, apariencia física, relaciones con los hombres.

\begin{abstract}
Studies on gender and humour in spontaneous conversation have noted that women's humorous practices in these contexts are characterized by their cooperative features and by their functionality primarily oriented to the reinforcement of solidarity and/ or the subversion of gender norms and stereotypes. The aim of this article is to illuminate the formal and functional characteristics of humour in the practice of gossip by analyzing extracts of two spontaneous conversations among Galician female undergraduate students who are in their early twenties. In contrast to the general
\end{abstract}


characterization of women's conversational humour in the literature, this analysis highlights the competitive functions of this kind of discourse and as its role in the maintenance and reinforcement of forms of female symbolic capital such as physical appearance and sexual/romantic relationships with men.

Keywords: conversation, humour, gossip, female undergraduate students, competitive functions, female symbolic capital, physical appearance, relationships with men. 


\section{Introducción}

Los chistes, las burlas, las historias divertidas o las salidas graciosas constituyen formas de crear humor que han estado estereotípicamente asociadas con el habla de los hombres en las culturas occidentales. Por ello, desde una perspectiva de género se ha destacado con frecuencia la visión general del humor como un tipo de discurso que está fuertemente ligado a la masculinidad y, en cambio, casi totalmente desvinculado de la feminidad; algunos de los primeros trabajos sobre lengua y género, como la conocida descripción de la «lengua de las mujeres» de Robin Lakoff ${ }^{1}$, reflejan y reproducen poderosamente esta idea, señalando incluso una falta de sentido del humor en las mujeres: «women can't tell jokes - they are bound to ruin the punch line, they mix up the order of things, and so on. Moreover, they don't «get» jokes. In short, women have no sense of humor ${ }^{2}$. Para explicar por qué el contar chistes es algo que se asocia con los hombres, Lozano Domingo ${ }^{3}$ señala que esta tarea discursiva conlleva asumir un papel protagonista y que esto no es compatible con el comportamiento «discreto» que se espera de las mujeres en muchos acontecimientos comunicativos. Por otra parte, el carácter competitivo que presentan determinadas prácticas humorísticas, como es el caso de las burlas y otras formas de agresión lúdica, tampoco encajan con los modelos de interacción «femeninos», que se basan en todo lo contrario, es decir, en la realización de actividades discursivas de carácter cooperativo que buscan la expresión de apoyo y la solidaridad de manera muy explícita, como contar problemas o experiencias personales negativas ${ }^{4}$.

1. LAKOFF, Robin. Language and woman's place. Text and commentaries. Editado por Mary Bucholtz. Oxford, Oxford University Press, 2004 (1975).

2. Ibíd., pp. 80-81.

3. LozANO DOMINGo, Irene. Lenguaje femenino, lenguaje masculino. ¿Condiciona nuestro sexo la forma de hablar? Madrid, Minerva, 1995.

4. ACUÑA FerReira, A. Virginia. «Complaint stories revisited. The 'masculine' performance of a 'feminine' genre in a conversation among Galician men». Sociolinguistic Studies 2.2 (2008), pp. 185-220. COATES, Jennifer. Women talk. Conversation between women friends. Oxford, Blackwell, 1996. COATES, Jennifer. Women, men and everyday talk. Londres, Palgrave, 2013. GüNTHNER, Susanne. «Complaint stories. Constructing emotional 
Sin embargo, desde la aparición de un interés específico por el humor desde una perspectiva de género, numerosos estudios han resaltado que este tipo de discurso también puede realizarse de forma cooperativa, de acuerdo con las características que se atribuyen a los modelos de interacción «femeninos». En un artículo pionero sobre este tema, Jenkins ${ }^{5}$ sostuvo que el humor de las mujeres no ha sido reconocido como tal porque presenta importantes diferencias con respecto al de los hombres: «up to now most things have been defined by men, including communication forms, so if women didn't do it like men, they didn't do it $»^{6}$. Basándose en su observación de las reuniones de un grupo de madres angloamericanas, esta autora destaca la narración frecuente de experiencias personales negativas en clave de humor, que servían para aliviar sentimientos de vergüenza y que buscaban la empatía de las interlocutoras $^{7}$. Desde su punto de vista, este tipo de historias constituyen una de las formas esenciales en que se manifiesta el humor de apoyo característico de las mujeres. Además, pone de relieve los comentarios que las participantes solían hacer para burlarse de los estereotipos sexistas que circulan en la sociedad, subrayando por tanto la función subversiva que cumplía el humor de las participantes en estas reuniones. Otros estudios señalan la importancia de estas dos formas de humor en el habla femenina; por una parte, se resalta que las mujeres cuentan historias humorísticas sobre experiencias personales negativas en mayor medida que los hombres ${ }^{8}$, en general, que el humor que expresa apoyo y que se realiza de forma colaborativa es más común en las

reciprocity among women», en Helga Kotthoff y Ruth Wodak (eds.): Communicating gender in context, Amsterdam, John Benjamins, 1997, pp. 179-218. Kendall, Shari y TANnEN, Deborah. «Discourse and gender», en Deborah Schiffrin, Deborah Tannen y Heidi E. Hamilton (eds.): The handbook of discourse analysis, Oxford, Blackwell, 2001, pp. 548-567. TANnEN, Deborah. You just don't understand. Women and men in conversation. Nueva York, William Morrow, 1990. TANnEN, Deborah. Género y discurso. Barcelona, Paidós, 1996.

5. JENKINS, Mercilee. «What's so funny? Joking among women», en Noelle Caskey, Sue Bremner, Birch Moonwomon y Noelle Caskey (eds.): Proceedings of the First Berkeley Women and Language Conference, University of California, Berkeley, Berkeley Women and Language Group, 185, pp. 131-151

6. Ibíd., p. 135.

7. Ibíd., p. 138-139.

8. ERVIN-TRIP, Susan y Martin D. Lampert. «Gender differences in the construction of humorous talk», en Kira Hall, Mary Bucholtz y Birch Moonwomon (eds.): Locating power. Proceedings of the Second Berkeley Women and Language Conference. Volume 1, Berkeley, CA, University of California, 1992, pp. 108-117. HAY, Jennifer. «Functions of humor in the conversations of men and women». Journal of Pragmatics 32 (2000), pp. 709-742. GEORGAKOPOUlOU, Alexandra. «Women, men and conversational narrative performances: Aspects of gender in Greek storytelling». Anthropological Linguistics 37 (1995), pp. 460-486. KotTHOFF, Helga. «Gender and joking: On the complexities of 
interacciones femeninas o mixtas, es decir, en acontecimientos comunicativos en los que participan mujeres ${ }^{9}$. Por otra parte, se hace hincapié en la utilización femenina del humor como una estrategia para desafiar y/o burlarse de las normas y/o estereotipos de género ${ }^{10}$, a veces incluso a través de prácticas estereotípicamente masculinas, como el humor sexual ${ }^{11}$. Acuña Ferreira ${ }^{12}$ aborda la realización de tipos de humor estereotípicamente masculino en conversaciones de jóvenes veinteañeras, como los chistes y las imitaciones, el empleo de lenguaje ordinario, o las bromas relacionadas con las borracheras, como formas de construcción de feminidades transgresoras.

Nuestro objetivo en este artículo es analizar la práctica de un tipo de humor que está asociado estereotípicamente con las mujeres y que sin embargo no parece haber sido abordado de forma empírica dentro de este campo: el humor que se produce en los cotilleos. En su artículo pionero sobre género y humor conversacional, Jenkins ${ }^{13}$ destacó que este es precisamente el único tipo de humor que se ha relacionado tradicionalmente con las mujeres, aunque las conversaciones femeninas que ella estudió no mostraban su práctica. Nuestros datos, sin embargo, incluyen conversaciones de jóvenes veinteañeras que contienen secuencias de cotilleo, en las que este tipo de habla se realiza desde una perspectiva humorística y/o burlona. Así pues, el objetivo más específico de este trabajo es analizar las características formales y funcio-

women's image politics in humourous narratives». Journal of Pragmatics 32 (2000), pp. 55-80.

9. HolmES, Janet. «Sharing a laugh: Pragmatic aspects of humor and gender in the workplace». Journal of Pragmatics 38 (2006), pp. 26-50.

10. KALČIK Susan. «... like Ann's gynecologist or the time I was almost raped: Personal narratives in women's rap groups». Journal of American Folklore 88 (1975), pp. 3-11. FARR, Marcia. «Echando relajo: Verbal art and gender among Mexicanas in Chicago», en Mary Bucholtz, A.C. Liang, Laurel A. Sutton y Caitling Hines (eds.): Cultural performances. Proceedings of the Third Berkeley Women and Language Conference, Berkeley, CA, University of California, 1994, pp. 168-186. FARR, Marcia. «Echando relajo: Verbal art and gender among Mexicanas in Chicago», en Mary Bucholtz, A.C. Liang, Laurel A. Sutton y Caitling Hines (eds.): Cultural performances. Proceedings of the Third Berkeley Women and Language Conference, Berkeley, CA, University of California, 1994, pp. 168186. HolmeS, Janet. «Sharing a laugh: Pragmatic aspects of humor and gender in the workplace». Op. cit. HOLMES, Janet. Gendered talk at work. Constructing gender identity through workplace discourse, Oxford, Blackwell, 2009.

11. ACUÑA FerReira, A. Virginia. Género y discurso. Las mujeres y los hombres en la interacción conversacional. Múnich, Lincom, 2009. GREENE, Rayna. «Magnolias grow in dirt: The bawdy lore of Southern women». Southern Exposure 4 (1977), pp. 29-33.

12. ACuña Ferreira, A. Virginia. Op. cit. ACuÑa FerReira, A. Virginia. «The humorous display of transgresor femininities: 'Sharing a laugh' in Spanish-Galician friendly talk among young women». Sociolinguistic Studies 6.1 (2012), 121-147.

13. JENKINS, Mercilee. Op. cit.

Feminismo/s 24, diciembre 2014, pp. 67-94 
nales de este tipo de humor, teniendo en cuenta las importantes funciones de competitividad que se han atribuido al cotilleo en general y al cotilleo de las mujeres en particular, desde diversas disciplinas. Antes de este análisis, por tanto, será importante revisar algunas investigaciones sobre el cotilleo que también tienen relevancia para el presente estudio.

\section{El cotilleo y las mujeres}

El cotilleo ha llamado la atención de los estudios de lengua y género, como forma de habla que ha estado estereotípicamente asociada con las mujeres en las sociedades occidentales ${ }^{14}$. Esta asociación se ha explicado principalmente como algo relacionado con la histórica división sexual de la esfera pública y privada ${ }^{15}$, aunque también se ha argumentado que los juicios peyorativos sobre el cotilleo de las mujeres responden a un intento de controlar la solidaridad femenina, considerada como una amenaza para la sociedad patriarcal ${ }^{16}$. Algunos estudios etnográficos han subrayado la importancia del cotilleo en la vida de las mujeres, como un canal ilegítimo de comunicación que posibilita el acceso femenino a la información relacionada con la vida pública ${ }^{17}$, y como un componente clave de la cultura oral femenina, esencial para la construcción de lazos de solidaridad entre las mujeres ${ }^{18}$.

En cambio, otros estudios descubren la utilización femenina del cotilleo como un arma para romper la armonía social y reestructurar las alianzas dentro del grupo. Las investigaciones de Goodwin ${ }^{19}$ analizan el cotilleo entre

14. Romaine, Suzanne. Communicating gender. Mahwah, NJ, Lawrence Erlbaum Associates, 1999.

15. SCOLlON, Ron y Suzanne SCOLlon. Intercultural communication. A discourse approach. Oxford, Blackwell, 1995.

16. RYSMAN, Alexander. «How the gossip became a woman». Journal of Communication 27 (1977), pp. 176-180. SPENDER, Dale. Man made language. Londres, Routledge y Kegan Paul, 1980.

17. HARDING, Susan. «Women and words in a Spanish village», en Rayna Reiter (ed.): Toward an anthropology of women, Nueva York, Monthly Review Press, 1975, pp. 283308. JONES, Deborah. "Gossip: Notes on women's oral culture». Women's Studies International Quarterly 3 (1980), pp. 193-198.

18. JONES, Deborah. «Gossip: Notes on Women's Oral Culture». Women's Studies International Quarterly 3 (1980), pp. 193-198.

19. Goodwin, Marjorie Harness. «He-said-she-said: Formal procedures for the construction of a gossip dispute activity». American Ethnologist 7 (1980), pp. 674-695. GOODWIN, Marjorie Harness. «Instigating: Storytelling as social process». American Ethnologist 9 (1982), pp. 799-819. Goodwin, Marjorie Harness. He-said-she-said: Talk as social organization among black children. Bloomington, Indiana University Press, 1990. GooDwin, Marjorie Harness. «Retellings, pretellings and hypothetical stories». Research on Language and Social Interaction 24 (1990/1991), pp. 263-276. 
niñas afroamericanas de un vecindario de Filadelfia como un proceso conflictivo, que se inicia con la producción de una historia instigadora, en la que una niña cuenta a otra lo que una tercera dijo de ella «a sus espaldas», propiciando el enfrentamiento entre ambas. Guendouzi ${ }^{20}$ resalta las funciones competitivas del bitching, un tipo de cotilleo fuertemente asociado con las mujeres que recibe esta etiqueta específica en inglés. Su análisis de esta práctica en conversaciones femeninas muestra que las participantes cooperan estrechamente entre sí para censurar moralmente a otras mujeres, en la medida en que su comportamiento supone una aberración desde el punto de vista de las normas de género. Por ello, esta autora pone de relieve la necesidad de prestar atención tanto al estilo como al contenido del discurso, y concluye que el bitching sirve para reivindicar capital social de forma competitiva mediante el refuerzo de normas sociales que establecen qué roles son aceptables para las mujeres; en sus propias palabras, el bitching puede definirse como «a form of gossip that involves comparative competition for social capital based on hegemonic images of femininity $»^{21}$.

\section{Tipos de cotilleo}

Desde la Psicología Social, Rosnow y Fine ${ }^{22}$ diferenciaron tres grandes funciones del cotilleo: la moralización, la información y el entretenimiento. En general, la bibliografía ha abordado ampliamente las dos primeras ${ }^{23}$, mientras que la función de entretenimiento ha recibido mucha menos atención. Como afirma Tholander ${ }^{24}$ «the idea that gossip is moralizing or norm enforcing is

20. GUENDOUZI, Jackie. «You'll think we're always bitching: the functions of cooperativity and competition in women's gossip». Discourse Studies 3.1 (2001), pp. 29-51.

21. Ibíd., p. 34.

22. ROSNOW, Ralph L. y FINE, Gary Alan. Rumor and gossip: The social psychology of hearsay. New York, Elsevier, 1976.

23. BERGMANN, Jörg R. Discreet indiscretions. The social organization of gossip. Nueva York: Aldine de Gruyter, 1993. Cox, Bruce A. «What is Hopi gossip about? Information management and Hopi factions». Man 5.1 (1970), pp. 88-98. EGGINS, Suzanne y SLADE, Diana. Analysing casual conversation. Londres, Continuum, 1997. GLUCKMAN, Max. «Gossip and scandal». Current Anthropology 4.3 (1963), pp. 307-316. GuENDOUZI, Jackie. «You'll think we're always bitching: the functions of cooperativity and competition in women's gossip». Discourse Studies 3.1 (2001), pp. 29-51. HALl, Joan Kelly. «Tengo una bomba»: The paralinguistic and linguistic conventions of the oral practice chismeando. Research on Language and Social Interaction 26.1 (1993), pp. 55-83. HAVILAND, John B. Gossip, reputation, and knowledge in Zinacantan. Chicago, University of Chicago Press, 1977.

24. THOLANDER, Michael. «Pupil's gossip as remedial action». Discourse Studies 5.1 (2003), pp. 101-129.

Feminismo/s 24, diciembre 2014, pp. 67-94 
perhaps the most accepted and widespread $\aleph^{25}$. Uno de los pocos trabajos que ha abordado el cotilleo orientado al entretenimiento es el capítulo de Morreall ${ }^{26}$ sobre la relación de este tipo de habla con el humor. Sin utilizar apoyo empírico, este autor sostiene que el cotilleo que se realiza desde un punto de vista humorístico es el «mejor» tipo de cotilleo, en la medida en que busca simplemente el entretenimiento, está libre de «mezquindad»y «malevolencia» y resulta incompatible con emociones negativas fuertes: «People cannot anger us or make us indignant, for instance, at the same time as they make us laugh $»^{27}$. En contraste, Tholander sugiere que incluso el cotilleo de entretenimiento tiende a ocultar intereses personales: «even if gossip might look light hearted and entertaining on the surface, it may be more serious at an underlying level» ${ }^{28}$.

Acuña Ferreira ${ }^{29}$ aborda el cotilleo en clave humorística de forma empírica, a través del análisis de extractos de conversaciones entre jóvenes veinteañeras gallegas. Desde el punto de vista funcional, los datos revelan que este tipo de cotilleo no solo sirve para entretenerse, sino que también conlleva otros beneficios, ya que puede actuar, por ejemplo, como una forma de obtener consuelo grupal ante un sentimiento de envidia, de incrementar la autoestima ante los problemas ajenos o de invalidar los éxitos de los demás. Estas funciones más implícitas encubren, a su vez, una competición comparativa entre las personas que participan en el cotilleo y aquella de la que se habla. Así, en este estudio se resalta que el cotilleo que se realiza de forma lúdica, humorística y burlona, como una forma de mofa indirecta, tampoco está libre de malicia y/o competitividad, de acuerdo con las argumentaciones en torno a las funciones de este tipo de habla que proceden de la Psicología Social ${ }^{30}$, y contrariamente, por tanto, a lo que sostenía Morrealli1 .

25. Ibíd., p. 104.

26. Morreall, John. «Gossip and humor», en Robert F. Goodman y Aaron Ben-Ze'ev A (eds.): Good gossip, Lawrence, University Press of Kansas, 1994, pp. 56-64.

27. Ibíd., p. 64.

28. THOLANDER, Michael. Op. cit., p. 105.

29. ACUÑA FERREIRA, A. Virginia. «Gossip as indirect mockery in friendly conversation: The social functions of 'sharing a laugh' at third parties». Discourse Studies 16.5 (2014), pp. 607-628.

30. Paine, Robert. 1967. What is gossip about? An alternate hypothesis. Man 2. 278-285. SulS, Jerry M. «Gossip as social comparison». Journal of Communication 27.1 (1977), pp. 164-168. WeRT, Sarah R. y SALOVEY, Peter. «A social comparison account of gossip». Review of General Psychology 8.2 (2004), pp. 122-137.

31. MORREALL, John. Op. cit. 


\section{Análisis de los datos}

En este apartado vamos a analizar cuatro fragmentos de dos conversaciones espontáneas procedentes del Corpus de Fala Bilingüe Galego/Castelán (Co. Fa.Bil) de la Universidad de Vigo $^{32}$, en las que participan estudiantes universitarias gallegas de poco más de veinte años que mantienen una relación de amistad. La actividad comunicativa se centra en cotillear de otras chicas y se desarrolla en la habitación de una residencia universitaria en un caso y en el servicio femenino de una cafetería en el otro; se trata de entornos discursivos «seguros», con un alto grado de intimidad, que permiten a las hablantes evitar o reducir las posibilidades de amenaza para su imagen positiva ${ }^{33}$. La grabación fue realizada en audio por uno de los miembros de cada grupo de amigas, con el propósito general de obtener datos conversacionales; ninguna de las participantes era consciente de que pudiese haber un interés más específico por la práctica de cotilleo como actividad comunicativa.

Las investigaciones sobre el cotilleo ofrecen distintas definiciones de este tipo de habla, como destaca Foster ${ }^{34}$, pero los casos que se van a analizar aquí se ajustan especialmente a la presentada por Taylor ${ }^{35}$, que define el «cotilleo prototípico» como habla entre dos o más personas acerca de la vida privada de una tercera "a sus espaldas», incluyendo sus amores, sus amistades, su matrimonio o su divorcio, «as well as her public activities insofar as these may throw light on her psychology or character ${ }^{36}$. Llamaremos Conversación A y Conversación B a cada una de las dos conversaciones de las que se han extraído los datos. El análisis se centrará en los rasgos formales y funcionales del discurso y se realizará turno por turno, haciendo hincapié en el carácter lúdico y humorístico de las contribuciones de las participantes.

32. El Corpus de Fala Bilingüe Galego/Castelán (Co.Fa.Bil) de la Universidad de Vigo está constituido por interacciones habladas que fueron grabadas en audio en contextos comunicativos «naturales» a través del método de la observación participante.

33. GUENDOUZI, Jackie. Op. Cit. El cotilleo se considera un acto comunicativo que amenaza la imagen positiva del hablante, en la medida en que se percibe socialmente de forma muy negativa.

34. FOSTER, Eric K. «Research on gossip: Taxonomy, methods, and future directions». Review of General Psychology 8.2 (2004), pp. 78-99.

35. TAYLOR, Gabriele. (1994). «Gossip as moral talk», en Robert F. Goodman y Aaron BenZe'ev (eds.): Good gossip. Lawrence, University Press of Kansas, 1994, pp. 34-46.

36. Ibíd, p. 34.

Feminismo/s 24, diciembre 2014, pp. 67-94 


\subsection{Conversación A: cotilleos en el servicio femenino}

En la Conversación A intervienen Nieves, Paula, María y Mónica ${ }^{37}$. El lugar de la interacción es el servicio femenino de una cafetería y la grabación tiene una duración total de casi treinta minutos. El Extracto 1 recoge la fase inicial de un cotilleo acerca de una chica que está saliendo con un chico al que todas conocen, según lo comentado previamente por una de las participantes. En esta fase inicial, que Eggins y Slade ${ }^{38}$ denominan third person focus, el discurso se centra en aportar información sobre la identidad de la chica:

\section{Extracto 1}

\begin{tabular}{|l|l|l|}
\hline 1274 & NIEVES & yo con- \\
\hline 1275 & & [yo conozco una Bea pero no sé si será la misma] \\
\hline 1276 & PAULA & [puta non petarda $(\mathrm{xx})$ ] \\
\hline 1277 & &.. \\
\hline 1278 & MARÍA & NO:: $\rightarrow$ \\
\hline 1279 & & ésta que andaba [mucho con::] \\
\hline 1280 & PAULA & $=\{[$ [p] a irmán de Pablo joder $\} \rightarrow$ \\
\hline 1281 & & $<1.5>$ \\
\hline 1282 & MARÍA & sabes? $=$ \\
\hline 1283 & NIEVES & $=$ que el padre está en \#localidad\#? \\
\hline 1284 & & $<$ asienten todas efusivamente $>$ \\
\hline 1285 & & el putón verbenero $\uparrow$ \\
\hline 1286 & & $<$ risas fuertes de todas $>$ \\
\hline 1287 & MÓNICA & es que es que sí $\uparrow=<$ riéndose $>$ \\
\hline 1288 & NIEVES & $=$ ya lo sé $\rightarrow=$ \\
\hline 1289 & MÓNICA & $=$ a ver si [lo sabe (mi madre)] \\
\hline 1290 & MARÍA & [jo:der $($ xx ] \\
\hline 1291 & NIEVES & [que está más sobada que un sobao Martínez] $=\rightarrow$ \\
\hline 1292 & LAURA & $=$ YO SIEMPRE DIGO $\rightarrow$ \\
\hline 1293 & & a ver cuánto [tiempo dura esto] \\
\hline 1294 & MARÍA & $\{[$ ac] [a] [QUE UN SOBAO QUÉ?] $\}=$ \\
\hline
\end{tabular}

37. Véase el Apéndice: Convenciones de Transcripción. Utilizamos seudónimos tanto en el caso de las participantes como en el de las terceras personas que son aludidas en la interacción.

38. EGGINS, Suzanne y Slade, Diana. Op. cit. 


\begin{tabular}{|l|l|l|}
\hline 1295 & NIEVES & $=\{[\mathrm{ac}]$ QUE ESTÁ MÁS SOBADA $\uparrow$ \\
\hline 1296 & & QUE UN SOBADO MARTÍNEZ $\} \rightarrow=$ \\
\hline 1297 & MARÍA & $=\mathrm{A}: \mathrm{H} \uparrow<$ risas de las demás> \\
\hline 1298 & & (te iba a decir yo) \\
\hline 1299 & & $<$ alguien tose $>$ \\
\hline 1300 & NIEVES & [yo lo siento mucho bueno] $\uparrow$ \\
\hline 1301 & MARÍA & {$[(\mathrm{xx})]=$} \\
\hline 1302 & NIEVES & $=$ si:: \\
\hline 1303 & & es muy amiga vuestra $\uparrow$ \\
\hline 1304 & & pero:: $[(\mathrm{xx})]$ \\
\hline 1305 & MÓNICA & $\{[$ ac] $[$ no no no $]\} \rightarrow=$ \\
\hline
\end{tabular}

Mientras Nieves expresa sus dudas acerca de si conoce a la chica aludida (líneas 1274-1275), Paula se refiere despectivamente a esta en gallego como unha petarda (línea 1276). En los turnos siguientes, María y Paula aportan información sobre quiénes son sus amistades y sus familiares (líneas 12781280), para ayudar a Nieves a darse cuenta de quién se trata. Tras una pausa (línea 1281), Nieves pregunta si su padre vive en determinada localidad (línea 1283), obtiene la confirmación de las demás (línea 1284), y entonces indica que ya sabe quién es la chica, identificándola como el putón verbenero (línea 1285), lo que provoca la risa de las demás (línea 1286). Mónica aprueba este comentario, entre risas (línea 1287), y Nieves se reafirma en que la conoce (línea 1288). En los siguientes turnos se produce un solapamiento de voces que impide comprender totalmente las intervenciones (líneas 1289-1291), pero sí se entiende una nueva aportación de Nieves, que utiliza un juego de palabras basado en el nombre y la marca de un producto de pastelería, que está más sobada que un sobao Martínez (línea 1291), para desplegar humor lingüístico y resaltar nuevamente la promiscuidad de la chica de manera burlona. Este chiste lingüístico pasa inicialmente desapercibido, porque está en superposición de voces, pero, en el siguiente turno, Laura expresa sus dudas acerca del futuro de la relación entre los dos jóvenes aludidos (líneas 1292-1293) y entonces María alza la voz para pedir a Nieves que repita su aportación previa (línea 1294). Esta repetición se produce en el turno inmediatamente posterior, con un volumen de voz también más elevado (líneas 1295-1296), y está seguida por una risa conjunta (línea 1297). Finalmente, Nieves pide disculpas por sus comentarios sobre la joven, preguntando indirectamente a sus compañeras si tienen algún tipo de amistad con ella (líneas 1300, 1303-1304), algo que Mónica niega inmediatamente (línea 1305). 
En resumen, este extracto recoge la fase inicial de un cotilleo en la que el habla se centra en despejar las dudas sobre la identidad de una de las terceras personas en las que se centra la actividad comunicativa. En este proceso, una de las participantes utiliza el descalificativo putón verbenero y realiza un chiste lingüístico, que está más sobada que un sobao Martínez, con varios fines: para indicar a sus compañeras que ya sabe quién es la tercera persona aludida, para mofarse de esta por su estilo de vida sexual y la reputación que tiene en este sentido, y para provocar la risa de las demás, contribuyendo al desarrollo del cotilleo en clave humorística. Las salidas graciosas de esta locutora reflejan la fuerza cultural del calificativo putón en la constitución y refuerzo del doble estándar sexual, que promueve la promiscuidad en los hombres, y en cambio la castiga en las mujeres ${ }^{39}$.

El humor desplegado se basa por tanto en un refuerzo de los discursos tradicionales sobre género y sexualidad y conlleva una agresión lúdica hacia la joven de la que se habla por la relación de pareja que ha iniciado con un chico. La realización de este tipo de ataque humorístico y la celebración del mismo por parte de todas las demás participantes a través de la risa sugieren un sentimiento común de envidia ante la noticia de esa relación y aportan un carácter competitivo y malicioso al discurso, ya que la descalificación peyorativa y burlona que se hace de la chica actúa como una forma de contrarrestar su «éxito» por esa relación. Desde el punto de vista del contenido, de la «sustancia» del discurso, en este extracto subyace una competitividad por las relaciones con los hombres; en los estudios específicos sobre género y sexualidad, este tipo de competitividad femenina es destacada como resultado de los discursos que establecen el matrimonio y la maternidad como máxima prioridad para las mujeres, y que de este modo fomentan la idea de «conseguir a un hombre» como algo primordial para ellas ${ }^{40}$.

En el Extracto 2, el cotilleo se encuentra en la fase que Eggins y Slade ${ }^{41}$ denominan substantiating behaviour, en la que «the speaker or speakers provide evidence or information which enables the participants to make a

39. CowIE, Celia y LeES, Sue. «Slags or drags». Feminist Review 9 (1981), pp. 17-31. LeES, Sue. Sugar and spice: Sexuality and adolescent girls. Londres, Penguin, 1986. WaLton, Marsha, WeATHERALl, Ann y JACKSON, Sue. «Romance and friendship in pre-teen stories about conflicts: "we decided that boys are not worth it». Discourse \& Society 13 (2002), pp. 673-689.

40. GRIFFIN, Christine. «Absences that matter: Constructions of sexuality in studies of young women's friendships». Feminism \& Psychology 10 (2000), pp. 227-245.

41. EgGins, Suzanne y SLADE, Diana. Op. cit. 
negative evaluation» ${ }^{42}$. Aquí el discurso se centra en el comportamiento de una chica que participó en un desfile de moda:

\section{Extracto 2}

\begin{tabular}{|c|c|c|}
\hline 1383 & LAURA & Y LO MEJOR NO FUE EN EL DESFILE $\rightarrow$ \\
\hline 1384 & & LO MEJOR FUE $\rightarrow$ \\
\hline 1385 & & QUE EN EL (probador) $\uparrow \uparrow$ \\
\hline 1386 & & $<1>$ \\
\hline 1387 & & la niña $\rightarrow$ \\
\hline 1388 & & todas dentro $\uparrow$ \\
\hline 1389 & & porque $\rightarrow$ \\
\hline 1390 & & $\{[\mathrm{p}][\mathrm{ac}]$ la mayoría no querían desfilar en bikini $\} \rightarrow$ \\
\hline 1391 & & ya fue ella allá $\uparrow$ \\
\hline 1392 & & y todas dentro $\uparrow$ \\
\hline 1393 & & así en plan $\rightarrow$ \\
\hline 1394 & & $\{[\mathrm{~b}]$ joder $\uparrow<$ voz falsa $>$ \\
\hline 1395 & & y esto no sé qué\} $\uparrow$ \\
\hline 1396 & & y en esto que ella se fue al primero $\rightarrow$ \\
\hline 1397 & & ya le quedaba como una patada en el culo $\uparrow$ \\
\hline 1398 & & y sale $\rightarrow$ \\
\hline 1399 & & (xx) así de los probadores $\uparrow$ \\
\hline 1400 & & <LAURA imita la salida de la chica de los probadores> \\
\hline 1401 & & $\{[a]$ QUÉ TAL? $\}<$ burlonamente, voz cursi> \\
\hline 1402 & PAULA & he he he \\
\hline 1403 & NIEVES & y $[y$ y::] \\
\hline 1404 & LAURA & [Y TODAS] $\rightarrow=$ \\
\hline 1405 & NIEVES & $=\mathrm{y}$ todas $[(\mathrm{xx}) \mathrm{ya}] \rightarrow<$ entre risitas $>$ \\
\hline 1406 & LAURA & [he he he] \\
\hline 1407 & & sí:: < entre risas> \\
\hline 1408 & & y todas $\rightarrow$ \\
\hline 1409 & & [bue::no] $\rightarrow$ \\
\hline 1410 & PAULA & {$[\mathrm{NON}] \rightarrow$} \\
\hline
\end{tabular}

42. Ibíd., p. 285.

Feminismo/s 24, diciembre 2014, pp. 67-94 


\begin{tabular}{|l|l|l|}
\hline 1411 & & É [QUE EU NON CRITICO ISO] $\rightarrow$ \\
\hline 1412 & NIEVES & [porque claro NO:] \\
\hline 1413 & PAULA & EU [O QUE CRITICO FOI] $\uparrow$ \\
\hline 1414 & NIEVES & {$[$ NO: $(\mathrm{xx})$ no fijo] $\downarrow=$} \\
\hline 1415 & PAULA & $=\{[\mathrm{dc}]$ A FO:RMA DE DESFILAR $\} \rightarrow=$ \\
\hline 1416 & NIEVES & $=$ yo no es eso $\uparrow$ \\
\hline 1417 & & es que $=$ \\
\hline 1418 & PAULA & $=$ É QUE QUE IMPORTA [SE $(\mathrm{xx})]$ \\
\hline 1419 & NIEVES & {$[$ DIO EL CA::NTE] $\uparrow$} \\
\hline 1420 & & dio [el CA::NTE] $\rightarrow$ \\
\hline
\end{tabular}

En este extracto, Laura produce una anécdota sobre el comportamiento de la joven que es objeto del cotilleo durante un desfile de moda. Eggins y Slade ${ }^{43}$ explican que en las anécdotas se presenta una crisis o complicación que, a diferencia de lo que sucede en las narrativas ${ }^{44}$, no está seguida por una resolución, sino por una reacción: «rather than being explicitly resolved, the crisis is reacted to in some way: by an expression of amazement, frustration, emarrasement, humiliation, etc» ${ }^{45}$. El discurso de Laura en este extracto se ajusta a la estructura de este tipo de historias, según estas autoras. En primer lugar, la hablante desarrolla la fase de orientación, cuando señala explícitamente que la mayoría de las chicas que participaban en el desfile no querían desfilar en bikini y que estaban todas dentro (líneas 1388-1390), sugiriendo así que les avergonzaba hacerlo. Seguidamente, Laura repite todas dentro y recrea la voz de alguien que expresa una queja por la posibilidad de tener que desfilar en bikini, joder y esto no sé qué (líneas 1394-1395), utilizando el discurso referido directo como una demostración ${ }^{46}$ de esa actitud negativa o sentimiento de vergüenza aparentemente generalizado; en contraste, se indica que la chica que es objeto del cotilleo se dirigió a los probadores, ya fue ella allá (línea 1391), y en esto que ella se fue al primero (línea 1396), empleando el adverbio ya y el conector narrativo y en esto que para sugerir la rapidez o la naturalidad con la que lo hizo y al mismo tiempo para anunciar el inicio de la fase

43. EGGins, Suzanne y SLADE, Diana. Op. cit.

44. LABOV, William y WALETZKY, Joshua. «Narrative analysis», en June Helm (ed.): Essays on the verbal and visual arts. Seattle, University of Washington Press, 1967, pp. 12-44.

45. EgGins, Suzanne y SLAdE, Diana. Op. cit., p. 237.

46. Clark, Herbert y Gerrig, Richard. "Quotations as demonstrations». Language 66, (1990), pp. 764-805. 
de reconstrucción del acontecimiento destacable que constituye el corazón narrativo de las anécdotas ${ }^{47}$.

Finalmente, Laura se centra en este acontecimiento clave y describe el momento en el que la protagonista de la historia sale del probador con el bikini puesto, resaltando inicialmente lo mal que le quedaba, ya le quedaba como una patada en el culo (línea 1397), para después representar su actitud de orgullo y/o ilusión al exhibirse ante las demás, haciendo una imitación no verbal (líneas 1399-1400), y recreando su voz preguntando cómo le sentaba, qué tal (línea 1401), con rasgos prosódicos de estilización paródica ${ }^{48}$, que sirven para caracterizar burlonamente al personaje por su voz «cursi».

Paula se ríe (línea 1402) y a continuación se produce una lucha por el turno entre Nieves y Laura, que tratan de completar la historia de forma paralela, entre risas, representando la reacción de las demás chicas que participaban en el desfile ante la aparición de la protagonista en bikini (y demostrando por tanto que ambas conocían los hechos, líneas 1404-1409). Paula utiliza un volumen de voz más fuerte para llamar la atención de sus compañeras sobre su punto de vista ante la actuación de la «víctima» del cotilleo en ese desfile (líneas 1410-1411, 1413, 1415, 1418), pero su estrategia no tiene mucho éxito, ya que Nieves interviene paralelamente (líneas 1412, 1414, 14161417). Ambas participantes compiten por destacar su propia opinión sobre la persona que está en el foco de la actividad comunicativa, de manera que el discurso adquiere un carácter evaluativo. En las líneas 1419-1420, Nieves eleva también el volumen de voz para resaltar una evaluación explícita de los hechos basada en la expresión coloquial dar el cante (líneas 1419-1420), que utiliza para criticar el comportamiento que tuvo la chica en cuestión, en contraste con el de las demás participantes en el desfile. Este comentario evaluativo actúa como la coda de una anécdota divertida, en la que se presenta un acontecimiento destacable por lo ridículo que resulta, cuya reconstrucción está orientada a provocar la risa de la audiencia como reacción ${ }^{49}$, pero también a suscitar un discurso evaluativo crítico que es más específicamente característico del cotilleo.

47. EgGins, Suzanne y Slade, Diana. Op. cit.

48. BAKHTIN, Mikhail M. «Discourse in the novel», en Michael Holquist y Caryl Emerson (eds.): The dialogic imagination: Four essays. Austin: University of Texas Press, 1981, pp. 259-422. GÜNTHNER, Susanne. «Complaint stories. Constructing emotional reciprocity among women», en Helga Kotthoff y Ruth Wodak (eds.): Communicating gender in context, Amsterdam, John Benjamins, 1997, pp. 179-218.

49. EGgINS, Suzanne y SLADE, Diana. Op. cit., p. 237. 
Desde una perspectiva de género, el contenido de esta anécdota gira en torno a un mundo fuertemente feminizado como es el de la moda y los desfiles de modelos, que ejerce una poderosa influencia en la reafirmación de la belleza, de la apariencia física y del aspecto en general, como parte esencial del capital simbólico ${ }^{50}$ (Bourdieu, 1987) disponible para las mujeres en la sociedad contemporánea, en consonancia con los discursos de género de épocas pasadas. Como ha destacado Guendouzi: «the media still puts forward restricted images of femininity that require women to live up to social ideals such as the 'good mother', 'looking young', and having the 'ideal body shape' $»^{51}$. En este extracto, la joven de la que se habla participa como modelo en un desfile, y la realización de este rol la sitúa como una «mujer de éxito» o un «modelo de feminidad», desde el punto de vista de estos discursos que ensalzan la belleza y la apariencia física como valores femeninos. Sin embargo, las locutoras se centran en su actuación en ese desfile, a través de la producción de una anécdota humorística, para mofarse de ella y para criticarla por su falta de reparos ante la posibilidad de tener que desfilar en bikini, en contraste con la vergüenza que mostraban las demás chicas que participaban en el desfile, y por su actitud presuntuosa al exhibirse orgullosa con esta prenda. En esta crítica burlona subyace una reivindicación de otros símbolos de feminidad, como la modestia ${ }^{52}$ y el pudor o la vergüenza ${ }^{53}$, que sirve de contrapeso al «éxito» de la víctima de estas críticas por su participación como modelo en un desfile. Nótese que, además, se llegan a negar explícitamente sus cualidades físicas para realizar este rol (línea 1397). De forma similar a lo que veíamos en el Extracto 1, el discurso adquiere connotaciones de competitividad o rivalidad por un tipo de capital simbólico femenino que logra u ostenta la tercera persona que es objeto de la actividad comunicativa, pero que las participantes tratan de contrarrestar o de anular a través de la crítica y la mofa. En este sentido, la anécdota humorística que recoge este extracto cumple también, por tanto, una función competitiva.

\subsection{Conversación B: cotilleos en la habitación de la residencia}

En la conversación B intervienen Olga, Vanesa y Laura. La interacción se desarrolla en este caso en la habitación de una residencia universitaria y se basa casi exclusivamente en la práctica de cotilleo, durante los veinticinco minutos

50. BourdieU, Pierre. Language and symbolic power. Londres, Polity Press, 1987.

51. GuendouZI, Jackie. Op. Cit., p. 31.

52. MilLs, Sara. Gender and politeness. Cambridge, Cambridge University Press, 2003.

53. COATES, Jennifer. Women talk. Conversation between women friends. Op. Cit. COATES, Jennifer. Women, men and everyday talk. Op. Cit. 
que abarca aproximadamente la grabación. Además, este cotilleo se centra en una única persona, Cristina, otra estudiante universitaria que conocen bien las tres participantes, pero sobre todo Laura, ya que fue su compañera de piso en la misma residencia donde tiene lugar la conversación y además solía salir con ella. La actividad comunicativa se basa en las historias e informaciones que aporta Laura en relación con la forma de ser y de actuar de Cristina, sus costumbres y su vida personal, especialmente sus relaciones con los chicos, a veces por petición explícita de las demás y otras veces en respuesta a sus muestras de interés. El discurso se produce generalmente en clave humorística y/o burlona; por ejemplo, en el Extracto 3, Laura se queja por la frecuencia con la que Cristina solía hablar por teléfono con sus novios o amigos y representa paródicamente la forma en que lo hacía:

\section{Extracto 3}

\begin{tabular}{|l|l|l|}
\hline 518 & LAURA & $=$ andaba todo el día $\uparrow$ \\
\hline 519 & & $<1.5>$ \\
\hline 520 & & es que $\rightarrow$ \\
\hline 521 & & era una cosa $\uparrow$ \\
\hline 522 & &.. \\
\hline 523 & & llamaba uno $\uparrow$ \\
\hline 524 & & colgaba $\rightarrow$ \\
\hline 525 & &.. \\
\hline 526 & & llamaba otro $\uparrow$ \\
\hline 527 & & a lo mejor se pasaba $\rightarrow$ \\
\hline 528 & & toda la noche $\uparrow$ \\
\hline 529 & & hablando por teléfono $\rightarrow=$ \\
\hline 530 & VANESA & $=\{[$ ac] ay eso sí:: \\
\hline 531 & & es verdá $\rightarrow$ \\
\hline 532 & & [eso sí porque él estuvo aquí]\} $\uparrow$ \\
\hline 533 & LAURA & [y cada mariconada::] $\uparrow=$ \\
\hline 534 & VANESA & $=$ = y la llamaron cada [cinco minutos] $\rightarrow$ \\
\hline 535 & LAURA & $\{[$ [p] [y cada mari-]\} $\uparrow$ \\
\hline 536 & & es que soltaba cada maricona:da $\uparrow$ \\
\hline 537 & & .. \\
\hline 538 & & $\{[$ a] mi amo:::r $\uparrow<$ burlonamente, voz cursi $>$ \\
\hline
\end{tabular}




\begin{tabular}{|l|l|l|}
\hline 539 & & mi peluSI::to $\uparrow$ \\
\hline 540 & & mi no sé qué $\} \rightarrow=$ \\
\hline 541 & VANESA & $=$ he he he $=$ \\
\hline 542 & LAURA & $=\{[$ ac $]$ AL PORTUGUÉS LO LLAMABA MIMOSÍN $\} \rightarrow=$ \\
\hline 543 & VANESA & $=$ he he he $=$ \\
\hline 544 & OLGA & $=$ he he he $=$ \\
\hline 545 & LAURA & $=$ mira $\rightarrow=<$ entre risas $>$ \\
\hline 546 & VANESA & $=$ he he he $=$ \\
\hline 547 & LAURA & $=$ yo de verdá $\uparrow$ \\
\hline 548 & & que $\rightarrow$ \\
\hline
\end{tabular}

En este extracto, Laura describe la costumbre de Cristina de hablar por teléfono con chicos de manera crítica (líneas 518-529), como algo desmesurado y molesto, usando formulaciones de casos extremos ${ }^{54}$ como todo el día (línea 518) y toda la noche (línea 528), y especificando que estas charlas telefónicas se mantenían una detrás de otra (líneas 523-526). Vanesa confirma la veracidad de esta información, señalando que ella misma observó también un comportamiento similar por parte de Cristina (líneas 530-532, 534), y Laura prosigue para criticar la forma en que hablaba con esos chicos, evaluando despectivamente las cosas que les decía como una mariconada (líneas 533, 535536). En las líneas 538-540, Laura introduce discurso referido dramatizado ${ }^{55}$, en el que se incluyen recursos de estilización paródica ${ }^{56}$, para mofarse del estilo de habla cursi que Mónica empleaba en esas conversaciones; utiliza un tono más agudo para crear una voz en falsetto y un tono burlón al reconstruir directamente sus palabras o expresiones para dirigirse a ellos, mi amor (línea 538) y mi pelusito (línea 539), con alargamiento vocálico en ambos casos. Esta representación paródica provoca la risa de Vanesa (línea 541). Seguidamente, Laura eleva el volumen de voz para llamar la atención de sus compañeras sobre el apelativo que Cristina empleaba para dirigirse cariñosamente a un hombre portugués con el que tuvo una relación, al portugués lo llamaba Mimosín (línea 542); el énfasis en el uso de este apelativo actúa como un recurso de evaluación implícita que refuerza la representación previa de Cristina como una chica cursi. Vanesa y Olga despliegan afiliación con esta mofa a través de la risa (líneas 543-544).

54. POMERANTZ, Anita. «Extreme case formulations: A way of legitimizing claims». Human Studies 9 (1986), pp. 219-229.

55. BERGMANN, Jörg R. Op. cit.

56. BAKHTIN, Mikhail M. Op. cit. GÜNTHNER, Susanne. Op. cit. 
Como en la anécdota humorística que recogía el Extracto 2, aquí se observa cómo se utiliza la reconstrucción paródica del discurso de la «víctima» del cotilleo, como estrategia para mofarse indirectamente de ella (véase también Acuña Ferreira) ${ }^{57}$; en este caso, la mofa se basa únicamente en esta estrategia, es decir, el discurso se centra en ridiculizar a Cristina por su forma de hablar por teléfono con los chicos con los que se relacionaba y por la frecuencia con la que lo hacía. El foco de la crítica y de la mofa hacia la persona que es objeto de la actividad comunicativa está de nuevo, como ocurría en el Extracto 1, en las relaciones sexuales/amorosas con los hombres, lo que saca a relucir nuevamente una competitividad subyacente por esta cuestión como fruto de los discursos de género predominantes, tal y como destacábamos previamente. En el presente extracto, Cristina aparece posicionada como una mujer exitosa en el terreno amoroso, en la medida en que recibe numerosas llamadas de hombres y aparentemente tiene o ha tenido varios novios, pero también recibe de manera indirecta, a través del formato del cotilleo, un ataque humorístico por la forma en que se comunicaba con ellos. La representación jocosa de su estilo de habla y de sus expresiones sirve para trivializar o menospreciar ese aparente éxito con los hombres y en este sentido el discurso adquiere un carácter competitivo.

Lo cierto es que gran parte del cotilleo sobre Cristina en esta conversación tiene que ver con sus asuntos amorosos: la apariencia física de sus novios, quiénes son o con quiénes ha tenido una relación, su forma de comportarse con ellos, etc. En el Extracto 4 se recoge una anécdota humorística contada por Laura, en la que se pone de relieve la actitud de Cristina en los bares nocturnos a los que ambas, junto con otras chicas, solían acudir para divertirse:

\section{Extracto 4}

\begin{tabular}{|l|l|l|}
\hline 846 & LAURA & una vez estábamos con unos viejos que se nos pegaran $\uparrow$ \\
\hline 847 & & y la tía $\rightarrow$ \\
\hline 848 & & he he he \\
\hline 849 & & y yo $\uparrow$ \\
\hline 850 & & estaba toda puesta $\uparrow$ \\
\hline 851 & & $\{[$ a] hey $\uparrow<$ <entre risas> \\
\hline 852 & & queréis conocer a Cristi::na?\} \\
\hline
\end{tabular}

57. ACuña Ferreira, A. Virginia. «Gossip as indirect mockery: The social functions of 'sharing a laugh' at third parties». Op. cit. 


\begin{tabular}{|l|l|l|}
\hline 853 & & he he he \\
\hline 854 & & y Cristina $\rightarrow$ \\
\hline 855 & & $<$ LAURA hace una imitación $>$ \\
\hline 856 & VANESA & [he he he] \\
\hline 857 & LAURA & [he he he] \\
\hline 858 & & y el tío $\rightarrow$ \\
\hline 859 & & y el viejo $\rightarrow$ \\
\hline 860 & & hoy no pescas nada mujer $\uparrow$ \\
\hline 861 & & no sé qué $=<$ entre risas $>$ \\
\hline 862 & VANESA & $=\{[$ ac] $[$ CÓ::MO?] $\}$ \\
\hline 863 & LAURA & [y decía] $<$ entre risas $>$ \\
\hline 864 & & hoy no pescas nada $\rightarrow$ \\
\hline 865 & & $($ xx $)$ \\
\hline 866 & & y la tía $\rightarrow$ \\
\hline 867 & & $\{[$ a] no $\rightarrow$ \\
\hline 868 & & no hay suerte $\rightarrow$ \\
\hline 869 & & $($ xx $\}$ \\
\hline 870 & & y yo $\rightarrow$ \\
\hline 871 & & va::le $\rightarrow$ \\
\hline 872 & VANESA & he he he \\
\hline 873 & LAURA & he he he \\
\hline 874 & & mira $\rightarrow$ \\
\hline 875 & & yo de verdad que aún lo pasé acojonante $\rightarrow<$ entre risas $>$ \\
\hline 876 & & también es cierto $\downarrow=$ \\
\hline 877 & VANESA & $=[$ sí] $<$ entre risas $>$ \\
\hline 878 & LAURA & {$[$ [xx)] todo lo que quieras $\uparrow$} \\
\hline 879 & & pero me lo pasaba acojoNAN:te $\rightarrow=$ \\
\hline 880 & VANESA & $=$ he he he $=$ \\
\hline
\end{tabular}

Como orientación de la anécdota ${ }^{58}$, Laura señala que ella y su grupo de amigas se encontraban acompañadas por unos hombres, a los que se refiere despectivamente como viejos (línea 846). Tras un falso comienzo, seguido por una risa (líneas 847-848), la hablante especifica que ella misma estaba toda puesta (línea 850), para sugerir que tenía ganas de gastar bromas, que es justamente

58. EgGins, Suzanne y SLADE, Diana. Op. cit.

Feminismo/s 24, diciembre 2014, pp. 67-94 
lo que se reconstruye a continuación. Como acontecimiento destacable de esta anécdota, Laura reconstruye en estilo directo cómo ella misma propone a esos hombres que conozcan a Cristina, recreando una voz en falsetto a través del uso de un tono más agudo, hey queréis conocer a Cristina (líneas 851-852); de nuevo, se ríe (línea 853), para resaltar así, implícitamente, lo divertida que resultaba (o iba a resultar) la situación, y seguidamente hace una imitación no verbal de Cristina en respuesta a esa propuesta de presentación, que provoca la risa de Vanesa, además de la suya propia (líneas 854-857). A juzgar por cómo se sigue desarrollando la anécdota, cabe suponer que esta imitación representa a Cristina mostrando una rápida disposición por conocer a esos hombres; así, en las siguientes líneas (858-861), Laura reconstruye en estilo directo cómo uno de estos personajes masculinos se dirige a Cristina para decirle hoy no pescas nada mujer (línea 860); de este modo, el hombre trata de ponerla en ridículo ante todos, insinuando con sorna que su búsqueda de hombres era evidente y que no iba a lograr su objetivo.

Vanesa pide una aclaración o repetición del comentario realizado por este personaje a través de una pregunta cuyos rasgos prosódicos, aceleración del tempo y aumento del volumen, expresan asombro o incredulidad (línea 862), de manera que Laura lo repite (líneas 863-865), y a continuación reproduce directamente, utilizando un tono de voz más agudo, la respuesta de Cristina a ese comentario, expresando resignación, no no hay suerte (líneas 866869). El discurso referido directo que recogen las líneas 870-871, y yo vale, puede interpretarse como inner speech ${ }^{59}$, es decir, como una recreación del pensamiento que la propia Laura tuvo en ese momento, y que parece expresar satisfacción ante la burla hacia Cristina, que en parte fue propiciada por ella misma, al presentarle a esos hombres que estaban en el local. Esta expresión funciona como la reacción de la anécdota, junto con la risa de Vanesa que se produce inmediatamente después (línea 872). Finalmente, la anécdota incluye una coda, en la que Laura se ríe y resalta lo bien que se lo pasaba al salir con Cristina, mira yo de verdad que aún lo pasé acojonante (líneas 874876, 878-879), mientras Vanesa sigue riéndose y expresa acuerdo con esta valoración final de la broma (líneas 877, 880).

Una vez más, en esta anécdota se pone así de relieve la idea de «conseguir a un hombre» como meta de las mujeres y como origen de competición o rivalidad entre ellas. En este caso, además, se hace referencia concreta y explícita a esta idea con el uso coloquial del verbo pescar por parte del personaje

59. TANNEN, Deborah. Talking voices. Repetition, dialogue and imagery in conversational discourse. Cambridge, Cambridge University Press, 1989.

Feminismo/s 24, diciembre 2014, pp. 67-94 
masculino que se burla de Cristina, la «víctima» de los cotilleos en esta Conversación $B$, precisamente por perseguir este objetivo, aparentemente sin éxito. La anécdota se basa en la reconstrucción de la burla que se hizo directamente de ella en aquel momento por ese motivo, incluyendo señales de que fue instigada, propiciada o buscada por la participante que cuenta lo ocurrido como otro personaje dentro del mundo de la historia. Al contar la anécdota, Laura se burla nuevamente de Cristina, pero ahora de forma indirecta, «saboreando» su triunfo al lograr que fuese ridiculizada y obteniendo, además, la complicidad de su interlocutora, Vanesa, a través de la risa. En los extractos anteriores, las mofas y las agresiones lúdicas realizadas indirectamente a través del cotilleo trivializaban o menospreciaban un éxito de la joven aludida desde el punto de vista de los ideales de feminidad; en este caso, sin embargo, el discurso humorístico desplegado supone la celebración de un fracaso, que acentúa de forma similar una rivalidad o competitividad subyacente.

\section{Conclusiones}

En este artículo se han analizado las características formales y funcionales del humor en la práctica de cotilleo entre jóvenes veinteañeras. Frente a la caracterización general del humor de las mujeres en términos de cooperación, solidaridad y subversión del género en estudios previos, en nuestro análisis se han puesto de relieve las funciones competitivas que realiza este tipo de discurso de manera encubierta o subyacente y su papel en el mantenimiento y refuerzo de valores dominantes de feminidad o formas de capital simbólico femenino como el aspecto y las relaciones sexuales/amorosas con los hombres. Las «víctimas» de los cotilleos analizados aparecen establecidas como tales en la medida en que lograron o tratan de lograr una de estas formas de capital simbólico femenino, pero el discurso sobre ellas se centra en criticarlas desde una perspectiva burlona por este motivo, a través de salidas graciosas que las etiquetan de forma despectiva, de anécdotas humorísticas y/o de representaciones paródicas de su estilo de habla. Este proceso incluye a veces una reivindicación implícita de otros valores tradicionalmente asociados con la feminidad, como el rechazo a la promiscuidad, la modestia o el pudor.

Una de las funciones más obvias del discurso en los extractos analizados es sin duda el entretenimiento y la idea de «compartir unas risas» a través de la interacción comunicativa; sin embargo, en nuestro análisis se ha demostrado que este divertimiento se basa en la ridiculización de la tercera persona que es objeto del habla y que esta mofa o burla indirecta que se hace de ella sirve además para menospreciar sus éxitos o celebrar sus fracasos en relación con esos dos valores de feminidad antes señalados: el aspecto y las relaciones 
con los hombres. Esta función más implícita de las formas de discurso humorístico que se han abordado refuerza las tesis defendidas por estudios previos sobre la competitividad subyacente en la práctica de cotilleo, especialmente de aquellos que proceden de la Psicología Social ${ }^{60}$; más concretamente, nuestro análisis apoya las conclusiones de Guendouzi sobre el bitching «as a means of competing for 'peer validated' versions of femininity in the social marketplace ${ }^{61}$ y sobre la importancia de que los estudios sobre género y discurso tengan no solamente en cuenta el estilo de organización del discurso, sino también la sustancia. A diferencia de los extractos conversacionales analizados por esta autora, en los que el cotilleo se realiza con «seriedad», y desde una perspectiva abiertamente moralizante, nuestros datos pueden interpretarse como ejemplos de una forma de bitching humorístico, en el que esa competición es expresada a través de la mofa o de la burla ${ }^{62}$.

Las funciones competitivas que encubre tanto el bitching moralizante como la variedad lúdica/humorística que aquí se ha resaltado tienen importantes implicaciones para los estudios sobre género y discurso, que han enfatizado el estilo cooperativo y la búsqueda de apoyo y solidaridad como rasgos característicos del habla de las mujeres, incluyendo sus prácticas humorísticas, mientras que los estilos de interacción competitivos han sido relacionados casi exclusivamente con el habla de los hombres y con la masculinidad. La práctica del bitching y del cotilleo humorístico como mofa indirecta pone de relieve los componentes competitivos que también puede incluir el habla entre mujeres, aunque en un nivel más profundo, así como el papel que ejercen a este respecto los valores de feminidad que han establecido y continúan fomentando las ideologías de género predominantes. En el fondo, el modo encubierto o indirecto en que se manifiestan estas formas de competición en la conversación entre mujeres puede interpretarse como un refuerzo de la relación más directa que se establece entre competición y masculinidad, es decir, como un factor que reafirma la idea de que competir abiertamente es un comportamiento que se considera aceptable (o incluso deseable) en los hombres, pero no en las mujeres. En este sentido, este tipo de prácticas discursivas pueden verse entonces como un recurso o estrategia especialmente útil para las mujeres, en la medida en que les permite competir entre sí de manera más aceptable. Aunque los discursos de género no incluyen o no suelen incluir la competición como ideal de feminidad, puede concluirse que al mismo tiempo la fomentan, de forma un tanto paradójica, en torno a valores como el aspecto

60. Paine, Robert. Op. cit. SULS, Jerry M. Op. cit. Wert, Sarah R. y SAlovey, Peter. Op. cit. 61. GuENDOUZI, Jackie. Op. cit., p. 17.

62. Véase también ACUÑa FerREIRA, A. Virginia. Op. cit.

Feminismo/s 24, diciembre 2014, pp. 67-94 
y las relaciones con los hombres, tal y como se ha puesto de manifiesto en nuestro análisis.

\section{Referencias bibliográficas}

ACUÑA FerreirA, A. Virginia. «Complaint stories revisited. The 'masculine' performance of a 'feminine' genre in a conversation among Galician men». Sociolinguistic Studies 2.2 (2008), pp. 185-220.

ACUÑa FerReira, A. Virginia. Género y discurso. Las mujeres y los hombres en la interacción conversacional. Múnich, Lincom, 2009.

ACUÑA FERREIRA, A. Virginia. «The humorous display of transgresor femininities: 'Sharing a laugh' in Spanish-Galician friendly talk among young women». Sociolinguistic Studies 6.1 (2012), 121-147.

ACUÑa FERREIRA, A. Virginia. «Gossip as indirect mockery in friendly conversation: The social functions of 'sharing a laugh' at third parties». Discourse Studies 16.5 (2014), pp. 607-628.

BAKHTIN, Mikhail M. «Discourse in the novel», en Michael Holquist y Caryl Emerson (eds.): The dialogic imagination: Four essays. Austin: University of Texas Press, 1981, pp. 259-422.

Bergmann, Jörg R. Discreet indiscretions. The social organization of gossip. Nueva York: Aldine de Gruyter, 1993.

BOXER, D. y CORTÉS-CONDE, Florencia. «From bonding to biting: Conversational joking and identity display». Journal of Pragmatics 27 (1997), pp. 275-294.

Bourdieu, Pierre. Language and symbolic power. Londres, Polity Press, 1987.

CLARK, Herbert y GERRIG, Richard. «Quotations as demonstrations». Language 66, (1990), pp. 764-805.

COATES, Jennifer. Women talk. Conversation between women friends. Oxford, Blackwell, 1996.

COATES, Jennifer. Women, men and everyday talk. Londres, Palgrave, 2013.

Cox, Bruce A. «What is Hopi gossip about? Information management and Hopi factions». Man 5.1 (1970), pp. 88-98.

COWIE, Celia y LEES, Sue. «Slags or drags». Feminist Review 9 (1981), pp. 17-31.

EDER, Donna. «Go get ya a French! Romantic and sexual teasing among adolescent girls», en Deborah Tannen (ed.): Gender and conversational interaction. Nueva York, Oxford University Press, 1993, pp. 17-31.

EGGINS, Suzanne y SLADE, Diana. Analysing casual conversation. Londres, Continuum, 1997.

ERVIN-TRIP, Susan y Martin D. Lampert. «Gender differences in the construction of humorous talk», en Kira Hall, Mary Bucholtz y Birch Moonwomon (eds.): Locating power. Proceedings of the Second Berkeley Women and Language Conference. Volume 1, Berkeley, CA, University of California, 1992, pp. 108-117. 
FARR, Marcia. «Echando relajo: Verbal art and gender among Mexicanas in Chicago», en Mary Bucholtz, A.C. Liang, Laurel A. Sutton y Caitling Hines (eds.): Cultural performances. Proceedings of the Third Berkeley Women and Language Conference, Berkeley, CA, University of California, 1994, pp. 168-186.

FOSTER, Eric K. «Research on gossip: Taxonomy, methods, and future directions». Review of General Psychology 8.2 (2004), pp. 78-99.

GEORGAKOPOUlOU, Alexandra. «Women, men and conversational narrative performances: Aspects of gender in Greek storytelling». Anthropological Linguistics 37 (1995), pp. 460-486.

GluCKMAn, Max. «Gossip and scandal». Current Anthropology 4.3 (1963), pp. 307-316.

GoodwIN, Marjorie Harness. «He-said-she-said: Formal procedures for the construction of a gossip dispute activity». American Ethnologist 7 (1980), pp. 674-695.

GoodwIn, Marjorie Harness. «Instigating: Storytelling as social process». American Ethnologist 9 (1982), pp. 799-819.

Goodwin, Marjorie Harness. He-said-she-said: Talk as social organization among black children. Bloomington, Indiana University Press, 1990.

GoodwIN, Marjorie Harness. «Retellings, pretellings and hypothetical stories». Research on Language and Social Interaction 24 (1990/1991), pp. 263-276.

GREENE, Rayna. «Magnolias grow in dirt: The bawdy lore of Southern women». Southern Exposure 4 (1977), pp. 29-33.

GRIFFIN, Christine. «Absences that matter: Constructions of sexuality in studies of young women's friendships». Feminism \& Psychology 10 (2000), pp. 227-245.

GUENDOUZI, Jackie. «You'll think we're always bitching: the functions of cooperativity and competition in women's gossip». Discourse Studies 3.1 (2001), pp. 29-51.

GÜNTHNER, Susanne. «Complaint stories. Constructing emotional reciprocity among women», en Helga Kotthoff y Ruth Wodak (eds.): Communicating gender in context, Amsterdam, John Benjamins, 1997, pp. 179-218.

HAY, Jennifer. «Functions of humor in the conversations of men and women». Journal of Pragmatics 32 (2000), pp. 709-742.

HALL, Joan Kelly. «Tengo una bomba»: The paralinguistic and linguistic conventions of the oral practice chismeando. Research on Language and Social Interaction 26.1 (1993), pp. 55-83.

HARDING, Susan. «Women and words in a Spanish village», en Rayna Reiter (ed.): Toward an anthropology of women, Nueva York, Monthly Review Press, 1975, pp. 283-308.

HaVILAND, John B. Gossip, reputation, and knowledge in Zinacantan. Chicago, University of Chicago Press, 1977. 
HolmeS, Janet. «Sharing a laugh: Pragmatic aspects of humor and gender in the workplace». Journal of Pragmatics 38 (2006), pp. 26-50.

Holmes, Janet. Gendered talk at work. Constructing gender identity through workplace discourse, Oxford, Blackwell, 2009.

JENKInS, Mercilee. "What's so funny? Joking among women», en Noelle Caskey, Sue Bremner, Birch Moonwomon y Noelle Caskey (eds.): Proceedings of the First Berkeley Women and Language Conference, University of California, Berkeley, Berkeley Women and Language Group, 185, pp. 131-151

JONES, Deborah. «Gossip: Notes on women's oral culture». Women's Studies International Quarterly 3 (1980), pp. 193-198.

KALČIK Susan.. «... like Ann's gynecologist or the time I was almost raped: Personal narratives in women's rap groups». Journal of American Folklore 88 (1975), pp. 3-11.

Kendall, Shari y TANNEN, Deborah. «Discourse and gender», en Deborah Schiffrin, Deborah Tannen y Heidi E. Hamilton (eds.): The handbook of discourse analysis, Oxford, Blackwell, 2001, pp. 548-567.

KotтhofF, Helga. «Gender and joking: On the complexities of women's image politics in humourous narratives». Journal of Pragmatics 32 (2000), pp. 55-80.

LAKOFF, Robin. Language and woman's place. Text and commentaries. Editado por Mary Bucholtz. Oxford, Oxford University Press, 2004 (1975).

LEES, Sue. Sugar and spice: Sexuality and adolescent girls. Londres, Penguin, 1986. LABOV, William y WALETZKY, Joshua. «Narrative analysis», en June Helm (ed.): Essays on the verbal and visual arts. Seattle, University of Washington Press, 1967, pp. 12-44.

LozAno Domingo, Irene. Lenguaje femenino, lenguaje masculino. ¿Condiciona nuestro sexo la forma de hablar? Madrid, Minerva, 1995.

Mills, Sara. Gender and politeness. Cambridge, Cambridge University Press, 2003.

MorreALl, John. «Gossip and humor», en Robert F. Goodman y Aaron Ben-Ze'ev A (eds.): Good gossip, Lawrence, University Press of Kansas, 1994, pp. 56-64. PAINE, Robert. «What is gossip about? An alternative hypothesis». Man 2 (1967), pp. 278-285.

POMERANTZ, Anita. «Extreme case formulations: A way of legitimizing claims». Human Studies 9 (1986), pp. 219-229.

RodríGUEZ-YÁÑEZ, Xoán P. y CASARES, Håkan. «The Corpus of Galician/Spanish Bilingual Speech of the University of Vigo: Codes tagging and automatic annotation». Estudios de Sociolingüística 3.2 y 4.1 (2002/2003), pp. 359-382.

Romaine, Suzanne. Communicating gender. Mahwah, NJ, Lawrence Erlbaum Associates, 1999.

RosnOw, Ralph L. y FINE, Gary Alan. Rumor and gossip: The social psychology of hearsay. New York, Elsevier, 1976. 
RYSMAN, Alexander. «How the gossip became a woman». Journal of Communication 27 (1977), pp. 176-180.

SPENDER, Dale. Man made language. Londres, Routledge y Kegan Paul, 1980.

SCOllon, Ron y Suzanne SCOllon. Intercultural communication. A discourse approach. Oxford, Blackwell, 1995.

Suls, Jerry M. «Gossip as social comparison». Journal of Communication 27.1 (1977), pp. 164-168.

TANnEN, Deborah. Talking voices. Repetition, dialogue and imagery in conversational discourse. Cambridge, Cambridge University Press, 1989.

TANEN, Deborah. You just don't understand. Women and men in conversation. Nueva York, William Morrow, 1990.

TANnen, Deborah. Género y discurso. Barcelona, Paidós, 1996.

TAYLOR, Gabriele. (1994). «Gossip as moral talk», en Robert F. Goodman y Aaron Ben-Ze'ev (eds.): Good gossip. Lawrence, University Press of Kansas, 1994, pp. 34-46.

THOLANDER, Michael. «Pupil's gossip as remedial action». Discourse Studies. 5.1 (2003), pp. 101-129.

Walton, Marsha, Weatherall, Ann y Jackson, Sue. «Romance and friendship in pre-teen stories about conflicts: «we decided that boys are not worth it». Discourse E Society 13 (2002), pp. 673-689.

WerT, Sarah R. y SAlOvey, Peter. «A social comparison account of gossip». Review of General Psychology 8.2 (2004), pp. 122-137.

\section{Apéndice: convenciones de transcripción}

\begin{tabular}{|l|l|}
\hline Letra redonda & Español \\
\hline Letra negrita & Gallego \\
\hline Línea de transcripción & Unidad de entonación \\
\hline$\uparrow$ & Entonación final ascendente \\
\hline$\downarrow$ & Entonación final descendente \\
\hline$\rightarrow$ & Entonación final más o menos sostenida \\
\hline$?$ & Entonación típicamente interrogativa \\
\hline.. & Micropausa (menos de un segundo) \\
\hline$<3>$ & Pausa medida en número de segundos \\
\hline o sea:: & Sonido alargado \\
\hline la lo- & Sonido truncado \\
\hline $\begin{array}{l}\text { allí es mucho eh? }= \\
=\text { ya ves }\end{array}$ & Encadenamiento de voces \\
\hline & \\
\hline
\end{tabular}

Feminismo/s 24, diciembre 2014, pp. 67-94 


\begin{tabular}{|l|l|}
\hline $\begin{array}{l}\text { y tú te estabas [meando] } \\
\text { [es que está] tres horas }\end{array}$ & Superposición de voces \\
\hline (parece $)$ & Transcripción dudosa \\
\hline$(\mathrm{xx})$ & Segmento ininteligible \\
\hline he he he & Risa \\
\hline LETRAS MAYÚSCULAS & Volumen relativamente fortis \\
\hline\{\} & Segmento al que afecta el fenómeno \\
\hline$\{[p]\}$ & Volumen relativamente piano \\
\hline$\{[a c]\}$ & Tempo relativamente acelerado \\
\hline$\{[a]\}$ & Tono más agudo \\
\hline$<$ riéndose $>$ & Comentarios adicionales \\
\hline
\end{tabular}

Feminismo/s 24, diciembre 2014, pp. 67-94 


\title{
EL GĖNERE I L'HUMOR EN INTERACCIONS DIDÀCTIQUES D' ALUMNES DE SECUNDÀRIA
}

\author{
MERITXELL MAZA \\ Universitat de Barcelona
}

Recibido: $15 / 09 / 2014$

Aceptado: 24/11/2014

\section{Resumen}

A partir de la articulación de tres ejes o focos de interés: el uso del humor por parte de los adolescentes, las cuestiones de género y las cuestiones que se plantean en torno a una investigación en didáctica de la lengua, este artículo profundiza en la forma y funcionamiento del humor como estrategia para abordar la construcción del espacio intersubjetivo.

Esta triple focalización favorece la reflexión en torno a la diferencia de recursos verbales, no verbales y paraverbales que movilizan los interlocutores de cada género a la vez que aporta materiales de discusión novedosos sobre la relación entre el uso del humor y el rol institucional que ocupan los interlocutores, principalmente teniendo en cuenta la imbricación del concepto de posturas enunciativas.

Palabras clave: humor, género, posturas enunciativas, subenunciación.

\begin{abstract}
This article explores the form and function of humour as a strategy for dealing with the construction of intersubjective space from the articulation of three axes or focuses: the use of humour by teenagers, gender concerns and the issues around research in language teaching.

On one hand, this paper discusses the difference in verbal, nonverbal and paraverbal resources that mobilize the speakers of each gender and, on the other hand, it raises a new relationship between the use of humour and the institutional role which have the interlocutors, especially in the interplay with the concept of "postures énonciatives».
\end{abstract}

Keywords: humour, gender, postures énonciatives, sous-énonciation.

Feminismo/s 24, diciembre 2014, pp. 95-114

DOI: $10.14198 / \mathrm{fem} .2014 .24 .05$ 



\section{Introducció i propòsits}

Aquest treball s'articula al voltant de tres eixos o focus d'interès: l'ús de l'humor per part dels adolescents, les qüestions de gènere i les qüestions que es plantegen al voltant d'una recerca en didàctica de la llengua.

Així doncs, si seguim algunes de les recerques que s'han fet sobre l'humor: Norrick $^{1}$, Attardo ${ }^{2}$ i Priego-Valverde ${ }^{3}$ conclourem que l'humor és un fenomen força complex i difícil de delimitar a causa de la seva natura multiforme. Aquest és el tret de sortida de la primera qüestió controvertida que proposo d'estudiar.

Per exemple, segons la seva gènesi, l'humor pot tractar-se d'acudits «enllaunats $»^{4}$ o de seqüències d'humor espontani co-construïdes per diversos participants -com les que exposa Priego-Valverde ${ }^{5}$. Però, si seguim les apreciacions de les investigadores del Laboratoire Parole et Language de la Universitat d'Aix-en-Provence, Roxane Bertrand i Béatrice Priego-Valverde ${ }^{6}$, i ens fixem en la «tonalitat» de l'humor, diverses opcions hi tornen a aparèixer. Així, l'humor podria tractar-se d'un acudit, d'ironia, de sarcasme, d'un joc de paraules o d'una simple broma, entre d'altres apreciacions. Si en comptes de focalitzar la gènesi o la tonalitat, ens centrem en els seus efectes, l'humor pot ser benèfic i/o amical i agressiu, o tot plegat. El que sobta és que, generalment, l'humor és diverses coses alhora (broma entre amics, sarcasme a l'escola, etc.). Es tracta, que els seus interlocutors sàpiguen captar aquestes ambivalències per apreciar-ne el sentit i poder, d'aquesta manera, conduir amb èxit la seva

1. NORRICK, Neal. «Repetition in canned jokes and spontaneous conversational joking». Humor 6 (4) (1993), pp. 385-402.

2. AtTARDO, Salvatore. Linguistics theories of humor. Berlin i New York, Walter de Gruyter, 1994.

3. PRIEGO-VALVERDE, Béatrice. L'humour dans la conversation familière: description et analyse linguistiques. Paris, LHarmattan, 2003.

4. Traducció lliure de l'original «canned» (cf. NORRICK, Neal. op. cit.)

5. Priego-VAlverde, Béatrice. Op. cit.

6. Bertrand, Roxane i Priego-VAlverde, Béatrice. «Does prosody play a specific role in conversational humor?». Pragmatics and Cognition 18 (2) (2011), pp. 333-356. 
interacció. Per tot plegat, privilegiarem l'estudi de l'humor des del vessant enunciatiu (v. apartat 2).

A aquesta primera qüestió controvertida s'hi afegeix el fet que parlar de diferències, en termes d'humor, entre homes i dones, en el cas concret que ens ocupa nois i noies, pot connotar, d'entrada, una mentalitat estereotipada i androcèntrica. En aquest sentit, hem de remetre'ns als treballs de Fendt ${ }^{7}$, des del vessant didàctic, que ens recorden que cal tenir en compte aquestes diferències, especialment, en la franja d'edat dels alumnes adolescents (es refereix a les edats compreses entre els 11 i els 13 anys). Per aquest pedagog alemany existeix un clar avançament biològic i mental per part de les noies respecte els nois. A més de les diferències biològiques i mentals que s'observen entre els nois i noies adolescents, s'ha de tenir en compte la transició, que té lloc en aquesta franja d'edats, de la infància a l'adolescència i la implicació consegüent d'una maduració respecte l'autoobservació i la reflexivitat. És en aquest fet que convergim en el terreny de la subjectivitat i, necessàriament, de la reflexivitat.

Aquesta última consideració sobre la reflexivitat, mitjançant la qual elaborem una «visió sinòptica» de la totalitat que ens permet situar en el món i definir-nos com a subjectes, obre el tercer focus d'atenció d'aquest article, que ens duu de manera inevitable a l'àmbit d'estudi en què ens situem: els contextos d'ensenyament i d'aprenentatge, cosa que delimita el context d'entrada, ja que totes les interaccions que analitzarem se situen en un context d'aula i es corresponen a l'observació que pretén reflexionar, a posteriori, sobre les dinàmiques d'aprenentatge.

Per tant, tenint en compte els aspectes fins aquí referits, puc definir els propòsits d'aquest article a partir de dos objectius: d'una banda, pretenem endinsar-nos en la forma i el funcionament de l'humor com a estratègia per tal d'abordar la construcció de l'espai intersubjectiu, tot observant, d'una banda, la diferència de recursos verbals, no verbals i paraverbals que mobilitzen els interlocutors de cada gènere i, de l'altra, observar si existeix una relació entre l'ús de l'humor i el rol institucional que ocupen els interlocutors, sobretot en la imbricació del concepte de postures enunciatives.

7. FendT, H. Die Entdeckung des Selbst und die Verarbeitung in der Pubertät [The discovery of the self and its persuasion in puberty]. Bern, Switzerland, Hans Huber, 1994. 


\section{Marc conceptual: apropament enunciatiu a l'humor}

dins un enunciat humorístic s'hi poden observar una multiplicitat d'enunciadors $^{8}$ a través dels quals el locutor ${ }^{9}$ fa parlar altres veus -en el sentit bakhtinià. Per tant, aquest apropament permet definir l'humor com el resultat d'una doble o, fins i tot, triple enunciació ${ }^{10}$. L'apropament enunciatiu a l'humor s'estructura al voltant de dos conceptes puntals, el de discurs polifònic, hereu del dialogisme de Bakhtín, i dels conceptes que emergeixen de l'interaccionisme: el contracte de paraula de Charadeau ${ }^{11}$, la preservació de la imatge de Goffman $^{12}$, les relacions de simetria i complementarietat de l'escola de Palo Alto, el principi de cooperació de Grice i la construcció de l'espai interactiu de Robert Vion ${ }^{13}$.

\subsection{Les postures enunciatives segons Rabatel}

Les postures enunciatives sorgeixen de la diferència entre L i E que va proposar Ducrot ${ }^{14}$. Un cop definides aquestes instàncies, observem que l'E, en qualsevol producció, té l'opció d'assumir ${ }^{15}$, o no, el contingut preposicional de l'enunciat que produeix. Aquest contingut preposicional en interacció és anomenat punt de vista (a partir d'ara PDV). A més a més, aquest PDV pot ser compartit, o no, per la resta d'interlocutors, la qual cosa duu a definir el concepte de postures. Aquest terme, que deriva de la sociologia, s'entén com el posicionament que adopten els participants en una conversa davant els enunciats que s'hi produeixen, tenint en compte que en una conversa els participants estan negociant i adaptant contínuament els seus enunciats amb finalitats diverses, una de les quals pot ser arribar al consens. En aquesta

8. Quant a l'enunciador o enunciadors (E/e), es correspon(en) a una posició enunciativa que adopta el $\mathrm{L}$ en el seu discurs i fa(n) referència a diferents veus que el locutor convoca en el seu discurs "pour envisager les faits, les notions, sous tel ou tel PDV» (cf. RABATEL, 2013).

9. Per locutor (L) s'entén la instància que produeix l'enunciat «dans ses dimensions phonétiques et phatiques ou scripturales» (cf. RABATEL. Op. cit.).

10. Priego-VAlverde, Béatrice. Op. cit.

11. CharAdEAU, Patrick. Langage et discours. Eléments de sémiolinguistique. Paris, Hachette, 1983.

12. GOFFMAn, Erving. Frame Analysis. Nueva York, Harper i Row, ([1974] 2006).

13. Vion, Robert. «La gestion pluridimentionnelle du dialogue». Cahiers de Linguistique Française 17 (1995), pp. 179-203.

14. Ducrot, Oswald. Le dire et le dit. Paris, Éditions de Minuit, 1984.

15. cf. prise en charge.

Feminismo/s 24, diciembre 2014, pp. 95-114 
negociació, Rabatel ${ }^{16}$, distingeix tres postures diferents: la coenunciació, la sobreenunciació i la sotsenunciació.

Així la coenunciació és la coproducció d'un PDV compartit per diversos enunciadors, la sobreenunciació és la coproducció d'un PDV dominant que L1/E1 -el sobreenunciador- reformula per tal de fer semblant de voler dir la mateixa cosa però amb alguna modificació amb l'objectiu d'afavorir l'orientació argumentativa que més el beneficiï segons els seus propòsits i la sotsenunciació és la coproducció d'un PDV dominat que el sotsenunciador -Ll/ E1- reformula tot distanciant-se'n, ja que aquest PDV prové d'una font a qui $\mathrm{Ll} / \mathrm{El}$ atorga un estatut prominent.

Així doncs, en un pla semàntic i cognitiu, la coenunciació equival a pensar i parlar amb els altres; la sobreenunciació a parlar i pensar per sobre dels altres -per tant, genera l'ocupació d'una posició alta, si més no, en el pla cognitiu, amb un benefici simbòlic i institucional; i la sotsenunciació, a redir els mots dels altres. La sotsenunciació indica que el L assumeix un PDV anterior, per diverses raons: perquè no en té un altre de millor, perquè no vol o no pot proposar-ne un altre, per estratègia deliberada, etc. Tal com explica Míriam Turró ${ }^{17}$ en la seva tesi doctoral el sotsenunciador es correspon al L que adopta un PDV que no és el seu per fer «entendre a l'altre o altres els signes de distància. Se'n distancia, però sense substituir el PDV de l'altre per un d'antagonista; a tot estirar en mostra un de sensiblement diferent». Així doncs, ser sotsenunciador és manifestar que el teu PDV s'elabora en relació al que diuen els altres, a la llum d'aquests altres.

\subsection{L'humor a l'adolescència}

Koestler ${ }^{18}$ parla de l'adolescent com aquell que riu de l'estranger que té un accent diferent, de la gent que vesteix d'una manera estranya, és a dir, aquell que riu d'allò que es desvia de la norma familiar. El fet d'assimilar aquesta diferència, el fet de no ser com els altres, és un dels tràngols que ha de superar l'adolescent. En aquest sentit, la psicologia del desenvolupament ${ }^{19}$ contempla l'adolescència com el període vital més difícil i complicat.

La transició de la infància cap a l'adolescència ha estat entesa com un pas cap a l'adquisició de l'autoobservació i la reflexivitat. La presa de consciència

16. RabaTel, Alain. Op. Cit.

17. TURRÓ, Míriam. Les interaccions orals en petits grups. Una oportunitat d'aprenentatge cognitiu, social i identitari. Universitat de Barcelona, 2013.

18. Koestler, Arthur. The act of creation. London, Pan books Ltd., 767, ([1964] 1966).

19. Per exemple, ERIKSON, 1968; citat a FÜHR, Martin. «Coping humor in early adolescence». Humor 15 (3), (2002), pp. 283-304. 
d'un mateix duu a un conflicte potencial quant a les expectatives que tenen els adolescents de la família, dels amics i del seu entorn. Segons Fend $t^{20}$ un dels principals objectius dels adolescents quant a definir el seu lloc a la societat és la primera relació intersexual. En paraules de Führ ${ }^{21}$ :

For both genders, sex is regarded as an important theme, and more important for boys than for girls. Both genders obviously like sex related jokes, but boys prefer them more than girls. And finally sex as a subject in own jokes is preferred by both genders, when contributing their favorite joke to the study.

El treball de Führ suggereix que una possibilitat de reacció per part dels adolescents enfront de la frustració o l'estrès que pot ocasionar el desig i les temptatives de ser acceptat pels altres és l'humor. Malgrat que l'adaptació de l'humor per fer front a situacions angoixants requereix un major grau d'experiència vital del que posseeixen la majoria d'adolescents, aquest estudi afirma que el fet de veure com d'altres utilitzen l'humor davant de certs inconvenients vitals, ofereix l'oportunitat de considerar-ne l'ús com a una eina per fer front al conflicte, primer pas cap a l'adopció de l'humor com a actitud vital.

El treball de Garcia ${ }^{22}$ ens ofereix un document sobre els treballs d'adaptació $^{23}$ de l'humor en l'adolescència, elaborat a partir de 367 articles publicats en anglès entre el 1998 i el juny del 2009. La recerca conclou que menys de la meitat dels estudis revisats consideraven una definició específica d'adaptació tot i que la majoria d'autors coincidien a descriure aquesta adaptació de l'humor en el context d'una resposta a l'estrès i a identificar-ne determinats tipus o formes. Per tant, Garcia ens demana tenir en compte que el terme coping és un constructe important en la comprensió de les reaccions a diferents factors estressants que experimenten els adolescents.

\section{Aspectes metodològics}

Per fer front als objectius que ens hem proposat en aquest article (v. apartat 1) ens cal fer ús d'una metodologia determinada. Per tant, enfocarem aquest article en el mètode qualitatiu, etnogràfic, basat en l'observació, l'anàlisi i la interpretació de les interaccions a l'aula.

20. FENDT, H. Op. cit., p. 29.

21. FÜHR, Martin. Op. cit.

22. GARCIA, Carolyn. "Conceptualization and Measurement of Coping During Adolescence: A Review of the Literature». Journal of Nursing Scholarship 42 (2010), pp. 166-185.

23. cf. coping. Per tant, quan parlo d'adaptació ho faig en el sentit dels esforços que fa algú per prevenir o disminuir l'amenaça, el dolor i la pèrdua, o per reduir l'angoixa que s'associa a qualsevol d'aquests sentiments. 
En aquest sentit, el corpus que presentem es correspon a la transcripció de 25 minuts d'una sessió de català de 1r d'ESO, enregistrada el dia 11 d'abril de 2013, en què un grup d'alumnes: la Caterina, el Baltasar, la Sara, la Sònia i la Soledad ${ }^{24}$ responen conjuntament les preguntes del qüestionari de la lectura que s'ha treballat a classe, Ulls de gat mesquí d'Ofèlia Dracs.

Pel que fa als criteris aplicats en la transcripció hem partit de la proposta de Calsamiglia i Tusón ${ }^{25}$ tot i que l'hem confrontat amb les solucions de diversos transcriptors per evitar al màxim els errors d'interpretació a l'hora d'analitzar les dades.

Per tal de fer l'anàlisi de les dades obtingudes, considerarem les dimensions que proposa el grup de recerca consolidat Plurilingüisme i Aprenentatge de Llengües de la Universitat de Barcelona. Així doncs, tindrem en compte tres dimensions: la dimensió interlocutiva (en què es refereixen aspectes com per exemple, qui origina el torn humorístic, les formes de transició en què s'origina el torn i els papers comunicatius que es desprenen del torn o torns en qüestió, entre d'altres), la dimensió temàtica (en què es té en compte si la intervenció inicia un tema, el dirigeix, hi reacciona o el reprèn) i la dimensió enunciativa (en què s'observen aspectes propis de la modalitat enunciativa, mitjançant la qual el parlant manifesta la seva actitud respecte si mateix, els interlocutors i allò que es diu).

Per poder contrastar tot plegat hem hagut d'aillar els fragments que continguessin passatges humorístics o que fossin reconeguts com a humorístics pels participants, tal com evidenciaven les seves rialles o el material verbal, paraverbal o no verbal que produien en relació al fenomen humorístic que havia tingut lloc. Aquests fragments pertanyents a la transcripció de la sessió de català que presentem els hem disposat en ordre cronològic ja que la noció de cronogènesi, pròpia del contracte didàctic, ens dóna prou informació per entendre els canvis d'estat que es produeixen en els interlocutors i que es tradueixen en l'emergència i la fluctuació de les diferents postures enuncitaves, ergo, amb l'aparició de l'humor. A més a més, la disposició cronològica dels fragments és una informació indispensable per entendre com s'avança tant en l'eix temporal de la sessió com de l'aprenentatge.

24. Els noms dels alumnes que apareixen en aquest treball són ficticis per tal de preservar-ne l'anonimat.

25. Calsamiglia, Helena i TUSÓn, Amparo. Las cosas del decir. Manual de análisis del discurso. Barcelona, Ariel, ([1997] 2007: 351). 


\section{Context}

En aquest sentit aquest estudi s'emmarca en un centre d'educació secundària de la capital del Vallès Oriental. El grup de treball que he gravat pertany al grup-classe F1 de 1r d'ESO -on se situen els alumnes amb millors resultats acadèmics-, compost d'un total de 18 alumnes: 7 nens i 11 nenes d'entre 12 i 13 anys.

Els dos fragments que exposem a continuació serveixen per entendre -a mode de context micro- el comportament de les noies, respecte les bromes del seu company Baltasar. En aquest sentit, tant la Caterina, com la Sònia, la Soledad i la Sara són alumnes amb una mitjana de notes superior al 8. Tot el contrari del Baltasar, un noi d'ètnia gitana amb moltes capacitats cognitives, però a qui no l'interessen els estudis.

D'una banda, les quatre noies del grup es prenen molt seriosament el treball a l'aula, al contrari del Baltasar. De l'altra, les noies són adolescents i comparteixen les mateixes inquietuds de qualsevol altre noi/a de la seva edat, tal com s'evidencia a continuació. La Sara està preocupada perquè duu xandall i té por que li diguin «choni» ( 146 ). Les companyes la corregeixen ( T 147, T 148 i T 149), gairebé a l'uníson, cosa que fa riure la Caterina (T 151):

146 SARA: yo no sé pero las que llevan chándal se llaman choni y yo no quiero llevar chándal XXX se llama choni

147 CATERINA: [cani]

148 SOLEDAD: [cani]

149 BALTASAR: [cani]

150 SARA: cani

151 CATERINA: @@@

152 BALTASAR: no tiene por qué

153 SOLEDAD: XXX

154 SARA: XXX si em fico chándal em diran choni

155 CATERINA: que no XXX

156 SOLEDAD: però no és portar chándal dir-te choni/ és maquillada i pentinada molt bé i portar chándal

El fet de saber que l'exercici està sent enregistrat, fa que elles es continguin i no expressin el que veritablement mostrarien si la sessió no hagués estat gravada ( $\mathrm{T} 245,246$ i 248). Tal com ho mostra el següent passatge en què el Baltasar ( T 244), ampliant el torn 241, fa referència per polisèmia a l'» [herba] de fumar»:

241 SARA: mixet i herbal

242 SOLEDAD: no\ però fulles

243 SOLEDAD: a mi no_

244 BALTASAR: ihierba de fumar o la de XXX? @@@ 
245 CATERINA: $\{(($ Al Baltasar, indignada $)) \mathrm{x}:: t\}$

246 SOLEDAD: *Baltasar

*((li fa un gest indicant-li la gravadora))

247 BALTASAR: me la sopla

248 CATERINA: bueno\me callo

249 BALTASAR: bueno peor para mi

\section{Anàlisi de dades}

Presentem, a continuació, una graella on s'especifica el segment de l'activitat ${ }^{26}$ que té lloc durant la sessió, la relació dels torns de paraula específics amb la temporització de les accions dels alumnes i el nucli temàtic de l'activitat que s'està tractant:

\begin{tabular}{|c|c|c|c|c|}
\hline $\begin{array}{l}\text { Seg- } \\
\text { ment }\end{array}$ & Torns & Durada & Accions & Nucli temàtic \\
\hline \multirow{7}{*}{ 遶 } & $1-58$ & 00:04:20 & $\begin{array}{l}\text { Resolen la pregunta } 1 \text { i } 2 \text { : ¿ Quan vas } \\
\text { començar a sospitar que hi havia alguna } \\
\text { cosa estranya? i ¿Què fa que es transformi } \\
\text { en un lloc terrorífic? }\end{array}$ & Lambient de l'escena. \\
\hline & $59-163$ & 00:11:39 & \multirow{2}{*}{$\begin{array}{l}\text { Resolen la pregunta 3: Distingeix els } \\
\text { substantius que connoten familiaritat dels } \\
\text { que connoten misteri. Quins predominen? }\end{array}$} & $\begin{array}{l}\text { Els substantius que } \\
\text { connoten misteri. }\end{array}$ \\
\hline & $164-259$ & $00: 15: 54$ & & $\begin{array}{l}\text { Els que connoten } \\
\text { familiaritat. }\end{array}$ \\
\hline & $260-331$ & 00:18:02 & \multirow{2}{*}{$\begin{array}{l}\text { Resolen la pregunta 4: Distingeix els } \\
\text { adjectius que connoten familiaritat dels } \\
\text { que connoten misteri. Quins predominen? }\end{array}$} & $\begin{array}{l}\text { Els adjectius que } \\
\text { connoten misteri. }\end{array}$ \\
\hline & $332-361$ & $00: 19: 21$ & & $\begin{array}{l}\text { Els que connoten } \\
\text { familiaritat. }\end{array}$ \\
\hline & $362-422$ & $00: 20: 32$ & $\begin{array}{l}\text { Resolen la pregunta 5: Per què l'autora } \\
\text { utilitza aquests verbs i no uns altres? }\end{array}$ & $\begin{array}{l}\text { Els verbs que parlen de } \\
\text { la pell de la protagonista. }\end{array}$ \\
\hline & $423-448$ & $00: 25: 55$ & $\begin{array}{l}\text { Resolen la pregunta } 6 \text { : Justifica a partir del } \\
\text { temps dels verbs del segons paràgraf del } \\
\text { text si l'autora parla d'una nit en especial o } \\
\text { en general. }\end{array}$ & Els temps verbals. \\
\hline
\end{tabular}

26. S'entén per segment d'activitat una forma d'organització de l'activitat conjunta, caracteritzada per l'articulació per part dels interlocutors d'uns patrons amb una cohesió temàtica interna, els quals designen allò que poden fer o dir els participants en el moment determinat de l'activitat conjunta. 


\section{Accions: resolen la pregunta $4^{27}$}

exemple a) El Baltasar, la Caterina, la Sara, la Sònia i la Soledad estan buscant adjectius de la lectura que connotin misteri. En el torn 278 el Baltasar reacciona creant noves associacions a partir dels adjectius negra i humida, tot situant el seu torn en el mode lúdic:

274 CATERINA: negra humida:

275 SOLEDAD: estem per la quatre

276 BALTASAR: ah éso es terror ¿no?

277 CATERINA: estem parlant misteri

278 BALTASAR: XXX \{((dirigint-se a la gravadora)) culol con perdón\}

279 CATERINA: negra humida

280 SÒNIA: ah

281CATERINA:@@@

282 BALTASAR:@@negra humida

283 SÒNIA: negra humida i què més@@@

284 BALTASAR: que entra y sale*@@@

$* \rightarrow(($ cares d'espant de les noies $))$

285 SOLEDAD: is'esfilagarsava és un verb no?

Les rialles dels torns 281 i 283 demostren que les noies són conscients del joc d'associacions a què juga el Baltasar. El torn 282 del Baltasar i el 283 de la Sònia, que acompanyen les rialles de la repetició verbatim de l'enunciat del torn 274, connoten una doble isotopia. Els torns del Baltasar (T 278 i T 284), actuen d'ancoratge per portar la seqüència a una isotopia escatològica i sexual. Així doncs, a partir del torn 274 de la Caterina («negra i humida») a què es correspondria el PDV1 [ adjectius que connoten misteri], el Baltasar n'oposa, per metonímia, el PDV2, explícit, [=culo] (T 278) i el PDV3, implícit, [ òrgan sexual masculí] (T 284). Aquests PDV produeixen l'esclat còmic en els enunciats polifònics i també dialògics -T 280, T 282 i T 283- en què s'escolten alhora els PDV1, PDV2 i PDV3.

La intervenció de la Soledad en el torn 285, serveix per dissimular, per contenir les rialles latents de les participants, i es converteix en una espècie de cortina de fum després de la intervenció del company en el torn 284. El torn 285, val a dir, que es genera, alhora, com a resposta de la comunicació no verbal que sorgeix entre les noies -les mirades d'espant-i serveix per reconduir el discurs al mode seriós.

27. Els quatre exemples aquí referits pertanyen a l'acció concreta de respondre la pregunta 4 del qüestionari, tal com es mostra a la graella que encapçala l'apartat 5. 
exemple b) Els nois confeccionen la llista d'adjectius que connotin misteri. La Sara proposa l'adjectiu «somort» (T 287) i les noies el repeteixen verbatim per tal d'apuntar-lo a la llista. El Baltasar no sap què vol dir aquesta paraula (T 290) i la Sara n'elabora una traducció errònia al castellà (T 291) que repeteix verbatim més endavant (T 293) i que fa riure el company, que s'adona de l'absurd (T 294):

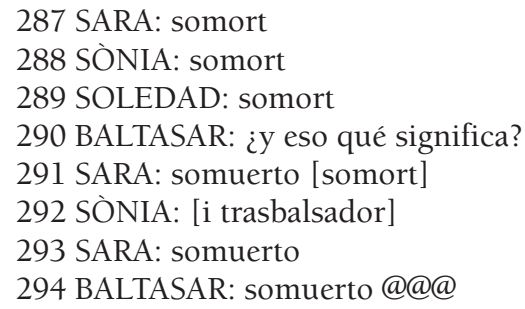

L'esclat còmic rau en el torn 291 de la Sara, en el moment en què aquesta noia dóna una traducció al castellà bisociada ${ }^{28}$ del mot «somort»: so $+\{((\mathrm{L} 1))$ mort $\}=$ so $+\{((\mathrm{L} 2))$ muerto $\}$.

La lògica interna que la Sara ha utilitzat per realitzar aquesta traducció no funciona. Aleshores ella mateixa autorepeteix el seu enunciat (T 293), fent d'altaveu del seu propi enunciat per posar-lo a col-lació públicament, a mode d'arrêt sur mot ${ }^{29}$. Per tant, es pot dir que el torn 293 té una funció metacomunicativa i alhora permet la Sara de fer autocrítica, de riure's d'ella mateixa. En el torn 294 el Baltasar riu perquè s'adona que «somuerto» no existeix en castellà.

exemple c) En el següent fragment el Baltasar té problemes per entendre la paraula «arrapadissa» (T 308, T 310, T 314 i T 315) i les companyes l'ajuden a fixar el mot. En el torn 310 el Baltasar reformula el primer adjectiu i juga amb la cacofonia: «arr» i amb la proximitat, suposada, del mot font: «arrapadissa» amb el mot reformulat: «arrivederci». En el torn 314 el Baltasar reformula el mot de les companyes i juga amb un hipotètic parònim, ja que el mot reformulat no existeix, és un ressò del castellà: «arrimadiza». En el torn 317 el Baltasar dóna una falsa definició d'arrapadissa, jugant un altre cop amb els parònims: «arrapa»/«arropa», un del català, l'altre del castellà respectivament.

28. Segons VianA, Amadeu (2004: 98): «bisociar és produir alhora una lectura separada (en termes de doble sentit) d'un terme o d'una situació i convergir al mateix temps en una lectura conjunta en el discurs».

29. Consisteix en la repetició d'una paraula per remarcar-ne algun aspecte sorprenent, cf. DEGOUMOIS, Virginie (2012). 


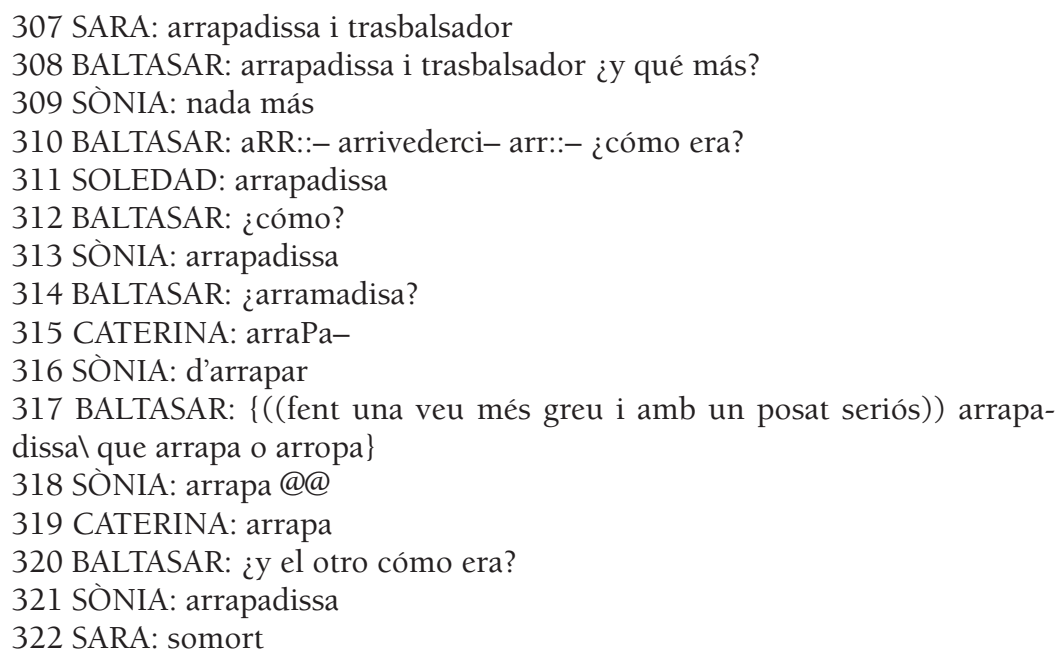

En Baltasar adopta una postura de sotsenunciador en aquesta seqüència que li permet fer semblant de no adonar-se de res. Les noies accepten el joc del company, tal com es veu en les nombroses correccions i repeticions que li fan al llarg dels torns. D'entrada podem dir que dels torns del Baltasar emergeix una triple enunciació. D'una banda, l'El que es correspon amb l'alumne que sap perfectament de què s'està parlant, tal com es veu en el torn 308, en què repeteix verbatim l'enunciat de la Sara sense cap problema de comprensió, però que és mandrós alhora de realitzar l'exercici: «¿y qué más?». D’una altra, l'e2 que es correspon amb l'adolescent rebel que juga a no saber res ( $\mathrm{T} 310$, T 314 i T 317) i es converteix en el centre d'atenció de les companyes, que es preocupen que entengui bé la paraula. Finalment, l'e3 que es correspon amb la persona castellanoparlant que no entén el català. No cal dir que aquesta darrera postura es construeix a partir d'una representació sociolingüística associada a una ideologia política. Així doncs, el Baltasar juga a identificar volgudament «arramadissa» amb «arrivederci» (T 310), la forma italiana que s'utilitza per acomiadar-se; «arrapadissa» amb «arramadisa» (T 314) -del castellà arrimadiza- i, «arrapa» amb «arropa» ( $\mathrm{T}$ 317), aquest cop, fent ús de l'enunciació neutralitzada pròpia del diccionari i de l'esborrament de les marques personals - tot plegat acompanyat de la impostació de la veu a nivell prosòdic- que demostren l'absurd de l'enunciat. Lassimilació del torn 310 constitueix la isotopia de lèxic estranger que utilitza l'enunciador -e3- per desqualificar el català -fent absurdes les equivalències- $\mathrm{i}$, de retruc, l'exercici.

Es pot dir, doncs que el L dels torns 310, 314 i 317 assumeix parcialment l'enunciat que produeix, ja que es basteix a partir d'un E que simula no 
entendre res, i castellanoparlant que no entén el català (no és el cas del Baltasar, que sí que l'entén, tot i que no li agradi gens parlar-lo).

Exemple d) En el següent fragment els nois estan elaborant la llista d'adjectius que connotin familiaritat. En el torn 356 el Baltasar relaciona els cinc adjectius de la llista i els recicla per comparar-los amb la seva manera de ser (T 359) situant-se en el mode lúdic que contrasta amb el mode seriós en què es troben les companyes.

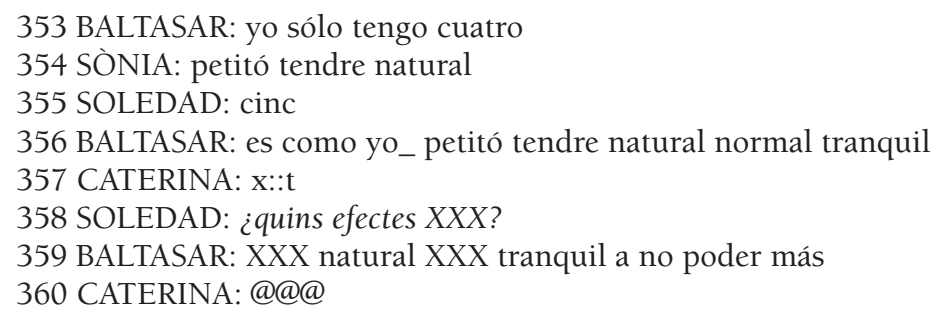

En aquest episodi crida l'atenció la bisociació que té lloc en els torns del Baltasar, el qual associa discursivament els cinc adjectius de familiaritat que han trobat en el text: petitó, tendre, natural, normal i tranquil, amb les seves característiques personals, alhora que en produeix una lectura dissociada, ja que aquests adjectius han estat localitzats en el text i l'objectiu no és pas descriure els trets físics i personals dels alumnes. Aquesta dissociació implícita de dos patrons diferents: d'una banda, la recerca d'adjectius en un text i, de l'altra, la descripció personal, amaga també una contradicció, una oposició entre els adjectius que el Baltasar identifica amb ell mateix i la realitat, és a dir, ell mateix. És a dir, per exemple, cap company triaria l'adjectiu «petitó» per descriure el Baltasar, ja que aquest alumne és més alt que la mitjana i té una complexió física robusta.

\section{Resum de la sessió}

El tret distintiu d'aquesta sessió és la fluctuació constant que es genera en la interacció entre el mode seriós i el mode lúdic. Així doncs, mentre que la Sara, la Soledad, la Sònia i la Caterina mantenen una actitud cooperativa que comporta una postura coenunciadora que se situa en un mode de comunicació seriós, el Baltasar utilitza la postura de sotsenunciador per distanciar-se dels enunciats emesos per les companyes i introduir l'humor en la interacció. Lunivers non-bona-fide $e^{30}$, per tant, és evocat pel Baltasar, i es confronta amb el

30. Per a Raskin (1985), l'humor és un mode de comunicació non-bona-fide, a partir del qual el L juga amb el llenguatge i les capacitats interpretatives de la resta d'interlocutors. 
mode seriós en què se situen les companyes, amb l'objectiu de mantenir una posició dominant en la interacció. Aquesta posició alta s'evidencia amb les accions de l'alumne per tal de cridar l'atenció de les companyes i ocupar els torns (exemples a, c i d) i pel fet que, tot plegat, apel.la la seva masculinitat (v. l'exemple c i, sobretot, l'exemple d).

No puc deixar de fer atenció als casos d'hibridació lingüística que s'observen en els exemples $b$ i $c$-mobilitzats per alumnes d'ambdós sexes-que mostren la relació quant a la creativitat del canvi de codi lingüístic i l'humor. En aquest sentit, les creacions verbals originades per canvi de codi operen una funció lúdica per, en expressió de Bensalah i Vincent ${ }^{31}$ : «débanaliser les mots/ maux». Efectivament, aquestes creacions són el resultat d'un conjunt d'afinitats entre la forma reeixida i els estats mentals dels subjectes en un context sociolingüístic concret. Aquests casos d'hibridació no són redundants, sinó el fonament mateix d'una creença de la llengua i de la dinàmica social.

\section{Discussió de resultats}

Si recupero els propòsits inicials que havia plantejat al principi d'aquest article pel que fa als recursos verbals, no verbals i paraverbals que, en relació a les qüestions de gènere, els alumnes i les alumnes mobilitzen quan creen i participen en els esdeveniments humorístics puc teoritzar, a partir del comportament de les dades, els següents aspectes:

\section{a) Recursos verbals}

Canvi de codi: Un dels recursos més interessants ha estat el del canvi de codi lingüístic per introduir humor. Aquest recurs funciona d'una forma doble: d'una banda, té lloc la infracció de la màxima de quantitat de Grice (exemples b i c), ja que aquest excés aparent, si més no, a nivell dels enunciats -tot i ser camuflat enginyosament pel canvi de codi-, és en realitat una mancança, a nivell cognitiu, per part dels alumnes. L'oposició: excés/mancança és el disjuntor de l'humor. A més a més, funciona de forma dialògica ja que hi ha un canvi d'orientació del PDV enunciat (cf. exemple c, per part del Baltasar). De l'altra, aquest recurs funciona d'una forma diferent quan la facècia obeeix a un joc de paraules sense canvi de PDV, i per tant, sense implicació del ressò dialògic (cf. exemple b, per part de la Sara). En els exemples s'ha observat

31. BenSALAh, Amina i VinCENT, Joseph. «La fonction humoristique du "mixlangue" dans le parler des jeunes algérois: détournements et innovations linguistiques», a Dominique Caubet [et. al.] (eds.): Parlers jeunes ici et Là-bas, Pratiques et représentations. Paris, l'Harmattan, 2004, pp. 149-173. 
una sèrie de creacions lingüístiques caracteritzades per una hibridació lingüística i cultural amb una connotació humorística. De la mateixa manera, tal com entenen Bensalah i Vincent ${ }^{32}$ el tema, aquesta barreja de codis en els exemples referits no és entesa de forma negativa, sinó que ho és en el sentit d'una «reconciliació identitària» conduïda a través de les funcions lúdiques del canvi de codi lingüístic. Així doncs, el fet que es destaqui un mot pertanyent a un altre codi lingüístic evidencia que aquest és tractat de forma metalingüística perquè justament s'entengui el joc lingüístic, que es manifesta a través de la reformulació. Aquesta focalització metalingüística configura el vessant humorístic com una de les dimensions de la competència interaccional (a partir d'ara, CI).

Lògica interna: Tal com proposa Béatrice Priego-Valverde ${ }^{33}$ en tots els exemples hi ha un ús de la lògica interna en el moment en què els alumnes giren el discurs al mode lúdic de què se serveixen per participar en la creació d'un món imaginari regit per una lògica diferent de la del món real i per poder, així, allargar al màxim aquests moments de distensió. Aquest reclam al mode de comunicació non-bona-fide és més present en els enunciats del Baltasar que en els de les noies. Tot plegat està en relació amb l'estudi etnogràfic que presenten Stephen Frosh i els seus col-legues ${ }^{34}$ centrat en una escola londinenca, en què revelaven la predominança de l'ethos masculí de passar-s'ho bé a l'escola i de buscar la manera de trencar amb els compromisos seriosos que les activitats acadèmiques exigeixen.

Temàtica adolescent (sexual): Apareix, en els torns del Baltasar -exemples a i $\mathrm{d}-$, la referència a un humor de temàtica pròpia dels adolescents $\mathrm{s}^{35}$ de natura escatològica i sexual o que gira entorn dels actes il-legals i prohibits, com el consum de drogues. A més a més, l'actitud que emana d'aquests enunciats, pròpia d'un noi rebel que no s'interessa pels temes acadèmics, és una actitud referida en l'estudi de Frosh i companyia, com a central «to being acceptable as masculine» ${ }^{36}$. Els nois, per tal d'aconseguir reconeixement social per part de la resta de la classe, intenten evitar les etiquetes d' «empollón» o «friki», fent ús d'un humor disruptiu, que s'oposa a les normes preestablertes per la comunitat educativa.

32. BENSALAH i VinCENT. Op. cit.

33. Priego-VAlverde, Béatrice. Op. cit.

34. Frosh, S., Phoenix, A., i Partman, R. Young Masculinities: Understanding Boys in Contemporary Society. London, Palgrave, 2002.

35. cf. FÜHR, 2002.

36. Frosh, Phoenix i Partman. Op. cit., p. 205.

Feminismo/s 24, diciembre 2014, pp. 95-114 


\section{b) Recursos no verbals}

En el corpus que presento aquests recursos són més rics en les noies que no pas en el Baltasar. En l'exemple a, el joc de mirades que connoten espant arran de l'enunciat sexual implícit emès pel noi del grup marca el grau de connivència que hi ha entre les noies. Les mirades femenines reaccionen a l'atac a la imatge pública comès per part del noi i basteixen una representació social comuna sobre la pertinència en context d'ensenyament-aprenentatge, cosa que legitima la reorientació de la conversa al mode seriós, propi de les noies segons l'observació realitzada.

c) Recursos paraverbals: prosòdia i apropiació de les particularitats individuals de la veu d'algú altre

Alguns dels torns de l'exemple a il.lustren allò que Chabanne ${ }^{37}$ exposava sobre la funció del material paraverbal en les interaccions verbals humorístiques. Per aquest autor la prosòdia acompleix una funció sintàctica, ja que mitjançant els fets prosòdics es dóna forma als senyals acústics que es reorganitzen a partir del dibuix que marca l'entonació per tal de ser descodificats. Els recursos prosòdics són més rics i variats, en general, en els torns del Baltasar que en els de les noies. En alguns casos les rialles dels alumnes, sobretot del Baltasar, tenen significació semàntica ja que la informació del cotext en què apareixen ens dóna informació metacomunicativa per interpretar sintàcticament aquests recursos paraverbals (T 282 de l'exemple a).

A més a més, mitjançant l'apropiació de la particularitat de la veu d'algú altre (v. exemple c, T 317), el Baltasar reformula els enunciats previs i els descontextualitza tot produint un enunciat dialògic. Així, en la resta de torns de l'exemple c s'hi observa diversos enunciadors, dels quals un, El, no es correspon amb el L1. D'una banda, El es correspon a un L fictici i, e2 es correspon a l'alumne que recicla les paraules de les companyes i hi associa una relació humorística.

En resum, aquests recursos verbals, no verbals i paraverbals mobilitzats per l'alumne i per les alumnes desencadenen una sèrie de processos humorístics que duen els interlocutors cap al desenvolupament d'una lògica interna, ja que aquests parteixen del mode lúdic i busquen d'aprofundir en el llenguatge

37. ChabANne, Jean-Charles. «Verbal, paraverbal et non-verbal dans l'interaction humoristique», a J.M. Durays i L. Rosier (eds.): Approches du discours comique, actes de la journée d'étude Adiscom-Corhum (juillet 1995). Bruxelles, Mardaga, (col-lecció «Philosophie et langage»), (1999), pp. 35-53. 
humorístic. A més a més, els alumnes -noies i noi- acostumen a jugar amb els significats i, per tant, a apel-lar a la noció de bisociació, que els permet introduir imatges d'ells mateixos i de la resta de participants en la conversa mitjançant els diferents posicionaments. En aquest sentit, durant el transcurs de la sessió destaca un consens general per part dels participants, es pot dir que l'alumne i les alumnes actuen de coenunciadors dels diversos PDV. En contraposició a aquesta actitud cooperativa, hi destaca el rol, sovint, de fals sotsenunciador per part del Baltasar, que se situa al marge del contracte didàctic establert per dur a terme les activitats. Dic fals sotsenunciador perquè aquest alumne es distancia, mitjançant la reformulació d'un PDV determinat, no només d'aquest PDV, sinó del mode seriós en què aquest PDV ha estat gestat $\mathrm{i}$, per tant, és l'encarregat de fer girar els enunciats produits per les companyes -noies- al mode lúdic. De fet, és la manera que aquest alumne té de captar l'atenció dels altres i de poder-s'hi comunicar.

A més a més, hem pogut observar en els exemples un funcionament peculiar de la postura de sotsenunciador. Aquesta postura, mobilitzada pel Baltasar (exemple c), s'ha relacionat amb l'aparició d'ironia mitjançant la força il.locutiva dels enunciats emesos per l'alumne. Aquesta força il.locutiva està relacionada amb la visió que tenen els altres -les noies- d'aquest alumne. De manera que és important tenir en compte el rol institucional que ocupa un alumne, ja que aquest afecta el rol subjectiu que adopta en la conversa.

Tot plegat ens duu a plantejar com a pertinent la relació d'humor i gènere, però també d'humor i de postures enunciatives, ja que un dels interrogants que es planteja després d'haver fet l'anàlisi de les dades és: la creació i/o participació en enunciats humorístics d'un/a alumne/a obeeix a qüestions de gènere $\mathrm{o}$, més aviat, al seu posicionament en la conversa, al rol subjectiu que ocupa (per tant, a la imatge que els altres tenen d'aquest/a) i a les postures enunciatives que mobilitza?

\section{Conclusió ${ }^{38}$}

Els exemples extrets del corpus que presentem ens permeten de sostenir que l'humor té tres funcions principals: en primer lloc, l'humor ajuda a adquirir un rol dominant en la interacció (exemples a, c i d), ja que els enunciats humorístics criden l'atenció de la resta de participants i mantenen la interacció en un punt determinat impedint que avanci; segon, l'humor serveix per autopromocionar-se un mateix (exemple d); i, tercer, l'humor pot ser utilitzat

38. Cal recordar aquí que les generalitzacions que es fan s'han d'entendre dins la singularitat del corpus que presento. 
per crear o mantenir la companyonia dins del grup (exemple b). Pel que fa a aquestes tres funcions, les dues primeres són clarament competitives i la darrera, cooperativa. A més a més, aquestes tres funcions no són mobilitzades de la mateixa manera pel parlant masculí i per les parlants femenines. Així doncs, coincidint amb el treball de Jennifer Coates ${ }^{39}$, que conclou que els parlants masculins fan servir l'humor com una forma d'exercir la dominació, és interessant observar que ha estat el Baltasar qui s'ha servit de les dues primeres funcions (v. supra) i que, en canvi, ha estat la Sara, és a dir, una de les noies, qui s'ha servit de la darrera de les funcions, de caire cooperatiu.

Com mostren els exemples que he presentat, en aquest cas l'humor és utilitzat pel noi i per les noies com una eina de construcció de gènere. El noi constitueix la seva masculinitat mitjançant la participació en enunciats de caire sexual i escatològic, i d'autopromoció de la pròpia imatge davant dels altres. En canvi, les noies juguen amb l'exploració del significat de les paraules amb l'objectiu de crear una rialla comuna que no suposi d'atacar la imatge dels altres. Paradoxalment, tal com diu Coates, les propietats úniques de l'humor també el converteixen en una eina valuosa de la deconstrucció de gènere. Pel que fa al procés de l'adquisició de la competència interaccional, el noi, en les seves facècies, explota el caràcter indirecte de l'humor per reconèixer la possibilitat de la vulnerabilitat i el fracàs, tal com mostra el fet de recórrer a la postura de fals sotsenunciador que hem observat per part del Baltasar. En canvi, les noies, amb la publicació de les seves mancances cognitives, usen l'humor per fer autocrítica, tal com s'aprecia en l'exemple $b$ per part de la Sara.

En aquest treball queda palesa la importància, tant per als parlants masculins com per als femenins, de l'ús de l'humor per construir lligams d'amistat i companyonia amb els altres. Ara bé, la imatge del que se suposa divertit o és objecte d'humor varia no només en funció del gènere, en la mesura que es pot afirmar que l'humor conversacional juga un paper clau en la construcció i la deconstrucció de les masculinitats i feminitats contemporànies, sinó també de les postures enunciatives, en la mesura que la imatge del rol subjectiu que un tingui de l'altre en la interacció, li atorgarà unes possibilitats humorístiques determinades.

39. COATES, Jennifer. «Gender and discourse analysis», a Michael Handford i James Gee (eds). The Routledge Handbook of Discourse Analysis. London, Routledge, 2011, pp. 90-103. 


\section{Referències bibliogràfiques}

Degoumois, Virginie. Le rôle des hétéro-répétitions comme technique de gestion des projets communicatifs: un moyen d'orientation des locuteurs vers les structures lexico-grammaticales de la parole antérieure. Université de Neuchâtel, 2012.

RABATEL, Alain. «Humour et sous-énonciation (vs ironie et sur-énonciation)». L'information grammaticale 137 (2013), p. 36-42.

RASKIN, Victor. Semantic Mechanisms of Humor. Dordrecht, Reidel, 1985.

Viana, Amadeu. Acròbates de l'emoció. Exploracions sobre conversa, humor i sentit. Tarragona, Arola editors, 2004. 
LOS MEDIOS DE COMUNICACIÓN SOCIAL 



\title{
EL HUMOR EN EL ARTÍCULO DE OPINIÓN ${ }^{1}$
}

\author{
JOSÉ JOAQUÍN MARTÍNEZ EGIDO \\ Grupo GRIALE \\ Universidad de Alicante
}

Recibido: 15/09/2014

Aceptado: 24/11/2014

\section{Resumen}

El objetivo de este trabajo es analizar el humor en diferentes artículos de opinión publicados en la prensa española por diferentes autores y autoras y, consecuentemente, poder dirimir las posibles diferencias en el uso y en el tratamiento del humor. Se parte de una doble fundamentación teórica: de la caracterización del artículo de opinión como un género del discurso periodístico, y de la concepción del humor que proporciona la Teoría general del humor verbal. Para ello se ha recopilado un corpus de 80 artículos de opinión, respetando en su compilación los criterios básicos para que sea relevante, y se han analizado las ocurrencias humorísticas, tanto en su descripción lingüística como en su finalidad en el discurso. Los resultados obtenidos demuestran cómo es utilizado el humor y como no todos los articulistas lo utilizan de igual forma.

Palabras clave: humor, discurso, artículo de opinión, género.

\begin{abstract}
The main goal of this paper is to analyze the humor in different opinion articles published in the Spanish press by different authors and consequently, to resolve the differences in the use and treatment of humor. It starts from a double theoretical foundation: the characterization of opinion articles as a genus of news discourse, and the conception of humor that provides the general theory of verbal humor. For this it has been collected a corpus of 80 articles reviewed, compilation respecting the basic criteria to be relevant, and used the humorous occurrences, both its linguistic description
\end{abstract}

1. Este trabajo cuenta con la ayuda del proyecto emergente GRE 12-01 «Lengua y Sexo: Uso del humor en hombres y mujeres» otorgado por la Universidad de Alicante.

Feminismo/s 24, diciembre 2014, pp. 117-141

DOI: 10.14198/fem.2014.24.06 
as its purpose in the discourse. The results show how it is used humor as not all use the same way.

Keywords: humor, speech, opinion article, genre. 


\section{Introducción}

En este trabajo confluyen dos líneas de actuación, por un lado, la caracterización del artículo de opinión como un determinado tipo textual y, por otro lado, la consideración y descripción del humor y, especialmente del humor verbal escrito, como posible integrante de este tipo de género periodístico que implemente la finalidad con la que se escribe, es decir, la persuasión del lector.

\subsection{El artículo de opinión y el humor}

Atendiendo a la primera consideración apuntada, un artículo de opinión sería un tipo de texto que participaría de la concepción pragmática de esta unidad y que podría definirse de la siguiente forma:

[...] Se entiende por texto el resultado de un acto de comunicación producido por un sujeto dado en una situación de intercambio social dada. El texto se caracteriza por las propiedades generales de todo hecho lingüístico: por una parte, por las condiciones de la situación contractual en la cual aparece con sus instrucciones discursivas y las características de su materialidad significante (oral, gráfica), así como con sus normas de construcción lingüística (morfológica, sintáctica); y, por la otra, por el hecho de que todo texto tiene como origen un sujeto, se presenta con las propiedades de la situación que lo sobredetermina en parte y con propiedades singulares dadas por la intervención individual ante de ese sujeto².

Según este concepto, en primer lugar, el artículo de opinión ${ }^{3}$ es uno de los modelos básicos del resultado del acto de comunicación que supone el periodismo. Responde a una de las finalidades de la prensa escrita como es el difundir y el crear una opinión sobre un tema que, de antemano, se sabe controvertido socialmente. Su autor o autora, quien suele ser alguien notable en la sociedad y no necesariamente periodista, expone su opinión sobre el tema

2. CHARADEAU, Patrick: «Los géneros: una perspectiva socio-comunicativa», en Martha Shiro, Patrick Charadeau y Luisa Granato (eds.): Los géneros discursivos desde múltiples perspectivas: teorías y análisis, Madrid, Iberoamericana-Vervuert, 2012, p. 38.

3. Véase la definición del periódico $A B C$ : <http://www.definicionabc.com/comunicacion/ articulo-de-opinion.php>, consultado el 26-05-2014. 
tratado, siguiendo unas determinadas instrucciones discursivas, de forma analítica o sintética ${ }^{4}$ y pretende siempre, bien de forma explícita o bien de forma más o menos velada, el que el lector termine siendo afín a su pensamiento, por lo que debe desarrollar una técnica textual argumentativa ${ }^{5}$ y unos

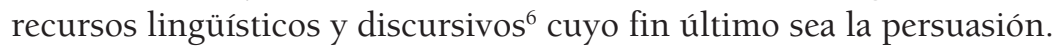

El artículo de opinión puede incluirse, por tanto, siguiendo una tipología textual basada en la finalidad de los textos, dentro de los textos argumentati$\operatorname{vos}^{7}$, en los que, aunque puedan adoptarse diferentes estructuras discursivas, siempre se parte de una premisa para conseguir una conclusión. El enlace entre ellas dos es el cuerpo de la argumentación, es decir, las razones o argumentos, que el autor esgrime para «probar o demostrar una proposición o para convencer de lo que se afirma o niega ${ }^{8}$.

Los posibles argumentos que un articulista puede utilizar suelen ser de variada índole, ya que, según su propio estilo de redacción, según el tema del que esté escribiendo y según al público al que se dirija, es decir, según el campo, el modo o el tenor ${ }^{9}$ que caractericen y predominen en el texto, serán más productivos unos que otros. Entre los tipos de argumentos que podría utilizar se encuentran tales como el uso de datos, el empleo de estadísticas o de hechos científicos, las citas de personas con autoridad, la inclusión de ejemplos, la construcción de analogías, la plasmación de generalizaciones o de verdades indiscutibles, el establecimiento de líneas lógicas de causa y consecuencia, e, incluso, incluir la propia experiencia personal.

Respecto a la segunda línea de actuación mencionada, se entiende por humor o humorismo «un modo de representar, enjuiciar o comentar la realidad, resaltando el lado cómico risueño o ridículo de las cosas de la realidad $»^{10}$, por lo que quizá podría ser un elemento importante en la construcción de un artículo de opinión integrado dentro de los argumentos o estrategias que el articulista plantee y desarrolle; de ahí que resulte necesario el estudio de la relación entre este tipo de discurso y el análisis pragmático del humor ${ }^{11}$.

4. VAN Dijk, Teun. La ciencia del texto. Barcelona, Paidós, 1978.

5. ÁlvareZ, Miriam. Tipos de escrito II: Exposición y argumentación, Madrid, Arco Libros, $1999^{4}$.

6. CuenCA, Maria Josep: «Mecanismos lingüísticos y discursivos de la argumentación». Comunicación, lenguaje y educación, 26 (1995), pp. 23-40.

7. ADAM, Jean-Michel. Les textes: types et prototypes. Récit, descripticon, argumentation, explication, et dialogue. París, Nathan Université, 1992.

8. RAE, <http://lema.rae.es/drae/?val=argumento>, consultado el 02-07-2014

9. Halliday, Michael. Language as Social Semiotic. London, Arnold, 1978.

10. RAE, <http://lema.rae.es/drae/?val=humorismo>, consultado el 02-07-2014

11. AtTARDo, Salvatore, Linguistic Theories of Humor, Berlín, Mouton de Gruyter, 1994. 
El estudio del humor verbal ${ }^{12}$, aunque reciente, tiene diferentes perspectivas de análisis en la actualidad, como la ofrecida por la Lingüística Cognitiva ${ }^{13}$ o las aportadas por la Teoría de la Relevancia ${ }^{14}$ o por la Teoría general del humor verbal ${ }^{15}$. De todas ellas, la que sirve de marco para este trabajo es la última, por considerarla la más abarcadora, al plantear seis recursos de conocimiento como son la oposición de guiones, ya que normalmente se plantea una incongruencia que el lector tiene que resolver; los mecanismos lógicos diseñados por el autor que el lector interpreta en su lectura comprensiva; la situación en la que se plantea el juego del humor, que, normalmente, no es esperable por el lector; la meta o el destino del humor, que no suele ser una persona objeto de la crítica; las estrategias narrativas que se utilizan para insertar el humor en el artículo de opinión; y, por último, el lenguaje utilizado en las elecciones léxicas, gramaticales o fónicas formalizadas por el autor o autora $^{16}$.

\subsection{Objetivos}

Tras lo expuesto, se procede a la posible implicación entre ambos aspectos: el artículo de opinión y el humor en él. Por ello, en primer lugar, cabe preguntarse si el humor tiene cabida en este tipo de género periodístico que, evidentemente, no puede ser calificado como texto humorístico y, en el caso de que la respuesta sea afirmativa, habría que responder a tres cuestiones concretas, que se corresponderían con los objetivos de este trabajo, a saber, en primer lugar, ¿cuál puede ser la función o finalidades que el humor desempeña en un artículo de opinión?, seguidamente ¿cómo se consigue su ejecución, es decir, con qué procedimientos lingüísticos, dentro de lo que son sus propias instrucciones discursivas, se logra? y, por último, ¿se puede hablar de diferencias de uso entre los articulistas hombre y las articulistas mujeres, es decir, se

12. RASkin, Victor (ed.), The Primer of Humor Research, Berlin, Mouton de Gruyter, 2008. Ruiz GuRILlo, Leonor, La lingüistica del humor en español, Madrid, Arco Libros, 2012.

13. BRÔNE, Geert, FeyaerTs, Kurt y Veale, Tony, «Introduction: Cognitive Linguistics approaches to humor, Humor, 19-3, pp. 203-228, 2006.

14. YUS, Francisco. «La Teoría de la Relevancia y la estrategia humorística de la incongruencia-resolución», Pragmalingüística 3-4, pp. 497-598.

15. RASKIn, Victor, Semantics Mechanisms of Humor, Reidel, Dordrecht, 1985. ATTARDO, Salvatore y RUSKIN, Victor, «Sript theory revis(it)ed: Joke similarity and logical mechanisms», Humor, 4 (3-4), pp. 293-347, 1991. ATTARDO, Salvatore, Humorous Texts: A Semantic and Pargmatic Analysis, Berlin, Mouton de Gruyter. RuIz GuRILLO, Leonor, Op. Cit.

16. RUIZ GuRILLO, Ibid., p. 36. Esta autora explica pormenorizadamente cada uno de estos seis recursos en las pp. 35-42. 
puede considerar el empleo del humor, así como sus características, como un elemento designativo de género?

\subsection{Metodología}

Para lograr estos objetivos, se ha diseñado una metodología ad hoc consistente, en primer lugar, en seleccionar un corpus textual que sirva de base para el análisis comparativo entre todos los textos. Posteriormente, se ha confeccionado una base de datos en la que se han consignado los datos extraídos de la descripción y del análisis de los textos mediante una serie de parámetros tales como la autoría, el tema, la tesis perseguida, la presencia o ausencia del humor, la finalidad de su uso y los recursos lingüísticos empleados para ello.

Respecto al corpus seleccionado, se parte del concepto ya consolidado de «corpus linguistico» definido como «a collection of pieces of language that are selected and ordered according to explicit linguistic criteria in order to be used as a sample of the language» ${ }^{17}$. De esta forma, todo corpus lingüístico debe poseer unas características que lo validen para poder estudiar de forma empírica cualquier aspecto intra-/intertextual o discursivo de la lengua en uso,

En este caso concreto, la selección del corpus textual cumple con aquellos rasgos que son considerados básicos: los textos son auténticos ya que han sido publicados por sus autores en la prensa diaria nacional ${ }^{18}$; todos pertenecen al mismo subgénero periodístico, el artículo de opinión, y presentan el mismo formato; su recopilación y posterior estudio se ha realizado en función de una finalidad concreta, que no es otra que el objetivo de este trabajo; todos responden a una cronología determinada que, en este trabajo, abarcaría los tres últimos meses del año 2013; y, por último, el conjunto de todos ellos es suficientemente representativo para configurar el arranque de una investigación como esta en la que se consigue la máxima ecuanimidad entre todos los componentes manejados.

Teniendo en cuenta todas las consideraciones precedentes, el corpus estudiado contempla 83 textos $^{19}$, de los que 38 han sido escritos por tres periodistas mujeres, Rosa Montero (16 textos, 7550 palabras), Elvira Lindo (9 textos, 5647 palabras) y Carmen Rigalt (13 textos, 6760 palabras); y 42 por

17. SinCLAIR, John. Preliminary recommendations on Corpus Tipology, EAG-TCWG-CTYP/P, versión de mayo de 1996. Pisa, EAGLES, 1996.

18. Los autores seleccionados publicaron su textos en: <http://www.elpais.com>, <http:// elmundo.es>, <http://www.eldiario.es>, <http://elperiodico.com>, <http://blogs.publico. es>.

19. Las referencias bibliográficas de todos ellos se encuentran en el Anexo I. 
tres periodistas hombres, Juan José Millás (17 textos, 5954 palabras), Ignacio Escolar (11 textos, 3657 palabras) y Moncho Alpuente (17 textos, 10351 palabras). En total, el corpus textual se compone de 39919 palabras, de las que 19957 pertenecen a las autoras y 19962 a los autores.

A su vez, todos estos autores y autoras pueden ser considerados como ideológicamente progresistas y con edades maduras, pues los más jóvenes serían Escolar, nacido en 1975, y Lindo en 1963, mientras que el resto estarían en la sesentena, Montero de 1951, Rigalt y Alpuente, ambos de 1949, y Millás de 1946. De ahí que, todos los resultados que se han obtenido, deban ser contemplados y entendidos de acuerdo a la representatividad y limitaciones que se han considerado en el establecimiento de este corpus textual.

\section{Análisis y resultados}

Los textos seleccionados no pertenecen al grupo denominado como textos humorísticos y, por tanto, no participan de su cauce pragmático. La consecuencia más importante de ello es que el lector no espera que aparezca este rasgo en el discurso porque la temática social no parece prestarse a ello. Ahora bien, lo observado en el corpus textual seleccionado da respuesta al primer interrogante que se planteaba ya que en muchos de ellos, independientemente de la seriedad del tema, el humor se integra como elemento utilizado dentro del discurso periodístico de opinión, por lo que puede pasarse al estudio y al análisis de él para dar respuesta a los tres interrogantes que restan.

\subsection{Análisis del humor en el corpus textual seleccionado}

De todos los textos compendiados, solo en uno de ellos el humor, y más concretamente el chiste, es el propio tema del artículo, el cual es utilizado por la autora como objeto de reflexión sin ambages para poner en tela de juicio lo que son nuestros propios principios culturales, como puede observarse en (1):

(1) Un periodista va a hacer una entrevista a un escritor judío en Moscú y se lo encuentra haciendo las maletas apresuradamente; el escritor, muy agitado, le explica al periodista que va a salir del país esa misma noche, porque se ha enterado de que están a punto de promulgarse unas terribles leyes discriminatorias y que van a encarcelar a los judíos y a los arquitectos. ¿Por qué a los arquitectos?, pregunta el periodista. ¿Por qué a los judíos?, contesta el escritor. $(15 / \mathrm{RM})^{20}$

20. Cada ejemplo del corpus textual se anota de esta manera: entre paréntesis, en primer lugar se pondrá el número del artículo que irá seguido, tras la barra, de las iniciales

Feminismo/s 24, diciembre 2014, pp. 117-141 
Este tipo de uso, a modo de explicación ejemplificadora, no deja de ser una traducción, una equivalencia de cómo cada uno de nosotros, o cada grupo social, puede ver e interpretar, consecuentemente, el mundo, tal y como puede deducirse de (2):

(2) Una ratita, parada sobre sus cuartos traseros, alza la cabeza al cielo y contempla el paso majestuoso de un murciélago con las alas extendidas. Y exclama con arrobada admiración: «¡Oh, mon Dieu! ¡Un angel!» (15/RM)

Tanto en (1) como en (2), aunque el objeto de análisis de la autora sea el mismo chiste, se nos ofrecen las claves de cómo es posible utilizar el humor dentro de este tipo de textos pues, en estos casos, mediante los mecanismos lógicos utilizados ${ }^{21}$, el lector observa cómo vemos cada uno de nosotros la realidad. El humor se ha utilizado como elemento pedagógico ya que, como se irá comprobando en el análisis realizado, el efecto final del uso del humor en este tipo de textos no es divertir, sino ganar la confianza del lector y, en definitiva, apoyar la tesis que se defienda en cada caso.

Como se dijo anteriormente, el juego que supone la oposición de guiones está presente siempre. Observemos (3) y la inclusión de la expresión «lanzarse al monte»:

(3) La cosa está tan rematadamente mal, en fin, que los científicos, que en España siempre fueron considerados un poco frikis, ahora se han visto obligados a lanzarse al monte del subempleo, la marginalidad y la bohemia. (3/ $\mathrm{RM}$ )

Esa expresión, convertida en metáfora cuando el lugar al que se va es al subempleo, la marginalidad y la bohemia, conlleva un rasgo de humor al comparar a los científicos con los evadidos de la justicia. Se rompe con el principio de informatividad ${ }^{22}$, al igual que ocurre en (4) con el empleo de la hipérbole al identificar, en un futuro, a los vendedores de un mercado ambulante con los científicos españoles, o en (5) con el uso de la misma figura, pero ahora para explicar una noticia concerniente al embarazo de la hija de una folklórica, al comparar tal hecho puntual con problemas sociales españoles:

del autor o de la autora (RM, Rosa Montero; EL, Elvira Lindo; CR, Carmen Rigalt; IE, Ignacio Escolar; JJM, Juan José Millás y MA, Moncho Alpuente). Todos los artículos seleccionados están agrupados en el anexo 1.

21. La imagen de un murciélago es interpretada como la imagen de un ángel atendiendo a las creencias del personaje.

22. LEVInSON, Stephen.C. Presumptive Meanings. The theory of Generalized Conversational Implicature. Massachusetts, Cambridge, 2000, p. 114. 
(4) De seguir así, dentro de poco todos los feriantes que venden camisetas y calcetines en los mercadillos serán probablemente científicos en busca de fondos. (3/RM)

(5) La noticia apenas trasciende la categoría de anécdota pero, en el último tramo de la semana, ha dado que hablar más que las becas Erasmus y el cierre de Canal Nou, convirtiéndose en un auténtico episodio nacional. (2/CR)

Siguiendo con la ruptura del mismo principio en la oposición de guiones, el humor se pone al servicio de la denuncia en el momento en que una frase famosa o aforismo se reproduce pero añadiendo información, tal y como ocurre en (6) con el añadido de «en las ganancias», o bien cuando se juega con la ironía y con el empleo de una frase coloquial hecha, «aún en las mejores familias», en (7):

(6) [...] por actualizar el tema del Barón de Coubertin, de «lo importante no es ganar sino participar» a «lo importante no es ganar sino participar en las ganancias». (1/MA)

(7) En el colmo de la persecución política, varios de los últimos purgados son altos cargos que el propio ministro había nombrado hace menos de dos años. El socialismo, como la conspiración judeomasónica de antaño, se infiltra aun en las mejores familias. (5/IE)

El humor se convierte en un vehículo amable para expresar una realidad social y política muy negativa, es decir, se utiliza como un elemento atenuador de denuncia que, no por suave, deja de ser muy eficiente. En ocasiones, también busca la complicidad del receptor con un diálogo directo, sabiendo que, en todo momento, este entra en el juego al comprender el sentido real de lo que se está diciendo, tal y como se aprecia en (8):

(8) Argentina también va a dejar la crisis un día de estos, ¿qué se creen? Lo que pasa es que tiene que encontrar el momento para hacerlo de forma limpia, a pelo, sin parches de nicotina ni sesiones de acupuntura o hipnotismo. $(17 / \mathrm{JJM})$

Abundando en esta misma idea, en (9) se denuncia una situación mediante una metonimia nada esperada ${ }^{23}$ para explicar la existencia de dos mundos en uno, que deja una sonrisa fría en el lector:

(9) Y, mientras la vida va dejando oleadas de cadáveres y un reguero de sangre a los pies del muro, en el interior de la zona elitista la gente sufre problemas tan extraños como el de tener que retirar miles de prótesis mamarias». (8/RM)

23. Se identifica y se caracteriza a toda una clase social con un elemento parcial como son las prótesis mamarias. 
Con el mismo procedimiento, en (10) la oposición de guiones vuelve a ocasionar humor, mediante la interpretación de símbolos, como qué sería para el ministro del interior una corona de espinas, situándola en paralelo con la necesidad de la existencia del flujo de ideas en nuestra sociedad:

(10) Si a Jorge Fernández Díaz, ministro del Interior y católico practicante, le hubieran preguntado en su día por la corona de espinas de Cristo, habría dicho que se trataba de un elemento de disuasión pasivo, para que las ideas de Jesús no atravesaran el cráneo, y que apenas producía rasguños superficiales. (14/JJM)

Si la oposición de guiones y el uso de mecanismos lógicos son recursos casi constantes en la producción de humor en este tipo de textos, lo mismo puede decirse de la selección de posibilidades lingüísticas que llevan a cabo los autores y las autoras. Entre ellos destaca el humor producido por el juego entre palabras parónimas con significados completamente diferentes, «olimpiada / limpiada» en (11), y «limpiada / olímpicas dimensiones» en (12), pero que, al unirse en la misma frase, consiguen el efecto de denuncia que busca el autor con un gran toque de humor:

(11) No necesitamos una Olimpiada sino una limpiada a fondo, ahora y no en el 2020. (1/MA)

(12) Madrid necesita una limpiada de olímpicas dimensiones. (1/MA)

$\mathrm{O}$ bien, el que se produce con las diferentes acepciones de significado del adjetivo «real» en (13), pero usado en una misma frase al lado de uno de sus antónimos, «irreal». Con este juego lingüístico se califica y se caracteriza el concepto de «Familia Real», del que claramente se desprende una connotación humorística:

(13) La Familia Real es la más irreal de todas. (4/CR)

También se encuentra el comentario a los eufemismos que utilizan los políticos. En (14), a partir de las palabras del Presidente del gobierno sobre las cuchillas en las vallas de Melilla, la articulista ironiza con los posibles significados del verbo «afectar» y del sustantivo «personas», de donde se desprende un humor que trata de ser moderadamente respetuoso con el propio Presidente:

(14) Dice Rajoy que «no sabe si» las cuchillas de las vallas de Melilla «pueden afectar a las personas». Frase que ya es digna en sí de un estudio semántico como muestra del eufemismo más vacuo. Por favor, señor Rajoy, defina usted «afectar»: ¿quiere decir que ignora si las concertinas pueden, por ejemplo, deprimir por lo feas que son a la personas? Y ya que estamos defina también «personas». ¿Se refiere a los turistas, a los guardias de fronteras, a los vecinos del lugar? (13/RM) 
Lo mismo sucede en (15) con el empleo de ciertas metáforas lexicalizadas como «puso la mano en el fuego» al combinarse con actuaciones que requieren la implicación del lector, «con las que usted y yo»; o bien en (16) con el uso del símil «sacadas de una caja de legos» combinado con una metáfora, «jibarizándolo», para rematar con el uso de un diminutivo derivado del uso anterior, «lastimilla»:

(15) Felipe González [...] puso la mano en el fuego por personas con las que usted y yo no iríamos al cine ni locos. (16/JJM)

(16) Da pena. En Madrid, las estatuas dedicadas a nuestros artistas parecen sacadas de una caja de Legos. [...] Se diría que sus dimensiones reflejan la idea inconsciente que nuestras autoridades han tenido siempre de la cultura: con supuesta generosidad promueven una estatua a un gran escritor, pero jibarizándolo [...] Las estatuas de artistas en Madrid no dan sombra, dan lastimilla. (6/EL)

En (17) la selección léxica que realiza la autora cambia la metáfora lexicalizada «noticias del corazón» por «noticias hepáticas», para referirse a la prensa que cuenta la vida social de personajes famosos. Es esa selección la que caracteriza y dota de humor su discurso por la connotación de «hígado» como repulsivo y desagradable, frente a la de «corazón» como sentimiento positivo y amor:

(17) No se me hagan los suecos y echen un vistazo a las noticias hepáticas de la semana. Digo bien: hepáticas. Y es que el corazón ha perdido muchos enteros. El hígado gana por goleada. (2/CR)

Como se puede comprobar hasta este momento, el juego con el lenguaje para producir humor puede ser considerado característico de algunos de estos textos. Además de lo ya expuesto, pueden añadirse fenómenos como la desautomatización de expresiones fraseológicas en (18) al cambiar «bien» por el parónimo «cien», o la inclusión del registro coloquial, con el que se violaría el principio de manera ${ }^{24}$, en (19) con la expresión «hasta las narices» y en (20) con la frase exclamativa « ia por la octava!» con la que, mediante la ironía, se consigue el efecto negativo perseguido para referirse a los continuos cambios en las leyes de educación, en contra del significado positivo que conlleva esta expresión en el mundo del deporte de competición:

(18) No hay mal que por cien no venga. (2/MA)

(19) Es muy probable que, como sucede en la vida real, tanto los familiares como los trabajadores de la prisión estuvieran de la monja hasta las narices. $(2 / \mathrm{EL})$

24. Ibidem, pp. 136-137.

Feminismo/s 24, diciembre 2014, pp. 117-141 
(20) Total, que aquí tenemos la LOMCE de Wert, la séptima ley de la democracia, a la que la oposición ha prometido derogar en cuanto pueda ( ¡a por la octava!) y que no pinta nada bien: parece reforzar los centros concertados y debilitar a los públicos, además de dificultar que padres y profesores elijan a los directores. (14/RM)

Lo mismo sucede en (21) en donde la sonrisa en los lectores aparece ya en la primera frase mediante la antítesis que supone el preocuparse por lo que, en principio, tendría que ser algo bueno, pero que no lo es al usar la expresión coloquial «no vales un pimiento». Esta forma de explicar un dato objetivo, como el que el presidente no haya sido espiado, demuestra la posición ideológica de la autora así como la crítica peyorativa hacia él, para lo que se sirve del rasgo del humor en su discurso:

(21) Sospecho que a Rajoy le preocupa más no haber sido espiado por Estados Unidos que haberlo sido. Si el imperio espía a 35 líderes mundiales y tú no estás entre ellos, verdaderamente es que no vales un pimiento. Y se diría que todo se reduce a eso: a que hablen de ti, a tu pequeño poder personal, a la pompa y el lucro. (7/RM)

Además, en el corpus textual seleccionado, también se observa la aparición de una determinada estrategia, más expositiva que narrativa, consistente en crear dos niveles de discurso, pero con la misma voz de la autora ${ }^{25}$, bien en tercera persona narrando, exponiendo, o bien, argumentando en tercera o en primera persona, como puede observarse en (22):

(22) Todo eso se refleja en nuestra lengua. Ya se sabe que la hablan 400 millones de personas; que es el segundo idioma materno del planeta, tras el mandarín, y que hay expertos que sostienen que, para 2045, será la lengua mayoritaria (aunque yo creo que para entonces hablaremos todos chino). (5/ $\mathrm{RM})$

Este recurso viene marcado por el uso de los paréntesis. Recuerda a los apartes de las representaciones teatrales cuando el actor deja de dirigirse a los otros actores y se dirige al público, mientras que el resto del elenco parece no escuchar nada; o en los monólogos, cuando el monologuista realiza un aparte trazando una línea paralela a su primer discurso ${ }^{26}$. En esos apartes es donde aparece el humor. Bien es cierto que dicho humor se recompone por la imagen cultural que se tiene de los chinos y con la referencia cultural, por ejemplo, del afloramiento de tanto establecimiento de esta nacionalidad, restaurantes,

25. Ducrot, Oswald. El decir y lo dicho. Polifonía de la enunciación, Barcelona, Paidós, 1986.

26. Ibid., El decir es como una representación teatral, una polifonía con diferentes voces 
bazares, tiendas baratas, etc., actuando un mecanismo lógico cultural como es la supuesta colonización oriental que está sufriendo occidente.

En (23) vuelve a darse la sorpresa que causa ese humor. Ante una aseveración importante y seria en la primera oración, la autora interrumpe su discurso con una frase encabezada por la interjección coloquial «hala» y que se centra en algo, aparentemente baladí para el tema del artículo, como es el hecho de perder lectores por tratar ese tema. El humor subraya por tanto la importancia del asunto y el cansancio de cierta parte de la sociedad ante ese mismo tema, la pobreza:

(23) Ayer lunes empezó la Semana contra la Pobreza, cuya fecha principal es el próximo jueves, que será el Día Internacional para la Erradicación de la Pobreza. Hala, ya he debido de perder como el $80 \%$ de los lectores de este artículo, porque estamos hartos de que nos hablen de pobres. (4/RM)

Este procedimiento del doble nivel de discurso se utiliza para la caracterización de diferentes elementos. Muchas veces por oposición, como en (24) y en (25) con el uso de los paréntesis. Además, en este último también se produce una fusión léxica entre el nombre del festival y el de la ciudad sede del mismo, que produce la palabra que da origen al humor:

(24) El librero no se lee todos los libros de principio a fin (es humano), [...] Eso es algo que, por ejemplo, Amazon, que no es un ser humano aunque venda libros, no sabe calibrar. (5/EL)

(25) Este puñado de matemáticos, físicos, biólogos y demás criaturas raras especializadas en diferentes ramas del saber están haciendo una gira, el Relámpago Tour, que comenzó el 1 de junio en el Festival Freak de Logroño (llamado prometedoramente Frikoño, para que vean por dónde anda la cosa) y que terminará el 17 de noviembre. (3/RM)

En otras ocasiones, este mismo fenómeno se produce por la definición de términos aparentemente con cierto rasgo de especialización como «anciana» en (26); o con el empleo de una oración adjetiva explicativa en (27) o, también, mediante una interpelación directa al propio lector, «díganles que van de mi parte» en (28):

(26) A las 2.30 de la mañana, una anciana (en la literatura de sucesos, todos los que tienen más de 50 años están catalogados como ancianos) había sido atropellada en la A6. (1/CR)

(27) Los analistas económicos, que no han acertado una desde que estalló la crisis, se apresuran a añadir que los movimientos de masas no constituyen una buenanueva en sí mismos, puesto que las masas que nos asisten no cargan bolsas. (10/CR)

(28) El viernes, los libreros celebran su día, el de las librerías. Abrirán hasta las diez. Díganles que van de mi parte: le harán un 5\% de descuento. (5/EL) 
Dentro de este tipo de texto donde prima la argumentación, se puede observar el uso de estrategias narrativas propias de otros tipos textuales. En (29) se sigue un esquema característico del monólogo humorístico, y así, con el empleo de una palabra, «metadatos», cuyo significado se desconoce y que se intenta explicar pero sin éxito, se logra la aparición del humor y con él la constatación de lo complicado que es el mundo en que vivimos:

(29) Si lo vamos entendiendo bien, EEUU no nos espía a todos, sino a metatodos. De ahí que se hable de metadatos, en vez de hablar de datos. Del mismo modo que un metadato es un dato sobre otro dato, un metatodo es un todo sobre un todo. Significa que para comprender lo que nos pasa necesitamos ciertos conocimientos de lingüística. (9/JJM)

Esta misma clase de procedimiento se comprueba en (30) donde la autora, hablando de las bondades del libro de papel frente al ordenador, recrea un momento verdaderamente cómico digno de formar parte de cualquier monólogo humorístico:

(30) Como resultado de estos inesperados sobresaltos, pasas de cantar un día las bondades del pequeño aparato a maldecirlo al día siguiente, cuando al derramarse un té sobre el teclado la portátil monería muere llevándose consigo casi todo lo que tú eres. Alzas los ojos a los dioses de ese Olimpo presidido por Steve Jobs, y con las manos alzadas preguntas: ¿y de qué coño sirve ahora un aparato cuyos poderes son para mí algo más parecido a la magia que a la tecnología? (4/EL)

Pero sobre todo es en (31) donde casi de forma alegórica, con la suma de todos los elementos que aparecen y por las connotaciones añadidas a la descripción del desastre en el Congreso, se denuncia la actuación del Partido Popular con una narración que estaría cerca de una crónica esperpéntica:

(31) Abochornados todavía por el fiasco de la candidatura madrileña nuestros representantes electos recibieron una ducha fría, los cielos se abrieron, descargaron su inclemente furia sobre la cúpula del Congreso y derramaron a chorros goterones manchados de yeso. En la tribuna de invitados, turistas japoneses eufóricos reían y sacaban fotos para humillar aún más a nuestros próceres. Dios, que de existir será de derechas, concentró sus manguerazos sobre los bancos de la izquierda pero hasta Fernández el ministro converso que se encontró con el Espíritu Santo junto a una tragaperras de Las Vegas sabia que la tormenta que se cernía sobre sus ungidas cabezas era un aviso más de la colérica deidad. Después de mí, el diluvio, que pase, murmuró para sí Mariano el irresoluto y por una puerta trasera del hemiciclo desapareció discretamente el responsable de la última rehabilitación de las cubiertas del histórico inmueble para buscar la factura de Pepe Gotera y Otilio, chapuzas a domicilio. No la encontró, a lo mejor se trataba de un pago en B, C, o X, tendría que rebuscar en el disco duro si es que aún lo conservaban en Génova 
13 porque últimamente les ha entrado en la sede del PP la manía de destruirlo todo, agendas, documentos, y archivos que pudieran incriminarles en algo, los discos duros los carga el diablo y habrá que pedirle un exorcismo a Rouco varela. (2/MA)

Hasta ahora, se ha visto cómo el humor es un elemento al servicio de la tesis que defienda en cada momento el autor o la autora, pero es quizá en la caracterización de las personas que integran parte de la vida social y política española donde más se muestre el humor como recurso, sobre todo al ser éstas objetos de burla. Así, en (32) con el significado estándar de su apellido, en (33) con la ironía que suponen sus conocimientos, en (34) con la identificación con una persona discapacitada, y en (35) con el doble significado del adverbio «cucamente», a escondidas o de forma muy fina, es Ana Botella, la alcaldesa de Madrid, el objetivo de la caracterización, de la burla:

(32) [...] villa y corte de la Botella no reciclada». (1/MA)

(33) $[. .$.$] digna heredera de tanta sabiduría. (1/MA)$

(34) Resulta curioso el trato que dan a Ana Botella en el PP. Como si sufriera una discapacidad que convirtiera en heroicos todos sus movimientos. Muy bien, Ana, muy bien, le susurran al oído con el tono con el que nos dirigimos a un niño que ha empezado a andar tarde y se cae con frecuencia. (12/JJM) (35) Botella y la basura. [...] Alguien le debería haber advertido que aun cuando se conceda muy cucamente, la gestión de la limpieza a manos privadas $[\ldots](8 / \mathrm{EL})$

Tampoco salen bien parados ni Rita Barberá ni Miguel Blesa: la primera es objeto de burla en (36) al comentar su orondo aspecto (siendo este uno de los pocos casos en que el humor se hace a costa del físico de la persona); el segundo lo es en (37) con el apelativo cariñoso del «tío Miguel» y la referencia cultural al mundo de la publicidad que supone «el primo de Zumosol»:

(36) Sacar el perfil bueno de Rita Barberá siempre fue misión imposible, no hay «photoshop» en el mundo que lo consiga, una foto de Rita vestida de fallera podría servir para asustar a los niños inapetentes: «Si no te lo comes tú vendrá Rita Barberá y se lo zampará ella». (10/MA)

(37) La noticia es indignante, especialmente para los españoles que no tienen un tío de Zumosol. Sin embargo, la principal responsable es la sobrina que recurre apurada al tío Miguel para que le eche una mano. (2/IE)

Por supuesto, los miembros del gobierno también son objetivo de caracterizaciones humorísticas. El Presidente, en (38), es cuestionado sobre la verdad de su discurso mediante la comparación con Kirchner y la metáfora «el discurso lleno de botox», el humor vuelve a ser un elemento dulcificador de la realidad al no llamarlo directamente «mentiroso»: 
(38) ¿Cómo creer a quien no confía en lo que dice? Es como votar a gente tan siliconada como Cristina Kirchner, por ejemplo: ¿cómo confiar en alguien cuya cara ya es una mentira? Pues Rajoy lo mismo: lleva el discurso lleno de bótox. (13/RM)

Lo mismo que los ministros de Interior en (39), en donde el articulista sitúa el discurso del político al nivel del de Forrest Gump con la connotación de falta de inteligencia que comporta; de sanidad en (40), con su desconocimiento de las marcas de coches; o de educación en (41), con la caracterización cómica de su proceder mediante la metáfora «entrar en bucle», identificable con el funcionamiento anormal de un ordenador:

(39) «Ofensa es lo que resulta ofensivo», asegura muy serio el ministro del Interior al explicar su reforma de la ley de seguridad ciudadana. En su inconsciente homenaje a Forrest Gump («tonto es el que dice tonterías), Jorge Fernández cae en la madre de todas las tautologías. ¿Qué es una ofensa a España? (9/IE)

(40) Rajoy [... mantiene en su Gobierno, contra toda evidencia, a Ana Mato, cuya ignorancia sobre las marcas de automóviles empieza a ser una memez en relación a lo que está aflorando al abrir las cajas de la Gurtel. (16/JJM)

(41) Lo de Wert. Nada que añadir. El ministro ha entrado en bucle. (8/EL)

Los mismos procedimientos se observan también en las caracterizaciones de otros políticos del Partido Popular, como en el caso del que fuera Presidente de la Diputación de Castellón, quien es calificado irónicamente como «delincuente ejemplar» en (42) pues, al ser un adjetivo no esperable, se vulnera de nuevo el principio de informatividad. Esa caracterización queda patente en el uso de los conceptos contrarios «limpio»y «estercolero»:

(42) Carlos Fabra: el delincuente ejemplar. [...] Es un político y un ciudadano ejemplar para el PP y para los ciudadanos de Castellón», dejó dicho Mariano Rajoy en julio de 2008. [...] Todo tan limpio y ejemplar como un estercolero. (10/IE)

Igual que en el caso de Esperanza Aguirre a la que se acusa en (43) de ir disfrazada y poco elegante en una fiesta sobre la elegancia, a la vez que se vuelve a producir ese doble discurso al lector al que anteriormente se hacía referencia:

(43) Desfiló Esperanza Aguirre disfrazada de señorita Pepis (ironías de la vida: ella aprovechó la fiesta convocada por Ralph Lauren para reírse de la elegancia). (4/CR)

Claro está, que este tipo de humor aplicado a políticos siempre está destinado a quienes piensen igual que el autor o la autora y que, por tanto, acepten este recurso como elemento caracterizador y no como elemento denigratorio de las personas a las que se refiere, puesto que es un procedimiento que denota 
claramente la ideología de emisores y receptores que, como se ha dicho, suelen coincidir.

Este tipo de procedimiento se utiliza para otros personajes de la vida social que, evidentemente, tampoco son muy apreciados por los articulistas, como en (44) al referirse a Urdangarín con un verso de una copla, en (45) para señalar una relación de la infanta Elena, o en (46) con la asignación de «arrimador profesional» a un supuesto playboy:

(44) $[\ldots]$ un deportista alto y rubio como la cerveza. (5/CR)

(45) Elena estaba en modo Astolfi. (5/CR)

(46) [...] Javier Rigau, un zascandil que se había dado a conocer como arrimador profesional. (9/CR)

A su vez, el humor también se esgrime para el efecto contrario, es decir, para alabar al personaje del que se habla, bien es cierto que presentándolo en la misma línea ideológica del autor, como puede observarse en (47) al usar elementos escatológicos para describir el proceso de redacción, o bien, simplemente, para mostrar en una metáfora, como un pionero del salvaje oeste americano, el valor de un infestado de SIDA en (48):

(47) Camba escribía como meaba, con aparente naturalidad y sencillez, aunque él prefería una metáfora aún más escatológica y provocadora para explicar su método. «Para hacer mi artículo yo me encierro por las tardes en un cuarto con un poco de papel. Allí comienzo a hacer esfuerzos y el artículo sale. Unas veces sale fácil, fluido, abundante; otras sale duro, difícil y escaso, pero siempre sale». Entre todos sus textos los hay especialmente geniales. (6/ IE)

(48) Por fortuna, hacía muy poco tiempo que se había infectado y pudo entrar a formar parte de un grupo de pacientes que se prestan a probar en carne propia ese experimento. Siempre es alentador para un enfermo verse como un valiente pionero de toda una comunidad de infectados. (3/EL)

En relación a este aspecto, habría que añadir que, aunque menos habitual, el humor vale para una caracterización del propio articulista, como en (49) donde la autora para expresar a qué hora volvió a casa, señala que era una buena hora en la que no se le podría tildar de borracha, o en (50) donde ella misma admite el uso de productos químicos para poder estar cuerdo en este mundo:

(49) De vuelta a casa tomé un taxi. Era una hora incierta: las dos y pico. Ni lo bastante pronto como para sentirme ridícula al meter la llave en la cerradura, ni lo demasiado tarde como para levantar sospechas de haberme bebido las reservas de ginebra del viejo Madrid. (1/CR)

(50) He tenido que recurrir al frasco de las sales para recuperar el entendimiento. (11/CR) 
Para finalizar este análisis habría que señalar que la crítica, y con ella el humor, no solamente se dirige hacia temas importantes social y políticamente, sino que en el afán demostrado en la caracterización de la España en que vivimos, en la situación de todos nosotros, otros temas aparentemente más triviales entran en las páginas de los periódicos dentro de los artículos de opinión. Estos sirven de contrapunto y de caracterización global de la sociedad, como ya se expuso en (5) con el embarazo de una chica y en (16) con el tema de las estatuas de Madrid; en (51) con la difusión de un anuncio publicitario en televisión para hablar sobre la calificación moral de los dos rombos; en (52) con una inauguración un tanto singular, pues al parecer el embajador fue el primero en usar unos váteres públicos, o en (53) y en (54) cuando el humor se desprende básicamente de la situación imprevista e inexplicable en la que se producen los hechos que se cuentan:

(51) $[\ldots]$ se ha hecho público el anuncio navideño de la lotería. Si, como dicen, van a volver los dos rombos, yo los estrenaría con dicho spot. Una criatura inocente no puede enfrentarse a este desfile de inquietantes personajes. ¿Es Navidad fantasmal es la que nos espera? Que vuelva el calvo. (8/EL)

(52) El otro día leí un titular que el embajador de los Países Bajos había inaugurado los váteres privados de Atocha. Estoy acostumbrada a las inauguraciones $[\ldots]$ Pero me costó asumir que un embajador se hubiera prestado a presidir la inauguración de unos váteres, por más privados que fueran. (3/ $\mathrm{CR})$

(53) Todo estupendo, pero los duendes de la imprenta, que se pasan por el arco del triunfo las bondades del matrimonio gay, donde decía esposo pusieron esposa, dejándome a mí a los pies de los caballos. (6/CR)

(54) Son los mismos que años atrás presumían de comprar caro y que de un tiempo a esta parte cultivan el saldo para impresionar. No hay nada más divertido que escuchar a una tonta del culo diciendo con el padadar en pompa: «este broche tan ideal lo he comprado en el mercadillo de Aladina por diez euros». (10/CR)

\subsection{Caracterización de los articulistas seleccionados}

Tras el análisis realizado y con los resultados obtenidos, se puede estar en disposición de caracterizar de forma singular a cada uno de los articulistas que con sus escritos, en el marco temporal seleccionado, han formado parte del corpus textual seleccionado antes de pasar al capítulo de conclusiones de este trabajo.

Moncho Alpuente tiene un estilo descriptivo y de denuncia de la situación externa en el que las caracterizaciones se realizan mediante el uso de la alegoría y de la hipérbole, llegando a un punto cercano al esperpento en el que él piensa que se ha convertido España. Sus temas son, como corresponde, 
actuales, y abarcan la realidad general del país, desde la Olimpiada de Madrid hasta las víctimas del franquismo, pasando por la inmigración africana en Italia o España, la actuación de parte del poder judicial, los espías norteamericanos en Europa y la ley de seguridad ciudadana, entre otros. No hay ningún tema nacional que escape a su visión e interpretación. En sus artículos, el humor tiene cabida como elemento integrador de su visión surrealista y de denuncia de la sociedad, tal y como constata para referirse a un pasado negro en (55):

(55) Cuando las pedorretas de La Codorniz resonaban más de la cuenta en el aire enrarecido, el régimen secuestraba o cerraba la revista temporalmente para que escarmentaran aquellos humoristas deslenguados y procaces. En aquel país de chiste se producía un humor negrísimo como correspondía al luto sempiterno impuesto por las autoridades, humor trágico y sarcástico como la sonrisa de una calavera. (14/MA)

En este autor, como se ha podido comprobar, el humor no está concebido para ser elemento ornamental o de captación de la benevolencia del lector, sino como ingrediente contrastivo de la realidad que presenta, tanto si se trata de la caracterización de personas, de ciudades o de ideas. Está presente en todos y en cada de sus escritos, formando parte intrínseca de su forma de trasladar sus propios pensamientos sobre la realidad española en cualquier de los aspectos que la configuran.

Ignacio Escolar comenta y denuncia aspectos que, en su mayor parte, se corresponden con asuntos políticos españoles tales como los relevos en los cargos del Ministerio de Hacienda, los problemas en la banca española, la desigualdad social española enfocada por el presidente del gobierno, la corrupción sindical o el problema de los niveles de la enseñanza en España. En su estilo de redacción, aunque el humor aparece en algunos de sus artículos caracterizando a alguna persona pública, no puede considerarse un elemento vertebrador de su estilo. Quizá sea debido a ese intento de formalidad que se intenta transmitir siempre por los periodistas considerados serios de la prensa política española.

Juan José Millás, articulista cotidiano de la prensa, no abandona su literariedad para analizar la realidad de la sociedad española, tanto en su vertiente social como política, al tratar temas como la candidatura de Madrid a las olimpiadas y, por inclusión, a la alcaldesa de Madrid, la corrupción política en el partido del gobierno, la denuncia del pensamiento monolítico, la situación económica y en ella, sobre todo, la pobreza. Su voz se alza personal reparando en detalles que, por extensión, se convierten en definidores temáticos. Evidentemente, el humor también es utilizado como elemento constructivo 
de su discurso, pero no es definitorio de este; le sirve para caracterizar muy negativamente a determinadas personas sin caer nunca en el insulto. Por ello, podría ser entendido como un elemento atenuador de la crítica personal, pero a su vez, como un elemento componedor de la propia vida social y política española como él mismo señala en (56):

(56) La intervención de Ana Botella ante los miembros del COI ha entrado ya en la historia del humor, como el despido de Cospedal o los monólogos de Carlos Floniano sobre la vida. Son esas grabaciones que llevas en el coche y que pones en los viajes largos para solaz de la familia. (11/JJM)

Rosa Montero centra su actividad crítica en los aspectos sociales de la vida española, dirigiendo sus opiniones hacia temas como los atentados internacionales, la inmigración, la glosa de excelentes líderes mundiales y las glosas tanto de mujeres importantes del mundo como de mujeres cotidianas en España. En muchos de estos artículos está presente el humor, pero un humor dirigido más hacia el público lector que hacia el propio concepto comentado, que también aparece. En esta autora, en ocasiones ese rasgo de humor sirve para construir un discurso paralelo, perfectamente conectado y dirigido a los lectores, por lo que sería uno de sus rasgos característicos. A su vez, es la única que dedica un artículo al humor en sí en el periodo cronológico seleccionado, en el que manifiesta que el humor es un rasgo que nos sitúa realmente como personas e, incluso, lo define en (57) otorgándole una función específica:

(57) El humor, ese maravilloso antídoto contra la ceguera de la autoimportancia, nos permite enfrentarnos a la media de nuestra menudencia. (15/RM)

Elvira Lindo, además de los llamados grandes temas como la justicia, la constitucionalidad, la enseñanza o las actuaciones políticas, se ocupa también de asuntos más cercanos como la estigmatización de ciertos enfermos, cierta publicidad, las estatuas o los libros y las librerías. En todos ellos el humor está presente, aunque quizá más en los establecidos en el segundo grupo, en los que, como novelista que es, se aproxima a la creación de un texto humorístico con la redacción de párrafos enteros que podrían formar parte de cualquiera de ellos. Con el desarrollo del humor caracteriza a personas y situaciones, así como también establece ese doble diálogo con el lector y, en todo ello, el fenómeno humorístico le sirve más para sugerir que para describir objetivamente.

Carmen Rigalt se caracteriza porque es, de todos los articulistas seleccionados, la que más parece alejarse del comentarista político al uso y, como contrapunto a ello, la que más cerca se sitúa de la prensa social y de la crónica social o rosa. Ahora bien, tanto si trata de la hija de una folklórica como de la muerte de una transeúnte anónima, de la familia real o de la crisis económica, 
de la ley del aborto o de una inauguración de unos váteres en Atocha, su discurso se tiñe de un halo de intelectualidad en donde no hay ningún comentario vacuo y donde el humor, se convierte en un elemento importantísimo para la caracterización de personas, de situaciones, o de conceptos, sin perder nunca un ápice de educación, pero a la vez siendo totalmente combativa y fuerte ante las injusticias y ante las actuaciones públicas que no comparte.

\section{Conclusiones}

El marco teórico, propiciado por la concepción del artículo de opinión como un tipo de texto definido y concreto y por el análisis del humor con la ayuda de Teoría general del humor verbal, se ha revelado como satisfactorio para la consecución de los objetivos que se perseguían con este trabajo. A lo que también ha ayudado notablemente la metodología empleada, y la configuración del corpus textual, al tener en cuenta el que debía ser lo más equilibrado y representativo posible, tal y como se explicó en su momento.

El primer objetivo, si los autores de artículos periodísticos de opinión usan el humor en ellos, ya quedó resuelto casi al comienzo de este trabajo puesto que en ese tipo textual se habla sobre asuntos públicos y sobre la gente que participa en ellos y el humor vale para ello. Ahora bien, los otros tres objetivos marcados se han tenido que ir resolviendo a lo largo del análisis realizado.

De esta forma, de los resultados obtenidos puede decirse que, en relación a cuál o cuáles pueden ser las funciones de este elemento en este tipo textual, el humor no puede ser considerado un argumento más del texto argumentativo, sino que formaría parte de sus propias instrucciones discursivas con el desempleo de diferentes finalidades dentro del marco discursivo de este tipo textual, que no persiguen el objetivo principal y habitual del humor, hacer reír o divertir, sino que se encamina a ser un coadyuvante al servicio de la tesis que se persiga. Entre esos empleos o finalidades que los articulistas utilizan en sus escritos destacarían:

a. Ser un elemento pedagógico que ayuda a que se entienda la realidad circundante.

b. Convertirse en el objeto de reflexión del articulista.

c. Servir para caracterizar personas, situaciones o conceptos.

d. Funcionar como elemento atenuador de la crítica que se realice y así evitar lo burdo y jugar con la inteligencia. 
e. Ser esgrimido para ganarse la confianza del lector que, normalmente, coincide ideológicamente con el articulista y que, por tanto, puede entender y compartir las mismas opiniones.

El cómo se consigue su ejecución, cómo se plasma el humor en los textos, planteado como otro interrogante, se ha constatado que, con la ayuda de la Teoría general del humor verbal, los recursos utilizados pueden agruparse, a modo de ejemplos concretos, en el uso de mecanismos lógicos [en (1 ${ }^{27}$ y en (2)], en la oposición de guiones [de (3) a (10)], en el uso particular del lenguaje [de (11) a (21)], en el uso de estrategias discursivas [de (22) a (31)], en dirigirse hacia una meta, o persona, [de (32) a (46)], o de la partida de determinadas situaciones [de (47) a (54)].

Estos recursos se formalizaron con el empleo de figuras literarias tales como símiles (15), metonimias (9) y (14), metáforas (3), (15) y (17), hipérboles (4) y (5), ironía (7); con la interpretación de símbolos (10); con el uso de fraseología (6) y (18); con el uso de los paréntesis (22) y (24); con el uso de juegos fónicos (25); el empleo de parónimos (11), (12) y (13), de antónimos (13), de eufemismos (14), de diminutivos (16) y de cambio de registro (19), (20) y (21), principalmente. En definitiva, se consigue la plasmación del humor con el empleo de los mismos recursos que se utilizan en los textos humorísticos propiamente dichos, por lo que la diferencia sustancial se encuentra en la finalidad o finalidades de su empleo, como ya se ha dicho anteriormente.

Por último, en la consideración del humor como un posible elemento designativo de género, el estudio llevado a cabo no puede concluir con que lo sea pues, el uso del humor y su forma de empleo aparecen en todos los articulistas vistos, hombres y mujeres, y las variaciones que puedan consignarse dependen más del estilo personal de cada uno de ellos que del ser hombre o mujer.

Ahora bien, en el corpus textual seleccionado, puede afirmarse que se ha encontrado una característica que utilizan las articulistas y que no aparece en ellos, y es en lo que se ha denominado en este trabajo estrategias discursivas expositivas o narrativas, es decir, en el hecho de que son las mujeres las que utilizan ese doble discurso para dirigirse a los lectores y ampliar o matizar lo dicho en el primer discurso, configurándose, por tanto, como un posible rasgo definitorio de género.

27. Los números entre paréntesis remiten a los ejemplos textuales reproducidos en este trabajo. 
Por lo tanto, dentro de lo que debe ser una continuación y una ampliación de este estudio en trabajos venideros, deben integrarse otros articulistas de diferentes edades y también de diferentes ideologías que los incluidos en este estudio.

\section{Referencias bibliográficas}

ADAM, Jean-Michel. Les textes: types et prototypes. Récit, descripticon, argumentation, explication, et dialogue. París, Nathan Université, 1992.

Álvarez, Miriam. Tipos de escrito II: Exposición y argumentación, Madrid, Arco Libros, $1999^{4}$.

AtTARDO, Salvatore, Linguistic Theories of Humor, Berlín, Mouton de Gruyter, 1994.

AtTARDO, Salvatore, Humorous Texts: A Semantic and Pargmatic Analysis, Berlin, Mouton de Gruyter, 2001.

ATTARDO, Salvatore y RUSKIN, Victor, «Sript theory revis(it)ed: Joke similarity and logical mechanisms», Humor, 4 (3-4), pp. 293-347, 1991.

BRÔNE, Geert, FeYAERTS, Kurt y Veale, Tony, «Introduction: Cognitive Linguistics approaches to humor, Humor, 19-3, pp. 203-228, 2006.

Charadeau, Patrick: «Los géneros: una perspectiva socio-comunicativa», en Martha Shiro, Patrick Charadeau y Luisa Granato (eds.): Los géneros discursivos desde múltiples perspectivas: teorías y análisis, Madrid, IberoamericanaVervuert, 2012, pp. 19-44.

CUENCA, Maria Josep: «Mecanismos lingüísticos y discursivos de la argumentación». Comunicación, lenguaje y educación, 26 (1995), pp. 23-40.

Ducrot, Oswald. El decir y lo dicho. Polifonía de la enunciación, Barcelona, Paidós, 1986.

HALlidaY, Michael. Language as Social Semiotic. London, Arnold, 1978.

LEVInSON, Stephen.C. Presumptive Meanings. The theory of Generalized Conversational Implicature. Massachusetts, Cambridge, 2000.

RASKIN, Victor, Semantics Mechanisms of Humor, Reidel, Dordrecht, 1985.

RASKIN, Victor (ed.),The Primer of Humor Research, Berlin, Mouton de Gruyter, 2008.

Ruiz GURILlo, Leonor, La lingüística del humor en español, Madrid, Arco Libros, 2012.

SINCLAIR, John. Preliminary recommendations on Corpus Tipology, EAG-TCWGCTYP/P, versión de mayo de 1996. Pisa, EAGLES, 1996.

VAn Dijk, Teun. La ciencia del texto. Barcelona, Paidós, 1978.

YUS, Francisco. «La Teoría de la Relevancia y la estrategia humorística de la incongruencia-resolución», Pragmalingüistica 3-4, pp. 497-598. 


\section{Webgrafía}

$<$ http://www.definicionabc.com/comunicacion/articulo-de-opinion.php $>$, consultado el 26-05-2014.

$<$ http://www.elpais.com>

$<$ http://elmundo.es>

$<$ http://www.eldiario.es>

$<$ http://elperiodico.com>

$<$ http://blogs.publico.es >

$<$ http://www.rae.es/>

\section{Anexo 1: listado de artículos}

(RM) Rosa Montero [http://elpais.com] (1/RM) «Epidemia», 01/10/2013. (2/ $\mathrm{RM}$ ) «La elección», 08/10/2013. (3/RM) «Esos maravillosos científicos raros», 13/10/2013. (4/RM) «Pobreza» 15/10/2013. (5/RM) «Palomear», 22/10/2013. (6/RM) «Todas esas víctimas calladas», 27/10/2013. (7/ RM) «La vida real», 29/10/2013. (8/ RM) «Raro, muy raro», 05/11/2013. (9/RM) «Aprendiendo a reír», 10/11/2013. (10/RM) «Mentiras», 12/11/2013. (11/RM) «Pura saña», 19/11/2013. (12/RM) «Cómo destruir a una persona», 24/11/2013. (13/RM) «No saber», 26/11/2013. (14/RM) «La séptima», 03/12/2013. (15/RM) «Un puñado de chistes», 08/12/2013. (16/RM) «Otra manera», 10/12/2013.

(EL) Elvira Lindo [http://elpais.com] (1/EL) «Constitución, 11/12/2013. (2/ EL) « ¿Existe la injusticia?», 08/12/2013. (3/EL) «El estigma», 04/12/2013. (4/

EL) «La vida lisboeta», 01/12/2013. (5/EL) «De librerías», 27/11/2013. (6/EL) «Nuestro Fernando», 24/11/2013. (7/EL) «Mal ejemplo», 20/11/2013. (8/EL) «Que vuelva el calvo», 17/11/2013. (9/EL) «Entre todos», 13/11/2013.

(CR) Carmen Rigalt [http://www.elmundo.es] (1/CR) Carmen Rigalt, «La mujer sin nombre», 05/11/2013. (2/CR) «El mausoleo Cantora extiende su mal fario», 10/11/2013. (3/CR) «Un embajador en el retrete», 13/11/2013. (4/ CR) «Aguirre, elegante sin fronteras», 17/11/2013. (5/CR) «Causa común», 20/11/2013. (6/CR) «Haciendo migas con la Marca Francia», 24/11/2013. (7/ CR) «El árbol de Navidad soy yo», 30/11/2013. (8/CR) «Progreso y castidad», 03/12/2013. (9/CR) «Las huerfanitas conquistan Madrid», 17/12/2013. (10/ CR) «Lección de vida», 18/12/2013. (11/CR) «El monstruo de las cejas blancas», 22/12/2013. (12/CR) «No es coreana, sino rumana», 24/12/2013. (13/ CR) «Progresistas», 31/12/2013.

(IE) Ignacio Escolar [http://www.eldiario.es] (1/IE). «Purga en hacienda», 08/10/2013. (2/IE) «El banco del tío Miguel», 12/12/2013. (3/IE) «Los datos 
sobre desigualdad que Rajoy no quiere ver», 09/12/2013. (4/IE) «Purga en Hacienda», 09/12/2013. (5/IE) «El analfabetismo español», 05/12/2013. (6/ IE) «No es la ley educativa, es la desigualdad y la historia», 04/12/2013. (7/IE) «La corrupción sindical», 02/12/2013. (8/IE) «Represión contra protestas», 02/12/2013. (9/IE) «Carlos Fabra: el delincuente ejemplar, 26/11/2013. (10/ IE) «Cuchillas contra el derecho a huelga», 25/11/2013. (11/IE) «Carta a Ana Botella (y a sus discípulos)», 18/11/2013.

(JJM) Juan José Millás [http://elpais.com/elpais] (1/JJM) «Cuestión de porcentajes», 06/10/2013. (2/JJM) «A otra cosa», 11/10/2013. (3/JJM) «Para qué sirve un ministerio», 13/10/2013. (4/JJM) «Historiales clínicos», 20/10/2013. (5/JJM) «Usted no se apure», 25/10/2013. (6/JJM) «Que les corten la cabeza», 27/10/2013. (7/JJM) «La rebaba», 01/11/2013. (8/JJM) «El eterno retorno», 03/11/2013. (9/JJM) «Gato encerrado», 08/11/2013. (10/JJM) «Un instante que hiere», 10/11/2013. (11/JJM) «Todo a precio de mercado», 17/11/2013. (12/JJM) « ¿Soy lista?, 22/11/2013. (13/JJM) «iEstamos fuera!, 24/11/2013. (14/JJM) «Yo no fui», 29/11/2013.(15/JJM) «Coherencia en la confusión», 01/12/2013. (16/JJM) «¿Cómo explicarlo? 06/12/2013. (17/JJM)«Un lugar en el mundo, 08/12/2013.

(MA) Moncho Alpuente [ http://blogs.publico.es/moncho-alpuente] (1/MA) «Limpiada 2020», 06/09/2013. (2/MA) «No hay mal que por cien no venga», 13/09/2013. (3/MA) Moncho Alpuente, «¿Dónde está Billy?, 20/10/2013. (4/MA) «Vuelve la boina», 27/09/2013. (5/MA) «El país de los milagros», 04/10/2013. (6/MA) «De Lampedusa a Melilla, 11/10/2013. (7/MA) Moncho Alpuente, «Leña al moro», 18/10/2013. (8/MA) «Rufufú en Madrid», 25/10/2013. (9/MA) «No estamos solos», 01/11/2013. (10/MA) «Fallos de Valencia», 08/11/2013. (11/MA) «El tiempo entre basuras», 15/11/2013. (12/MA) «Sonría a sus verdugos», 22/11/2013. (13/MA) «El niño que quería ser juez», 29/11/2013. (14/MA) «Honorables espías», 06/12/2013.(15/ MA) «Carita de ministro», 13/12/2013. (16/MA) «Madrid, ciudad sitiada», 20/12/2013, (17/MA) «La vida privada de Caja Madrid», 27/12/2013. 



\title{
EL «ESTILO DE LA CARNE» EN MAIKRUX Y FALETE: FEMINIDAD, HUMOR Y AGENCIA
}

\author{
AMAia Álvarez URIA \\ Universidad del País Vasco \\ Raquel (Lucas) Platero MÉNDeZ \\ Universidad Rey Juan Carlos \\ MARÍA ROSÓN VILLENA \\ Universidad Autónoma de Madrid
}

Recibido: 15/09/2014

Aceptado: 24/11/2014

\section{Resumen}

Maikruz y Falete son dos personajes televisivos que forman parte de la cultura popular vasca y española y que performan identidades de género no hegemónicas, pues encarnan feminidades fuertes a pesar de haber sido asignados como varones en el nacimiento. Nuestro análisis atiende a cómo el humor y lo vernáculo más que desactivar su posible potencialidad política, los convierte en una parte del imaginario cultural de «posibilidad» y agencia. Esto es posible no sólo por lo que Maikrux y Falete «son» sino por que la audiencia puede reapropiarse de ciertos aspectos placenteros que ellos transmiten, para empoderarse y realizar identificaciones plurales y complejas.

Palabras clave: humor, queer, señoras, folclóricas, crip, recepción

\begin{abstract}
Maikrux and Falete are two TV figures which form part of Basque and Spanish popular culture. Both of them perform non-hegemonic gender identities, embodying strong femininities despite the fact they were assigned as male at birth. Our analysis deals with humour and the vernacular, in which we highlight that instead of deactivating their possible political potentiality, their role in the cultural imagination allows "possibility» and agency. This is possible not only because of what Maikrux and Falete
\end{abstract}


«are» but rather because the audience can reappropriate certain pleasures that they embody, empowering the audiences with complex and plural identifications.

Keywords: humour, queer, señoras/ladies, folcloricas, crip, reception 


\section{Introducción}

¿A qué se debe el éxito mediático de Falete y Maikrux?, ¿porqué baten records de audiencia?, ¿qué placeres nos provoca verles en la televisión? Nuestro objetivo en este artículo es proporcionar algunas reflexiones que parten del estudio de dos personas que encarnan feminidades fuertes, presentes en la cultura popular vasca y española, y que fueron asignados al nacimiento como sujetos varones ${ }^{1}$. Éstos son Maikrux, un personaje de ficción interpretado por el actor Anjel Alkain en el programa televisivo de humor Kontuz atsuak!, de ETB1, y el cantante de copla y flamenco Falete, también conocido por su participación en programas de televisión como Splash! Famosos al agua, de Antena 3. La pregunta clave que ha guiado nuestra investigación es el planteamiento de por qué estas personas, que podríamos considerar como disidentes de género son, en principio, aceptados por las audiencias televisivas vasca y española contemporáneas sin que su «gender trouble» suponga necesariamente un cuestionamiento de las normas de género hegemónicas. Más que pensar que Maikrux o Falete funcionan socialmente a la manera de «freaks», permitiendo una vía de escape basada en el humor pero que desactiva las posibles implicaciones políticas, pensamos que tanto la cultura popular como el humor son dos lugares de posibilidad, que pueden llegar a transformarse en territorios abonados para las resistencias, basadas éstas fundamentalmente en el placer y la agencia que las audiencias pueden elaborar a partir de recepciones y/o identificaciones plurales y complejas.

Hemos organizado la discusión en cuatro epígrafes, donde abordamos el «estilo de la carne» o la performatividad de género en femenino que despliegan Maikrux y Falete, algunas notas sobre los protagonistas de este artículo, pasando a abordar la importancia del humor por herramienta para la agencia.

1. Este artículo es fruto de la mesa redonda «Feminidades impostadas» presentada por las autoras en el XV Congreso Internacional de Mujeres Filósofas, Alcalá de Henares (Madrid), 29 de junio de 2014. Este artículo se enmarca dentro de los siguientes proyectos de investigación I+D del Ministerio de Economía y Competitividad: «Colectivos en los márgenes: su exclusión por el derecho en tiempos de crisis (2013-2015)» (DER 2012-34320) $\mathrm{y}$ «La historia del arte en España: devenir, discursos y propuestas» (HAR 2012-32609). 
Seguidamente reflexionamos sobre algunas ideas culturales que han conformado los estereotipos de señoras y folclóricas, así como el legado cinematográfico donde vincular las experiencias que nos producen Maikrux y Falete, para terminar con las conclusiones, donde destacan algunas ideas principales: la necesidad de abrir el campo de estudio relativo de la cultura contemporánea, atendiendo a cierta parte de la cultura popular que promueve lógicas no binarias en relación al género, así como a la ausencia de este tipo de propuestas en nuestros contextos académicos, lo cual se traduce en la falta de participación en los debates internacionales.

\section{2. ¿Cómo estudiar «el estilo de la carne»?}

Antes de iniciar el análisis creemos importante introducir teóricamente algunos de nuestros planteamientos. Entendemos el cuerpo trascendiendo la clásica división occidental mente versus cuerpo, para hablar del continuum de la experiencia, algo ya presente en la filosofía de Baruch Spinoza y que ha sido retomado por las teorías del «giro afectivo $»^{2}$. Por feminidades entendemos maneras o estilos de habitar el cuerpo, que no necesariamente se delimitan a un sexo asignado en el nacimiento, una anatomía fija o una documentación oficial determinada. Fue Judith Butler en El género en disputa, quien interpretó el género como «estilos de la carne», «un "acto", por así decirlo, pero es al mismo tiempo intencional y performativo $»^{3}$. Estos actos se repiten constantemente, por ello para Butler, la construcción del género es una copia de una copia, una repetición sin original, incidiendo así en el carácter performativo, teatralizado o actuado, de toda identidad. Al fijarnos en Maikrux y Falete, en tanto que son sujetos mediáticos femeninos que encarnan ciertos «estilos de la carne», se podría entender que estamos introduciendo «una mirada sobre lo excepcional o lo minoritario»: nada más lejos de nuestra intención. Todas las personas producimos ciertas maneras de encarnar lo que entendemos como «género», «sexo» o «sexualidad», categorías que además, se presentan alineadas para producir una inscripción heterosexualizante de los sujetos. No sólo la feminidad «ha de ser propia» de las mujeres y la masculinidad «exclusiva» de los hombres, sino que han de ser concordantes con la asignación en el nacimiento, la socialización

2. Clough, Patricia (ed.). The Affective Turn: Theorizing the Social. Durham, Duke University Press, 2007. Para un excelente estado de la cuestión sobre este tema desde una perspectiva de género véase Medina DomeneCH, Rosa María. «Sentir la Historia. Propuestas para una agenda de investigación feminista en la historia de las emociones». Arenal. Revista de Historia de las Mujeres 19/1 (2012), pp. 161-199.

3. BUTLER, Judith. El género en disputa. El feminismo y la subversión de la identidad. Barcelona, Paidós, 2007, p. 271. 
y el reparto de roles sociales desiguales, dentro de un marco de relaciones heterosexistas. La elección de Falete y Maikrux como objeto de análisis tiene más que ver con el hecho de que ejemplifican cómo el humor puede ser una herramienta de agencia, tanto para las audiencias como para los protagonistas.

Por otra parte, tanto Maikrux como Falete se pueden entender como relativos al ámbito de la cultura popular, que es un concepto que entendemos siguiendo a Pierre Bourdieu ${ }^{4}$. En consecuencia, no nos detenemos tanto en las características del producto u objeto cultural, el propio Falete o de Maikrux, como en la forma de recibirlos. La recepción en la cultura popular se caracteriza por ser emocional, expresiva y corporal -por supuesto, feminizada-, mientras que en la cultura de élite es distanciada, intelectualizada y con desapego. En la academia del Estado español, la cultura popular se ha tendido a interpretar desde una perspectiva propia del marxismo clásico, que fue central en la oposición antifranquista, especialmente a través de las teorías de las industrias culturales desarrolladas por Theodor Adorno y Max Horkheimer ${ }^{5}$, en la cuales primaba el entendimiento del adoctrinamiento ideológico unidireccional, de arriba abajo, sobre todo en regímenes totalitarios.

Frente a ello, Jo Labanyi ${ }^{6}$ propone seguir el pensamiento gramsciano de hegemonía y contrahegemonía para el análisis cultural: frente a la unidireccionalidad, Antonio Gramsci entiende la cultura como un lugar de lucha entre una pluralidad de fuerzas, de grupos sociales entre sí heterogéneos y fragmentados, dominantes y subalternos, que pugnan por la hegemonía a través de la constante negociación y que se relacionan mediante el doble proceso de complicidad y resistencia. Incluso cuando las clases tradicionales son hegemónicas, «la necesidad de negociar el consentimiento mediante prácticas culturales les proporciona un espacio a las clases subalternas» ${ }^{7}$. Por tanto, el subalterno no es un sujeto pasivo y absolutamente manipulado culturalmente, sino, que dentro de sus circunstancias, es un sujeto con agencia, entendida como capacidad de acción y actuación. Estas ideas conectan directamente con el pensamiento de Walter Benjamin o Mikhail Bakthin, así como con las teorías poscoloniales, pues las identidades culturales se piensan como viajes de ida y vuelta, en los cuales los subalternos pueden, en un proceso de mímica y reciclado, apropiarse de aspectos

4. Bordieu, Pierre. La distinción. Criterio y bases sociales del gusto. Madrid, Taurus, 1998.

5. Adorno, Theodor W. y HORKHEIMER, Max: «La industria cultural. Ilustración como engaño de masas», en Dialéctica de la ilustración, Madrid, vol. 3, Akal, 2007, pp. 133-182.

6. LabanyI, Jo. «Gramsci and the Spanish Cultural Studies». Paragraph 22/1 (1999), pp. 95-113.

7. LABANYI, Jo. «Música, populismo y hegemonía en el cine del primer franquismo», en Luis Fernández Colorado y Pilar Couto Cantero (eds.): Cuadernos de la Academia. La herida de las sombras. El cine español de los años 40, núm. 9, 2001, p. 84. 
de la cultura dominante para sus propósitos tácticos. En consecuencia, el marco teórico gramsciano ayuda a entender la recepción de los productos culturales desde el punto de vista de la posible apropiación y resignificación por parte de los usuarios o espectadores según sus intereses, y no sólo desde la perspectiva del adoctrinamiento o manipulación propagandística de unos mensajes determinados y emitidos por parte del poder político, que son asumidos pasivamente.

Este tipo de aproximaciones son mucho más flexibles y permiten recuperar las experiencias relacionadas con la producción cultural desde la complejidad de la vida cotidiana, más allá de la consideración de los programas, las películas o los personajes como textos culturales, a través de los que los distintos poderes tratan de diseminar sus mensajes mediante mecanismos de adoctrinamiento y propaganda. Nos permite recuperar los placeres y emociones que las audiencias sienten cuando escuchan cantar a Falete o perciben la irreverencia de Maikrux al entrevistar a personajes famosos, pero especialmente nos remite a la capacidad para reelaborar y resignificar estas experiencias según sus intereses y su situación vital. También, nos ayuda a entender que la cultura proporciona experiencias multisensoriales (ver, escuchar, tocar, sentir ganas de reírse, imaginar, por ejemplo) en lugar de fijarnos únicamente en textos, imágenes o representaciones, que están más centradas en el ámbito de la mirada, entendida ésta desde el posicionamiento del control y el poder.

\section{Algunas notas sobre Maikrux y Falete}

A continuación introducimos brevemente a los dos protagonistas que abordamos en este artículo, Maikrux y Falete. Maikrux es el personaje cómico televisivo encarnado e interpretado por el actor Anjel Alkain, en el programa de humor Kontuz atsuak! (Cuidado con las viejas) de la televisión autonómica vasca ETB1. Anjel Alkain como Maikrux junto con Iñake Irastorza como Maikarmen, son dos señoras sin marido y jubiladas que protagonizaron «Gure atsuak» (nuestras viejas), en un sketch semanal dentro el programa de humor Wazemank (jvamonxs!), emitido entre 2005 y 2007. En el curso 2012/2013 esta pareja cómica volvió a la pantalla en un programa propio, el citado Kontuz atsuak!, con la intención de hacer un «Salvados con humor» ${ }^{8}$, y que en palabras de Maikrux: «Humor e información, esa es la clave de nuestro éxito» ${ }^{9}$. La palabra «atso(a)» o su variante dialectal «atsu(a)» significa en su primera acepción

8. URKIZU, Urtzi. «Finlandia' saioa desagertu ostean, 'Kontuz atsuak!' helduko da ETBlera». Berria (10-07-2012), p. 28.

9. MitXelEnA, Eñaut. «Herriak behar gaitu, bestela ez gintuzten hainbeste maiteko». Aizu! 376 (Abril de 2013), pp. 30-33. 
'mujer anciana' o 'vieja', en la segunda, 'parienta' o 'contraria', y en la tercera, 'tía' o 'chorba'. En varios dialectos de la lengua vasca, además, tiene cierta connotación negativa, por lo que resulta una palabra con una fuerte carga semántica la elegida para dar título y cuerpo al programa y a los personajes en cuestión.

Según el actor Anjel Alkain: «Siempre he sido un poco transgresor con el mundo del euskera, con el mundo de los bertsolaris y con todo aquello que sea cercano al mundo euskaldun (...) Vamos a reírnos un poco de lo que conocemos» ${ }^{10}$. Al describir a estas señoras, dice que: «Maikarmen y Maikrux pueden ser nuestras tías, vecinas o madres; son dos mujeres ocurrentes y peculiares, dos solteronas que han perdido la vergüenza al envejecer» ${ }^{11}$. Las mismas Maikrux y Maikarmen señalan que «el pueblo nos quiere» ${ }^{12}$. Y al responder Alkain cómo se siente al interpretar a una mujer se queja del tiempo necesario para maquillarse, la dificultad de encontrar zapatos de su tamaño y del dinero que ha gastado en cuchillas de afeitar ${ }^{13}$, aunque al mismo tiempo afirma que «a los hombres nos gusta hacer de mujer» ${ }^{14}$.

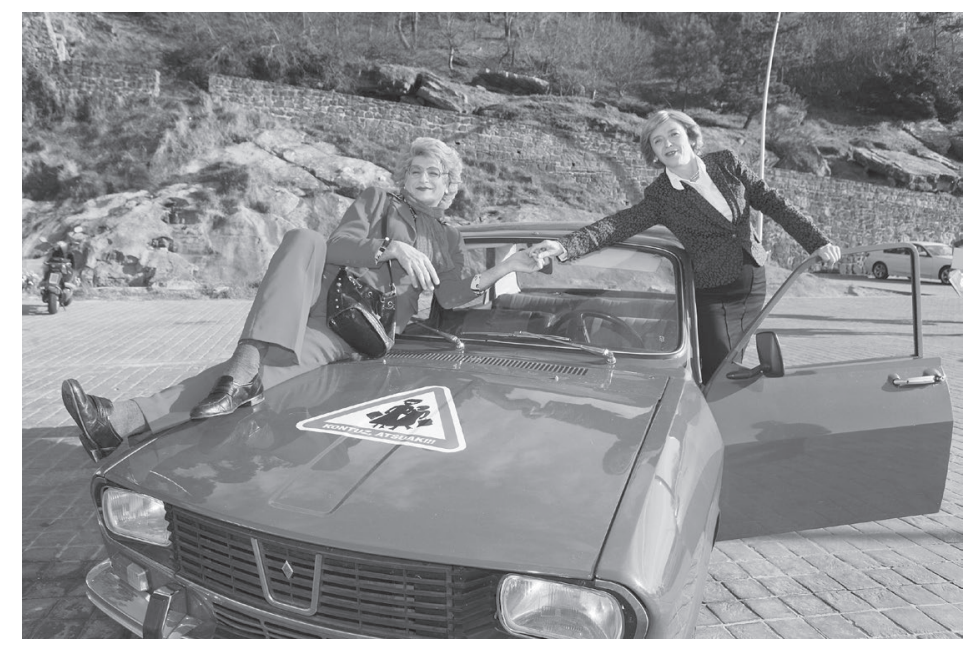

Foto 1. Foto de Maikrux y Maikarmen, «nuestras viejas». Revista Aizu! 376 (Abril de 2013), pp. 32. Fotógrafo Gorka Estrada.

10. LAKUNZA, Rosana. «Hay programas donde no hay intención de innovar: son demasiado cuadrados». Deia (19/09/2011), p. 66.

11. ETXEBERRIA, Idoia. «Earki gatxink!». Berria (27-01-2006), pp. 4 y 5.

12. MitXelena, Eñaut. Op. cit.

13. LASA, Iñaki. «Bizitzak ba al du zentzurik barrerik egin gabe ba?». Berria (06-01-2013), p. 36.

14. LoPEZ, Elisa. «¿Hacer de mujer? Pues sí, a los hombres nos gusta». Diario Vasco (0910-2011), p. 82 .

Feminismo/s 24, diciembre 2014, pp. 143-162 
Maikrux es una abuela vasca tradicional, que cuida mucho su imagen para mantener su estatus social respetable, y a la vez, participa activamente en la vida social entrevistando a personajes conocidos en la sociedad vasca, actuando como una solterona curiosa y desvergonzada, un sujeto heterosexual deseante, inteligente, está empoderada, es aventurera y tiene la complicidad de su compañera, Maikarmen: «Nosotras sí que somos unas pedazo de chicas! La chispa de la jubilación, las más frescas del frontón. Es mucho mejor dos de 60 que 6 de 20, ¡vas a comparar! $»^{15}$. El actor Anjel Alkain ha interpretado en varias ocasiones a personajes femeninos como cómico televisivo, pero Maikrux ha sido el que más recorrido y éxito ha tenido. En la cultura en lengua vasca durante todo el siglo XX han existido posiciones de género y sexualidad que se pueden «in between», borrosas o trans si se quiere, mayoritariamente éstas han contribuido a regular y normalizar las normas sociales de género ${ }^{16}$; es en el cambio de siglo cuando se ha recurrido asiduamente a personajes femeninos encarnados por cis-hombres ${ }^{17}$ con los que se ha abierto la posibilidad de transgresión.

Si nos fijamos ahora en Falete, o Rafael Ojeda Rojas como consta en su documentación oficial, a pesar de sus cinco discos de copla y flamenco ${ }^{18}$ y ser hijo de uno de los Cantores de Hispalis, su popularidad está más asociada a su participación en programas de televisión. Sobre todo es conocido por los chistes recurrentes que se hacen sobre él, su aspecto y el relato de su vida sentimental en los medios de comunicación. Falete abría su monólogo en el programa Club de la Comedia, de La Sexta, el pasado 18 de julio de 2014, diciendo: «Soy cantante de flamenco y copla. Probablemente en estos últimos años sea el personaje sobre el que más chistes y parodias se hayan hecho». Hablaba abiertamente de este tratamiento humorístico, que nos remite al proceso de «espectacularización» que vive, por el cual los medios de comunicación ofrecen representaciones y contenidos sobre Falete que tienen por objeto producir entretenimiento a costa de subrayar aquellos

15. <https://www.youtube.com/watch?v=QqT3oCY4Opg> (consultado el 8-09-2014).

16. ÁlvAREZ-URIA, Amaia. «Euskal trans literarioak. Trans ezkutuen kartografia bat XX. mendeko euskal literaturan», en Isa Castillo y Iratxe Retolaza (eds.): Genero ariketak. Feminismoaren subjektuak, San Sebastián, EDO!, 2013, p. 140.

17. El prefijo «cis» significa «junto a», «el mismo que». Recientemente se ha empezado a usar este prefijo para denominar a las personas que no son trans (prefijo que significa enfrente de, ir más allá), son aquellas personas para las cuales coinciden la identidad de género, su expresión de género y el sexo asignado en el nacimiento con las expectativas tradicionales sobre cómo han de ser los hombres y las mujeres.

18. Su discografía se compone de los siguientes álbumes: Amar duele (2004), Puta mentira (2006), Coplas que nos han matao (2007), ¿Quién te crees tú? (2008) y Sin censura (2012) 
aspectos más controvertidos de su vida. Las cuestiones más cotidianas de su vida se convierten en parte del menú de la parrilla televisiva, son productos mediáticos sobre cuestiones que para otros son incluso tediosas, como aprender a conducir por ejemplo (que fue objeto del programa Famosos al $\left.V_{\text {Volante }}^{19}\right)$. No se puede decir que Falete no sea consciente de tal proceso: «Ustedes no se pueden imaginar lo difícil que es ser Falete. Sí, Falete, el de los chistes de Falete», como afirmaba en el Club de la Comedia, una espectacularización que le reporta popularidad y difusión, ya que «yo no duermo, me voy directamente a publicidad», ya que «hay artistas a los que resulta muy difícil salir en la tele, y para mí, lo más difícil es no salir» ${ }^{20}$. Estas y otras declaraciones en relación a su persona nos muestran un Falete que no es una «victima de los medios», sino más bien, alguien que utiliza el humor como forma resistencia desde un cuerpo disidente, tanto por su feminidad masculina como por su discapacidad (en sus palabras: «tengo un 'brazo de trapo' por culpa de una parálisis braquial ${ }^{21}$ ). Su sexualidad está siempre presente en las entrevistas, donde se evidencia la necesidad de los medios de fijar su identidad de género, frente a lo cual Falete responde con ciertos recursos que tienen que ver con la resistencia, como es la hipervisibilidad, como se ve en esta entrevista:

Así que un día que mi madre estaba haciendo gazpacho en la cocina con el cuchillo en la mano, tendría yo 13 años, le dije: «Mamá, me gustan los hombres», y ella me dijo, con el cuchillo apuntándome: «¿Qué hago, te mato?», pero desde el principio me apoyó, y me dijo que tenía que respetar a todo el mundo para ser respetado(...) Así que tuve la infancia, y sobre todo la adolescencia, más feliz del mundo. Un poquito cabra loca, eso sí, porque hacía cosas que no tenían pies ni cabeza, pero con el tiempo fui viendo que podía vivir de esto, de cantar, y que la gente me aceptaba sin tener que aparentar, sin esconderme, ni pensar que soy más de lo que soy, un artista. El mariquita gracioso, no; iyo soy artista! Y maricón después. Maricón suena a bóveda. Gay suena muy light. Y yo soy muy intenso para todo ${ }^{22}$.

19. Falete participó en el programa Famosos al Volante, de La Sexta, el 4 de mayo de 2012.

20. Falete en el programa Club de la Comedia, de La Sexta, emitido el 18 de julio de 2014.

21. Splash! Famosos al agua, programa de Antena 3, emitido el 4 de marzo de 2012.

22. Mora, Miguel. «Universo Falete». El País (13-03-1999). <http://elpais.com/diario/2005/03/13/eps/1110698813_850215.html > (consultado el 13-09-2014).

Feminismo/s 24, diciembre 2014, pp. 143-162 


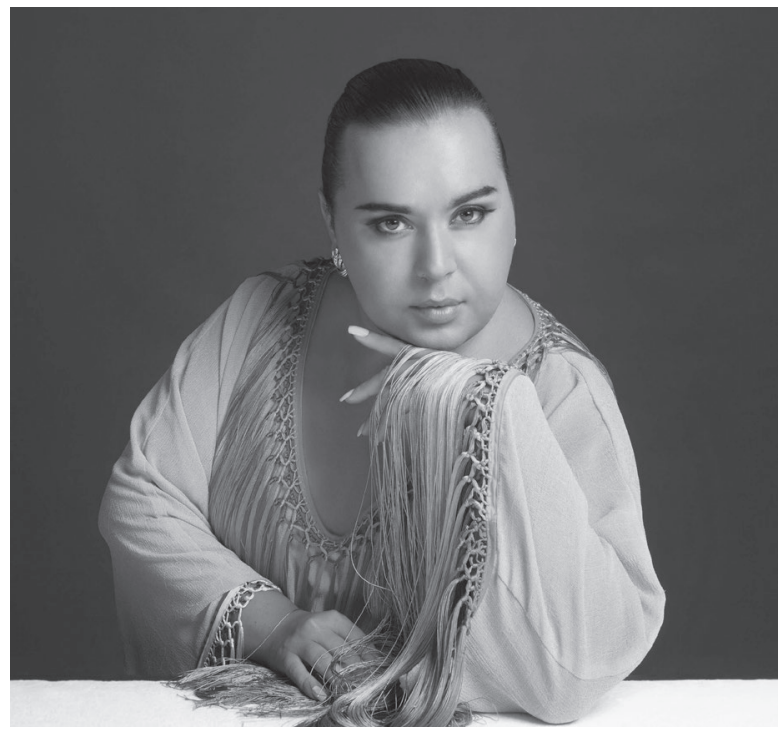

Foto 2. Foto de Falete en su web oficial. Ver http://www.faleteoficial.com

No sólo la reapropiación queer del insulto y la hipervisibilidad evitan la posibilidad de ser atacado como homosexual (ya nadie le puede llamar maricón, ya que él mismo lo hace), también desplazan el humor y la injuria hacia su aspecto, donde los medios producen chistes y hablan de su ropa, su feminidad, su peso, entre otras cuestiones. El propio Falete participa de este desplazamiento, señalando que su chiste favorito es éste: «Tienes más peligro que Falete en un buffet libre». Además, los medios dan visibilidad a comentarios que le señalan como sujeto no deseable, como éste: «Falete usa brujería para atraer a los hombres, sin importar si son gays o heteros», en palabras de su ex Isaac en un programa de televisión de $2009^{23}$, desdeñando que es protagonista de éxito de todos los programas en los que participa. Por otra parte, además de la hipervisibilidad, Falete también recurre a singularizar su forma de encarnar el «estilo de la carne», saliéndose de la lógica binaria, afirmando: «No soy ni hombre ni mujer, soy Falete», o «Lo que yo llevo no es ni de hombre ni de mujer; es de Falete», haciendo referencia a la ropa que diseña para sí mismo. Falete está atravesado por procesos de hipervisibilidad, que evidencian su feminidad encarnada en un cuerpo de cis-varón del que por otra parte se

23. VIÑAU ENA, Nacho. «Supuestamente, Falete embruja a los heteros y los convierte en gays». <http://www.ambienteg.com/curiosidades/supuestamente-falete-embruja-a-losheteros-y-los-concierte-en-gays/> publicado el 11-08-2009 (consultado el 12-09-2014). 
hacen chistes sobre su sobrepeso, y al mismo tiempo, se produce cierta invisibilidad de su diversidad funcional, que sólo es conocida para el gran público tras participar en el programa de televisión Splash! ${ }^{24}$, como ya apuntábamos.

\section{Humor y «estilo de la carne» en la televisión}

La función crítica del humor posibilita, dentro de los límites que le impone un medio comercial como la televisión, representar posturas conservadoras que reafirman el status quo al tiempo que crear fisuras en el mismo. Asimismo, el travestismo y las rupturas con los límites del género tradicional, como las que encarnan Maikrux y Falete, exponen y desafían las identidades estables, poniendo en crisis las categorías férreas de género (Garber 1997)25. Maikrux encarna o puede encarnar, las dos caras mencionadas: la de un personaje familiar y cercano que reproduce el discurso hegemónico de la cultura vasca tradicional y la que se muestra como un cis-hombre travestido ${ }^{26}$, a quien le gusta «vestirse de mujer» y "provocar al personal». Por otra parte, Falete muestra una feminidad singular, una repetición sin original, que juega con las nociones normativas de señora y flamenca, al tiempo que se mofa de tal señalamiento. Contaba jocosamente que alguien le había dicho: «¿Tiene hora, señora?» A lo que respondía: ¿Señora a mí? Con lo joven que yo soy» ${ }^{27}$. El humor que despliegan Maikrux y Falete atenúan la posible discriminación que pudieran recibir, un fenómeno que invita a la necesidad de un análisis crítico de lo cómico ${ }^{28}$. Maikrux y Falete encarnan y provocan la risa y, al mismo tiempo, traspasan lo prohibido, lo censurado, lo tabú; el humor es un espacio privilegiado donde se produce el imaginario cultural $^{29}$. No hay que olvidar que la risa es un hecho social construido en cada cultura, según parámetros de género, clase, raza, edad u otras diferencias interseccionales cruciales. El humor y la risa aluden a sistemas simbólicos con los que cada cultura imagina su existencia, donde el humor sirve para la afirmación y para la subversión

24. SPLASH! FAMOSOS AL AGUA, Ibíd.

25. GARBER, Marjorie. Vested interests. Cross-Dressing and cultural anxiety. New York, Routledge, 1997.

26. Ver nota 16.

27. EL CLUB DE LA COMEDIA, Ibíd.

28. Horlacher, Stefan. «A short introduction to theories of humour, the comic and laughter» en Gaby Pailer; Andreas Böhn; Stefan Horlacher y Ulrich Scheck (eds.): Gender and laughter. Comic affirmation and subversionin traditional and modern media. Amsterdam, Rodopi, 2009.

29. ibídem.

Feminismo/s 24, diciembre 2014, pp. 143-162 
de las identidades, al usar los roles, las relaciones y las jerarquías de género ${ }^{30}$. También es cierto que en las interacciones sociales, la risa a menudo funciona como un instrumento de poder ${ }^{31}$; si alguien amenaza con transgredir las normas, la sociedad usará la risa para su resocialización y reintegración ${ }^{32}$. La risa también opera como un indicador de las tensiones y contradicciones en una sociedad y permite analizar críticamente situaciones y mecanismos sociales, tales como los límites de la normalidad, del cuerpo o el binarismo de género, por los que son aludidos Falete y Maikrux.

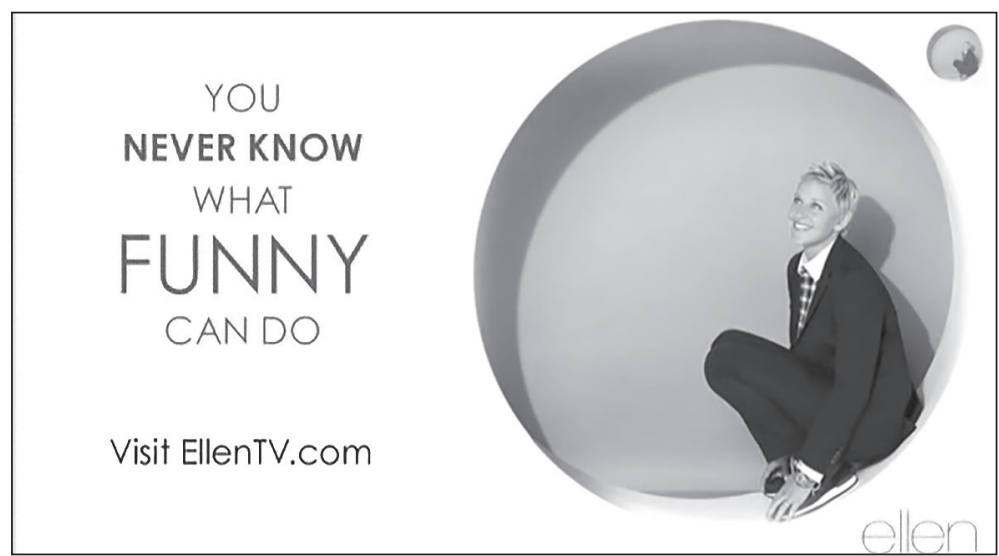

Foto 3. Foto promocional del «Show de Ellen», un programa norteamericano actual de entrevistas, protagonizado por la comediante Ellen Degeneres, famosa por haber salido del armario como lesbiana y que goza de gran popularidad. El eslógan que utiliza su programa es «You never know what funny can do» (No sabes lo que se puede conseguir siendo graciosa).

El humor libera del miedo y la censura, ataca a la ideología oficial y pone en valor la cultura popular, tal y como argumentaba Bakhtin en $1968^{33}$ y puede poner en peligro el orden establecido, al ofrecer al público el control de la situación y romper así las jerarquías y la unidireccionalidad. Lo que va en

30. BÖHN, Andreas. «Subversions of gender identities through laughter and the comic? en Gaby Pailer; Andreas Böhn; Stefan Horlacher y Ulrich Scheck (eds.): Gender and laughter. Comic affirmation and subversionin traditional and modern media. Amsterdam, Rodopi, 2009.

31. PAILER, Gaby; BÖHn, Andreas; HORLACHER, Stefan y SCHECK, Ulrich (eds.). Gender and laughter. Comic affirmation and subversionin traditional and modern media. Amsterdam, Rodopi, 2009.

32. Ibíd.

33. Ibíd.

Feminismo/s 24, diciembre 2014, pp. 143-162 
contra del comportamiento socialmente aceptado nos produce risa, como una señora hablando de «temas picantes» o Falete en bañador de volantes saltando a una piscina; esta risa puede ser un mecanismo de defensa frente a lo que tenemos como «normal» o tomamos por costumbre ${ }^{34}$, o bien, puede ser una muestra de complicidad. En este sentido Maikrux, al trasgredir el comportamiento modoso y asexual que se atribuye a las señoras vascas, está casi más cerca del estereotipo del travesti. El travesti juega intencionalmente con los roles, es el ejemplo clásico de la performatividad de género y de contrapoder o contrahegemonía, encarnando las resistencias frente al discurso hegemónico, al tiempo que puede reproducir tentativa e imperfectamente tal discurso. Marjorie Garber muestra el asombro que ha despertado el travesti a lo largo de la historia así como el poder que tiene el transgénero ${ }^{35}$, donde lo trans y el cross-dressing cuestionan directamente la categoría de género, la delimitación de lo femenino y lo masculino. Y por ende, desafían el pensamiento binarista, provocando una "crisis de las categorías» y desestabilizando las simetrías, las complementariedades y el control sobre lo conocido:

One of the most consistent and effective functions of the transvestite in culture is to indicate the place of what I call 'category crisis' (...) the extraordinary power of transvestism to disrupt, expose and challenge, putting in question the very notion of the 'original' and of stable identity (...) 'category crisis': a failure of definitional distinction, a borderline that becomes permeable, that permits of border crossings from one (apparently distinct) category to another: black/with, Jew/Christian, noble/bourgeois, master/servant, master/ slave. The binarism male/female, one apparent ground of distinction (...) is itself put in question or under erasure in transvestism, and a transvestite figure, or a transvestite mode, will always function as a sign of overdetermination -a mechanism of displacement from one blurred boundary to another ${ }^{36}$.

El travestismo se ha usado en el humor en periodos históricos en los que la forma y el contenido se correspondían estrictamente, tanto en el arte como en la vida social, donde el detonante cómico se produce por la incongruencia entre lo esperado/conocido. El juego de sorpresas y revelaciones es inherente en el cross-dressing y en el cambio de roles de género, pero ¿nos reímos con o de Maikrux y Falete? Reírse de alguien aludiría a la denigración, una sanción por romper una norma mientras que reírse con supone una identificación con el sujeto transgresor. Por eso, planteamos ¿con quién y de quién nos reímos

34. ÁLVAREZ-LÓPEZ, Sonia. «Functions and strategies of male humour in cross-gender interactions». Estudios de Sociolingüistica: Linguas, Sociedades e Culturas 3-4:2-1 (2002), pp. 173-205.

35. GARBER, Marjorie, op cit.

36. GARBER, Marjorie. Op. cit. p. 16.

Feminismo/s 24, diciembre 2014, pp. 143-162 
en los chistes de Falete («Tengo más presión que los tacones de Falete»)? ¿al deseo de quién apela Maikrux cuando dice del revisor del tren «iQué guapo! Está como para sentir picores, eh? $»^{37}$. Podría parecer a primera vista que son comentarios que refuerzan la «gordofobia» o la heterosexualidad obligatoria, pero aluden a cierto uso de un «mundo al revés» (nadie es lo que parecía a priori), que puede incitar a plantear la inestabilidad de identidades y relaciones.

Por otra parte, la televisión y los medios de comunicación donde aparecen Maikrux y Falete son espacios socioculturales de transmisión y producción de información, donde se producen representaciones y construyen valores, formas de vida, creencias, roles y significados. La TV influye en las subjetividades contemporáneas, al construir y transmitir discursos para ser, sentir y pensar, donde los sujetos tienen identificaciones y fantasías más fluidas o inesperadas de lo que se ha pensado a priori desde el feminismo. En consecuencia, ¿cómo se ha de valorar desde un punto de vista feminista y queer el éxito de audiencia y popularidad de Maikrux y Falete? Recordemos que Maikrux ha sido parte de dos programas populares y exitosos de la ETBl y que el salto de Falete en Splash! tuvo una cuota de pantalla del 41,4\% con 5,4 millones de espectadores. Si bien una de las tácticas típicas para socavar a las mujeres es usar la confusión, el humor y la ridiculización de las representaciones comunes y tópicas sobre sus roles ${ }^{38}$, en el caso de Maikrux o Falete más que generar injurias y probablemente sin que sea una apuesta consciente, los medios están evidenciando la falta de «naturalidad» que tiene la feminidad y así su carácter performativo. Asimismo, la edad también influye en la (re)clasificación en las normas de género, ya que las señoras «a cierta edad» tienen mayor libertad para dar rienda suelta al humor ${ }^{39}$, lo que facilita que Maikrux lo use en sus interacciones, invierta las relaciones de poder (re)presentando una identidad ambigua y «diferente», aunque esta trasgresión no tenga consecuencias duraderas ni cambie necesariamente las relaciones de poder ${ }^{40}$.

El estudio del humor y la agencia a través de Maikrux y Falete puede ayudar a descubrir cómo se forman las «identidades en interacción», explicitando el orden social, donde las construcciones discursivas de lo que es la

37. <https://www.youtube.com/watch? v=i2W4YR3AmNc> (consultado el 8-09-2014)

38. Valladares, Catia Elisa. Análisis del discurso de género en los programas televisivos de producción nacional dirigidos a mujeres. El Salvador, Tesis Doctoral, 2012, pp. 49-50.

39. KotTHOFF, Helga. «Gender and humor: the state of the art». Journal of Pragmatics 38 (2006), pp. 4-25.

40. CRAWFORD, Mary. «Gender and humor in social context». Journal of Pragmatics 35 (2003), pp. 1413-1430. 
masculinidad y la feminidad deben de estar situadas en su contexto cultural. En este sentido, nos preguntamos por la recepción de quienes ven la televisión en euskera y siguen Kontuz atsuak! o ven programas en los que se habla o aparece Falete. La interpretación que hacen las audiencias así como el placer que pueden sentir en las experiencias multisensoriales que producen Falete y Maikrux plantean que, al igual que como ocurre con las comedias clásicas de cross-dressing como Con faldas y a lo loco (Billy Wilder, 1959), existen posibilidades de identificación y agencia que rompen con la noción de adoctrinamiento o de identificación con un sujeto idéntico, donde ¡Nadie es perfecto!

\section{Señoras y folclóricas}

En este epígrafe abordamos las nociones de «señoras» y «folclóricas» en la medida que se han entendido habitualmente como lugares totalizantes y adoctrinadores, invisibilizando su potencial transformador y de empoderamiento. Centrándonos en el imaginario desplegado en el Estado español sobre la cultura popular folklórica y en relación al pasado reciente, Manuel Vázquez Montalbán reivindicó en Crónica sentimental de España ${ }^{41}$ la cultura popular relativa a la dictadura franquista. No en vano fue un temprano lector de Gramsci que entendió esta «subcultura» como un vehículo privilegiado de una memoria proletaria, y, concretamente de las mujeres, quienes en muchos casos fueron las portadoras de la memoria de los vencidos; tanto en sus análisis culturales como en su producción poética ${ }^{42}$, se detiene en los seriales radiofónicos, en las coplas o las canciones populares, además de en el cine, entendido como espectáculo y experiencia emocional y cotidiana. Estos medios fueron, para Vázquez Montalbán, capaces de generar una alternativa a la ideología oficial, conformando rituales colectivos, muchas veces femeninos, a partir de resignificaciones emocionales subalternas, alternativas a la ideología oficial.

Esta memoria de los parias, que se puede entender desde «la conciencia de responsabilidad memorialística» ${ }^{43}$, es la que retoma el artista José Pérez Ocaña en sus performances, cuando pasea en 1977 del brazo de Nazario por la Rambla de Barcelona al ritmo del pasodoble Francisco Alegre escrito por

41. VÁzQuez Montalbán, Manuel. Crónica sentimental de España. Barcelona, Bruguera, 1980.

42. VÁzQuez Montalbán, Manuel. Una educación sentimental; Praga. Madrid, Cátedra, 2001.

43. VeRnON, Katheen M.: «Memoria histórica y cultura popular: Vázquez Montalbán y la resistencia española», en José F. Colmeiro (coord.): Manuel Vázquez Montalbán: el compromiso con la memoria, Woodbridge, Tamesis, p. 24. 
Quintero, León y Quiroga en 1945 e interpretado por Juanita Reina ${ }^{44}$. Se está reapropiando esa cultura popular o traficando, como dice Beatriz Preciado ${ }^{45}$, con lo cursi, lo religioso, lo folklórico, lo andaluz o lo ultramarica; también se hace eco del lenguaje de los marginados. Por ello, a diferencia del planteamiento de esta filósofa, no entendemos que la cultura popular fue «cautiva» de la ideología franquista nacional-católica, sino que como ya hemos comentado, pensamos que ésta fue generalmente un espacio de posibilidad y de agencia, precisamente porque fue capaz de procurar esa recepción emocional donde las personas pudieron construir subjetividades ciertamente intactas, donde se expresaron o disfrutaron creando esos espacios de significación, físicos o virtuales, propios. Eso es lo que las mujeres vencidas, Vázquez Montalbán, Ocaña o Falete recuerdan, componiendo una particular y poderosa genealogía.

Seguramente junto con las folklóricas, otro de los tropos de significación de la cultura popular travesti o "gender queer» sea el de las «señoras». En ambos casos se conforman feminidades fuertes y empoderadas. La figura de la «señora» se suele relacionar con lo respetable, lo inofensivo, lo recatado, entre lo asexuado y lo hipersexualizado, pues un determinado estatus de edad y carácter le otorga una mayor permisibilidad social. Sin duda, las «señoras» forman una parte muy significativa de la cultura popular que alude a la feminidad travesti, lo que ha proporcionado a las audiencias cinematográficas y televisivas una serie de referentes previos y unas estrategias concretas para su entendimiento. En relación a los mismos, el humor suele ser la estrategia que procura su normalización, pero al tiempo donde reside su capacidad de resistencia, pensemos en Mrs. Doubtfire (Chris Columbus, 1993), interpretada por Robin Williams.

Pongamos en conversación los finales de las siguientes películas: Con faldas y a lo loco (Billy Wilder, 1959), Mi querida señorita (Jaime de Armiñan, 1971) y Tootsie (Sydney Pollack, 1982). En los tres casos, los sujetos «in between» han despertado deseo en otros personajes de la película, y por extensión también lo han hecho en parte de la audiencia. Es especialmente interesante el twist final de las tres películas, pues con sugerencias que se elaboran a través del humor, la idea principal que subyace es que es en el género borroso donde reside el poder de atracción de los tres personajes protagonistas. En

44. Véase la película Ocaña, retrato intermitente (Ventura Pons, 1978).

45. PRECIADO, Beatriz: «La Ocaña que merecemos: Campceptualismo, subalternidad y políticas performativas», en Ocaña 1973-1983: acciones, actuaciones, activismo, Barcelona/ Vitoria-Gasteiz, La Virreina. Centre de la Imatge/ Centro Cultural Montehermoso Kulturunea, 2011, p. 96. 
este sentido, Falete y Maikrux tienen una genealogía en este cine de comedia, donde el éxito se enmarca en su capacidad para apelar a todo tipo de audiencias. Este lugar borroso al tiempo que hipervisible permite una identificación muy plural de las audiencias, que disfrutan de la trasgresión de forma vicaria, pudiendo señalar a Falete y a Maikrux como dos «feminidades fuertes», similar a las «femmes of power» que describe Ulrika $\mathrm{Dahl}^{46} \mathrm{O}$ «las perras» de Itziar $\mathrm{Ziga}^{47}$. También, necesariamente alude al propio gusto cultural occidental por el travestismo de los hombres que se visten de mujeres, así como a la posibilidad de entender cierta suspensión de aquellas normas que rigen nuestras vidas, si se quiere de cierto «mundo al revés», donde algunos sujetos pueden jugar con la rigidez de las normas sociales, lo cual genera una importante fascinación por parte del público.

\section{Conclusiones}

En este artículo, donde elegimos abordar a Maikrux y Falete como exponentes de sujetos trasgresores que encarnan feminidades fuertes en los medios de comunicación español y vasco, hemos apuntado brevemente a una área de investigación que si bien es notoria en los contextos anglosajones, adolece de falta de suficiente atención por los estudios feministas y queer locales. Nos referimos tanto al estudio de lo vernáculo, como también de aquello que está denostado por frívolo, efímero o popular; es un trabajo que requiere de una voluntad por valorar lo cotidiano y aquello que se puede entender como relativo a la «sociología ordinaria» ${ }^{48}$, perteneciente a la cultura popular o los estudios específicos sobre la televisión y el humor. En este sentido, cabe señalar que abundan estudios anglosajones sobre figuras mediáticas como RuPaul ${ }^{49} \mathrm{O}$ sobre las series de televisión como L-word ${ }^{50}$ o Queer as Folk ${ }^{51}$; por el contrario, el vacío es total si abordamos la presencia de Falete o Maikrux u otras figuras

46. VolCANO, Del LaGrace y DAHL, Ulrika. Femmes of power. Exploding Queer Femininities. London, Serpent's Tail, 2008.

47. ZIGA, Itziar. Devenir perra. Barcelona, Melusina, 2009.

48. Ver por ejemplo el trabajo que desarrollan Amparo Lasén y Elena Casado sobre la sociología ordinaria en <http://sociologiaordinaria.com> (consultado el 12-09-2014).

49. Drag queen, modelo y compositor norteamericana que ha participado en numerosos programas y películas de éxito desde los año 90.

50. Ha sido la primera serie norteamericana de éxito que aborda el lesbianismo, que fue dirigida por Ilene Chaiken y emitida entre 2004-2008 por la cadena Showtime. En el Estado español se tradujo por «L» (de lesbiana) y fue emitida por Canal+.

51. Esta serie británica que aborda la vida de un grupo de gays de clase media fue volvió a filmar en Estados Unidos y Canadá, siendo producida por Showtime y Temple St. Productions, alcanzando gran éxito en su emisión entre 2000 y 2005. En el Estado español se emitió entre 2006 y 2007 en Cuatro.

Feminismo/s 24, diciembre 2014, pp. 143-162 
transgresoras locales. A través de nuestra reflexión también hemos apuntado hacia la importancia de la recepción, a la necesidad de cierto giro gramsciano presente en los estudios culturales para entender que no siempre la cultura popular provoca procesos totalizadores y adoctrinantes, sino que como apunta Labanyi, las audiencias negocian según sus propios intereses gracias a su capacidad de apropiación, subjetiva y generalmente empoderadora.

Maikrux y Falete utilizan el humor para poder ser, participando en la construcción de su presencia mediática, al tiempo que juegan con los límites de lo real y la ficción, así como de lo público y lo privado, poniendo en cuestión estas clasificaciones binarias. Maikrux y Falete encarnan cierta «gestión» de lo normativo y lo transgresor, donde no son necesariamente víctimas ni sujetos pasivos, lo cual dificulta su fácil adscripción a una mirada binaria sobre si refuerzan o trasgreden los binarismos de género o sobre la sexualidad. El estudio de su lugar como sujetos que están en la encrucijada de lo queer, las señoras, lo folklórico, la cultura vasca y lo crip $^{52}$ requiere de marcos de análisis radicales, propios de los estudios decoloniales, queer, postfeministas, críticos con diversidad funcional y el antirracismo. En este sentido, nuestro trabajo sobre Falete y Maikrux pretende emparentarse con un ámbito internacional de estudio que valora el aporte de estas figuras a la configuración del imaginario social y cultural local y global, subrayando su importancia como parte del legado y la genealogía de los subalternos. El estudio de Falete y Maikrux requiere marcos de interpretación que devengan en análisis complejos, excediendo la lógica binaria de si transgreden o subrayan las normas más convencionales sobre los géneros, si son o no son queers, si los medios de comunicación los utilizan de forma espectacular para vender «risas» o, si por el contrario, su sentido del humor es una arma arrojadiza que nos enfrenta con nuestras contradicciones, evidenciando lo artificial de nuestras normas sociales. «Nadie es perfecto», ni siquiera Falete y Maikrux.

52. Literalmente «crip» es una expresión coloquial ofensiva que se usa para designar a una persona que tiene una discapacidad y no puede servirse de algunos de sus miembros. También es un movimiento social crítico de las personas con diversidad funcional que luchan contra la noción de normalidad, revelándose contra la obligatoriedad de tener un cuerpo perfecto según los cánones vigentes, un estándar sobre la inteligencia, sobre los comportamientos sexuales, sociales o culturales, entre otros. Véase PLATERO, Raquel (Lucas) y Rosón María. «De 'la parada de los monstruos' a los monstruos de lo cotidiano: La diversidad funcional y sexualidad no normativa». Feminismo/s, 19 (2012), pp. 127-142. 


\section{Referencias bibliográficas}

ADORNo, Theodor W. y HORKHEIMER, Max: «La industria cultural. Ilustración como engaño de masas», en Dialéctica de la ilustración, Madrid, vol. 3, Akal, 2007, pp. 133-182.

ÁlVAREZ-LÓPEZ, Sonia. «Functions and strategies of male humour in cross-gender interactions». Estudios de Sociolingüistica: Linguas, Sociedades e Culturas 3-4:2-1 (2002), pp. 173-205.

ÁlvareZ-UriA, Amaia. «Euskal trans literarioak. Trans ezkutuen kartografia bat XX. mendeko euskal literaturan», en Isa Castillo y Iratxe Retolaza (eds.): Genero ariketak. Feminismoaren subjektuak. San Sebastián, EDO!, 2013, pp. 139-163.

BöHN, Andreas. «Subversions of gender identities through laughter and the comic?», en Gaby Pailer; Andreas Böhn; Stefan Horlacher y Ulrich Scheck (eds.): Gender and laughter. Comic affirmation and subversion in traditional and modern media. Amsterdam, Rodopi, 2009, pp. 49-64.

Bordieu, Pierre. La distinción. Criterio y bases sociales del gusto. Madrid, Taurus, 1998.

BUTLER, Judith. El género en disputa. El feminismo y la subversión de la identidad. Barcelona, Paidós, 2007.

Clough, Patricia (ed.). The Affective Turn: Theorizing the Social. Durham, Duke University Press, 2007.

CRAWFORD, Mary. «Gender and humor in social context». Journal of Pragmatics 35 (2003), pp. 1413-1430.

ETXEBERRIA, Idoia. «Earki gatxink!». Berria (27-01-2006), pp. s 4-5.

GARBER, Marjorie. Vested Interests. Cross-Dressing and Cultural Anxiety. New York, Routledge, 1997.

HORLACHER, Stefan. «A short introduction to theories of humour, the comic and laughter», en Gaby Pailer; Andreas Böhn; Stefan Horlacher y Ulrich Scheck (eds.): Gender and laughter. Comic affirmation and subversion in traditional and modern media. Amsterdam, Rodopi, 2009, pp. 17-47.

KotThofF, Helga. «Gender and humor: The state of the art». Journal of Pragmatics 38 (2006), pp. 4-25.

LabanYI, Jo. «Gramsci and the Spanish Cultural Studies». Paragraph 22/1 (1999), pp. 95-113.

LABANYI, Jo. «Música, populismo y hegemonía en el cine del primer franquismo», en Luis Fernández Colorado y Pilar Couto Cantero (eds.): Cuadernos de la Academia. La herida de las sombras. El cine español de los años 40, núm. 9, 2001, pp. 83-97.

LAKUNZA, Rosana. «Hay programas donde no hay intención de innovar: son demasiado cuadrados». Deia (19-09-2011), p. 66. 
LASA, Iñaki. «Bizitzak ba al du zentzurik barrerik egin gabe ba?». Berria (06-012013), p. 36.

LÓPEZ, Elisa. «¿Hacer de mujer? Pues sí, a los hombres nos gusta». Diario Vasco (09-10-2011), p. 82.

Medina Domenech, Rosa María. «Sentir la Historia. Propuestas para una agenda de investigación feminista en la historia de las emociones». Arenal. Revista de Historia de las Mujeres 19/1 (2012), pp. 161-199.

MitXelenA, Eñaut. «Herriak behar gaitu, bestela ez gintuzten hainbeste maiteko». Aizu! 376 (Abril de 2013), pp. 30-33.

MorA, Miguel. «Universo Falete». El País, (13-03-1999), <http://elpais.com/diario/2005/03/13/eps/1110698813_850215.html > (consultado el 13-09-2014)

NORRICK, Neal R. y CHIARO, Delia. (eds.). Humor in interaction. Amsterdam, Benjamins, 2009.

PAiler, Gaby; BÖHN, Andreas; Horlacher, Stefan y SCHECK, Ulrich (eds.). Gender and laughter. Comic affirmation and subversion in traditional and modern media. Amsterdam, Rodopi, 2009. Págs. 49-64.

Platero, Raquel (Lucas) y Rosón María. «De 'la parada de los monstruos' a los monstruos de lo cotidiano: La diversidad funcional y sexualidad no normativa». Feminismo/s, 19 (2012), pp. 127-142.

PRECIADO, Beatriz: «La Ocaña que merecemos: Campceptualismo, subalternidad y políticas performativas», en Ocaña 1973-1983: acciones, actuaciones, activismo, Barcelona/Vitoria-Gasteiz, La Virreina. Centre de la Imatge/ Centro Cultural Montehermoso Kulturunea, 2011, pp. 72-169.

UrkizU, Urtzi. «'Finlandia' saioa desagertu ostean, 'Kontuz atsuak!' helduko da ETBlera». Berria (10-07-2012), p. 28.

Valladares, Catia.Elisa. Análisis del discurso de género en los programas televisivos de producción nacional dirigidos a mujeres (Tesis Doctoral). El Salvador, 2012.

VÁzQuez Montalbán, Manuel. Crónica sentimental de España. Barcelona, Bruguera, 1980.

VÁzQuez Montalbán, Manuel. Una educación sentimental. Praga, Madrid, Cátedra, 2001.

VERNON, Katheen M.: «Memoria histórica y cultura popular: Vázquez Montalbán y la resistencia española», en José F. Colmeiro (coord.): Manuel Vázquez Montalbán: el compromiso con la memoria, Woodbridge, Tamesis, 2007, pp. 21-34.

VIÑAU ENA, Nacho. «Supuestamente, Falete embruja a los heteros y los convierte en gays». <http://www.ambienteg.com/curiosidades/supuestamente-faleteembruja-a-los-heteros-y-los-concierte-en-gays/> publicado el 11-08-2009 (consultado el 12-09-2014).

VolCANO, Del LaGrace y DAHL, Ulrika. Femmes of power. Exploding Queer Femininities. London, Serpent's Tail, 2008.

ZIGA, Itziar. Devenir perra. Barcelona, Melusina, 2009. 


\title{
EL SEXISMO COMO BLANCO DEL HUMOR EN LAS REDES SOCIALES ${ }^{1}$
}

\author{
ANA MANCERA RUEDA \\ Universidad de Sevilla
}

Recibido: $15 / 09 / 2014$

Aceptado: 24/11/2014

\section{Resumen}

Partiendo de las seis fuentes de conocimiento para la explicación del humor identificadas por la Teoría general del humor verbal, y del modelo pragmático desarrollado por el grupo GRIALE, en este trabajo se analiza un corpus de 1.526 mensajes publicados en la red social Twitter. Estos contienen una o varias etiquetas utilizadas por los internautas para denunciar el contenido sexista de las declaraciones de ciertos políticos españoles. En qué medida se sirven del humor los usuarios de esta red de microblogging para mostrar su repulsa hacia las afirmaciones de sus representantes, $o$ cuáles son los mecanismos lógicos y las principales marcas o indicadores del humor que pueden encontrarse en este tipo de mensajes son algunos de los interrogantes a los que se tratará de responder.

Palabras clave: sexismo, humor, ironía, discurso mediado por ordenador, Twitter

\begin{abstract}
On the basis on the six sources of knowledge for explanation of humor identified by the General Theory of Verbal Humor and the pragmatic model developed by the GRIALE group, in this paper, a corpus of 1,526 messages posted on the Twitter social network is analyzed. They contain one or more hashtags used by netizens to denounce

1. Este estudio se enmarca en el seno del Proyecto FFI2011-23573, «Variación y adaptación en la interacción lingüística en español», financiado por el Ministerio de Ciencia e Innovación, que desarrolla en la actualidad el grupo de investigación El español hablado en Andalucía (HUM-134). Agradecemos los valiosos comentarios de dos evaluadores anónimos sobre una versión anterior de este trabajo.
\end{abstract}

Feminismo/s 24, diciembre 2014, pp. 163-192

DOI: $10.14198 / \mathrm{fem} .2014 .24 .08$ 
the sexist affirmations of certain Spanish politicians. What porcentaje represents the use of humor in this network, or what the logical mechanisms and major brands or indicators of humor are more common in this type of messages are some of the questions that we will try to respond.

Keywords: sexism, humor, irony, computer-mediated discourse, Twitter 


\section{Introducción}

El objetivo de esta investigación es averiguar en qué medida los usuarios de la red social Twitter se sirven del humor verbal y de la ironía como estrategias para otorgar un mayor grado de difusión a sus críticas hacia determinados representantes políticos que han alcanzado notoriedad pública por la formulación de un tipo de declaraciones susceptibles de ser calificadas como sexistas. Para ello analizamos un corpus de 1.526 tuits cuya comprensión está supeditada al conocimiento de la situación comunicativa que motivó su publicación. De ahí que hayamos decidido dedicar este epígrafe introductorio a la explicación de los aspectos de la actualidad noticiosa más relevantes para la interpretación de los mensajes recopilados. A continuación, basándonos en la Teoría general del humor verbal (General Theory of Verbal Humor) (en adelante, TGHV) y en el modelo pragmático desarrollado por el grupo GRIALE para el estudio de las marcas e indicadores del humor y de la ironía, llevaremos a cabo una caracterización de los distintos tipos de tuits que pueden localizarse en nuestro corpus analítico. Por último, abordaremos un estudio cuantitativo para tratar de sopesar la representatividad de los mensajes de carácter humorístico entre todos aquellos que utilizan etiquetas como \#MachismoPSOE, \#machismoPP o \#dimisioncastelao para formular actos de amenaza a la imagen de los políticos.

A principios de julio de 2014, el Ministerio del Interior del Gobierno de España publicó en su página web una serie de consejos para prevenir una violación ${ }^{2}$. Entre ellos se encontraba el de echar «las cortinas al anochecer para evitar miradas indiscretas», o el de utilizar «silbatos para ahuyentar al delincuente». Esto suscitó la indignación de varias diputadas del Partido Socialista (PSOE), que acusaron al departamento que dirige el ministro del Partido Popular (PP) Jorge Fernández Díaz, de culpabilizar a la mujer. Las redes sociales fueron el principal medio utilizado por estas representantes

2. «Servicios al ciudadano: Prevención de la violación», Ministerio del Interior, Gobierno de España, disponible en: <http://www.interior.gob.es/web/servicios-al-ciudadano/segu$\mathrm{ridad} /$ consejos-para-su-seguridad/prevencion-de-la-violaci\%C3\%B3n>, consultado el 01-09-2014. 
para manifestar sus críticas. Por ejemplo, Susana Sumelzo, secretaria de Administraciones Públicas del PSOE, publicó el siguiente mensaje en su perfil de Twitter ${ }^{3}$ :

Susana Sumelzo (@SSumelzo). «La realidad supera la ficción: Interior recomienda cerrar las cortinas de casa para evitar violaciones http://www.eldiario. es/_11804c75_@eldiarioes».18-08-2014.Tuit.

Y a él respondieron muchos de sus seguidores con tuits como este, con los que mostraban su conformidad con sus puntos de vista:

Manuel Terrón(@manuelteher).«@SSumelzo@eldiarioes esto es de traca o ciencia ficción.Se creen que somos tontos o algo más?». 20-08-2014. Tuit.

Pero el debate sobre dicho tema adquirió repercusión en las redes sociales a raíz de una entrevista realizada por la cadena radiofónica Onda Cero a Francisco Javier León de la Riva, alcalde de Valladolid ${ }^{4}$, ciudad en la que se acababa de producir una violación. Al ser preguntado por su opinión sobre las recomendaciones del Ministerio de Interior, el edil del PP contestó lo siguiente:

«Tú piensa que entras en un ascensor y hay una chica con ganas de buscarte las vueltas. Se mete contigo en el ascensor, se arranca el sujetador o la falda y sale dando gritos de que la has intentado agredir. Por lo tanto, ojo con ese tema, que tiene doble lectura. De ida y de vuelta».

Tales declaraciones generaron gran malestar entre los internautas, muchos de los cuales se sirvieron del humor para manifestar su postura crítica. Por ejemplo, el siguiente mensaje fue enviado por la activista social Ada Colau, bien conocida por haber sido la portavoz de la Plataforma de Afectados por la Hipoteca (PAH) hasta mayo de 2014:

3. Al igual que Facebook o LinkedIn, Twitter constituye una plataforma en línea que se basa en la creación de un perfil susceptible de ser actualizado de manera periódica por medio del envío de mensajes. El enunciador puede decidir difundirlos públicamente u optar por distribuirlos solo de manera restringida entre los miembros de su círculo de contactos. Twitter se asemeja también a otras redes sociales en que sus mensajes pueden enviarse desde un sitio web o por medio de SMS, mensajería instantánea u aplicaciones creadas ad hoc para móviles. Además, de forma similar a las bitácoras, permite crear contenidos que, al tiempo que se muestran en la página del perfil del usuario, son difundidos de manera inmediata a otros internautas que han elegido la opción de recibirlos. Sin embargo, hay un rasgo que le es peculiar: sus textos no pueden exceder el límite de 140 caracteres. De ahí que suela identificársela como una plataforma de microblogging o nanoblogging, a medio camino entre las bitácoras y las redes sociales.

4. «Valladolid en la Onda. Entrevista con el Alcalde de Valladolid», Onda Cero, 21-082014. Disponible en: <http://www.ondacero.es/audios-online/emisoras/valladolid/valladolid-onda-entrevista-alcalde-valladolid-jueves-agosto_2014082100059.html>, consultado el 01-09-2014. 


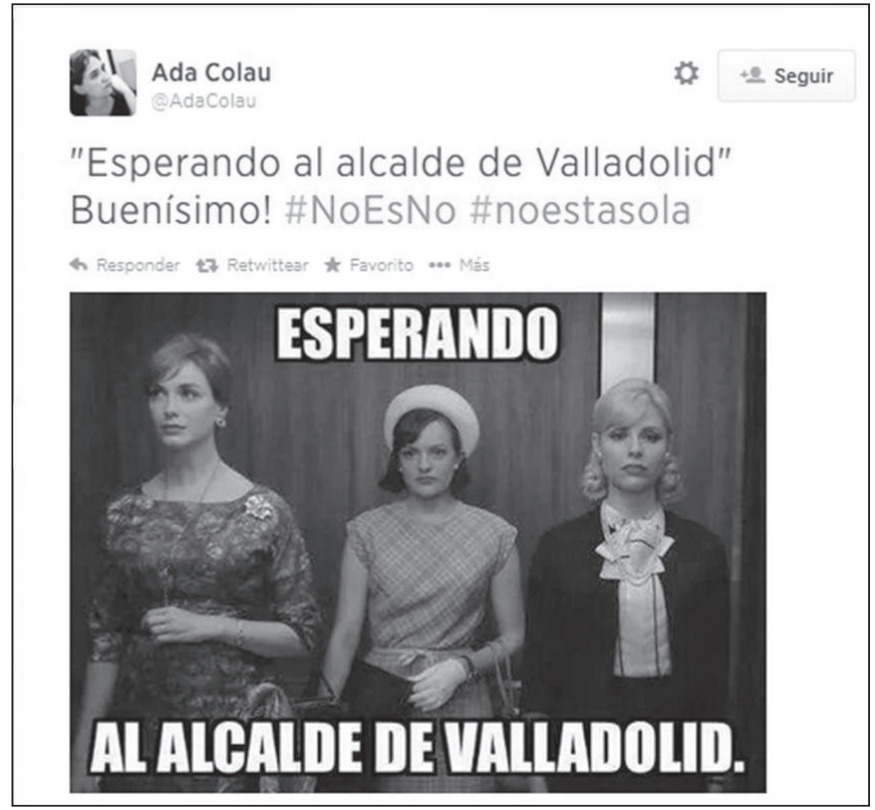

IMAGEN 1: Tuit publicado en el perfil de Twitter de Ada Colau (@AdaColau) el 22-082014. Disponible en: <https://twitter.com/AdaColau/status/502901723535773697>, consultado el 01-09-2014

A continuación, Colau manifestó su opinión de que el edil vallisoletano se merecía «una lluvia de sujetadores y zapatos de tacón» en su próximo acto público, a lo que una de sus seguidoras en Twitter respondió con una imagen de un sujetador. La activista catalana retuiteó, es decir, reenvió este mensaje a través de su propio perfil, para otorgarle mayor difusión, y añadió el hashtag 5 \#EscracheDeSujetadores, animando a otras usuarias a llevar a cabo una protesta virtual mediante la publicación de imágenes de sujetadores en sus cuentas:

5. José Luis Orihuela define el hashtag o 'etiqueta' como una palabra clave que, precedida del signo de la almohadilla (\#), sirve para identificar el tema de un mensaje. Cuando esta es utilizada de manera recurrente en un gran número de tuits durante las últimas horas puede llegar a convertirse en trending topic, es decir, en 'tema del momento' en un determinado país, o en una ciudad concreta. Orihuela, José Luis. Mundo Twitter. Barcelona, Alienta, 2011, p. 34. 


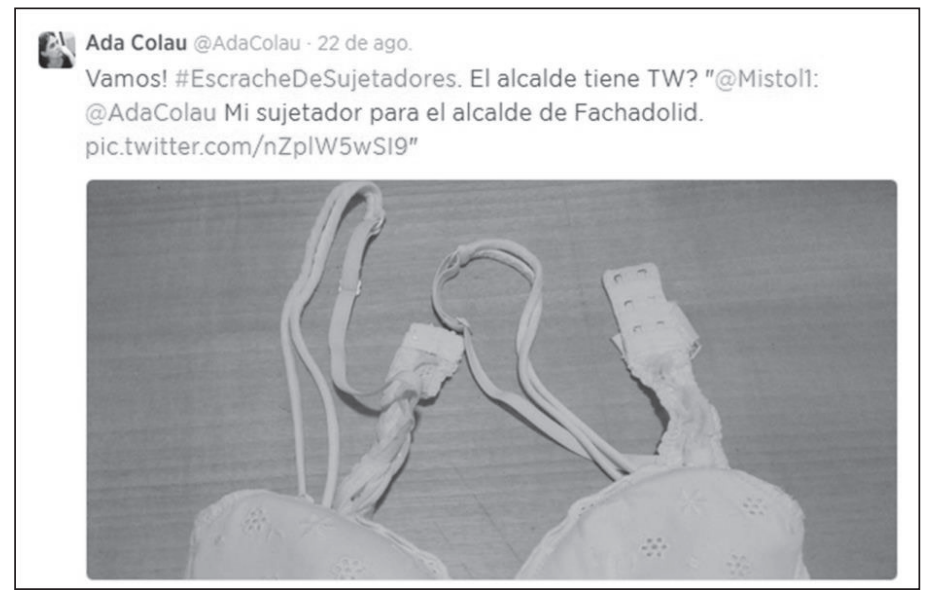

IMAGEN 2: Tuit publicado en el perfil de Twitter de Ada Colau (@AdaColau) el 22-082014. Disponible en: <https://twitter.com/AdaColau/status/502909836850626560>, consultado el 01-09-2014

Esta iniciativa tuvo una extraordinaria acogida ${ }^{6}$, pero no solo entre las usuarias, sino también entre los internautas varones, que tuitearon imágenes de su ropa interior o incluso de sujetadores que portaban sobre su torso. Además, el «escrache virtual» fue más allá de Twitter, ya que medio centenar de personas se concentró frente a la sede del consistorio de Valladolid, que fue rodeado por una cadena de sujetadores y por múltiples pancartas que abogaban «por una ciudad libre de alcaldes machistas».

No es la primera vez que el comentario sexista de un político suscita indignación en las redes sociales. Así, pocos días antes de que León de la Riva formulara sus polémicas declaraciones, el alcalde de Málaga, Francisco de la Torre, trató de defender el operativo de seguridad puesto en práctica

6. De ello se hicieron eco numerosos medios de comunicación. Cfr. por ejemplo la siguiente noticia publicada en El Mundo: «Ada Colau inicia en Twitter un \#EscracheDeSujetadores virtual contra el alcalde de Valladolid», El Mundo, 23-08-2014, disponible en: <http:// www.elmundo.es/espana/2014/08/23/53f8c77be2704e221b8b4577.html>, consultado el 01-09-2014. O esta otra, difundida por los Servicios Informativos de la cadena de televisión Telecinco: «Escrache en Twitter contra León de la Riva en el [sic] se le 'lanzan' virtualmente sujetadores», Telecinco, 23-08-2014, disponible en: <http://www.telecinco. es/informativos/sociedad/Ada-Colau-Twitter-Leon-Riva_0_1848525202.html>, consultado el 23-08-2014. 
durante la feria de su ciudad (donde presuntamente acababa de tener lugar la violación de una chica de 20 años por parte de cinco jóvenes de entre 17 y 23 $a_{n ̃ o s}{ }^{7}$ ) sosteniendo que «en España hay más de mil violaciones al año», $y$ «no se puede poner un policía detrás de cada ciudadano». Esto motivó tuits tan sarcásticos como el siguiente:

LoveWillTearUsAznar (@lwtuaznar). «Según el alcalde de Malaga, el ébola dejará de tener importancia cuando haya más de mil muertos al año. $\mathrm{O}$ algo así». 18-08-2014. Tuit.

También durante esa semana otro edil, en este caso el de Toledo, Emiliano García-Page, hizo unas afirmaciones que podrían calificarse de machistas, al manifestar su opinión de que el escándalo de los papeles del ex tesorero del PP Luis Bárcenas se había producido porque los dirigentes de este partido «no saben hacer nada sin la chacha», y «lo cierto y verdad es que no pienso que Cospedal ${ }^{8}$ sepa pasar la aspiradora». Esto le reportó numerosas críticas al secretario general de los socialistas de Castilla-La Mancha, tantas que en Twitter la etiqueta \#MachismoPSOE se convirtió en trending topic:

Ana María Saá García (@AnaSaaG). «Orgulloso de ser \#TT? García-Page (PSOE): «Yo no tengo claro que Cospedal sepa pasar la aspiradora» http:// www.cadenaser.com/espana/articulo/emiliano-garcia-page-tengo-clarocospedal-sepa-pasar-aspiradora/csrcsrpor/20140821_srcsrnac_17/Tes... \#MachismoPSOE». 22-08-2014. Tuit.

Sin embargo, no era la primera vez que dicha etiqueta cobraba protagonismo, pues ya había sido utilizada por los usuarios de Twitter para mostrar su rechazo a unas declaraciones del secretario de organización del PSOE de Huelva, Jesús Ferrera, quien ante las malas cifras de empleo dadas a conocer en marzo de 2013 afirmó que la ministra de Empleo Fátima Báñez «debería dedicarse a otra cosa», ya que a su juicio «estaría mejor en San Juan del Puerto [localidad natal de la ministra] haciendo punto de cruz». A esta descalificación respondieron los internautas con tuits como el siguiente:

7. Sin embargo, finalmente el caso fue archivado, y se liberó a los presuntos agresores. Cfr. por ejemplo la siguiente noticia: «Los jóvenes detenidos por la presunta violación en Málaga solo se sienten "seguros" en casa», La Vanguardia, 23-08-2014, disponible en: <http://www.lavanguardia.com/local/sevilla/20140823/54413952739/jovenes-violacionmalaga-casa.html>, consultado el 01-09-2014.

8. María Dolores de Cospedal, secretaria general del Partido Popular desde 2008.

Feminismo/s 24, diciembre 2014, pp. 163-192 


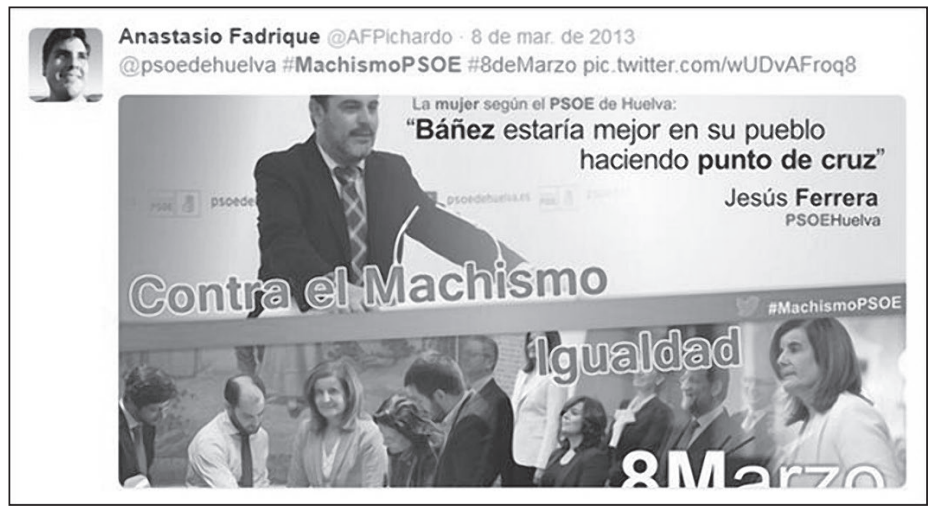

IMAGEN 3: Tuit publicado en el perfil de Twitter de Anastasio Fadrique (@AFPichardo) el 08-03-2013. Disponible en: <https://twitter.com/AFPichardo/ status/310045736899313665>, consultado el 01-09-2014

Asimismo, las palabras del presidente del Consejo General de la Ciudadanía en el Exterior José Manuel Castelao Bragaño, para quien «las leyes son como las mujeres, están para violarlas», o las del ministro de Agricultura Miguel Arias Cañete, que afirmó que «a los regadíos hay que manejarlos como a las mujeres, con mucho cuidado, que le pueden perder a uno», suscitaron en Twitter una miríada de opiniones en contra, manifestadas en mensajes que hacían uso del hashtag \#machismoPP. Dicha etiqueta fue también utilizada por los internautas para criticar a este político del Partido Popular cuando concurrió como cabeza de lista de su partido a las elecciones de 2014 al Parlamento Europeo. En esta ocasión, la causa de que su comportamiento se calificara de machista fueron las afirmaciones que realizó en el transcurso del cara a cara con Elena Valenciano, la candidata del PSOE, durante el cual sostuvo que «el debate con una mujer es difícil. Si demuestras superioridad intelectual, eres machista». Tales comentarios suscitaron gran hilaridad en las redes sociales, donde se difundieron mensajes como este:

Rosa F. Lastra (@rosaferlas). «Cañete no acierta con las palabras: dijo anoche que ganarán las elecciones como señores http://www.diariocritico.com/nacional/arias-canete/elecciones-europeas-2014/455916\#.U32QLp8noe5.twitter ... ... \#HomoCañetus \#MachismoPP». 22-08-2014. Tuit.

Adviértase el uso que se hace en el tuit precedente, de los hashtags \#MachismoPP y \#HomoCañetus. Esta última etiqueta fue utilizada también por los usuarios para criticar al candidato del PP haciendo uso tanto del humor gráfico como del humor verbal, en mensajes como el siguiente: 
No solo los representantes de los dos grandes partidos mayoritarios fueron objeto de burla en Twitter a raíz de comentarios sexistas acerca de sus colegas de otras formaciones políticas. Por ejemplo, el hashtag \#chochitodeoro surgió a raíz de las palabras publicadas en la bitácora personal de un concejal del Bloque Nacionalista Gallego en Cambados (Pontevedra), Xaquín Charlín González, quien se refirió a la vicepresidenta del Gobierno con el sobrenombre de «chochito de oro», tras difundirse en los medios de comunicación que el contrato para sus reconocimientos ginecológicos financiado con dinero público ascendía supuestamente a 40.000 euros. El rechazo que tal

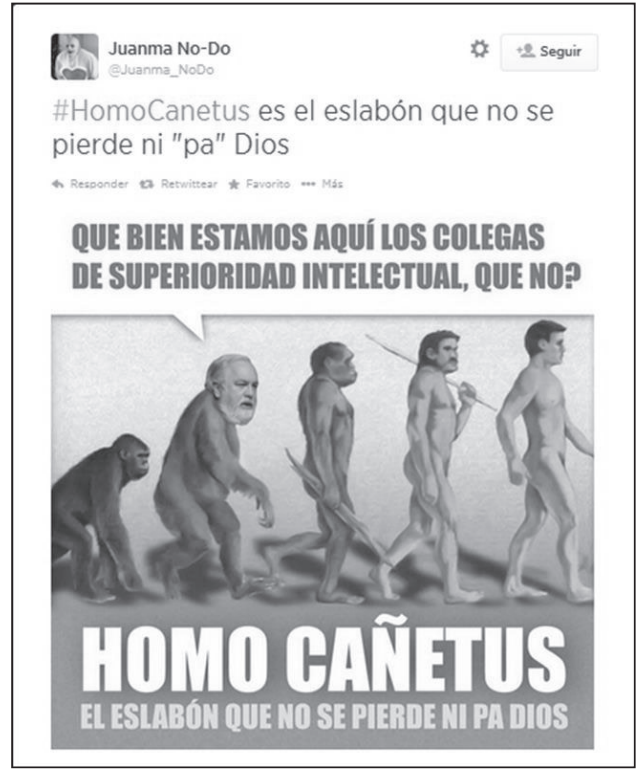

IMAGEN 4: Tuit publicado en el perfil de Twitter de Juanma No-Do (@Juanma_ NoDo) el 16-05-2014. Disponible en: <https://twitter.com/Juanma_NoDo/ status/467340537314676737>, consultado el 01-09-2014 aseveración suscitó en las redes sociales se trasladó a la opinión pública fuera del ámbito digital, y finalmente el político tuvo que dimitir:

Alfonso (@alfonsojag). «@mbdc76 según he visto, ha dimitido el autor perteneciente a la derecha rancia (o es del BNG) del \#ChochitoDeOro». 11-062013. Tuit.

Por último, entre los mensajes de Twitter que vamos a estudiar en las páginas siguientes se encuentran aquellos en los que se hace uso de la etiqueta \#ToniCantóFacts para criticar al portavoz de UPyD en la Comisión de Igualdad del Congreso de los Diputados, a raíz de la publicación del siguiente tuit:

Toni Cantó (@Tonicanto1). «La mayor parte de las denuncias por violencia de género son falsas. Y los fiscales no las persiguen. Las estadísticas son sesgadas». 25-02-2013. Tuit. 
Algo que suscitó una serie de reacciones en contra, manifestadas en su mayoría en un tipo de comunicación non bona fide $e^{9}$ caracterizada, como veremos, por el uso del humor verbal:

Libertad (@Sahakiel). «El maltrato a la mujer son los padres \#tonicantofacts». 25-02-2013. Tuit.

Hay que tener en cuenta que el número de mensajes que emplea una determinada etiqueta está sometido a fluctuaciones considerables motivadas por la actualidad noticiosa. Por ejemplo, en agosto de 2014, a raíz de los intentos del gobierno español por lograr que Miguel Arias Cañete fuera designado comisario de la Unión Europea, muchos internautas, para establecer un «hilo de conversación ${ }^{10}$ en torno a dicho asunto de la actualidad noticiosa, volvieron a recurrir a la etiqueta \#HomoCañetus, que no había vuelto a ser utilizada prácticamente desde los comicios europeos del 20 de mayo:

Pilar L. (@Maxuxta).«\#HomoCanetus, el superior, no será comisario. http:// www.infolibre.es/noticias/politica/2014/08/26/el_complicado_que_canete_ sea_nominado_para_una_comisaria_economica_20862_1012.html ... Que se dedique a sus negocios». 26-08-2014. Tuit.

Con ello queremos mostrar cómo algunas etiquetas están sujetas a un uso más dilatado a lo largo del tiempo. Este es el caso también de \#machismoPP, \#machismoPSOE o \#ToniCantóFacts. Por ejemplo, la parodia del parlamentario de UPyD parece haberse convertido en uno de los pasatiempos favoritos de los usuarios de Twitter, algo que atestiguan mensajes como el siguiente:

NuevasDegeneraciones (@nn_dgg). «Es pronto para un \#ToniCantóFacts o hay que retomar las cosas que son ETA o \#CulpaDelComunismo?». 12-012013. Tuit.

\section{Corpus y metodología}

Nuestro estudio se fundamenta en el análisis de un total de 1.526 tuits que contienen alguna de las siguientes etiquetas: \#machismoPSOE, \#machismoPP, \#MachismoARV, \#chochitodeoro, \#dimisioncastelao, \#CastelaoDimision,

9. RASKIN, Victor. Semantic Mechanisms of Humor. Reidel, Dordrecht, 1985.

10. Las palabras contenidas en la etiqueta suelen indicar el tema del tuit, lo que Tíscar Lara asocia a una «función discursiva». Gracias a la etiqueta es posible «coser hilos de conversación, recapitular ideas, tejer conversaciones alrededor de un tema determinado e incluso entrar espontáneamente en conversaciones ajenas con el simple uso de su misma palabra clave». LARA, Tíscar. "Twitter y sus funciones comunicativas». Tíscar.com, 13-02-2012. Disponible en: <http://tiscar.com/2012/03/11/twitter-y-susfunciones-comunicativas/>, consultado el 15-09-2014. 
\#HomoCañetus, \#ToniCantóFacts, \#escrachedesujetadores, \#EscracheDeSujetadores ${ }^{11}$. Con el objeto de averiguar en qué medida los internautas se sirven del humor verbal para denunciar las declaraciones de carácter sexista formuladas por los políticos antes mencionados, hemos recopilado la totalidad de los tuits que hacen uso de alguno de estos diez hashtags.

El trabajo que presentamos es de naturaleza exploratoria, interpretativa y cuantitativa, realizado desde una perspectiva pragmalingüística a partir del análisis del humor verbal. Este se lleva a cabo a partir de las interpretaciones inductivas del analista. Todos los textos, extraídos verbatim, fueron recopilados entre el 29 y el 30 de agosto de 2014 mediante la herramienta de analítica social Topsy Pro Analytics y conforman un corpus monolingüe, delimitado en la variedad diatópica del español peninsular, de aproximadamente 40.600 palabras. Para su análisis partimos de la TGHV, ya que esta propuesta ${ }^{12}$ «todavía hoy sigue siendo el punto de referencia de las investigaciones lingüísticas $y$ afines al humor $»^{13}$. Asimismo, para el estudio de las marcas e indicadores del humor verbal nos apoyamos en el modelo pragmático desarrollado por el grupo GRIALE ${ }^{14}$.

\section{Análisis del corpus}

La TGHV se basa en seis fuentes de conocimiento para la explicación del humor: la oposición de guiones, el mecanismo lógico, la situación, la meta, la estrategia narrativa y el lenguaje. A continuación, vamos a llevar a cabo el análisis de nuestro corpus de acuerdo con las fuentes mencionadas, lo que nos permitirá identificar distintas categorías de mensajes. Estas no son excluyentes. Además, la mayor parte de los tuits recopilados poseen un rasgo común: tienen como meta (es decir, como blanco de la burla) a políticos que han formulado declaraciones de carácter sexista, a los que se trata de ridiculizar. Sin

11. En este caso hemos comprobado que la búsqueda de dicha etiqueta en la que la primera letra de cada lexía aparece en mayúscula arroja también una gran cantidad de resultados, de ahí que hayamos decidido incluirla también en nuestro corpus.

12. ATTARDO, Salvatore y Victor RASKIN. «Script theory revis(it)ed: Joke similarity and joke representation model». Humor 4 (3-4) (1991), pp. 293-347.

13. RUIZ GuRILlo, Leonor. La lingüística del humor en español. Madrid, Arco/Libros, 2012, p. 24.

14. Cfr. Ruiz Gurillo, Leonor. Op. cit.; Ruiz GuRillo, Leonor y María Belén Alvarado ORTEGA. Irony and humor: from pragmatics to discourse. Ámsterdam, John Benjamins, 2013; Alvarado OrTega, María Belén y Leonor Ruiz GuRillo. Humor, ironía y géneros textuales. San Vicente del Raspeig, Publicaciones de la Universidad de Alicante, 2013, entre otros múltiples trabajos.

Feminismo/s 24, diciembre 2014, pp. 163-192 
embargo, no es este el caso de todos los tuits que hemos analizado. Por ejemplo, la etiqueta \#chochitodeoro no solo contribuyó a otorgar mayor difusión a los actos de amenaza hacia la imagen ${ }^{15}$ del político del BNG que dirigió tal comentario peyorativo a la vicepresidenta el Gobierno, sino que fue también incluida en una serie de tuits en los que se hacía uso del humor verbal para mofarse de ella,

Actor porno retirado (@OjeteAlmendra). «Soraya Saenz de Santamaria se gasta $40.000 €$ en el ginecólogo o en el veterinario? \#LaDuda \#ChochitoDeOro». 11-06-2013. Tuit.

y de otros miembros de su partido:

Gjavierescribano (@pacomontoyah).«Que quede claro que solo le pueden llamar \#chochitodeoro a soraya saez de santamaria su marido y el alcalde de Valladolid». 11-06-2013. Tuit.

Por otra parte, aunque las peculiares características de estos mensajes ${ }^{16}$ hacen que nos resulte muy difícil adscribirlos a un determinado género, como sucede con otros tipos de comunicación mediada por un dispositivo digital ${ }^{17}$, lo predominante son las secuencias de carácter argumentativo. No en vano, Twitter es utilizado por los internautas fundamentalmente para manifestar sus puntos de vista,

Pilar (@Pigomezsa).«\#chochitodeoro No me extraña que haya mujeres q se ofendan: el oro es muy poco acogedor. Me resisto a perder el humor por comentarios indignos». 12-06-2013. Tuit.

a veces con notables dosis de ironía:

Felipe Suárez(@FSuarez_Arosa). «Yo entiendo al alcalde de VALLADOLID, es un galán, un Paul Newman, quedan pocos en este país de pandereta \#EscracheDeSujetadores». 26-08-2014. Tuit.

Además, en los tuits que conforman nuestro corpus encontramos tanto secuencias descriptivas,

15. Brown, Penelope y Stephen C. LeVInSON. Politeness: Some universals in language usage. Cambridge, Cambridge University Press, 1978 [1987].

16. De carácter público y con una extensión limitada a los 140 caracteres.

17. Cfr. por ejemplo AlCÁntara Plá, Manuel. «Las unidades discursivas en los mensajes instantáneos de wasap». Estudios de Lingüística del Español 35 (2014), pp. 223-242. 


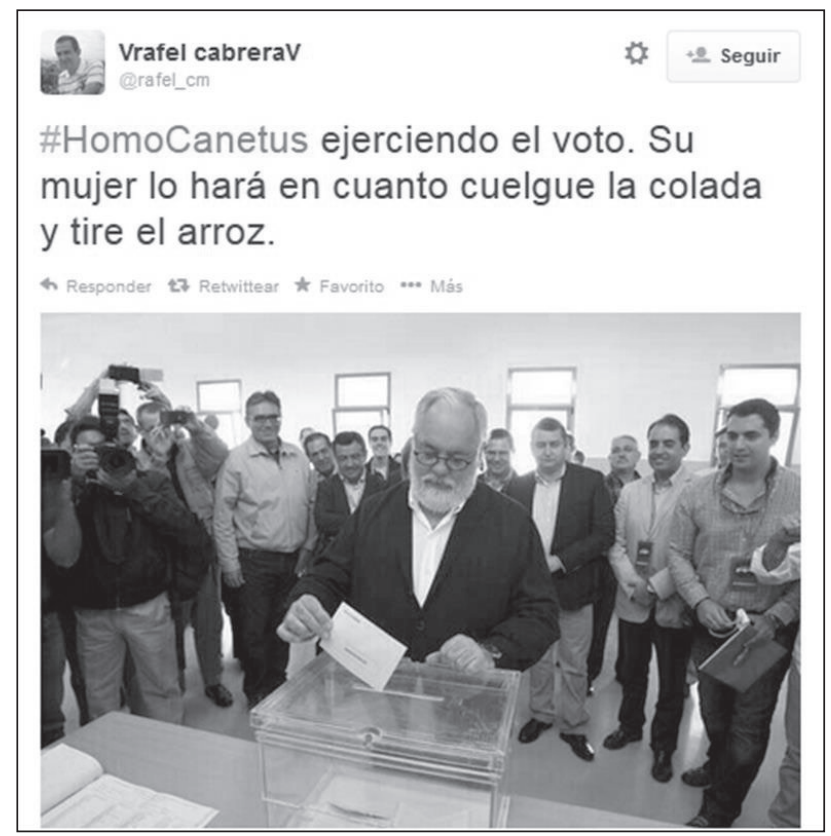

IMAGEN 5: Tuit publicado en el perfil de Twitter de Vrafel cabreraV (@rafel_cm) el 25-05-2014. Disponible en: <https://twitter.com/rafel_cm/status/470502952667729920/ photo/1>, consultado el 13-09-2014

como narrativas:

José G. Arribas (@HoTseChu). «Cuando le tiraron los sujetadores se oyó un estruendo de cadenas que se rompían \#EscracheSujetadores». 24-08-2014.

Tuit.

Y hay también mensajes que recrean la interacción conversacional. Como el siguiente, en el que se evoca el supuesto diálogo entre la líder de UPyD y un enajenado Toni Cantó que se niega a tomarse la medicación, lo que parece servir al internauta para explicar lo incongruente de sus declaraciones:

Marcos Torre (@MarcosTorre89). «Rosa Diez - «Toni te has tomado la pastilla?» - «No! La escupo» - «ahora entiendo...» \#tonicantofacts». 25-02-2013.

Tuit.

Tras estas precisiones sobre la diversidad de metas y de estrategias narrativas que pueden identificarse en los mensajes que conforman nuestro corpus, vamos a presentar la categorización de tuits que hemos llevado a cabo. 


\subsection{Tuits humorísticos sustentados en la oposición de guiones}

El planteamiento de la TGHV parte de la Teoría Semántica del Humor basada en guiones (Script-based Semantic Theory of Humor) (en adelante, TSHG) desarrollada en 1985 por Victor Raskin ${ }^{18}$. Según este autor, para poder considerar un texto como humorístico deben advertirse en él al menos dos guiones diferentes que se oponen entre sí a la manera de una relación antonímica, superponiéndose de forma parcial o total ${ }^{19}$. Por ejemplo, en los mensajes de Twitter que hacen uso de la etiqueta \#EscracheDeSujetadores resulta frecuente la identificación de esta prenda femenina con un arma, al ser exhibida para «agredir metafóricamente» al alcalde de Valladolid. De ahí que sea calificada como «peligrosa»,

Carlos Miguel Corral (@duenderepublica).«\#EscracheDeSujetadores todos los vehículos que van a Valladolid sin registrados, buscan a un peligroso sujetador escondido en una maleta». 24-08-2014. Tuit.

y que deba ser incautada por la guardia civil:

Lluís Ahicart (@lluisahicart).«La G.Civil de Valladolid incauta armas de feminizacion preparadas ataque coordinado ascensores \#EscracheDeSujetadores pic.twitter.com/tioEomphwj». 30-08-2014. Tuit.

Además, al guion sobre la violación en un ascensor evocado por De la Riva en sus declaraciones se opone el de la corrupción política en tuits como este, que equipara a los ediles con atracadores:

Paloma Lucas (@palomalhidalgo).«\#EscracheDeSujetadores Yo no subo en ascensores con alcaldes, porque en lugar de perder el sujetador perdería la cartera...». 24-08-2014. Tuit.

En estos mensajes los mecanismos lógicos ${ }^{20}$ se sustentan en relaciones sintagmáticas:

18. RASKIN, Victor. Semantic Mechanisms of Humor. Reidel, Dordrecht, 1985.

19. Cfr. Ruiz GuRILlo, Leonor. La lingüistica del humor... Op. cit. para una explicación más detallada de la que podemos realizar aquí.

20. Cfr. la taxonomía de los mecanismos lógicos elaborada por ATTARDO, Salvatore, HEMPELMANN, Christian F. y Sara Di MAIO. «Script oppositions and logical mechanisms: Modelling incongruities and their resolutions». Humor 15-1 (2002), pp. 3-46, y su aplicación al análisis de un conjunto de chistes en español llevada a cabo por Ruız GuRILLO, Leonor. La lingüística del humor... Op. cit. Existe un cierto debate sobre la necesidad o no de tener en cuenta los mecanismos lógicos en la comprensión del humor. A juicio de Christie Davies: «Meanings within texts derive from external social contexts and cognitive processing happens within that bundle of cells, chemicals and electrical exchanges, the brain. There is a real and material world out there and logical mechanisms cannot be studied in isolation from it, nor can the properties of that 
Sergio \#SiSePuede (@310Sergio). «Los toros se ofrecen a que los maten en la plaza para no sufrir el acoso de sus vacas según \#ToniCantóFacts». 26-022013. Tuit.

El internauta juega aquí con la yuxtaposición de dos de los temas sobre los que acababa de pronunciarse Toni Cantó: el supuesto acoso que reciben los hombres por parte de determinadas mujeres, por un lado, y la defensa de las corridas de toros, por otro. Estos dos guiones se oponen de forma que se atribuyen al astado decisiones humanas.

Además, algunas relaciones sintagmáticas se basan en relaciones espaciales directas que se apoyan en un paralelismo, como el que conlleva la dilogía del verbo comer en el siguiente tuit:

Lendakari (@natxox). «Comerle el \#chochitodeoro a la vice y morir por ingestión de metales pesados». 11-06-2013. Tuit.

Mensajes como el anterior, de naturaleza soez, difícilmente pueden comprenderse si el internauta no se encuentra al tanto de la actualidad noticiosa que ha motivado el surgimiento de una determinada etiqueta. De ahí que hayamos considerado necesario dedicar las primeras páginas de este artículo a la explicación de la situación que motiva la publicación de cada hashtag, pues su conocimiento resulta imprescindible para comprender los textos humorísticos y sus inferencias.

Entre los indicadores ${ }^{21}$ del humor más frecuentes en este tipo de mensajes se encuentran también figuras retóricas como la de la prosopopeya, que lleva a atribuir acciones propias de seres humanos a objetos inanimados,

Carlota Muñoz (@Carlotilla2). «Abrir mi cuenta y que me asalten miles de sujetadores... Pues buenos días y \#escrachesujetadores, hombre por favor!». 23-08-2014. Tuit.

o a animales de diversa naturaleza:

world bein ferred from humor theories or indeed literary or political theories. The authors have tried to meet my doubts about logical mechanisms but instead have made me doubt humor theory in general. Do not push GVTH too hard; words consisting entirely of consonants do not necessarily imply the deity». DAVIES, Christie. «Logical mechanisms: A critique». Humor 24, número 2 (2011), pp. 159-165, p. 165. Asimismo, resultan de gran interés los otros trabajos publicados en el volumen 24 (número 2) de la revista Humor, a raíz de que se cumplieran en 2011 veinte años del surgimiento de la TGHV.

21. Los miembros del grupo GRIALE diferencian entre los conceptos de marca e indicador atendiendo a su función. Así, las primeras poseen un valor procedimental, ya que ayudan a identificar el humor, mientras que los indicadores contienen humor en sí mismos. 
Víctor Suárez (@Victor_Suarez). «Los toros ponen denuncias de maltrato falsas \#ToniCantóFacts». 25-02-2013. Tuit.

Y los ejemplos de comparaciones y metáforas zoomórficas pueden multiplicarse con facilidad:

Calpurnio (@Calpur100).«Cañete como un gorila ante el monolito del conocimiento. Pero no es un monolito, es un canapé gigante. \#HomoCañetus». 20-05-2014. Tuit.

Quique Muela (@whomples). «Cañete Bravo http://pocket.co/svrV9 \#HomoCanetus se convierte en \#HomoAvestruz». 21-05-2014. Tuit.

\subsection{Tuits humorísticos basados en razonamientos imperfectos de carácter hiperbólico}

Por otra parte, los mecanismos lógicos que intervienen en la resolución del humor en muchos de los mensajes que conforman nuestro corpus se fundamentan en razonamientos imperfectos de carácter hiperbólico, como el que lleva a otorgar una fuerza destructiva a un sujetador,

José G. Arribas (@HoTseChu). «Cuando le tiraron los sujetadores se oyó un estruendo de cadenas que se rompían \#EscracheSujetadores» ${ }^{22}$. 24-08-2014. Tuit.

o el que exagera la actitud despreciativa de Miguel Arias Cañete hacia las mujeres:

Sergio Beecher (@Sergiano93). «Cañete ha visto a una mujer en un colegio electoral y ha pensado que era la que limpiaba. \#HomoCañetus \#EleccionesEuropeas». 25-08-2014. Tuit.

Véase también el siguiente mensaje, en el que tras la etiqueta en la que el eslogan del PP durante la campaña de las elecciones europeas presenta sus lexías fusionadas se introduce un sintagma nominal que da pie a un razonamiento imperfecto basado en una exageración:

ZERO (@CorrupcionZero).«\#LoQueEstaEnJuegoEs MI BOCATA DE CHORIZO \#MejorCiudadDeTapas \#HomoCañetus \#VotaAOtros \#votaamono pic. twitter.com/uiJoWPZhxj». 20-05-2013. Tuit.

22. Advertimos en este mensaje ciertas reminiscencias literarias, como este conocido verso de Garcilaso de la Vega: «En el silencio solo se escuchaba un susurro de abejas que sonaba». La estructura sintáctica del complemento directo es idéntica, así como el propósito de producir una aliteración y evocar el sonido correspondiente dando lugar a la figura retórica conocida con el nombre de paronomasia. También puede encontrarse cierta similitud con el conocido microrrelato de Augusto Monterroso: «Cuando despertó, el dinosaurio todavía estaba allí». 
El uso de las mayúsculas revela una aserción intensificada que la competencia pragmática del lector será capaz de atribuir a Arias Cañete, del que los internautas hacían mofa constante a causa de sus gustos gastronómicos. Por lo tanto, las mayúsculas actúan aquí como marcas que ayudan a identificar el humor.

Y lo mismo podría decirse de las comillas que podemos encontrar en el siguiente mensaje, que remite al enlace de una noticia que informa sobre el hecho de que tras las polémicas declaraciones de Miguel Arias Cañete durante el debate con Elena Valenciano, la imagen del candidato popular fuera prácticamente suprimida de la propaganda sobre el próximo mitin de su partido:

Salvador Faus Verdú (@SFausVerdu). «El PP 'esconde' a \#HomoCañetus en el Mitin de Valencia http://www.levante-emv.com/comunitat-valenciana/2014/05/21/pp-esconde-canete-mitin-valencia/1114662.html ... via @ levante_emv».21-05-2013. Tuit.

Por tanto, el uso de las comillas actúa aquí como clave de contextualización ${ }^{23}$ que ayuda a los lectores a recuperar el sentido cabal de dicho enunciado. Y es que los signos tipográficos y retóricos familiares a los lectores europeos no indican por sí mismos la ironía o el humor, pero adquieren esta propiedad en un contexto circunstancial, textual e intertextual específico ${ }^{24}$.

Además, en nuestro corpus hemos podido comprobar cómo determinados hashtags pueden actuar también como marcas del humor. Esto es lo que sucede con la etiqueta \#ToniCantóFacts en los siguientes mensajes,

LacrataZGZ (@LacrataRebel). «Los animales no tienen derechos, las denuncias por violencia de genero son falsas, el explotador Amancio Ortega es un heroe \#ToniCantoFacts». 31-05-2013. Tuit.

MAG (@MAGuisado).«Me parece fenomenal la propuesta de Toni Cantó de que las mujeres puedan también votar \#ToniCantófacts». 10-03-2013. Tuit.

donde dicho hashtag figura al final del tuit, y su presencia ayuda a disipar cualquier duda que pudiera albergar el lector sobre el carácter irónico o humorístico de su aserción previa, como explica este internauta:

23. GuMPERZ, John Joseph. Discourse Strategies. Cambridge, Cambridge University Press, 1982.

24. Hutcheon, Linda: «Poética de la ironía», en Pierre Schoentjes (ed.): La poética de la ironía, Madrid, Cátedra, 2003, pp. 241-250. 
Miky Gaza (@miky_co).«@MaGo_36 jajajaja... Mujer, cuando se pone el \#ToniCantoFacts o similar, ya se da por hecho que es cachondeo... xD». 12-02-2013. Tuit.

Por último, también podemos encontrar indicadores del humor en este tipo de mensajes, como la locución verbal abrir la boca, que en el siguiente tuit experimenta una desautomatización semántica ${ }^{25}$, al alterarse en cierta medida el significado de la unidad fraseológica original:

Max Pradera (@maxpradera).«El PP quiere que Cañete no abra ya la boca ni para comer. Será alimentado mediante una sonda. \#HomoCañetus». 20-052014. Tuit.

\subsection{Tuits con remates (punch lines) humorísticos}

El carácter humorístico de otro tipo de mensajes que conforman nuestra corpus no se hace patente hasta la lectura del miembro discursivo situado en último término. Este se asemeja a los remates (punch lines) con los que se cierran los chistes, pues producen en el lector ese mismo efecto inesperado. Véase la apódosis de la siguiente oración condicional:

J. L. Tamborino (@JTamborino). «Si pegan a las mujeres y matan a los toros, es porque antes...algo harían...\#ToniCantóFacts». 26-02-2013. Tuit.

El humor en tales tuits se basa en razonamientos imperfectos que se sustentan en conocimientos compartidos. Por ejemplo, en el siguiente mensaje, al enunciado inicial en el que se hace alusión a la victoria del Partido Popular en las elecciones europeas se le yuxtapone otro en modalidad exclamativa cuya intencionalidad humorística solo puede ser cabalmente interpretada por aquellos internautas que recuerden unas declaraciones formuladas por Miguel Arias Cañete en enero de 2013, durante su etapa al frente del Ministerio de Agricultura, Alimentación y Medio Ambiente, con las que instaba al consumo de yogures caducados basándose en que, a su juicio, no suponían un grave perjuicio para la salud:

25. TimofeEva, Larissa: «Las unidades fraseológicas», en Leonor Ruiz Gurillo y Xosé Antonio Padilla García (eds.): Dime cómo ironizas y te diré quién eres. Una aproximación pragmática a la ironía, Fráncfort, Peter Lang, 2009, pp. 193-217. 


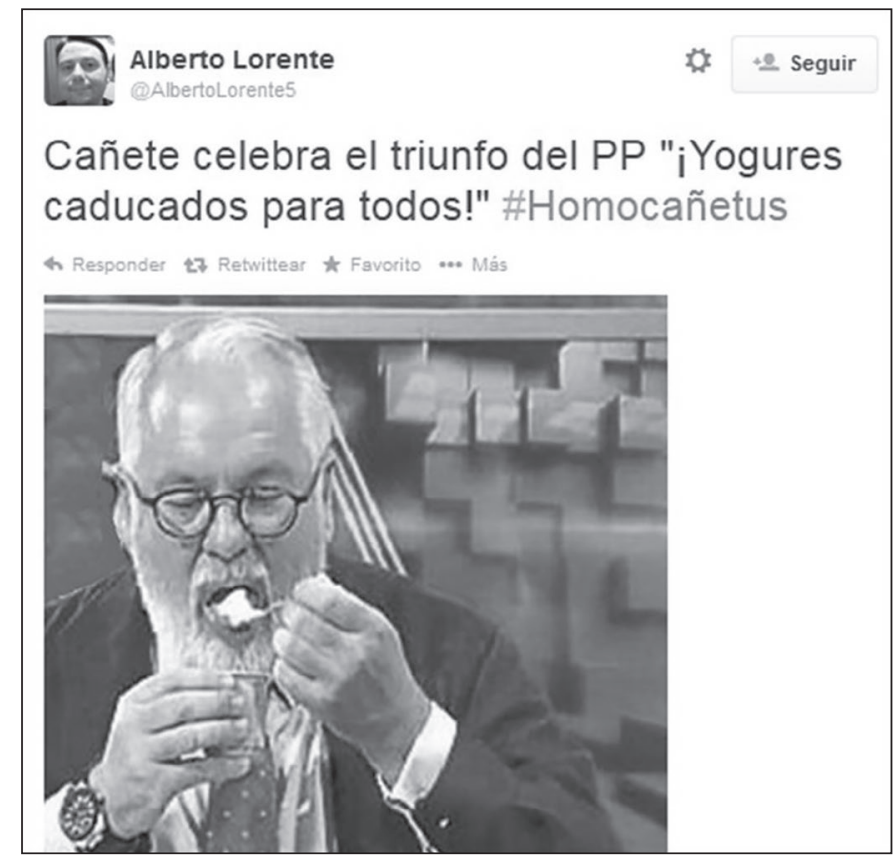

IMAGEN 6: Tuit publicado en el perfil de Twitter de Alberto Lorente (@AlbertoLorente5) el 27-05-2014. Disponible en: <https://twitter.com/AlbertoLorente5/ status/471362213182459904>, consultado el 12-09-2014

\subsection{Tuits humorísticos con apoyatura de imagen}

En mensajes multimodales como el anterior, o como el que mostramos a continuación, los guiones conviven en un mismo espacio discursivo ${ }^{26}$, ya que el texto publicado en el tuit remite a un contexto político cuyo carácter humorístico solo puede comprenderse al contemplar la fotografía que lo acompaña:

26. Padilla, Xosé Antonio y Elisa GiRonZeTti: «Humor e ironía en las viñetas cómicas periodísticas: un estudio pragmático-intercultural», en María Elena Placencia y Carmen García (eds.): Pragmática y Comunicación Intercultural en el mundo hispanohablante, Ámsterdan, Rodopi, 2012, pp. 93-133. 


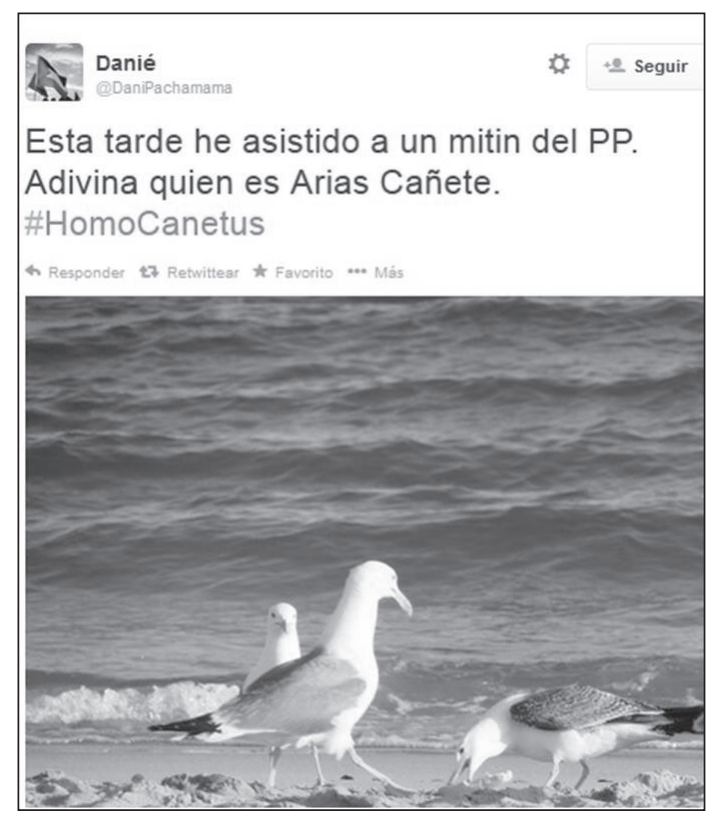

IMAGEN 7: Tuit publicado en el perfil de Twitter de Danié (@DaniPachaMana) el 16-052014. Disponible en: <https://twitter.com/DaniPachamama/status/468858811672186882/ photo/1>, consultado el12-09-2014

Este tipo de chistes se encuentran supeditados a la vigencia de un determinado hecho noticioso y dependen en gran medida de los conocimientos compartidos entre el autor y su modelo de audiencia. Por ejemplo, es posible que la afición por la gastronomía del candidato del PP a las elecciones al Parlamento Europeo no sea conocida por una buena parte de la sociedad española, para la que la interpretación de la imagen 7 resultará incompleta (aunque no sea errónea del todo). Y es que para la comprensión del humor es preciso contar con una triple competencia por parte del lector ${ }^{27}$. Así, su competencia genérica le permitirá identificar el mensaje como perteneciente al género de la parodia. Por otra parte, sus competencias lingüística e ideológica lo harán capaz de interpretar adecuadamente la fotografía de las aves que constituyen el símbolo del Partido Popular, y de descifrar en conjunción con

27. HutCHEON, Linda. «Ironie, satire, parodie, une approche pragmatique de l'ironie». Poétique 46 (1981), pp. 141-155. 
esta imagen el sentido implícito ${ }^{28}$ de las palabras que conforman el discurso proferido, en las que se infiere una velada alusión a la supuesta afición por la comida de Miguel Arias Cañete. También en la interpretación del siguiente tuit se hace necesaria una «competencia pragmático-comunicativa solvente, recompensada con el placer que produce descubrir los sentidos implícitos suscitados por el locutor ${ }^{29}$ :

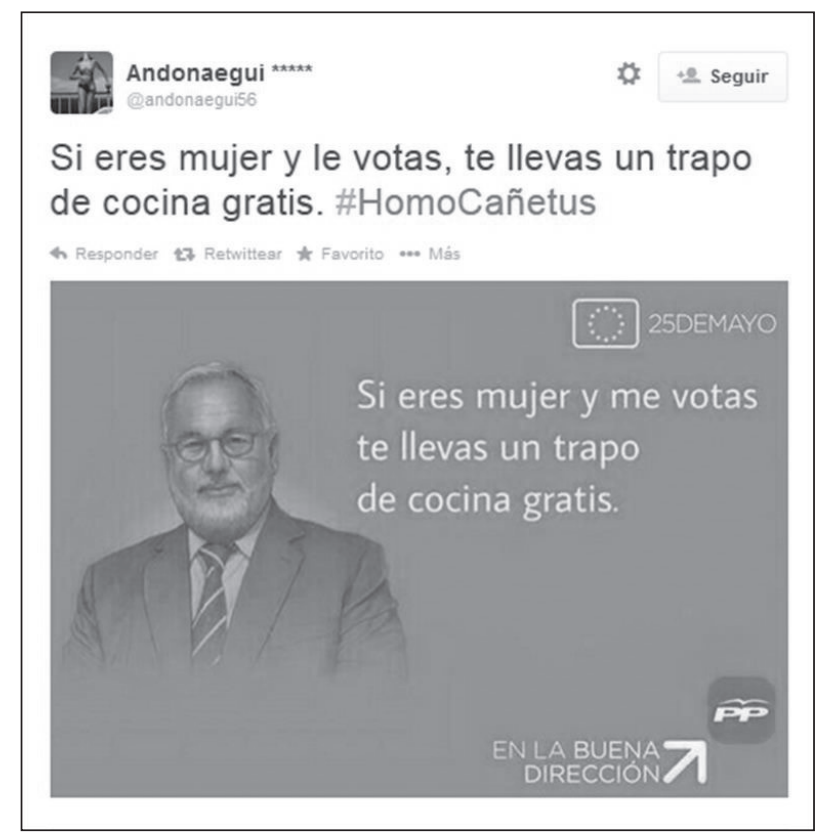

IMAGEN 8: Tuit publicado en el perfil de Twitter de Andonaegui (@andonaegui56) el 16-05-2014. Disponible en: <https://twitter.com/andonaegui56/ status/470120750209576960/photo/1>, consultado el 12-09-2014

Además, lo incongruente de este mensaje en el que se hace uso de la modalidad de intimación para pretendidamente recabar el voto femenino supone una ruptura en la isotopía discursiva, pues lo esperable en los

28. Cfr. también la teoría de la manifestación implícita de UTSUMI, Akira. «Verbal irony as implicit display of ironic environment: Distinguishing ironic utterances from non irony». Journal of Pragmatics 32 (2000), pp. 1777-1806.

29. MÉNDEZ GARCÍA DE PAREDES, Elena: «Humor y televisión en España», en Philippe Merlo y Begoña Riesgo (coords.): L'humour hispanique, Lyon, Université Lumière, vol. 1, 2003, pp. 149-189, p. 154. 
eslóganes electorales como el que se parodia no son las ofertas de obsequios, algo más propio del discurso publicitario. Por tanto, nos encontramos ante una nueva oposición de guiones. Además, las palabras del internauta parecen presentarse como muestras de «heterogeneidad enunciativa mostrada $»^{30}$, al ser atribuidas implícitamente al candidato del Partido Popular mediante el uso de la primera persona del singular en la imagen que acompaña el tuit.

Adviértase también cómo las palabras finales de este otro tuit juegan con la dilogía del sustantivo botella en el contexto particular que se presenta en el enlace inicial, que remite a un vídeo donde puede verse a la alcaldesa de Madrid, Ana Botella, formulando unas declaraciones que podrían calificarse de incoherentes:

CHINASKI (@chinaski_00). «http://facebook.com/photo.php?v= 909551985726684 ... . . . Será por esto q \#HomoCanetus se considera superior intelectualmente a las mujeres? Esto se llama BOTELLA VACÍA \#ARV». 21-05-2014. Tuit.

El sintagma nominal que aparece intensificado implica una inversión del principio de Informatividad, de acuerdo con la reformulación llevada a cabo por el grupo GRIALE sobre la inversión de los principios de Stephen C. Levinson $^{31}$. Es decir, al ocasionar una situación humorística provocada por la multiplicación de referentes evoca tanto el nombre propio de la representante del PP, como la expresión paremiológica «ver la botella medio llena o medio vacía», al tiempo que sugiere que la capacidad oratoria de esta se había visto mermada a causa del alcohol.

\subsection{Tuits paródicos}

Existen también en esta red de microblogging numerosas cuentas-parodia, creadas por internautas anónimos que se apropian de la identidad de personajes de relevancia pública para criticarlos o reírse de ellos ante sus seguidores. La mayor parte de dichas cuentas tiene una media de entre 100 y 250.000 seguidores, lo que unido a la difusión muchas veces viral de algunos de sus mensajes, que son retuiteados o reenviados regularmente de unas cuentas a

30. AuthiER-RevUZ, Jacqueline. «Hétérogénéité montrée et hétérogénéité constitutive: éléments pour une approche de l'outre dans le discourse». DRALAV 26 (1982), pp. 91-151.

31. LeVInSOn, Stephen C. Presumptive Meanings. The Theory of Generalized Conversational Implicature. Cambridge, Massachusetts, 2000. 
otras, indica que estas tienen un fuerte impacto en la red social. Como se indica en la página web de Twitter ${ }^{32}$, la suplantación de identidad o la creación de cuentas que fingen ser de otra persona con el fin de confundir o engañar es, en principio, una infracción de las reglas de la compañía. No obstante, de acuerdo con la Política de Suplantación de Identidad de la misma, sí está permitido crear cuentas parodia si el nombre de usuario difiere del nombre del sujeto parodiado, si la cuenta se distingue con un calificativo como no soy, falso o admirador, y si en el perfil se indica claramente: «Esto es una parodia» o «Cuenta de Parodia». Por ejemplo, el nombre de la alcaldesa de Valencia, Rita Barberá, se confunde premeditadamente con el de un conocido estudio de animación norteamericano en este perfil, desde el que se publican mensajes que parodian su manera de expresarse:

Rita Hanna Barbera (@truita_barbera). «No os metaís con Toni Cantó, joder... que a mí me dió clases de valenciano, vale?:-(\#tonicantofacts». 10-09-2011. Tuit.

Y hasta el álter ego de la ex presidenta de la Comunidad de Madrid, Esperanza Aguirre, recurre a la etiqueta \#EscracheSujetadores para mostrar su actitud crítica hacia las declaraciones del alcalde de Valladolid:

Esppeonza (@EsppeonzAguirre). «\#EscracheSujetadores nuevo modelo con cierre delantero para que sea mas fácil arrancarlo señor Alcalde pic.twitter. com/IIhq57Gjle». 22-08-2014. Tuit.

Alice Marwick y Danah Boyd ${ }^{33}$ proponen el concepto de contexto colapsado para explicar cómo Twitter engloba numerosas identidades en una sola, ya que la mayor parte de los usuarios de esta red social administran distintos perfiles a la vez, usando seudónimos y apodos y creando fakesters, es decir, cuentas en las que el autor simula ser un personaje célebre, con el objetivo de ocultar su propia identidad o adaptarse a distintos roles sociales ${ }^{34}$.

32. Disponible en: <https://support.twitter.com/articles/72692-pol-xed-tica-de-usurpaci-xf3-n-de-identidad>. Última consulta: 05-10-2014.

33. MARWICK, Alice y Danah BOYD. «I tweet honestly, I tweet passionately: Twitter users, context collapse, and the imagined audience». New Media \& Society 13 (1) (2010), pp. 114-133.

34. Un estudio más detallado acerca del uso humorístico de las cuentas parodias podemos encontrarlo en PANO ALAMÁN, Ana y Ana MANCERA RUEDA. «Identidades falsas y cuentas parodia en Twitter: análisis de la ironía y del humor verbal». Discurso y sociedad (en prensa). 


\subsection{Tuits irónicos}

Para Robert Escarpit ${ }^{35}$, uno de los recursos prototípicos del humor es la ironía. Si bien, es preciso tener en cuenta que, como hace notar Salvatore Attardo $^{36}$, hay ejemplos de ironía que no pueden considerarse en modo alguno humorísticos. Como el siguiente, donde un internauta dirige una apelación directa a la vicepresidenta del Gobierno en la que se sirve de un cuantificador indefinido:

El japonés (@_El_japones).«Sí señora, eso es enfrentarse al sistema, contra los recortes despilfarro. $40.000 €$ en ginecólogo me parecen pocos \#chochitodeoro». 11-06-2013. Tuit.

En virtud del contexto compartido que le confiere el hashtag motivado por la situación comunicativa ya descrita anteriormente, los lectores serán capaces de interpretar este mensaje ateniéndose a una inversión del principio de Cantidad, por el que poco pasa a adquirir una interpretación de elevada magnitud escalar. No en vano, la ironía es «una contradicción de valores argumentativos» ${ }^{37}$, pues en un nivel primario el enunciado implica realizar una afirmación original de p, con apariencia de sinceridad asertiva, para significar realmente que no se está de acuerdo con ella. Según Alain Berrendonner ${ }^{38}$, la enunciación tiene un valor argumentativo ostensible gracias a los marcadores argumentativos del propio enunciado, pero en su interpretación pueden intervenir también leyes del discurso como la ley de la lítote, capaz de dotar a la enunciación de un valor argumentativo derivado. De ahí la paradoja argumentativa que implica todo enunciado irónico. En nuestro corpus esta se pone de manifiesto, por ejemplo, por medio de sufijaciones aumentativas susceptibles de actuar como indicadores de ironía de contradicción, como en el caso del sustantivo nivelazo, utilizado en el siguiente tuit para censurar las palabras de Miguel Arias Cañete que se reproducen a continuación:

35. ESCARPIT, Robert. El humor. Buenos Aires, EUDEBA, 1962.

36. ATtARDO, Salvatore: "On the pragmatic nature of irony and its rhetorical aspects», en Németh Eniko (ed.): Pragmatics in 2000: Selected Papers from the 7th International Pragmatics Conference (IPrA), Antwerp, 2001, pp. 52-66.

37. Berrendonner, Alain. Elementos de Pragmática Lingüística. Barcelona, Gedisa, 1987, p. 151.

38. Ibíd., p 152. 


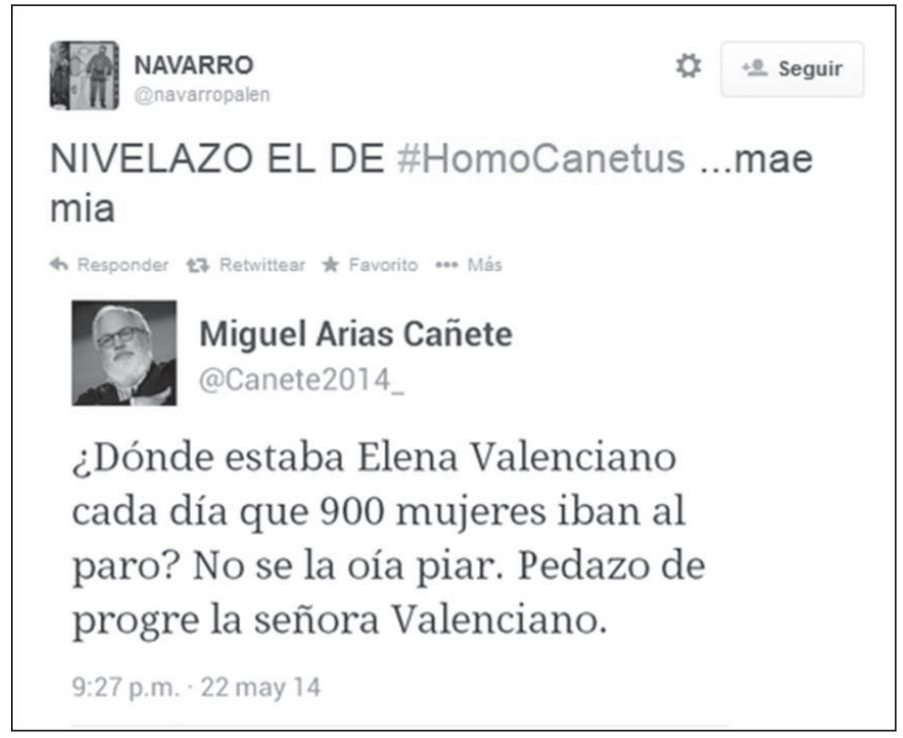

IMAGEN 9: Tuit publicado en el perfil de Twitter de Navarro (@navarropalen) el 22-052014. Disponible en: <https://twitter.com/navarropalen/status/469578936692006913/ photo/1>, consultado el 15-09-2014.

\section{Estudio cuantitativo}

Ya Nicholas Negroponte ${ }^{39}$ o Manuel Castells ${ }^{40}$ advirtieron del inmenso potencial que poseen las redes sociales para la democracia, debido a que la hiperconectividad que promueven permite construir conglomerados de relaciones, y descubrir patrones de pensamiento comunes. De hecho, según José Luis Orihuela $^{41}$, las redes sociales operan como un sistema sináptico que facilita la organización espontánea de sus participantes.

No extraña por tanto que los internautas recurran a Twitter para convocar un \#escrachedesujetadores ${ }^{42}$, para pedir la dimisión del presidente del Consejo General de la Ciudadanía en el Exterior mediante los hashtags \#dimisióncastelao o \#CastelaoDimision, o para calificar de \#machismoPSOE, \#machismoPP o \#MachismoARV las declaraciones sexistas de un político.

39. Negroponte, Nicholas. Being Digital. Nueva York, Knopf, 1995.

40. CASTElls, Manuel. La Galaxia Internet. Barcelona, Areté, 2001.

41. Orihuela, José Luis. Op. cit.

42. Esta idea «virtual» se plasmó también en una manifestación frente al consistorio vallisoletano, en la que las asistentes exhibieron sus sujetadores. 
Además, en ocasiones los usuarios de esta red de microblogging se sirven de la ironía o del humor para formular actos de amenaza hacia la imagen de sus representantes. Como puede apreciarse en la tabla que mostramos a continuación, en nuestro corpus esto resulta especialmente recurrente en el caso de las etiquetas \#ToniCantóFacts (donde el número de tuits que hacen uso de la ironía o del humor representa el $72,47 \%)$, \#chochitodeoro $(52,40 \%)$ y \#HomoCañetus (52,18\%):

TABLA 1: Cómputo de la presencia de mensajes que hacen uso de la ironía o el humor en el corpus analizado

\begin{tabular}{|c|c|c|c|c|c|}
\hline & $\begin{array}{l}\text { Número } \\
\text { total de } \\
\text { tuits }\end{array}$ & $\begin{array}{l}\text { Número de } \\
\text { mensajes } \\
\text { con alguna } \\
\text { muestra } \\
\text { de ironía o } \\
\text { humor }\end{array}$ & $\begin{array}{l}\text { Mensajes } \\
\text { humorísticos } \\
\text { publicados } \\
\text { desde } \\
\text { un perfil } \\
\text { masculino }\end{array}$ & $\begin{array}{l}\text { Mensajes } \\
\text { humorísticos } \\
\text { publicados } \\
\text { desde } \\
\text { un perfil } \\
\text { femenino }\end{array}$ & $\begin{array}{l}\text { Mensajes } \\
\text { humorísticos } \\
\text { publicados } \\
\text { desde un } \\
\text { perfil en el } \\
\text { que no puede } \\
\text { determinarse } \\
\text { la identidad } \\
\text { masculina o } \\
\text { femenina de } \\
\text { su autor }\end{array}$ \\
\hline \#escrachedesujetadores & 34 & $15(44,11 \%)$ & 4 & 10 & 1 \\
\hline \#EscracheDeSujetadores & 386 & $87(22,53 \%)$ & 24 & 50 & 13 \\
\hline \#HomoCañetus & 389 & $203(52,18 \%)$ & 98 & 38 & 67 \\
\hline \#ToniCantóFacts & 218 & $158(72,47 \%)$ & 104 & 17 & 37 \\
\hline \#dimisióncastelao & 140 & $12(8,57 \%)$ & 7 & 3 & 2 \\
\hline \#CastelaoDimision & 61 & $11(18,03 \%)$ & 6 & 1 & 4 \\
\hline \#chochitodeoro & 166 & $87(52,40 \%)$ & 52 & 13 & 22 \\
\hline \#MachismoARV & 36 & $7(19,44 \%)$ & 2 & 2 & 3 \\
\hline \#machismoPSOE & 22 & $3(13,63 \%)$ & 1 & 2 & 0 \\
\hline \#machismoPP & 74 & $17(22,97 \%)$ & 6 & 10 & 1 \\
\hline TOTAL & 1.526 & $600(39,31 \%)$ & $304(50,66 \%)$ & $146(24,33 \%)$ & $150(25 \%)$ \\
\hline
\end{tabular}

Nada extrañan estos datos si se tiene en cuenta que los hashtags \#ToniCantóFacts, \#chochitodeoro y \#HomoCañetus ya surgieron con la finalidad interpersonal de provocar la hilaridad entre los internautas. Y algo similar podría decirse de \#escrachedesujetadores $(44,11 \%)$ y \#EscracheDeSujetadores $(22,53 \%)$, etiquetas con las que se promovía una forma un tanto peculiar de protesta consistente en la exhibición de esta prenda interior femenina. No obstante, no es este el caso de \#machismoPP (22,97\%), \#MachismoARV 
(19,44\%), \#CastelaoDimision (18,03\%), \#machismoPSOE (13,63\%) y \#dimisióncastelao $(8,57 \%)$, surgidas preferentemente para mostrar el rechazo de los usuarios de esta red social por los comentarios denigrantes sobre las mujeres formulados por los políticos ya mencionados.

Por tanto, prima en los tuits que hacen uso de estas etiquetas la finalidad argumentativa, y solo en contados casos se pretende suscitar la risa. En tales ocasiones se hace uso de lo que podríamos considerar un humor subversivo que trata de sacar a la luz debilidades y contradicciones ocultas de las prácticas de poder ${ }^{43}$.

Dada la situación enunciativa que motiva la creación de este tipo de hashtags, surgidos para condenar la exhibición de machismo llevada a cabo por un político, cabría plantearse si son los internautas o las internautas los que más recurren a la ironía y al humor en sus mensajes. Como muestran los datos expuestos en la tabla precedente, creemos que los mensajes que mueven a la hilaridad fueron publicados en su mayoría por hombres (50,66\%), tal vez porque las mujeres se sienten más reacias a bromear sobre declaraciones en las que el sexo femenino es el principal referente. Así, solo el 24,33\% de los tuits con carácter humorístico parecen haber sido publicados por las internautas. Decimos parecen puesto que Twitter ofrece a sus usuarios la posibilidad de registrarse utilizando un perfil falso. Además, el 25\% de los mensajes de nuestro corpus en los que se hace uso del humor o la ironía han sido publicados desde cuentas como@piensomor o @Salitre_48, en las que no podemos realizar ninguna suposición sobre el sexo de quien se esconde tras ellas. Y, en general, las cifras que ofrecemos en la tabla 1 sobre la identidad masculina o femenina de los internautas no son más que meramente orientativas, por la posibilidad que ofrece esta red social de escribir desde el anonimato, adoptando un nombre de usuario sin correspondencia con la personalidad real.

\section{Conclusiones}

Basándonos en las seis fuentes en las que se sustenta la TGHV, en este trabajo hemos llevado a cabo un análisis de cómo los usuarios de Twitter se sirven de la ironía y del humor verbal para criticar a sus representantes políticos, a raíz de declaraciones o de la exhibición de comportamientos sexistas por parte de estos. Etiquetas como \#machismoPP, \#machismoPSOE, \#escrachedesujetadores o \#HomoCañetus contribuyen aquí a construir un marco cognitivo

43. BAJTín, Mijaíl. La cultura popular en la Edad Media y el Renacimiento. Madrid, Alianza Editorial, 1987.

Feminismo/s 24, diciembre 2014, pp. 163-192 
(en el sentido de George Lakoff ${ }^{44}$ ) que favorece la difusión de una contraargumentación respecto a las opiniones manifestadas por dichos políticos. No en vano, los hashtags no solo facilitan la clasificación de contenidos por su temática, sino que crean redes de mensajes y, por añadidura, de internautas que publican, leen y contestan a esos mensajes, llegando incluso a retuitearlos.

Para otorgar mayor difusión a sus críticas, los usuarios de esta red social realizan una serie de elecciones léxicas, gramaticales y fónicas, escogiendo de entre las diversas variables disponibles aquellas más apropiadas al contexto y a su finalidad interpersonal de divertir al lector, similares a las ya analizadas por Leonor Ruiz Gurillo ${ }^{45}$ a partir de la aplicación de los rasgos metapragmáticos propuestos por Jef Verschueren ${ }^{46}$. Tales elecciones son susceptibles de interpretarse como marcas e indicadores del humor verbal, al potenciar determinados mecanismos lógicos.

El estudio de cómo estos aspectos se plasman en nuestro corpus nos ha permitido identificar seis categorías distintas de mensajes, según pueda otorgárseles una interpretación humorística en virtud de una oposición de guiones, de su carácter hiperbólico, la existencia de un remate, o su naturaliza multimodal. Asimismo, hemos distinguido también entre tuits paródicos e irónicos. No obstante, de acuerdo con los resultados de nuestro análisis cuantitativo, el uso de los hashtags estudiados responde a una estrategia argumentativa encaminada a dañar la imagen pública de los líderes machistas, pero con la que no siempre se pretende suscitar la risa. Si bien, en los casos en los que prima tal intencionalidad humorística, parecen ser los hombres los que se decantan por este tipo de contenidos. Tal vez porque las mujeres se sienten más reacias a bromear sobre declaraciones en las que el sexo femenino es el principal referente. En cualquier dato, esta hipótesis no resulta fácil de demostrar, ya que la mayor parte de los internautas que publican sus mensajes en esta red social se escuda en el anonimato. Quizás porque, como han puesto de manifiesto Andreas H. Jucker ${ }^{47}$ o Seong-Jae $\mathrm{Min}^{48}$, la no revelación de la

44. LakofF, George. No pienses en un elefante: lenguaje y debate político. Madrid, Complutense, 2007.

45. RuIz GuRiLlo, Leonor. La lingüística del humor... Op. cit.

46. VersChUEREN, Jef. Para comprender la pragmática. Madrid, Gredos, 1999 [2002].

47. JUCKER, Andreas H. «Mass media communication at the beginning of the twenty-first century: Dimensions of change». Journal of Historical Pragmatics 4 (1) (2003), pp. 129-148.

48. Min, Seong-Jae. «Online vs. Face-to-Face deliberation: effects on civic engagement». Journal of Computer-Mediated Communication 12 (4) (2007). Disponible en: <http:// jcmc.indiana.edu/voll2/issue4/min.html>, consultado el 15-09-2014. 
identidad permite expresar la propia opinión de manera directa, al tiempo que propicia la comunicación desinhibida que mueve a la hilaridad.

\section{Referencias bibliográficas}

AlCÁNTARa Plá, Manuel. «Las unidades discursivas en los mensajes instantáneos de wasap». Estudios de Lingüística del Español 35 (2014), pp. 223-242.

Alvarado Ortega, María Belén y Leonor Ruiz Gurillo. Humor, ironía y géneros textuales. San Vicente del Raspeig, Publicaciones de la Universidad de Alicante, 2013.

ATTARDO, Salvatore: «On the pragmatic nature of irony and its rhetorical aspects», en Németh Eniko (ed.): Pragmatics in 2000: Selected Papers from the 7th International Pragmatics Conference (IPrA), Antwerp, 2001, pp. 52-66.

ATTARDO, Salvatore y Victor RASKIN. «Script theory revis(it)ed: Joke similarity and joke representation model». Humor 4 (3-4) (1991), pp. 293-347.

Attardo, Salvatore, Hempelmann, Christian F. y Sara Di MAIO. «Script oppositions and logical mechanisms: Modelling incongruities and their resolutions». Humor 15-1 (2002), pp. 3-46.

AuthIER-RevUZ, Jacqueline. «Hétérogénéité montrée et hétérogénéité constitutive: éléments pour une approche de l'outre dans le discourse». DRALAV 26 (1982), pp. 91-151.

BAjtín, Mijaíl. La cultura popular en la Edad Media y el Renacimiento. Madrid, Alianza Editorial, 1987.

Berrendonner, Alain. Elementos de Pragmática Lingüística. Barcelona, Gedisa, 1987.

Brown, Penelope y Stephen C. Levinson. Politeness: Some universals in language usage. Cambridge, Cambridge University Press, 1978 [1987].

CAstells, Manuel. La Galaxia Internet. Barcelona, Areté, 2001.

DAVIES, Christie. «Logical mechanisms: A critique». Humor 24, número 2 (2011), pp. 159-165.

ESCARPIT, Robert. El humor. Buenos Aires, EUDEBA, 1962.

GumPerz, John Joseph. Discourse Strategies. Cambridge, Cambridge University Press, 1982.

HUTCHEON, Linda. «Ironie, satire, parodie, une approche pragmatique de l'ironie». Poétique 46 (1981), pp. 141-155.

HutCheOn, Linda: «Poética de la ironía», en Pierre Schoentjes (ed.): La poética de la ironía, Madrid, Cátedra, 2003, pp. 241-250.

JUCKER, Andreas H. «Mass media communication at the beginning of the twentyfirst century: Dimensions of change». Journal of Historical Pragmatics 4 (1) (2003), pp. 129-148. 
LAKOFF, George. No pienses en un elefante: lenguaje y debate político. Madrid, Complutense, 2007.

LARA, Tíscar. «Twitter y sus funciones comunicativas». Tíscar.com, 13-02-2012. Disponible en: <http://tiscar.com/2012/03/11/twitter-y-sus-funciones-comunicativas/>, consultado el 15-09-2014.

LEVInSON, Stephen C. Presumptive Meanings. The Theory of Generalized Conversational Implicature. Cambridge, Massachusetts, 2000.

MARwiCK, Alice y Danah BoyD. «I tweet honestly, I tweet passionately: Twitter users, context collapse, and the imagined audience». New Media E Society 13 (1) (2010), pp. 114-133.

MÉNdez García DE PAREDES, Elena: «Humor y televisión en España», en Philippe Merlo y Begoña Riesgo (coords.): L'humour hispanique, Lyon, Université Lumière, vol. 1, 2003, pp. 149-189.

Min, Seong-Jae. «Online vs. Face-to-Face deliberation: effects on civic engagement». Journal of Computer-Mediated Communication 12 (4) (2007). Disponible en: <http://jcmc.indiana.edu/voll2/issue4/min.html>, consultado el 15-09-2014.

Negroponte, Nicholas. Being Digital. Nueva York, Knopf, 1995.

OriHuela, José Luis. Mundo Twitter. Barcelona, Alienta, 2011.

PAdilla, Xosé Antonio y Elisa GIRONZETTI: «Humor e ironía en las viñetas cómicas periodísticas: un estudio pragmático-intercultural», en María Elena Placencia y Carmen García (eds.): Pragmática y Comunicación Intercultural en el mundo hispanohablante, Ámsterdan, Rodopi, 2012, pp. 93-133.

PANO AlamÁn, Ana y Ana MANCERA RUEDA. «Identidades falsas y cuentas parodia en Twitter: análisis de la ironía y del humor verbal». Discurso y sociedad (en prensa).

RASKIN, Victor. Semantic Mechanisms of Humor. Reidel, Dordrecht, 1985.

RuIz Gurillo, Leonor. La lingüística del humor en español. Madrid, Arco/Libros, 2012.

Ruiz Gurillo, Leonor y María Belén Alvarado OrTega. Irony and humor: from pragmatics to discourse. Ámsterdam, John Benjamins, 2013.

TIMOFEEVA, Larissa: «Las unidades fraseológicas», en Leonor Ruiz Gurillo y Xosé Antonio Padilla García (eds.): Dime cómo ironizas y te diré quién eres. Una aproximación pragmática a la ironía, Fráncfort, Peter Lang, 2009, pp. 193-217. UTSUMI, Akira. «Verbal irony as implicit display of ironic environment: Distinguishing ironic utterances from non irony». Journal of Pragmatics 32 (2000), pp. 1777-1806.

VersCHUEREN, Jef. Para comprender la pragmática. Madrid, Gredos, 1999 [2002]. 
LA COMPETENCIA HUMORÍSTICA 



\title{
EL HUMOR VERBAL EN NIÑOS DE EDUCACIÓN PRIMARIA: DESARROLLO DE LA CONCIENCIA METAPRAGMÁTICA
}

\author{
LARISSA TIMOFEEVA TIMOFEEV \\ Universitat d'Alacant \\ Grupo ACQUA (http://dfelg.ua.es/acqua) \\ Grupo GRIALE (http://dfelg.ua.es/griale)
}

Recibido: 15/09/2014

Aceptado: 24/11/2014

\section{Resumen}

Este trabajo constituye un estudio sobre el humor verbal en niños y niñas de $4 .^{\circ}$ curso de Educación Primaria (9-10 años). Tres grandes vías articulan el análisis. En primer lugar, el debate sobre las presuntas diferencias de género en la interpretación y el uso del humor verbal obtiene un interés especial en el caso de los niños, dado su menor nivel de «contaminación» por las convenciones y prejuicios sociales. En segundo lugar, se detecta la práctica ausencia de estudios sobre el humor infantil desde el punto de vista lingüístico, ya que el grueso de las investigaciones sobre el tema proviene de la psicología evolutiva. En tercer lugar, la etapa de edad objeto de este estudio responde a un periodo crucial en el desarrollo lingüístico y, especialmente, metalingüístico del niño.

Palabras clave: Humor infantil, conciencia metapragmática, perspectiva de género.

\begin{abstract}
This paper focuses on some aspects of humour acquisition, based on the analysis of humorous narratives written in Spanish by 9-10-year-old schoolchildren. The analysis is supported by three main ideas. Firstly, the debate about gender differences of humour processing becomes especially interesting in the case of children due to their less cultural and social «contamination». Secondly, an important lack of linguistic studies about children's humour is revealed since the main body of research is of
\end{abstract}


developmental psychology. Thirdly, the age period analysed in this paper is one of the most important in linguistic and, especially, metalinguistic development of children.

Keywords: Children's humour, metapragmatic awareness, gender perspective.

Feminismo/s 24, diciembre 2014, pp. 195-219 


\section{Introducción}

Este trabajo constituye una presentación general de un estudio sobre el humor verbal en niños y niñas de $4 .^{\circ}$ curso de Educación Primaria (9-10 años). Ha sido realizado en el marco del proyecto de investigación «Innovaciones lingüisticas del humor: géneros textuales, identidad y enseñanza del español» (FFI2012-30941) ${ }^{1}$.

La idea y el propósito del estudio obedecen a una serie de razones surgidas a raíz de la investigación previa sobre el tema. En primer lugar, el debate sobre las presuntas diferencias de género en la interpretación y el uso del humor verbal obtiene un interés especial en el caso de los niños, dado su menor nivel de «contaminación» por las convenciones y prejuicios sociales. En este sentido, nos parece esencial analizar si niños y niñas codifican de la misma manera sus enunciados humorísticos o muestran divergencias en lo que a las marcas e indicadores lingüísticos atañe.

En segundo lugar, nuestras indagaciones han revelado la práctica ausencia de estudios sobre el humor infantil desde el punto de vista lingüístico. Es sólida y relativamente prolija la investigación sobre el tema desde la psicología evolutiva que se dedica a la formación y el desarrollo de la competencia humorística en niños como parte de su maduración cognitiva y psicológica². En estos casos, el humor lingüístico se analiza como elemento integrante de la competencia global, pero nunca se observa desde su propia identidad. Por este motivo, un estudio como el que aquí presentamos se presenta innovador,

1. Este proyecto de investigación, dirigido por la Dra. Leonor Ruiz Gurillo, se lleva a cabo por el Grupo GRIALE (http://dfelg.ua.es/griale/). El estudio que se presenta fue coordinado por la Dra. Larissa Timofeeva, y su realización fue posible gracias a la ayuda y colaboración de los investigadores L. Aliaga, B. Alvarado, A. Mura, A. Pérez, S. Rodríguez y L. Ruiz.

2. cfr. McGhee, P. E. Humor: Its Origin and Development. San Francisco, W. H. Freeman, 1979; McGHEE, P. E. Understanding and Promoting the Development of Children's Humor. Dubuque, Kendall Hunt Publishing, 2002; MARTIN, R. A. The Psychology of Humor: An Integrative Approach. Burlington, Elsevier Academic Press, 2007; HOICKA, E. «The Pragmatic Development of Humor», en D. Mathews (ed.). Pragmatic Development in First Language Acquisition. Amsterdam, John Benjamins, 2014, pp. 219-238. 
pues pone el foco en la faceta lingüística del humor teniendo la psicología como telón de fondo. Nos interesamos por el aspecto «visible» del humor verbal, ya que son los elementos lingüísticos concretos, englobados bajo las denominaciones de marcas e indicadores del humor ${ }^{3}$, los que centran nuestra atención.

En tercer lugar, la etapa de edad objeto de este estudio -de 9-10 añosresponde a un periodo crucial en el desarrollo lingüístico y, especialmente, metalingüístico del niño ${ }^{4}$. Sus actuaciones verbales muestran cada vez menor grado de «cosificación», esto es, se hacen más abstractas e independientes de la presencia de los objetos en el entorno. Asimismo, la conciencia metapragmática se va perfilando y el discurso infantil va incorporando contenidos inferenciales acordes con el contexto lingüístico y extralingüístico.

Todos estos aspectos aparecen imbricados en el complejo fenómeno del humor verbal infantil. En lo que sigue, propondremos algunas líneas para avanzar en su investigación. Para ello, en primer lugar explicaremos los fundamentos teóricos de nuestro estudio (§ 2) para, a continuación, presentar la estructura (§ 3) y algunos resultados provisionales del mismo (§ 4). Unas breves conclusiones ( $\$ 5$ ) cerrarán el trabajo.

\section{Fundamentos teóricos}

Como hemos comentado, los niños que participaron en el estudio que exponemos aquí presentan un perfil de investigación muy interesante. Tal interés se apoya en, al menos, tres pilares teóricos. Por un lado, el desarrollo de la competencia metapragmática centra nuestra atención, pues los niños de la edad estudiada se encuentran en un momento clave marcado por el paso desde una comunicación epipragmática hacia una nueva fase caracterizada por la capacidad de, no solo ajustar su mensaje al contexto sino también de explicar y explicitar conscientemente sus decisiones pragmáticas. Por otro lado, dentro de dicha habilidad metapragmática, la competencia humorística experimenta un cambio sustancial en la franja vital estudiada en que el lenguaje empieza a adquirir un papel fundamental. Finalmente, en tercer lugar, el desarrollo de la habilidad escrita se presenta como un aspecto esencial

3. Para más detalle vid. Ruiz GuriLlo, L. La lingüística del humor en español. Madrid, Arco/ Libros, 2012, pp. 78-86.

4. Piaget, J. El lenguaje y el pensamiento del niño pequeño. Barcelona, Paidós, 1987; GoMBERT, J. «Metalinguistic development in first language acquisition», en L. Van Lier \& D. Corson (Eds.), Encyclopedia of Language and Education. Volume 6, Knowledge about language. Dordrecht/Boston, Kluwer Academic Publishers, 1997, pp. 43-51. 
dadas las características de nuestra investigación. A continuación presentaremos sucintamente los puntos clave de cada uno de los tres ámbitos teóricos implicados.

\subsection{La conciencia metapragmática}

El uso del lenguaje con fines comunicativos se fundamenta en un conocimiento consciente sobre el funcionamiento del sistema lingüístico y las relaciones que este establece con el contexto. Dicho de otro modo, todo acto verbal presupone un "control intencional de los parámetros lingüísticos que determinan la eficiencia del mensaje, en concordancia con aspectos extralingüísticos de la situación en la cual el enunciado se presenta» $»^{5}$. La conciencia metapragmática se entiende, por tanto, en relación a dicho control o capacidad del hablante de organizar su mensaje lingüístico de la manera que consiga inducir a su interlocutor hacia una respuesta perlocutiva buscada ${ }^{6}$.

Según defiende Verschueren ${ }^{7}$, la conciencia metapragmática se convierte en una noción imprescindible para poder entender nuestro comportamiento lingüístico:

Reflexive awareness is so central that all verbal communication is selfreferential to a certain degree, or that there is no language use without a constant calibration [...] between pragmatic and metapragmatic functioning. This phenomenon forms the proper domain of metapragmatics ${ }^{8}$

A pesar de su evidencia, la conciencia metapragmática no deja de ser una noción demasiado abstracta ${ }^{9}$. En palabras de Verschueren ${ }^{10}$, «awareness is not measurable, and the notion lends itself to easy speculation». Por eso, un estudio sobre los aspectos metapragmáticos obtiene su concreción en el análisis de las diversas pistas verbales utilizadas por los interlocutores que evidencian la conciencia reflexiva subyacente a la comunicación lingüística.

La conciencia metapragmática se adquiere en la infancia y es producto de nuestra educación comunicativa. Las circunstancias y las experiencias

5. CRespo, N. y Alvarado, C. «Conciencia metapragmática y memoria operativa en niños escolares». Literatura y Lingüística, 21 (2010), p. 95.

6. cfr. PortolÉs J. Pragmática para hispanistas. Madrid, Síntesis, 2004, pp. 31-46.

7. VERSCHUEREN, J. «Notes on the role of metapragmatic awareness in language use», Pragmatics, 10:4 (2000), pp. 439-456.

8. Ibíd., pp. 445-446.

9. cfr. GOMBERT, J. «Metalinguistic development in first language acquisition», p. 44; STUDE, J. «The acquisition of metapragmatic abilities in preschool children», en Bublitz, W. \& Hübler, A. (eds.), Metapragmatics in use. Amsterdam, John Benjamins, 2007, pp. 199-220.

10. VERSCHUEREN, op. cit., p. 445.

Feminismo/s 24, diciembre 2014, pp. 195-219 
verbales que rodean al niño durante su infancia perfilan su conocimiento sobre el lenguaje y le capacitan para reflexionar y expresar sus reflexiones sobre los comportamientos lingüísticos propios y de otras personas.

De acuerdo a esta visión, se destacan tres fases en la adquisición de la competencia metapragmática: de adquisición inicial, la epipragmática y la metapragmática ${ }^{11}$. En la primera fase de adquisición inicial el niño aprende a utilizar las primeras formas lingüísticas relacionadas de manera unívoca con determinados contextos. En la fase epipragmática el infante toma conciencia de que la relación entre lo lingüístico y lo contextual es más heterogénea, pero todavía no discrimina entre ambas informaciones. El ajuste de las formas lingüísticas a las circunstancias contextuales, por tanto, se realiza de manera automática, con consiguientes fallos ocasionales especialmente cuando tal ajuste se basa en una relación no literal. En esta fase epipragmática el niño todavía no sabe explicitar verbalmente sus decisiones pragmáticas. Es a partir de aproximadamente seis años cuando se aprende a discernir entre el mensaje lingüístico y el contexto, así como a ejercer un control sobre la relación que establecen ambas informaciones en el uso. El niño adquiere una competencia metapragmática que, además, le capacita para explicar explícitamente cómo realiza dicho control, tanto desde el punto de vista productivo como interpretativo.

\subsection{El humor}

Dentro de la competencia metapragmática en general, la expresión lingüística del humor constituye una de las habilidades más complejas. En este apartado haremos una breve revisión de los aspectos más relevantes del proceso de adquisición del humor en niños (2.2.1.) y del estudio del humor infantil desde la perspectiva de género (2.2.2.).

\subsubsection{Adquisición del humor}

La evolución de la competencia humorística transcurre imbricada en el desarrollo cognitivo general del niño y va progresando acorde a las diversas fases de maduración. Si bien los bebés protagonizan sus primeras actuaciones humorísticas -manifestadas a través de risa o sonrisa- a la temprana edad de 6 meses, el proceso global no se completa hasta los 10-11 años. A partir de esa edad se considera que el niño ya posee todas las herramientas cognitivas y lingüísticas para interpretar y producir el humor.

11. Gombert, J. Metalinguistic development. New York, Wheatsheaf, 1992. 
Diversos estudios apuntan a que hay dos ingredientes básicos cuya comprensión articula la formación de la competencia humorística en niños: la incongruencia y la intención. La incongruencia se relaciona con la sorpresa que nace de la discrepancia con las expectativas existentes respecto a un objeto, un hecho, etc. Como señala Cunningham ${ }^{12}$, se ha observado que ya los bebés menores de 7 meses ríen notablemente más ante un estímulo espontáneo e inesperado que ante uno repetido y previsible, lo que indica que la noción de incongruencia empieza a formarse a partir de las primeras manifestaciones del humor en la vida del bebé.

En lo que se refiere a la intención, a la edad de 14-18 meses los niños se muestran capaces de distinguir entre acciones intencionadas y los errores no premeditados. Un poco más tarde, a partir de 25 meses, ya pueden discernir entre una broma y un error, basándose, precisamente, en su carácter intencionado o no. El valor de estos descubrimientos, según Hoicka y Gattis ${ }^{13}$, reside principalmente en el hecho de que a través del humor el niño comprende que detrás de una acción humana puede haber una intención, aun cuando dicha acción es errónea ${ }^{14}$. Esta idea entronca directamente con la formación de la competencia metapragmática, ya que la comprensión de la intención humorística -primero desde la perspectiva interpretativa y más tarde también desde la productiva-implica un control consciente de la relación que se establece entre la información verbal y no verbal explícita y el valor implícito del mensaje.

La formación de la competencia humorística en niños atraviesa varias fases evolutivas que van parejas a su maduración cognitiva y lingüística. En 1979 Paul McGhee propone un modelo de desarrollo del humor infantil basado en la correlación con las cuatro etapas del desarrollo cognitivo de Piaget $^{15}$. Tras una reformulación posterior ${ }^{16}$, el autor considera la existencia de 6 fases -incluido un periodo inicial de pre-humor- por las que atraviesa el niño en su desarrollo del humor:

12. Cunningham, J. «Children's humor», en W. G. Scarlett, S. Naudeau, D. Salonius-Pasternak, I. Ponte (eds.), Children's play. SAGE publications, 2005, p. 99.

13. HoICKA, E. y GATTIS, M. «Do the wrong thing: how toddlers tell a joke from a mistake», Cognitive Development, 23 (2008), pp. 180-190.

14. En este sentido vemos también un punto de encuentro con la pragmática básica de Grice según la cual, se infrinjan o no las máximas conversacionales que propone, el Principio de cooperación siempre regulará la comunicación humana (GRICE, P. H. Studies in the Way of Words. Cambridge, MA, Harvard University Press, 1989).

15. Piaget, J., op. cit.

16. MCGHEE, P. E. Understanding and Promoting the Development of Children's Humor.

Feminismo/s 24, diciembre 2014, pp. 195-219 
Stage 0: Laughter Without Humor, de 0 a 6 meses;

Stage 1: Laughter at the Attachment Figure, de 6 a 12-15 meses;

Stage 2: Treating an Object as a Different Object, de 12-15 meses a 2-3 años;

Stage 3: Misnaming Objects or Actions, de 2 a 3-4 años;

Stage 4: Playing With Words, de 3 a 5-6 años;

Stage 5: Riddles and Jokes; a partir de 6-7 años.

El grupo de edad que abordamos en nuestro estudio se situaría en esta última franja evolutiva de Riddles and Jokes. Durante este periodo, gracias al progreso de la capacidad metalingüística, el niño mejora el control metapragmático de sus producciones lingüísticas. Por otro lado, su capacidad de manejar en su mente varios esquemas cognitivos a la vez y de imaginar o prever los posibles resultados de sus acciones, sin que tenga que realizarlas, le enseña la reversibilidad del pensamiento, esto es, que las operaciones mentales pueden ser revertidas anulando, de esta forma, sus efectos ${ }^{17}$. Todos estos aspectos capacitan al niño a entender el humor basado en la ambigüedad, los dobles sentidos y otras formas más sofisticadas del pensamiento. Si al principio de esta etapa el infante se dedica a memorizar las distintas bromas y chistes basados en juegos de palabras (actuación epipragmática) con el fin de compartirlos con sus amigos y la gente de su entorno, poco a poco su madurez metapragmática motiva su creatividad para generar sus propias muestras humorísticas. Otro aspecto fundamental que caracteriza este estadio tiene que ver con la fase de resolución del acto humorístico. Martin ${ }^{18}$ comenta que varios estudios han apuntado hacia la idea de que los niños van evolucionando desde el humor basado exclusivamente en la incongruencia hacia el humor fundamentado en la incongruencia-resolución ${ }^{19}$, y la transición coincide más o menos con el último estadio de McGhee. Otras investigaciones han sembrado alguna duda al respecto señalando que los niños en estadios anteriores igualmente utilizan procedimientos resolutivos, pero de otra índole; y que los niños mayores, o incluso los adultos, siguen disfrutando del humor que contiene solo incongruencia. Sin embargo, lo que sí parece cierto es que la comprensión de una estructura humorística tradicional (propia de un chiste, por ejemplo), con la incongruencia que se resuelve al final, se adquiere en ese último estadio de Riddles and Jokes.

En lo que se refiere al comportamiento lingüístico, cabe suponer que en este estadio fluctuará entre las actuaciones más epipragmáticas y las ya

17. MARTIN, R. A., op. cit., p. 240.

18. Ibíd., pp. 241-243.

19. Para las diversas concepciones teóricas del humor y sus componentes remitimos al lector a Ruiz GuRILlo, L. Op. cit. 
propiamente metapragmáticas. Esto está acorde con lo reflejado por la propuesta de $\mathrm{McGhee}^{20}$. Como se observa, algunas franjas de edad pertenecen a varias etapas evolutivas a la vez, lo cual significa que el niño no «abandona» radicalmente el estadio anterior para pasar al siguiente, sino que "convive» en varios de ellos. De esta forma, por ejemplo, un niño que se encuentra en el estadio 4 puede seguir encontrando divertido el humor propio de las etapas anteriores, aunque tenga dificultades todavía para interpretar el humor característico del estadio 5 .

\subsubsection{El humor y la perspectiva de género}

Junto con las investigaciones sobre la adquisición del humor, los estudios que abordan el tema desde la perspectiva de género tienen ya cierta tradición en la psicología. No obstante, tal tradición no es para nada continuista, ya que los trabajos más recientes rompen con la visión anterior que se ha reconocido como sesgada y carente de fundamento científico. Se han dejado de lado las afirmaciones sobre la ausencia del sentido del humor en las mujeres ${ }^{21}$ y se ha dirigido mayor atención hacia el humor espontáneo que surge en los contextos de interacción naturales ${ }^{22}$. Esta nueva perspectiva ha permitido demostrar que no existen diferencias esenciales entre la producción humorística de hombres y mujeres, si bien cada sexo muestra ciertas preferencias cualitativas. Por ejemplo, hombres y mujeres muestran índices similares en el uso de bromas agresivas, especialmente en el grupo de las personas de su mismo sexo. No obstante, los hombres se identifican más con el humor hostil y las bromas «enlatadas», mientras que las mujeres optan por las anécdotas propias o de otras personas. Tal recurso a experiencias personales también es utilizado por las mujeres para consolar o ayudar a sus amigos a superar situaciones difíciles, lo que se enmarca dentro de la tendencia general que han mostrado las mujeres en recurrir en mayor medida que los hombres al humor para crear o mantener los lazos de solidaridad en el grupo ${ }^{23}$. Estas «preferencias» humorísticas se forjan ya en la infancia, como han puesto de manifiesto algunas investigaciones.

20. MCGHEe, P. E. Understanding and Promoting the Development of Children's Humor.

21. LAKOFF, R. Language and Woman's Place. New York, Harper \& Row, 1975.

22. MARTIN, R. A. Op. cit., pp. 147-150.

23. Ibíd., p. 149.

Feminismo/s 24, diciembre 2014, pp. 195-219 
En referencia a este tema, Lyon ${ }^{24}$ alude a un estudio de Socha y Kelly ${ }^{25}$ que muestra que hasta los 7 años las producciones humorísticas infantiles presentan un cariz más prosocial, mientras que a partir de dicha edad -y coincidiendo más o menos con el último estadio evolutivo de la clasificación de McGhee $^{26}$ - su humor se vuelve cada vez más antisocial. Desde el punto de vista de género, al parecer a esa edad los chicos generan más humor agresivo y hostil que las chicas, y estas, a su vez, son menos proclives a dar muestras públicas de su sentido del humor. No obstante, los investigadores apuntan que semejante interpretación obedece a la perspectiva de adultos (padres y profesores), y no ha sido corroborada por los propios menores. Dicho de otro modo, los niños y niñas participantes en los estudios no tienen la misma percepción, tanto en lo que se refiere a mayor agresividad del humor de los chicos como a la «timidez» humorística de las $\operatorname{chicas}^{27}$. Bajo este prisma se plantea, por ejemplo, la necesidad de definir adecuadamente las nociones de agresividad u hostilidad que manejamos en relación al humor infantil, pues ello contribuiría a su correcto tratamiento educativo ${ }^{28}$.

\subsection{La competencia escrita}

Como señala Verschueren ${ }^{29}$ "writing is a verbal activity involving a generally high degree of consciousness in the making of linguistic choices (in comparison to more spontaneous oral interaction)». Por tanto, la elaboración de un texto escrito exige por parte del niño un alto nivel de madurez metalingüística, y metapragmática en particular. Como señalan Crespo, Benítez y Pérez ${ }^{30}$, el infante ha de realizar una representación mental de una situación retórica del escrito, a saber, su tópico, su posible destinatario y el propósito del escrito. «Esta representación le permite suplir la carencia de un contexto empírico y perceptible, típico de la lengua oral $»^{31}$.

24. LYON, C. «Humour and the young child. A review of the research literature». Televizion, 19 (2006), pp. 6-7.

25. SOCHA, T. J. \& KellY, B. «Children making 'fun': humorous communication, impression management, and moral development». Child Study Journal, 24:3 (1994), pp. 237-252.

26. MCGHEE, P. E. Understanding and Promoting the Development of Children's Humor.

27. cfr. BERGEN, D. «Humor, play and child development», en Klein, A. (ed.). Humor in children's lives. Westport, Praeger, 2003; LyON, C. Op. cit.

28. LYON, C. Op. cit., p. 7.

29. VeRSCHUEREN, J. Op. cit., p. 444.

30. Crespo, N., Benítez, R., PÉREZ, L. «Conciencia metapragmática y la habilidad para producir narraciones escritas», Revista Signos, 43:73 (2010), pp. 185-187.

31. Ibíd., p. 185. 
La franja de edad objeto de nuestro estudio está representada por escolares que han sido instruidos en la escritura durante al menos 4 años, desde que empezaron Educación Primaria. Por este motivo, su competencia escrita todavía no está plenamente asentada y era previsible que sus textos tuvieran muchos rasgos de oralidad al ser este el «terreno» que mejor conocen. De hecho, Crespo, Benítez y Pérez ${ }^{32}$ subrayan que en un estudio con niños de 8 años los participantes mostraron en sus narraciones bastante confusión en las secuencias temporales, pobreza de elementos cohesivos y otros rasgos que permiten concluir que los niños escriben como hablan.

En lo que se refiere a los tres componentes de la situación retórica -el tópico, el destinatario y el propósito- el primero, en el caso de nuestro estudio, fue suministrado por los propios investigadores, con el objetivo de no distraer a los niños en la búsqueda de un tema adecuado y de centrar su esfuerzo en el desarrollo del tema en sí. Esto nos permitía, además, homogeneizar las muestras y evitar que la elección más o menos acertada del tema determinara su carácter humorístico.

Por su parte, el componente del destinatario o lector del texto constituye uno de los aspectos más difíciles de manejar ${ }^{33}$. Como subrayan Crespo, Benítez y Pérez ${ }^{34}$, la tarea de elaborar el texto teniendo en mente a sus destinatarios se complica si estos no se encuentran en el contexto inmediato como pasa en la modalidad escrita. El niño, por tanto, ha de representarse mentalmente a su lector y atribuirle ciertas características, ya que ello determinará, por ejemplo, el registro que decida emplear. El joven escritor, consecuentemente, recurre a ciertas estrategias para suplir la ausencia de un lector claramente identificable, que pueden consistir en el empleo de esquemas, dibujos, acotaciones y explicaciones de todo tipo. Todos estos recursos pretenden clarificar aquellos aspectos susceptibles, en opinión del niño, de ser interpretados erróneamente y asegurar así la comprensión correcta del texto por parte del lector. En nuestro estudio lo único que sabían los escolares era que sus narraciones formaban parte de una investigación llevada a cabo por unos profesores de la Universidad de Alicante, aunque no parece que lo entendieran como información sobre los destinatarios de sus textos. Sin embargo, los niños sí que recurrieron a diversas técnicas de «creación» de su lector, tal y como veremos en el § 4 .

Respecto al tercer componente de situación retórica -el propósito- los participantes del estudio fueron informados que su tarea consistía en narrar

32. Ibíd., pp. 192-194.

33. cfr. CRESPO, N., BENÍTEZ, R. y CÁCERES, P. «La comprensión oral del lenguaje no literal y su relación con la producción escrita en escolares», Revista Signos, 40:63 (2007), p. 35.

34. Crespo, N., Benítez, R., Pérez, L. Op. cit., p. 186. 
una historia. Por tanto, el propósito del texto también fue acotado previamente lo que hizo que los niños optaran en su mayoría por la tipología narrativa, la más fácil para ellos, por otro lado.

\section{Estructura del estudio}

A continuación presentaremos la estructura del estudio, centrándonos en los objetivos, datos de los participantes, metodología y procedimientos, así como los aspectos básicos del procesamiento de datos.

\subsection{Objetivos del estudio e hipótesis de trabajo}

Tras presentar el andamiaje teórico que sustenta nuestro estudio, los objetivos que nos planteamos se pueden resumir según sigue:

- Observar la relación entre la expresión lingüística del humor y las fases de desarrollo del humor como competencia metapragmática en niños y niñas de 9-10 años.

- Analizar el uso de marcas e indicadores lingüísticos del humor por parte de niños y niñas a la edad estudiada en relación al nivel de desarrollo de su competencia escrita.

Respecto al primer objetivo planteado, acorde al modelo de $\mathrm{McGhee}^{35}$ los escolares de 9-10 años ya han alcanzado el último estadio de desarrollo del humor (Riddles and Jokes) donde el uso creativo del lenguaje es central. Asimismo, su competencia humorística está imbricada dentro del proceso de su maduración metapragmática que aún se está consolidando a esa edad. Crespo ${ }^{36}$ y Crespo, Benítez, Pérez ${ }^{37}$ muestran con datos empíricos que a los 8 años los niños todavía presentan una conciencia fundamentalmente epipragmática, por lo que en nuestro caso era esperable que el uso de procedimientos epipragmáticos aún fuera elevado. Asimismo, y dado el carácter no sistemático de la conciencia metapragmática, era previsible encontrar tanto las muestras epipragmáticas como las metapragmáticas dentro de las mismas narraciones.

Relacionado con lo anterior, Crespo, Benítez y Pérez ${ }^{38}$ subrayan la práctica ausencia de ejemplos del lenguaje figurado (ironía, fraseología, metáforas, hipérboles) en las narraciones de los niños de 8 años, lo que denota un nivel

35. McGHeE, P. E. Understanding and Promoting the Development of Children's Humor.

36. CRESPO, N. «La medición de la conciencia metapragmática de los niños: resolviendo la ambigüedad en la comprensión oral», RLA, 47:2 (2009), pp. 69-88.

37. Crespo, N., Benítez, R., Pérez, L. Op. cit.

38. Ibíd., p. 192. 
todavía bajo de desarrollo metapragmático. Teniendo en cuenta que nuestros informantes ya se encuentran en cotas algo superiores, y que la expresión del humor exige altas dosis de figuratividad, era esperable que la presencia de elementos figurados en las narraciones fuera mayor.

En referencia al segundo objetivo planteado, si bien el humor de los participantes en nuestro estudio se suponía más metapragmático, cabía esperar que la tarea de producir un texto escrito en un tiempo limitado iba a representar cierta dificultad. Ello se reflejaría en un notable apego a la oralidad, por lo que las marcas e indicadores del humor más frecuentes también serían más propios de la modalidad oral.

En lo que concierne a las diferencias de género, en el estudio citado de Crespo, Benítez y Pérez ${ }^{39}$ las niñas obtuvieron unas calificaciones significativamente superiores en su nivel de expresión escrita. Ello sugiere que si la tendencia se mantiene, las niñas de nuestro estudio presentarían una mayor diversidad en el uso de marcas e indicadores del humor. Por el contrario, si no existen demasiadas diferencias en este sentido, es posible que sea debido a que la brecha de la expresión escrita entre ambos sexos haya disminuido. El análisis de los datos obtenidos en el estudio también puso de manifiesto otros aspectos interesantes desde la perspectiva de género que se debaten en el $\$ 4$.

\subsection{Datos de los participantes}

El estudio que presentamos en este trabajo se llevó a cabo durante el curso académico 2012-2013 y en él participaron 149 alumnos de $4 .^{\circ}$ curso de Educación Primaria procedentes de cinco colegios -cuatro públicos y uno privadosituados en diversos puntos de la provincia de Alicante. Tras una revisión, la muestra se depuró hasta 148 narraciones. En la siguiente tabla recogemos los datos de los centros y la distribución de los participantes.

39. Ibíd., p. 194.

Feminismo/s 24, diciembre 2014, pp. 195-219 


\begin{tabular}{|c|c|c|c|c|}
\hline Centro & Tipo & Zona & $\begin{array}{l}\text { Programa } \\
\text { lingüístico }\end{array}$ & $\begin{array}{c}\mathrm{N}^{\circ} \text { de } \\
\text { participantes }\end{array}$ \\
\hline DIVINA AURORA (Beneixama) & público & valencianoparlante & $\begin{array}{c}\text { Programa } \\
\text { d'ensenyament } \\
\text { en valencià } \\
(\mathrm{PEV})\end{array}$ & 13 \\
\hline $\begin{array}{l}\text { MARE DE DÉU DEL CARME } \\
\text { (La Canyada) }\end{array}$ & público & $\begin{array}{l}\text { predominantemente } \\
\text { valencianoparlante }\end{array}$ & $\begin{array}{c}\text { Programa } \\
\text { d'incorporació } \\
\text { progressiva } \\
\text { (PIP) }\end{array}$ & 10 \\
\hline ANTONIO MACHADO (Elda) & público & castellanoparlante & ----- & 41 \\
\hline $\begin{array}{l}\text { INMACULADA CONCEPCIÓN } \\
\text { (Torrevieja) }\end{array}$ & público & castellanoparlante & ----- & 48 \\
\hline $\begin{array}{l}\text { SAN ALBERTO MAGNO } \\
\text { (Monforte del Cid) }\end{array}$ & privado & castellanoparlante & \begin{tabular}{|c|} 
Programa \\
para el uso \\
progresivo \\
del inglés \\
como lengua \\
vehicular \\
(PUPILV); \\
francés o \\
alemán a partir \\
de $3^{\circ}$ de EP
\end{tabular} & 37 \\
\hline
\end{tabular}

1. Datos de los participantes

Como muestra la tabla, los resultados de nuestro estudio permiten una interpretación atendiendo a diversas variables, a saber, el sexo del alumno, el tipo de centro (público o privado), así como el entorno y el programa lingüísticos que sigue en su centro.

Respecto a la distribución por género, entre los 148 informantes 75 eran chicas y 73 chicos, lo que constituye $50,68 \%$ y 49,32\% respectivamente, tal y como recoge el siguiente gráfico:

40. Para más información sobre los programas PEV y PIP consúltese la web de la Conselleria d'Educació, Cultura i Esport de la Generalitat Valenciana http://www.cece.gva. es/ocd/sedev/es/pro_edu_bil.htm. Para saber más sobre PUPILV, diríjase a la web del Colegio San Alberto Magno http://www.sanalbertomagno.eu/proyectos-educativos/ idiomas.html. 


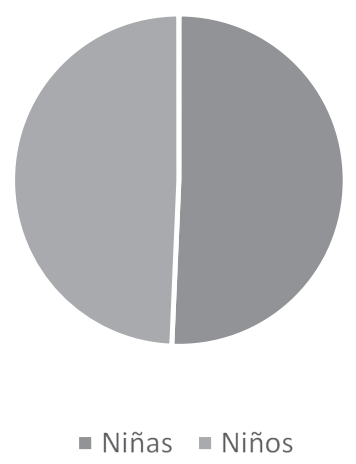

2. Distribución de informantes por género

\subsection{Procedimientos y metodología empleados}

La tarea que realizaron los participantes en el estudio consistía en una narración humorística con el siguiente tema:

\section{Un cuento humorístico}

IMAGÍNATE QUE EN EL MARCO DE UN PROGRAMA DE INTERCAMBIO ESCOLAR TIENES QUE PASAR DOS SEMANAS COMO ALUMNO DE UN COLEGIO EN... ¡MARTE!

Cuéntanos cómo es tu día de colegio, tus asignaturas, tus profesores, tus compañeros, qué hacéis en el patio, cómo te comunicas con tus amigos marcianos, cómo es el idioma en que hablas con ellos... ¡Seguro que es divertido!

\section{Tema de la narración}

El ejercicio era anónimo y lo único que tenían que indicar los informantes era su sexo, marcando la casilla correspondiente.

Como se observa, el enunciado de la tarea pretende acotar, tanto el tópico (colegio marciano) como el propósito de la situación retórica (narración humorística) (§ 2.3). La elección del tema, o tópico, obedece a los siguientes criterios:

- Que sea un tema cercano y conocido por todos los alumnos, independientemente de las características de sus centros;

- Que sea un tema lo suficientemente abierto para permitir a los participantes un amplio marco para la creación;

- Que sea un tema adecuado para construir un relato humorístico. 
De esta manera, el tema propuesto sitúa a los niños en uno de los ámbitos de donde proviene la mayor parte de ejemplos humorísticos de su vida ${ }^{41}$. Al mismo tiempo, el mundo escolar conocido por los participantes se traslada a otra dimensión planetaria, contexto que nos pareció susceptible de generar situaciones de incongruencia en las que basar la narración.

Respecto a la actuación de los profesores de los centros participantes, todos ellos se esforzaron en crear una predisposición positiva y despertar el interés de sus alumnos hacia la tarea.

\subsection{Procesamiento de datos}

Todas las narraciones recogidas fueron etiquetadas de acuerdo con el siguiente código: Centro/Sexo/Número correlativo, donde A marca que es niña y $\mathrm{O}$, que es niño. Así por ejemplo, el código SA5 indica que se trata de la narración realizada por una alumna del colegio San Alberto Magno correlativamente numerada como 5; IO16 se refiere a la narración número 16 de un alumno del colegio Inmaculada Concepción, etc.

El procesamiento de las narraciones desembocó en la creación de una base de datos Excel donde se recogen las distintas marcas e indicadores lingüísticos que utilizaron los niños y niñas en sus narraciones para expresar el humor. No obstante, esta fase del estudio también reveló una serie de deficiencias que serán subsanadas en el futuro, como por ejemplo, la ausencia de un marcador que mida las muestras epipragmáticas frente a las metapragmáticas, la carencia de un indicador del humor hostil o agresivo, o un reflejo más preciso en dicha base de datos de los elementos gráficos que usaron los informantes al describir sus intercambios lingüísticos con los alumnos «marcianos».

\section{Debate y análisis de algunos resultados}

En este apartado analizaremos algunos resultados del estudio en relación a los objetivos planteados.

\subsection{El humor y la conciencia metapragmática}

En nuestra hipótesis de trabajo planteábamos que para la franja de edad estudiada la presencia de muestras epipragmáticas en la expresión del humor aún sería notable. No obstante, el diseño inicial de nuestro estudio no contempló una herramienta de medición de este aspecto, por lo que en estos momentos nuestras consideraciones se basan en las impresiones generales de los

41. cfr. Bergen, D. Op. cit.; LyON, C. Op. cit. 
investigadores participantes. En este sentido, las narraciones humorísticas de los niños de $4 .^{\circ}$ de Primaria demuestran un nivel bastante alto de conciencia metapragmática ya que se hace un uso reflexivo del lenguaje. Uno de los ejemplos más claros de ello lo encontramos en la «lengua marciana» que inventan los informantes en sus relatos. Veamos algunos casos:

1. Cuando empezo a hablar la profesora me di cuenta que el idioma marciano era que las palabras estaban al revés por ejemplo de lengua=augenl. [...] Acabamos de comer y nos fuimos al patio y me encontre con el que hable y me dijo aloh arto zev em omall nairda [...] (SA5) ${ }^{42}$

2. Al día siguiente nos dimos cuenta que a las palabras les añadian una $u$ y si esa palabra tenia u se la quita van. Quando tocaron a mi puerta me pregunte: ¿Quién seria? Cuando abri la puerta era un marciano que decia: tuoma t niforme (SA7)

Como se observa, en estos ejemplos la invención del idioma sigue un determinado patrón que se adapta al contexto del relato humorístico. Todo ello indica una clara conciencia metapragmática de los jóvenes escritores que son capaces, no solo de realizar una reflexión sobre el lenguaje, sino de explicitarla a través de la invención de una lengua sistematizada. Asimismo, tal «juego» reflexivo del lenguaje con fines humorísticos es propio del último estadio de desarrollo del humor (Stage 5: Riddles and Jokes) según McGhee ${ }^{43}$, lo que confirma que nuestros informantes ya han alcanzado un alto nivel de control sobre el lenguaje y su uso para diversos fines comunicativos.

No obstante, dentro de este mismo tópico, es representativo el número de ejemplos que muestran una visión mucho más epipragmática, como sucede en 3:

3. [...] hablamos en el idioma marciano ola en marciano és coto, adiós es patarra, etc. (IO16).

La inventiva lingüística no parece seguir en este caso ninguna pauta claramente identificable. Más bien parece que lo único que guía al escritor es el absurdo fónico de los términos inventados. En otras palabras, este tipo de humor corresponde al estadio Playing With Words, en la que la construcción de la incongruencia se basa en procedimientos más epipragmáticos que no discriminan entre lo lingüístico y lo contextual y buscan solo la «sorpresa» visible o audible.

42. En todos los ejemplos se preserva la redacción y la ortografía originales.

43. MCGHEE, P. E. Understanding and Promoting the Development of Children's Humor. 
Las narraciones analizadas presentan más pruebas de la todavía fuerte impronta epipragmática, no solo en relación a la lengua inventada, como sucede en 4 y 5 :

4. las asignaturas que hacemos son las siguientes: Canguro, tonto, sombrilla en el medio, mapa (gorila gorigolia) (IA8)

5. En el nuevo colegio que voy me divierto mucho hay muchas asignaturas cómo oparetolxo qué es matemáticas, sotomarreplucos qué es lengua, casacorotamopatolimas que es cono, rasdatelaunatimosco qué es valenciá, rrrapatografitica qué es inglés, etc. (IO16)

No obstante, esto no significa que los escolares que participaron en el estudio se muevan todavía en el humor epipragmático. De hecho, en ocasiones dentro de la misma redacción encontramos ejemplos de la «convivencia» de ambas fases. Veámoslo en 6:

6. Mis asignaturas son muy divertidas tenemos: matemarcía, lenguina, educación martica, conocimiento del miedo, lecturma, mosico y ramarten (IO3)

En este caso, si bien la sistematicidad en la creación de los nombres de las asignaturas resulta algo confusa, la utilización reiterada de los segmentos ma o mar indica que el alumno busca conscientemente una conexión de sus creaciones léxicas con el contexto del «currículo» marciano.

Una combinación interesante la encontramos también en 7:

7. Para ir al colegio llevan mochilas coete asi es como las llamo yo porque en marciano es: mrmaques chuques. ¡A que esa palabra es rarísima! (IA5)

Se observa que la palabra inventada es incongruente meramente en su aspecto sonoro. No obstante, en el mismo enunciado a continuación la informante explicita una reflexión ( $i$ A que esa palabra es rarísima!) que muestra que existe una discriminación entre la incongruencia de la forma fónica y el contexto de una lengua inventada. De alguna manera, la apostilla que deja la niña actúa como un elemento resolutivo ante la incongruencia formal del término que inventa.

Esta adición de la fase de resolución también indica el tránsito hacia un humor más metapragmático. De hecho, desde el punto de vista estadístico hemos constatado que en 19 casos los informantes recurren a la estructura de incongruencia-resolución en sus producciones humorísticas. Si bien este número solo representa el 12,84\% del total, su presencia es reseñable. En este sentido, desde la perspectiva de género, cabe observar que de esas 19 narraciones 13 son de autoría femenina, lo que duplica el número de muestras masculinas (gráficos 4 y 5 ). 


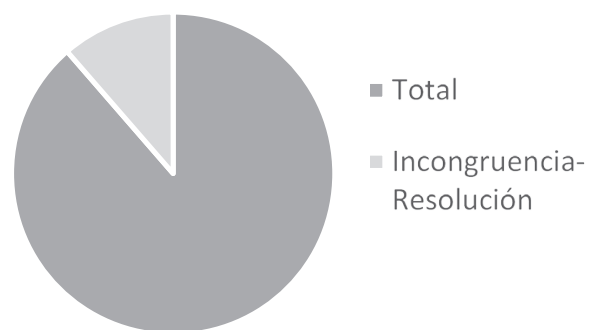

4. Incongruencia-Resolución en las narraciones infantiles

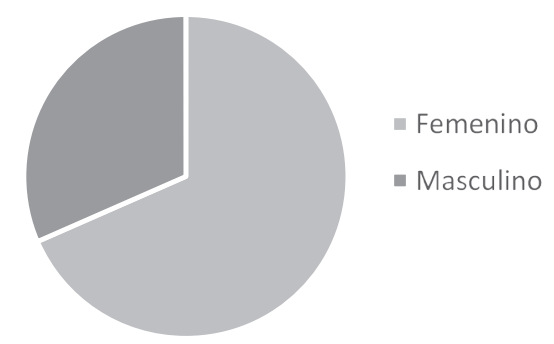

5. Incongruencia-Resolución: distribución por género

Otro indicador de que los escolares de nuestro estudio ya han alcanzado un importante nivel de conciencia metapragmática en su producción humorística es la presencia del lenguaje figurado. La hipótesis planteada al respecto (vid. § 3.1) de que sus índices serían mayores - por la edad de nuestros informantes y por la tarea encargada- se ha confirmado. En el siguiente gráfico se refleja la presencia de las muestras figuradas en las composiciones analizadas:
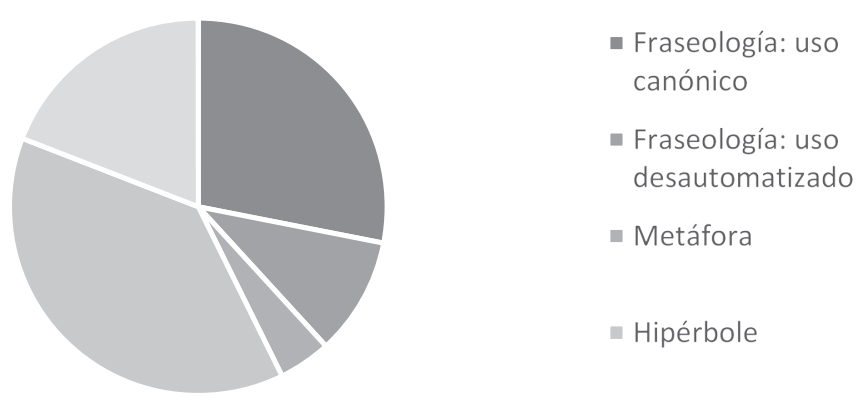

6. Lenguaje figurado

No se han observado diferencias notables en el uso de estos elementos entre chicos y chicas.

Para concluir este primera parte, podemos decir que la percepción de los investigadores es que las chicas, en general, muestran cotas ligeramente más altas de conciencia metapragmática que se reflejan en una mejor producción escrita y en un uso más variado de marcas e indicadores verbales del humor. No obstante, este aspecto necesita una comprobación empírica más enfocada y perfilada que esperamos acometer en el futuro. 


\subsection{El humor y la expresión escrita}

En lo que atañe a la expresión escrita, la mayor parte de los participantes de nuestro estudio han construido narraciones razonablemente coherentes, aunque con abundantes faltas de ortografía y bastantes carencias en el uso de elementos cohesivos. El uso de la puntuación ha sido más que deficiente lo que indica que la competencia escrita todavía se encuentra en plena formación y que muchos de los escolares a esa edad, a pesar de tener un aceptable control metasemántico y metapragmático, aún no son capaces de hacer una organización gráfica de su discurso oral mediante los signos de puntuación. En general, podemos decir que la tendencia de que los niños y las niñas escriben como hablan todavía es muy fuerte. La sensación común de los investigadores que participaron en el estudio es que las chicas presentan una escritura más cuidada, tanto en la letra como en la elaboración del texto, aunque esta sensación no fue comprobada estadísticamente.

Respecto a la representación de situación retórica, cabe señalar que dentro del tópico global que propusimos a los escolares también marcamos algunos posibles subtópicos. La construcción de las incongruencias se ha basado en algunos de ellos. Dentro de los mismos el «aspecto físico» de los marcianos ocupa el primer lugar, ya que aparece en el $66,89 \%$ de las composiciones. Lo siguen los subtópicos de «vida académica» $(60,14 \%)$, situaciones de «choque cultural» $(54,05 \%)$, «alimentación» $(24,32 \%)$ y «medios de transporte» $(19,59 \%)$. En el gráfico 7 reflejamos estos datos en números absolutos:

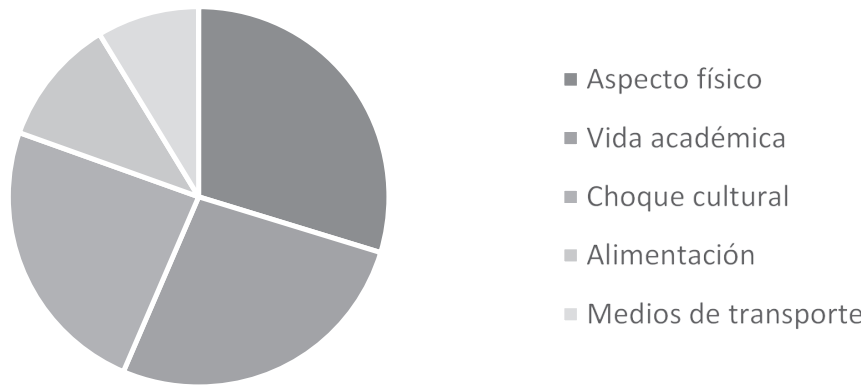

7. Distribución de subtópicos

En lo que concierne a la distribución por género, solo en los subtópicos de «alimentación» y de «aspecto físico» hay diferencias reseñables. En el primero, de los 36 casos recogidos 21 son de escritoras chicas, mientras que los chicos describen las costumbres alimentarias marcianas en 15 narraciones. En 
referente al subtópico de «aspecto físico», de los 99 casos 53 son de chicas y 46 de chicos. Si bien las diferencias no son demasiado grandes, llama la atención la preferencia de las informantes femeninas por el tema de la «comida marciana». En esta línea, una investigación secundaria podría analizar no solo las diferencias cuantitativas sino también las cualitativas en el tratamiento de estos dos subtópicos por parte de chicas y chicos.

En nuestro estudio hemos confirmado, además, que los chicos manifiestan un humor más agresivo. No habilitamos ningún instrumento de medición de este aspecto, pero hemos detectado que solo las narraciones masculinas contienen muestras de humor violento. Lo vemos, por ejemplo, en 8 donde el autor al describir a los marcianos ataca de manera agresiva su imagen:

8. [...] las gafa er de vichos ivan descalzos en el patio se tiran muchos pedo son super guaros cochinos asta se mean tiran los mocos los pedos los guardan duermen en el sue no san ven contar los números son tontos (IO11).

El análisis de los cinco indicadores del humor más usados por los escolares en sus narraciones revela otros aspectos interesantes. El gráfico 8 refleja estadísticamente tales indicadores:
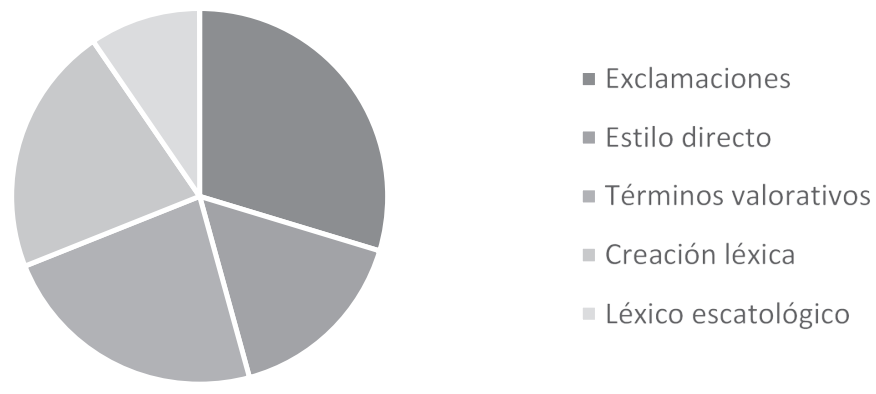

8. Cinco marcas e indicadores del humor más usados

Observamos que indicadores como «exclamaciones», «estilo directo» o «creación léxica» evidencian, de nuevo, que el apego a la oralidad es importante. Por su parte, la presencia del indicador «léxico escatológico»-propio sobre todo de los estadios del humor anteriores y que entre nuestros informantes supone 28 casos- concuerda con la idea de que los niños no abandonan drásticamente un estadio previo para pasar al siguiente, sino que «conviven» en varios de ellos a la vez. En lo que concierne a su reparto por género, el uso del léxico escatológico es solo ligeramente mayor en chicos (16 narraciones) 
que en chicas (12), dato que ha sido algo sorpresivo ya que esperábamos una mayor diferencia a favor de los chicos.

La difícil tarea de representarse mentalmente al destinatario de su texto lleva al niño a adoptar estrategias para «crear» a su lector y asegurarse así la correcta comprensión de su relato. Entre tales estrategias se encuentran explicaciones, precisiones o dibujos, entre otros elementos. El joven escritor se toma estas precauciones por no estar seguro de su control sobre la situación retórica de su relato lo que refleja su propia desconfianza en sus habilidades escritas. A continuación proponemos algunos ejemplos que ilustran claramente lo dicho. El primero, una parte del cual ya ha sido analizada arriba, contiene varias acotaciones que pretenden guiar al lector hacia una interpretación correcta de elementos humorísticos:

9. Para ir al colegio llevan mochilas coete asi es como las llamo yo porque en marciano es: mrmaques chuques. ¡A que esa palabra es rarísima! También tienen música y la más famosa es proma broma estail, es como ganga estail pero en marciano (IA5)

En 9 observamos claramente cómo la informante se encuentra muy pendiente de su posible lector. Primero, le invita a compartir su reflexión metalingüística sobre el carácter raro de la palabra marciana. A continuación, le aclara el significado de la pieza musical marciana. En suma, ante la imposibilidad de obtener un feedback inmediato, como sucede en la modalidad oral, la alumna adopta una actitud protectora con su potencial destinatario y le facilita la tarea interpretativa. Asimismo, tal y como ya veíamos en el § 4.1., estos elementos desempeñan la función de resolución frente a la incongruencia planteada por el léxico inventado.

Esto mismo sucede en 10, donde la informante «traduce», y por tanto resuelve, el nombre incongruente del colegio marciano para que su lector capte adecuadamente la intención humorística de su peculiar creación léxico-gráfica:

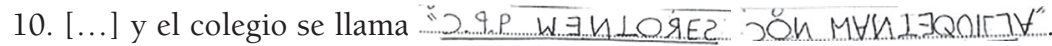
Sería, colegio público y privado «Mentores con mantequilla» (SA2)

En 11, a su vez, es el recurso de dibujo que desempeña la misma función aclaratoria y resolutiva:

11. Cuándo llegué al colegio en marte (llegue en nave) marte era gigante. Allí no habia nadie y era super raro porque en cuanto llegue ya me parecia tener alucinaciones, ví un marciano con tres ojos y tres pies, yo lo llamaría el triple-tres» (IO32)

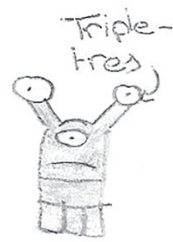


En todos estos ejemplos los autores de las narraciones buscan suplir la falta de inmediatez con el destinatario e intentan imaginar, «crear» a su lector al que proporcionan pistas interpretativas.

\section{Conclusiones}

En este trabajo hemos presentado un estudio sobre el humor verbal en niños y niñas de 9-10 años. La tarea se llevó a cabo con los alumnos de diversos centros de la provincia de Alicante y consistió en la escritura de una narración humorística sobre un tema dado. Nuestro objetivo general era observar el uso de marcas e indicadores lingüísticos del humor en relación al desarrollo de la conciencia metapragmática ${ }^{44}$ y de la competencia escrita. Asimismo, la perspectiva de género ha sido otro punto de atención.

Algunos de los resultados debatidos en este trabajo muestran que a la edad de 9-10 años los niños y las niñas ya manifiestan una conciencia metapragmática bastante alta, al menos en comparación con los resultados de los experimentos realizados con los niños de 8 años $^{45}$. Como consecuencia, el humor de nuestros informantes ya recurre al uso de marcas e indicadores lingüísticos propios del último estadio -Riddles and Jokes-del desarrollo del humor según $\mathrm{McGhee}^{46}$. No obstante, la presencia de procedimientos más epipragmáticos y propios de estadios del humor anteriores (sobre todo, del Playing With Words) es notable. Ello confirma que los niños no «abandonan» las etapas anteriores para pasar a la siguiente, sino que «conviven» en varios estadios.

Desde la comparación por género, en la franja de la edad analizada las niñas parecen mostrar una competencia metapragmática algo más alta y su humor se articula con mayor frecuencia en dos fases, de incongruencia y de resolución. Dicho esto, el dato necesita una comprobación más exacta que se abordará en investigaciones futuras.

Estas consideraciones están acordes con el análisis de la competencia escrita, donde las niñas por lo general han presentado narraciones más cuidadas. En términos globales, el peso de la oralidad sigue siendo notable. Solo en el caso de los varones se han detectado muestras del humor agresivo. Asimismo, las niñas han manifestado una curiosa preferencia por el subtópico de alimentación marciana.

44. GOMBERT, J. «Metalinguistic development in first language acquisition»; VERSCHUEREN, J. Op. cit.

45. vid. Crespo, N., Benítez, R., Pérez, L. Op. cit.

46. MCGHEE, P. E. Understanding and Promoting the Development of Children's Humor.

Feminismo/s 24, diciembre 2014, pp. 195-219 
En lo que se refiere a las marcas e indicadores del humor concretos, no se han detectado diferencias significativas entre niños y niñas. Sin embargo, esta comparación se tiene que abordar en un trabajo más particularizado y centrado, y no en una presentación global como esta.

\section{Referencias bibliográficas}

BERGEN, D. «Humor, play and child development», en Klein, A. (ed.). Humor in children's lives. A guidebook for practitioners. Westport, Praeger, 2003, pp. $17-32$.

CRESPO, N., BENÍTEZ, R. y CÁCERES, P. «La comprensión oral del lenguaje no literal y su relación con la producción escrita en escolares». Revista Signos, 40:63 (2007), pp. 31-50.

CRESPO, N. y Alfaro, P. «La conciencia metapragmática en la edad escolar». Boletin de lingüistica [online], 21:32 (2009). Disponible en: http://www.scielo. org.ve/scielo.php?script=sci_arttext\&pid=S0798-97092009000200002\&lng $=$ es\&nrm=iso

CRESPO, N. «La medición de la conciencia metapragmática de los niños: resolviendo la ambigüedad en la comprensión oral», RLA, 47:2 (2009), pp. 69-88.

CRESPO, N. y AlFARO, P. «Desarrollo tardío del lenguaje: la conciencia metapragmática en la edad escolar». Universitas Psychologica, 9:1 (2010), pp. 229-240.

CRESPO, N. y AlVARADO, C. "Conciencia metapragmática y memoria operativa en niños escolares». Literatura y Lingüística, 21 (2010), pp. 93-108.

CRESPO, N., BENíteZ, R., PÉREZ, L. «Conciencia metapragmática y la habilidad para producir narraciones escritas», Revista Signos, $43: 73$ (2010), pp. 179-209.

Cunningham, J. «Children's humor», en W. G. Scarlett, S. Naudeau, D. SaloniusPasternak, I. Ponte (eds.) Children's play. SAGE publications, 2005.

GOMBERT, J. Metalinguistic development. New York, Wheatsheaf, 1992.

GOMBERT, J. «Metalinguistic development in first language acquisition», en L. Van Lier \& D. Corson (Eds.), Encyclopedia of Language and Education. Vol. 6. Knowledge about language. Dordrecht/Boston, Kluwer Academic Publishers, 1997, pp. 43-51.

GRICE, P. Studies in the Way of Words. Cambridge, MA, Harvard University Press, 1989.

HoickA, E. «The Pragmatic Development of Humor», en Pragmatic Development in First Language Acquisition, Matthews, D. (ed.), Amsterdam, John Benjamins, 2014, pp. 219-238.

HoickA, E. y GatTis, M. «Do the wrong thing: how toddlers tell a joke from a mistake», Cognitive Development, 23 (2008), pp. 180-190.

LAKOFF, R. Language and Woman's Place. New York, Harper \& Row, 1975. 
LYON, C. «Humour and the young child. A review of the research literature». Televizion, 19 (2006), pp. 4-9. Disponible en: http://www.br-online.de/jugend/izi/ english/publication/publications-televIZIon.htm.

MARTIN, R. A. The Psychology of Humor: An Integrative Approach. Burlington, Elsevier Academic Press, 2007.

McGHEE, P. E. Humor: Its Origin and Development. San Francisco, W. H. Freeman, 1979.

McGHEE, P. E. Understanding and Promoting the Development of Children's Humor. Dubuque, Kendall Hunt Publishing, 2002.

Piaget, J. El lenguaje y el pensamiento del niño pequeño. Barcelona, Paidós, 1987.

PORTOLÉs, J. Pragmática para hispanistas. Madrid, Síntesis, 2004.

Ruiz Gurillo, L. La lingüística del humor en español. Madrid, Arco/Libros, 2012.

SochA, T. J. \& Kelly, B. «Children making 'fun': humorous communication, impression management, and moral development». Child Study Journal, 24:3 (1994), pp. 237-252.

STUDE, J. «The acquisition of metapragmatic abilities in preschool children», en Bublitz, W. \& Hübler, A. (eds.), Metapragmatics in use. Amsterdam, John Benjamins, 2007, pp. 199-220.

VERSCHUEREN, J. «Notes on the role of metapragmatic awareness in language use», Pragmatics, 10:4 (2000), pp. 439-456. 



\title{
EVOLUCIÓN DEL HUMOR EN LA MUJER: DESDE PRIMARIA A LA UNIVERSIDAD ${ }^{1}$
}

\author{
LAURA M. ${ }^{a}$ Aliaga AgUZA \\ Grupo GRIALE \\ Universidad de Alicante
}

Recibido: 15/09/2014

Aceptado: 24/11/2014

\section{Resumen}

El comportamiento de hombres y mujeres se desarrolla de forma diferente desde edades tempranas, adoptando roles diferentes que influyen en nuestra forma de apreciar el mundo. Del mismo modo que los hombres y mujeres poseen distintas visiones del mundo, también entienden de forma diferente el humor. Antiguamente se pensaba que las mujeres no entendían el humor (Lakoff, 1975), sin embargo, esta concepción está cambiando (Ervin-Tripp and Lampert, 1992, o Hay, 1995). El objetivo de este artículo es analizar la evolución del humor en la mujer desde la etapa escolar, concretamente $4{ }^{\circ}$ de primaria, hasta el primer año universitario. Para ello, nos basaremos en dos corpus creados por el grupo GRIALE de la Universidad de Alicante para comparar los mecanismos humorísticos utilizados por hombres y mujeres.

Palabras clave: Evolución, Humor, Mujer

\begin{abstract}
Human behavior in men and women develops in different way from very early ages, taking different roles that influence the way we see the world. As men and women have different sights of the world, they also understand humor in a different way. In the past, it was thought that women did not understand humor (Lakoff, 1975), nevertheless, this point of view is changing (Ervin-Tripp and Lampert, 1992, or Hay, 1995). The goal of this paper is to analyze humor evolution in women from their
\end{abstract}

1. Este artículo se integra en el Proyecto I+D FFI2012-30941 «Innovaciones lingüísticas del humor: géneros textuales, identidad y enseñanza del español».

Feminismo/s 24, diciembre 2014, pp. 221-242

DOI: $10.14198 / \mathrm{fem} .2014 .24 .10$ 
schoolchild, to their first university year. To do so, we will base on two corpus, created by GRIALE group from Alicante university, to compare humor mechanisms used by men and women.

Keywords: Evolution, Humor, Woman

Feminismo/s 24, diciembre 2014, pp. 221-242 


\section{Introducción}

El comportamiento entre hombres y mujeres se desarrolla de forma diferente desde edades muy tempranas, ya que, dependiendo de nuestro sexo, adoptamos roles diferentes que influyen en nuestra forma de apreciar el mundo. Este hecho condiciona nuestra vida desde antes del nacimiento, esto es, el género se empieza a desarrollar en el momento en que los padres conocen el sexo del bebé, puesto que no se compran las mismas cosas para un niño que para una niña (Jule, 2008: 6). Del mismo modo que hombres y mujeres poseen distintas visiones del mundo, también entienden de forma diferente el humor. Si seguimos a Lakoff (1975: 56), siempre se ha pensado que las mujeres no tienen sentido del humor y no entienden las bromas, puesto que no cuentan chistes y si lo hacen, suelen arruinar el punch line al mezclar el orden de los acontecimientos. Actualmente esta concepción está cambiando, ya que hay trabajos que demuestran que las mujeres poseen sentido del humor, pero es diferente al de los hombres (por ejemplo, Ervin-Tripp and Lampert, 1992; o Hay 1995).

Por su parte, Ojeda Alba (2010) señala que hay pocos estudios que se centren en la competencia humorística en niños y los que hay, se centran en la apreciación y no en la creación del humor, con alguna excepción como por ejemplo, Droz y Ellis, 1996. Por ello, realiza un estudio en el que pretende identificar tendencias y patrones de género de hombres y mujeres en la etapa escolar que estudian una segunda lengua. En este artículo se establecen varias conclusiones interesantes: a) El humor se utiliza más en la etapa secundaria que en primaria. Este hecho confirma la afirmación de Manke (1998: 363) que señala que los niños y adolescentes carecen de las habilidades cognitivas necesarias tanto para producir como para entender el humor; b) los chicos se sienten más cómodos al realizar bromas que las chicas, de ahí que las chicas lo utilicen menos y por este motivo se piense que las chicas carecen de humor; y, c) las mujeres se sienten restringidas por los roles de género debido a la educación que han recibido. 
Partiendo de este hecho, el grupo GRIALE² de la Universidad de Alicante se propuso estudiar las diferentes manifestaciones del humor en los niños de primaria en la segunda fase del proyecto I+D (FFI2012-30941) Innovaciones lingüisticas del humor: géneros textuales, identidad y enseñanza del español, dirigido por la doctora Ruiz Gurillo. Para ello se elaboraron unos cuestionarios donde los niños de cuarto de primaria (curso 2012-2013) de 5 colegios de la provincia de Alicante, debían escribir unos relatos humorísticos anónimos sobre un intercambio escolar en Marte. Este estudio se completará en el curso 2014-2015, creando otro modelo de relato humorístico para los alumnos de sexto de primaria, con el objeto de comprobar la evolución en la competencia humorística de los niños.

Por otra parte, tras el inicio de las investigaciones de género y humor con las narraciones de primaria, surgió otro proyecto, Red docente Humor y perspectiva de género: análisis y aplicaciones didácticas (2012-2013 Modalidad II), coordinado por Larissa Timofeeva. Con ello se pensó que era una buena manera de disponer de datos complementarios en alumnos universitarios. En este estudio se pedía a alumnos de la universidad de Alicante que escribiesen anécdotas humorísticas sobre malentendidos culturales de forma anónima.

En este artículo nos proponemos realizar un estudio contrastivo en el humor femenino desde la primera fase de la educación, concretamente cuarto de primaria, hasta el primer año de la etapa universitaria, con el objetivo de comparar el uso de una serie de marcas, indicadores e inferencias que se repiten en los cuestionarios creados en el seno del grupo GRIALE para los proyectos anteriormente citados. Por un lado, la elección de cuarto de primaria

2. El Grupo GRIALE según se presenta en su página web, http://dfelg.ua.es/griale/index. html, es el Grupo de Investigación sobre la ironía y el humor en español del Área de Lengua Española del Departamento de Filología Española, Lingüística General y Teoría de la Literatura de la Universidad de Alicante. Fundado en 2002, ha contado hasta el momento con tres proyectos $\mathrm{I}+\mathrm{D}$, así como con diversas ayudas de la Universidad de Alicante. En el proyecto actualmente en vigor (FFI2012-30941: «Innovaciones lingüísticas del humor: géneros textuales, identidad y enseñanza del español» participan también dos miembros externos de reconocido prestigio: Salvatore Attardo, de la Texas A \& M University-Commerce (Estados Unidos) y Javier Muñoz-Basols, de la University of Oxford (Gran Bretaña). Sus objetivos principales son el análisis pragmático de la ironía y el humor, la observación de aspectos socioculturales, como la incidencia del género en su empleo, y la aplicación de los resultados a la clase de español como lengua extranjera. Destacan como publicaciones conjuntas el libro de Leonor Ruiz Gurillo y Xose A. Padilla (eds.) (2009): Dime cómo ironizas y te diré quién eres. Una aproximación pragmática a la ironía. Frankfurt, Peter Lang; el trabajo colectivo del grupo GRIALE (2011): ¿Estás de broma? 20 actividades para practicar la ironía en clase de ELE. Madrid, Edinumen; y la obra de Leonor Ruiz-Gurillo y M. ${ }^{a}$ Belén Alvarado-Ortega (eds.) (2013): Irony and Humor: From Pragmatics to Discourse. Amsterdam, John Benjamins. 
viene suscitada debido a que a esta edad los niños ya son capaces tanto de crear como de comprender humor en distintos niveles, llegando al nivel del absurdo. Como señala Benavent (1970: 111-112):

Se alcanza la madurez de la comprensión cómica alrededor de los 10 años, al completarse con los contrastes entre causa y efecto y los contrastes con la realidad habitual; risas producidas por la proyección de situaciones de la vida cotidiana; risas producidas por la degradación de algo que somete u oprime (reglas, leyes y personas); gusto por lo cómico intelectual y el chiste; aumenta notablemente el número de gags cómicos que desencadenan la risa: estereotipos, inversiones, inferencias, etc.; risas provocadas por todo tipo de desviación de la normalidad; incipiente sentido del humor, tanto en el plano personal como en el interpersonal; control de las manifestaciones hiláricas a pesar de la comprensión del estímulo risible.

A partir de este momento el niño ha alcanzado la madurez cómica siendo capaz de controlar sus impulsos humorísticos y hacer reír a sus compañeros. Por otro lado, se ha elegido el primer año universitario, puesto que pensamos que es en esta etapa donde se alcanza la madurez tanto intelectual como social. Aquí ya se es capaz de tomar decisiones responsables y seleccionar el tipo de humor que hace reír al individuo. De este modo, podremos apreciar la evolución que ha tenido el humor desde el inicio de la madurez hasta su consolidación. Tras el análisis pretendemos contestar las siguientes cuestiones: ¿las mujeres son capaces de producir humor desde su infancia? ¿Existen mecanismos humorísticos que se utilicen en todas las etapas? ¿Se utilizan las inferencias, las marcas y los indicadores humorísticos de la misma forma en ambas etapas? ¿Está la mujer restringida por la educación -y no utiliza el humor-o es capaz de producir humor? La hipótesis de la que partimos es que las mujeres poseen humor a lo largo de toda su vida; sin embargo, no se ríen de las mismas cosas que los hombres, porque el ser humano está determinado humorísticamente, no por la educación, sino por el entorno, esto es, existe un cierto determinismo humorístico. Como muchos aspectos del desarrollo del ser humano, el humor viene determinado por las distintas experiencias tanto vitales como culturales. Por ello, hacemos humor de lo que conocemos, esto es, es el entorno el que nos determina sobre qué reír y hacer reír.

En este artículo en primer lugar explicaremos tanto el corpus de primaria (§ 2.1), como el universitario ( $\S 2.2$ ), utilizados para nuestro estudio. A continuación, nos centraremos en el análisis práctico (§ 3), donde compararemos dos indicadores lingüísticos (fraseología e hipérbole), una marca (exclamación) y dos inferencias humorísticas (choque cultural y situación ridícula) que se utilizan en ambos corpus y, así, llegaremos a las conclusiones pertinentes (§ 4). 


\section{Presentación del Corpus}

En este epígrafe nos centraremos en la explicación de los dos corpus de los que se han extraído los ejemplos seleccionados para este análisis cualitativo. Explicaremos cómo se han obtenido y cómo se han recopilado tanto los datos del corpus de primaria (§ 2.1), como los del corpus universitario (§ 2.2).

\subsection{Corpus de Primaria}

El Corpus de Primaria lo hemos extraído de un estudio relacionado con el Proyecto «Innovaciones lingüísticas del humor: géneros textuales, identidad y enseñanza del español» del grupo GRIALE, cuya investigadora principal es Leonor Ruiz Gurillo. El Grupo GRIALE de la Universidad de Alicante al que pertenecemos pretende investigar en la segunda fase del proyecto I+D mencionado si existen diferencias de uso del humor entre hombres y mujeres. Por ello, siguiendo la propuesta de Ojeda Alba (2010), se decidió comenzar por obtener narraciones de alumnos de $4 .^{\circ}$ de primaria, redacciones que se repetirán a los mismos alumnos en dos años académicos. En estas redacciones se pedía a los alumnos de $4 .^{\circ}$ de primaria de 5 colegios de la provincia de Alicante que escribiesen un relato humorístico de forma anónima sobre un intercambio escolar a Marte con el título Un cuento humorístico (Figura 1). Estos colegios son: Colegio Público «Divina Aurora» de Beneixama, Colegio Público «Mare de Déu del Carme» de Canyada, Colegio Público «Antonio Machado» de Elda, Colegio Público «Inmaculada Concepción» de Torrevieja y Centro Privado «San Alberto Magno» de Monforte del Cid.

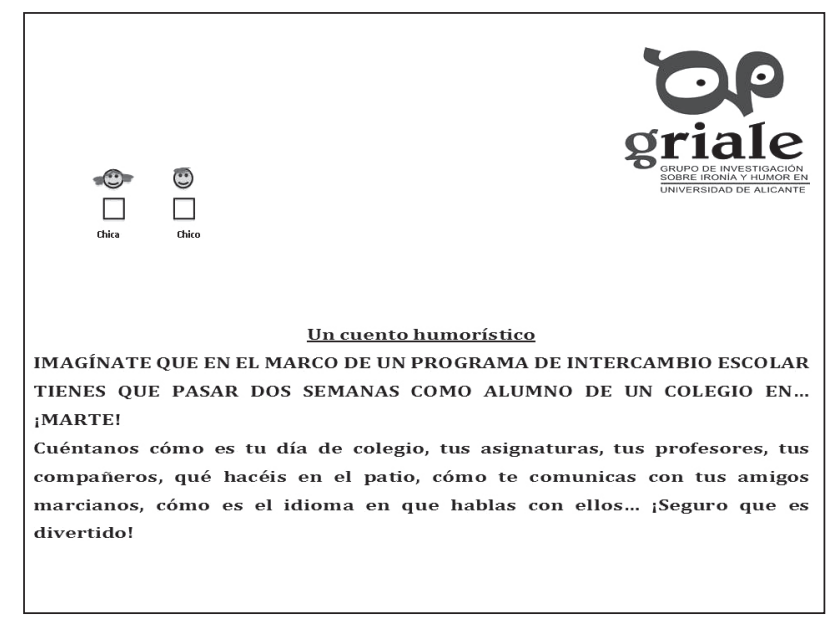

Figura 1: Modelo de redacción propuesta para los alumnos de $4 .^{\circ}$ de primaria. 
Tras la recogida de datos, se elaboró una base de datos con el programa Microsoft Access y posteriormente se exportaron los resultados al programa Microsoft Excel. Las variables que se tuvieron en cuenta para la elaboración de la base de datos fueron: sexo (femenino / masculino), tipo de centro (público / privado) y línea del centro (castellano / valenciano/ multilingüe). El procedimiento que se llevó a cabo para la recogida de datos se realizó en varias fases: en primer lugar, el grupo GRIALE se puso en contacto con los colegios seleccionados para el estudio y se estableció una fecha para la recogida de redacciones. En segundo lugar, se procedió al etiquetado de las redacciones. De esta manera, cada redacción tiene un código para poder identificarlas. La primera letra representa al colegio al que pertenece dicha redacción ( $\mathrm{A}=$ Colegio Público Antonio Machado, Elda; B = Colegio Público Divina Aurora, Beneixama; I = Colegio Público Inmaculada Concepción, Torrevieja; M = Colegio Público Madre de Déu, La Canyada; S = Centro Privado San Alberto Magno, Monforte del Cid), la segunda letra identifica el sexo del alumno (A niña y O niño) y, por último, aparece el número de redacción. De este modo, tendríamos que SA1, sería una redacción escrita por una niña del Centro Privado San Alberto Magno en Monforte del Cid. En tercer lugar, se realizó una lectura y volcado de la información, con la que se elaboró la base de datos.

Así, se obtuvieron 148 redacciones. Entre ellas 75 fueron escritas por niñas y 65 contienen humor, lo que representa un 43'92\%. Por otro lado, obtuvimos 72 narraciones escritas por niños, de las cuales 60 tienen humor, lo que representa un 40'54\%. En una de las redacciones no está indicado el sexo del alumno, porque se dejó la casilla correspondiente sin rellenar.

\section{Corpus Primaria}

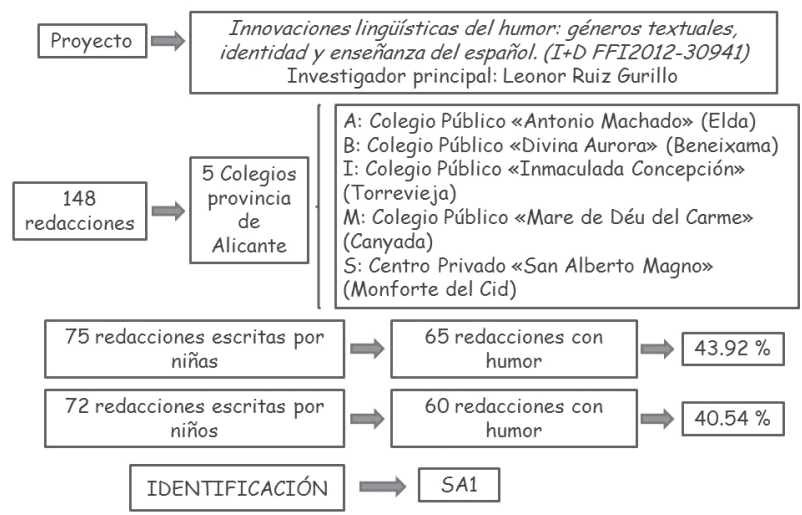

Figura 2: Cuadro-resumen de los participantes de $4 .^{\circ}$ de primaria

Feminismo/s 24, diciembre 2014, pp. 221-242 


\subsection{Corpus universitario}

El corpus universitario se ha extraído de un estudio relacionado con la Red docente humor y perspectiva de género: análisis y aplicaciones didácticas (20122013 Modalidad II) del grupo GRIALE, cuya coordinadora es Larissa Timofeeva. Tras el inicio de las investigaciones sobre género y humor con las narraciones de primaria, se creó un proyecto para recopilar datos complementarios sobre los recursos humorísticos utilizados por alumnos universitarios. Para este estudio se creó un cuestionario donde se pedía a alumnos universitarios que escribiesen de forma anónima anécdotas humorísticas que conociesen a

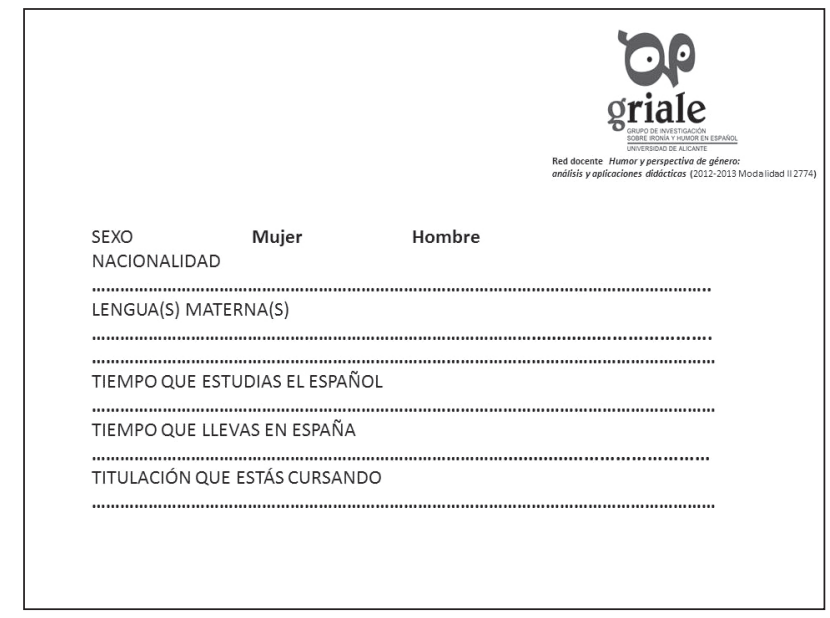

Un relato humorístico

En cada país hay costumbres y tradiciones que llaman la atención o pueden parecer extrañas para un extranjero. Muchas veces, son el origen de los tópicos y creencias, algunos verdaderos y otros no tanto. En el caso de España hay muchos ejemplos: en la película Misión Imposible 2 las Fallas valencianas se mezclan incomprensiblemente con la Semana Santa sevillana; muchos extranjeros creen que La Tomatina, que se celebra en Buñol, es una especie de fiesta nacional; o que la siesta es una costumbre a la que todos los españoles, sin excepción, dedican un par de horas al día; por no mencionar los casos "clásicos" del flamenco y los toros.

Sin embargo, cuando vamos al extranjero o nos comunicamos con las personas de otros países, nos damos cuenta de que con frecuencia los tópicos no son ciertos, lo cual puede provocar situaciones embarazosas o cómicas. Cuéntanos alguna historia que te haya pasado a ti o a alguien que conoces por culpa de una creencia falsa o un malentendido cultural.

Figura 3: Modelo de redacción propuesta para los alumnos universitarios.

Feminismo/s 24, diciembre 2014, pp. 221-242 
causa de una creencia falsa o malentendido cultural, bajo el título Un relato humorístico (Figura 3). Dichos alumnos son, por una parte, estudiantes de español de la universidad de Alicante con un nivel B2 y alumnos nativos pertenecientes tanto al grado de traducción como al de filología de dicha universidad.

A partir de los datos extraídos de los cuestionarios se elaboró una base de datos con el programa Microsoft Access y se exportaron los resultados al programa Microsoft Excel. Las variables que se consideraron para crear este corpus fueron: sexo (masculino / femenino), nacionalidad, lengua materna, tiempo que estudia español y tiempo que lleva en España. El procedimiento que se llevó a cabo para la elaboración de la base de datos fue el mismo que se realizó en la base de datos de primaria. En primer lugar, el grupo GRIALE se puso en contacto con los responsables de los departamentos de español, traducción y filología de la universidad de Alicante donde se pasó el cuestionario y se estableció una fecha límite de entrega. En segundo lugar, se creó el código de cada redacción para poder identificarlas. La primera letra corresponde a la nacionalidad ( $\mathrm{N}$ nacional y $\mathrm{E}$ extranjero), la segunda letra representa el sexo del participante (A chica y O chico) y, por último, se indica el número de redacción. Así tendríamos que NA53, sería una redacción escrita por un hablante nativo femenino.

De este modo, se obtuvieron 161 redacciones. Entre ellas 111 fueron escritas por hablantes nativos, concretamente 84 de ellas fueron redactadas por mujeres y 56 tienen humor, lo que representa un $366^{\prime} 65 \%$. Y 27 por hombres de las cuales 13 poseen humor, esto es, un $8^{\prime} 07 \%$.

\section{Corpus Universidad}

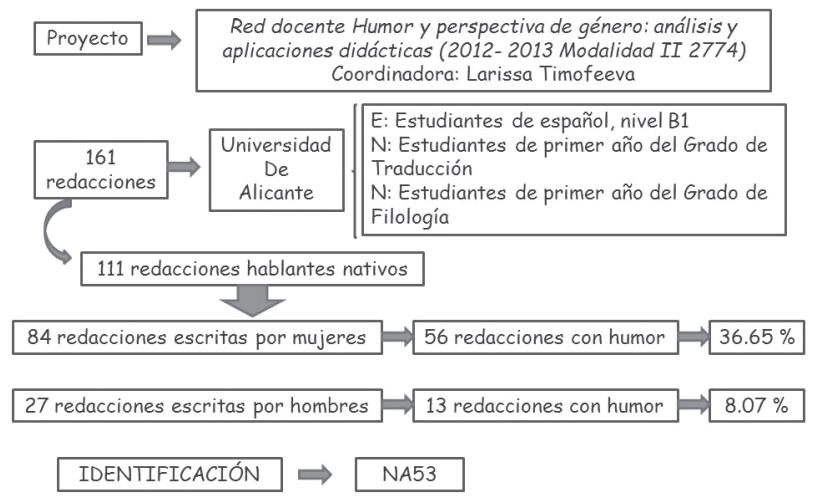

Figura 4: cuadro - resumen de los participantes universitarios.

Feminismo/s 24, diciembre 2014, pp. 221-242 


\section{Análisis}

En este apartado realizaremos el análisis práctico donde veremos, por una parte, dos indicadores (la fraseología y la hipérbole) y una marca (la exclamación) como elementos que identifican enunciados humorísticos y, por otra parte, dos inferencias humorísticas (el choque cultural y la situación ridícula) como formas de captar el humor. Todos estos mecanismos humorísticos se utilizan tanto en la fase primaria como en la fase universitaria. La selección de estas marcas, indicadores e inferencias se debe a que aparecen en una proporción similar en ambos corpus. El resto de elementos propuestos por GRIALE para la elaboración de la base de datos de ambos grupos de narraciones será analizado en trabajos posteriores.

Antes de comenzar con el análisis definiremos los mecanismos humorísticos seleccionados para facilitar la comprensión de los ejemplos. Ruiz Gurillo y Padilla García (2009) distinguen entre marcas e indicadores que ayudan a que el oyente / lector realice correctamente el proceso de inferencia en los enunciados irónicos. Partiendo de esta base amplían su objeto de estudio al humor (por ejemplo, Ruiz Gurillo, 2012; Ruiz Gurillo y Alvarado Ortega, 2013; Alvarado Ortega y Ruiz Gurillo, 2013). Siguiendo al grupo GRIALE entendemos por marca aquel elemento que aparece de forma escrita $u$ oral y ayuda a identificar un enunciado como humorístico, mientras que el indicador es un elemento humorístico en sí mismo. Ambos elemento ayudan al proceso cognitivo de inferencia para interpretar el humor, es decir, la inferencia es el proceso que lleva a cabo el oyente para concebir el enunciado como humorístico.

A continuación, analizaremos los mecanismos humorísticos seleccionados para este artículo. En primer lugar, prestaremos atención al indicador fraseológico ( $\$ 3.1$ ); en segundo lugar, observaremos el indicador hipérbole (§ 3.2); en tercer lugar, nos centraremos en la marca exclamación (§ 3.3); y, por último, las inferencias seleccionadas, esto es, las situaciones ridículas ( $\S$ 3.4.1) y el choque cultural (\$ 3.4.2)

\subsection{La fraseología como indicador humorístico}

En este epígrafe veremos unos ejemplos donde el indicador fraseológico es el encargado de crear el efecto hilarante. Se trata de un recurso bastante utilizado en ambos corpus, aunque más común en las redacciones universitarias, posiblemente debido al vocabulario más amplio que poseen dichos sujetos. Siguiendo al grupo GRIALE (Ruiz Gurillo y Padilla García, 2009), los indicadores son elementos que crean humor por sí mismos, esto es, poseen humor 
en su construcción interna, concretamente, el indicador fraseológico juega tanto con el significado literal de la expresión como con el idiomático para conseguir el efecto cómico.

A continuación, analizaremos cuatro ejemplos, dos casos extraídos del corpus de primaria y otros dos del corpus universitario, que representan la evolución que ha sufrido el uso de fraseología con intención humorística en la mujer.

\subsubsection{Corpus de primaria}

En este apartado comentaremos dos casos extraídos de las redacciones de primaria donde se utiliza alguna expresión fraseológica para crear el efecto cómico. En el primer caso (1), la niña está describiendo cómo eran sus profesores en Marte:

(1) «Mis profesores eran la bomba literalmente, cuando jugábamos a la bomba los profes se hacían una bola y jugábamos con ellos»

[SA9]

En este ejemplo, la niña ya posee conciencia del valor fraseológico, puesto que comprende que estas expresiones tienen tanto significado literal como figurado, siendo el más común el significado figurado. En este caso, el humor se crea a partir del significado literal de la expresión fraseológica «ser la bomba», además, para dejar claro que utiliza dicho significado utiliza el término «literalmente» que ayuda al efecto cómico y que indica que discrimina ambos significados. En el ejemplo (2), otra niña está describiendo cómo es el lenguaje en Marte y sus impresiones hacia este idioma:

(2) «Porque es que es como si me hablaras en chino no entiendo nada. Aunque si yo no entiendo nada mi profesor o me lo vuelve a explicar o colleja al canto»

[BA11]

En este caso, el humor comienza a partir de la comparación con el uso de la unidad fraseológica «hablar en chino» y termina con el fraseologismo «colleja al canto», donde la niña muestra de manera humorística que no entendía nada del idioma marciano y su profesor tenía que volver a explicárselo. En ambos casos se ha utilizado el significado idiomático de la expresión fraseológica y por ello el emisor no ha necesitado señalar que era de forma «literal» como ocurre en el ejemplo (1). Además, en gran número de los cuestionarios humorísticos de primaria encontramos esta conciencia lingüística que sirve 
como marco para crear humor, puesto que el hecho de no entender a los marcianos les resulta cómico a los niños.

\subsubsection{Corpus universitario}

En este epígrafe comentaremos dos ejemplos extraídos del corpus universitario en el que se utiliza el indicador fraseológico para la creación de humor. En estos ejemplos apreciamos la utilización de expresiones fraseológicas para realizar autohumor. Veamos el ejemplo (3) y (4) donde ambas chicas recurren a unidades fraseológicas para expresar sus sentimientos vergonzantes y, de este modo, crear el efecto cómico:

(3) «Hace varios años, cuando fui a Inglaterra me sentí como un mono de feria, como un motivo de diversión con temas como el de los toros o las sevillanas»

[NA140]

(4) «De repente, la mujer de la casa [...] me invitó a pasar a la cocina y vi en la cocina muchos alimentos encima de la mesa y una paella. [...] Después de mucha presión, porque todos los invitados no me quitaban ojos de encima y yo en muchos momentos no sabía ni qué hacer, la paella estaba hecha»

[NA148]

En el ejemplo (3) la protagonista de la historia está relatando distintas anécdotas de cómo fue su estancia en Inglaterra. Dicha estancia, en un primer momento resultó incómoda, debido a los estereotipos que se tienen de los españoles. Sin embargo, utiliza este hecho para crear humor a través del significado idiomático de la unidad fraseológica «ser un mono de feria» donde expresa sus sentimientos de forma cómica. En el ejemplo (4), de nuevo debido a los estereotipos que se tienen de los españoles, cuando la protagonista de la historia llegó a la casa en la que se iba a alojar, todos la estaban esperando para darle la bienvenida y la obligaron a hacer una paella. En esta situación incómoda, la protagonista se convierte en el blanco de la burla, puesto que no sabía cocinar. En el fragmento seleccionado lo que crea humor es el uso de la unidad fraseológica que incentiva el sentimiento de incomodidad de la joven.

\subsubsection{Conclusión}

En estos cuatro ejemplos apreciamos que tanto en la etapa de primaria como en la universitaria se utiliza el mismo recurso humorístico, esto es, las unidades fraseológicas, ya sea con su significado literal, ya sea con su significado idiomático. Sin embargo, el cambio se produce en el blanco de la burla. 
Mientras que en primaria se crea humor a partir de los demás, en la etapa universitaria se ríen de uno mismo realizando autohumor, convirtiéndose a sí mismos en el objetivo de las bromas.

\subsection{La hipérbole como indicador humorístico}

En este apartado analizaremos el indicador humorístico hipérbole. Como hemos señalado anteriormente el indicador humorístico es un mecanismo que posee humor en sí mismo. En este caso, a través de la hipérbole se exagera una situación o los rasgos de un personaje y así se consigue el efecto cómico.

\subsubsection{Corpus de primaria}

En general, este indicador es muy utilizado por los niños de primaria para describir tanto a sus profesores como a sus compañeros marcianos, como muestra el ejemplo (5), aunque también lo utilizan para indicar la gran dificultad del idioma como vemos en (6):

(5) «El profe podrido tiene 10 cabezas, 145 piernas, 500 bocas y 5525 orejas»

[IA20]

(6) «Huy, huy, huy, huy, esto no me lo enseñó ni en tres años»

[BA11]

En (5) se recurre a la exageración para describir a su profesor y es lo que crea el efecto cómico. Además, nos parece conveniente señalar, que en muchas ocasiones dichas descripciones vienen acompañadas de un dibujo. En (6) el humor también aparece a través de la exageración cuando el emisor intenta explicar lo difícil que es el idioma marciano. En este caso el blanco de la burla sería el profesor debido a que es incapaz de enseñar el idioma a la niña, en lugar de afirmar que no fue capaz de aprenderlo. A esto hay que añadirle la repetición onomatopéyica que introduce la hipérbole. Cabe resaltar que para los niños son los marcianos los que son diferentes, ya que no hemos encontrado ejemplos donde sean los marcianos los que se extrañen cuando observan el aspecto físico de los niños de la Tierra.

\subsubsection{Corpus universitario}

En este subapartado trataremos un ejemplo donde se utiliza la hipérbole como mecanismo humorístico. Se trata de un indicador poco utilizado en comparación con el uso que se realiza en primaria. La hipérbole se utiliza para mostrar 
el concepto que tienen los extranjeros de los españoles, siendo el español el blanco de la burla, como se muestra en (7):

(7) «Un joven estadounidense me dijo que seguro que a mí me gustaba el flamenco y que se me daba muy bien. Les contesté que ni sabía que ni me gustaba, no me creyeron y se pusieron a dar palmas. Les repetí que no me gustaba, que en realidad lo odiaba, alucinaron un poco, y a modo de broma, me dijeron que seguro que era la deshonra del país»

[NA75]

En (7) el efecto cómico aparece a través de la hipérbole que se utiliza en estilo indirecto donde los extranjeros piensan que la protagonista de la historia es la deshonra del país porque no le gusta el flamenco, todo un tópico fuera de nuestras fronteras. Así, se convierte en el blanco de la anécdota. Además, dicho indicador se introduce con la expresión «a modo de broma», la chica del ejemplo quiere dejar claro que el recurso que utiliza es para crear hilaridad. Por otra parte, nos parece conveniente señalar que el tópico de que los españoles tienen que saber flamenco se repite en muchas de las redacciones junto con otras marcas, indicadores e inferencias diferentes.

\subsubsection{Conclusión}

El indicador hipérbole es un recurso humorístico muy utilizado por las niñas de primaria para crear humor, sobre todo, para exagerar los rasgos físicos de los marcianos o la dificultad del idioma. Sin embargo, según se avanza en edad y madurez es un recurso que se usa en menor proporción.

\subsection{La exclamación como marca humorística}

En este epígrafe nos centraremos en la marca más utilizada en ambos corpus. Siguiendo al grupo GRIALE (Ruiz Gurillo y Padilla García, 2009), una marca es un elemento que ayuda a crear el efecto humorístico, pero no es humorístico es sí mismo. La exclamación ayuda al emisor a señalar una expresión que desea resaltar para que el receptor preste más atención a ese enunciado, puesto que hay alguna inferencia que debe realizar que sin esos signos no haría.

\subsubsection{Corpus de primaria}

Entre las marcas humorísticas que encontramos en ambos corpus, la más utilizada es la exclamación, siendo más numerosa en el corpus de primaria, que se utiliza para llamar la atención sobre algún aspecto. Además, nos parece 
conveniente señalar que siempre se utiliza junto a otro indicador o inferencia. Por ejemplo, en (8):

(8) «De repente solté i¿Qué?! Habláis mi idioma. Los marcianitos dijeron que pensaban que hablábamos raro, no como ellos. ¡Me quedé de piedra! ¡Pero si ellos eran los raritos!»

La niña utiliza la exclamación para mostrar su asombro a través de la unidad fraseológica «quedarse de piedra» cuando se percata de que para los extraterrestres es rara. El giro humorístico aparece cuando la niña matiza a través de la exclamación y el uso del diminutivo que realmente los raros son los extraterrestres y no ella. De este modo cambia el blanco de la burla, donde en un principio se centraba en ella, finalmente son los marcianos. En otro caso en el que encontramos la marca exclamación, (9), se utiliza para expresar que el idioma que usan los marcianos es muy complicado:

(9) «También lo que más me ha asombrado era el idioma en el que hablaban, ¡me ha costado un montón aprenderlo!, pero por lo menos soy bilingüe porque ¡sé español y marciano!»

[IA5]

En (9) en primer lugar se utiliza la exclamación para mostrar el esfuerzo que ha tenido que realizar la protagonista para poder aprender el idioma marciano. En segundo lugar, podemos comprobar la conciencia lingüística que tienen los niños de primaria, puesto que no le ha importado tener que aprender un idioma tan difícil, ya que esto la ha convertido en una persona bilingüe. Este hecho es el que crea el efecto cómico en el fragmento seleccionado.

\subsubsection{Corpus universitario}

Al igual que ocurre en el corpus de primaria, en el universitario la marca exclamación se utiliza para resaltar algún indicador o inferencia, es decir, con el uso de esta marca el emisor pretende llamar la atención sobre el lector para que sepa que se trata de un enunciado humorístico. En el caso (10) se trata de una situación vergonzante que le ocurre a la protagonista a causa de un malentendido cultural.

(10) «El día que una compañera mía que practicaba deporte conmigo me invitó a su casa. Como yo sabía que era rusa cuando entré en su casa me quité automáticamente los zapatos. Mi amiga no se dio cuenta de mi acción y cuando entré en el salón ¡vi que estaban sus padres y sus hermanos con zapatos!»

[NA144]

Feminismo/s 24, diciembre 2014, pp. 221-242 
La exclamación se utiliza para mostrar la situación embarazosa en la que se vio involucrada la protagonista, a través de la contradicción entre las costumbres que pensaba que tenían los rusos -quitarse los zapatos al entrar en casa-y lo que realmente sucedió -solamente ella iba descalza. De este modo, la protagonista se convierte en el blanco de la broma.

\subsubsection{Conclusión}

La exclamación es la marca humorística más utilizada tanto en el corpus de primaria como en el universitario, debido a que puede acompañar a cualquier indicador e inferencia que el emisor considere que debe resaltar para que el lector / oyente se percate del efecto cómico que se quiere transmitir. No obstante, aparece en mayor proporción en primaria debido posiblemente a que las universitarias dominan más signos gráficos que las niñas.

\subsection{Dos tipos de inferencias humorísticas}

En este apartado trataremos la inferencia, concretamente nos centraremos en dos tipos de inferencias que, en ocasiones, están muy relacionadas entre sí, esto es, las situaciones ridículas (§ 4.4.1) y el choque cultural (§ 4.4.2). Siguiendo a Grice (1975) entendemos por inferencia aquello que no se dice expresamente en el texto, pero se deduce del mismo. Desde nuestro punto de vista, el choque cultural podría considerarse un tipo dentro de las situaciones ridículas, ya que dichas situaciones comprometidas muchas veces aparecen debido a culturas diferentes en contacto.

\subsubsection{Las situaciones ridículas}

En este epígrafe mostraremos dos ejemplos, uno extraído del corpus de primaria (§ 3.4.1.1) y otro del corpus universitario (§ 3.4.1.2), donde el efecto humorístico se crea a partir de dos situaciones ridículas, en las que se ven involucradas las protagonistas de cada anécdota, que se producen por desconocimiento cultural sobre el país.

\subsubsection{Corpus de primaria}

En el corpus de primaria encontramos menos casos en los que se describan situaciones humorísticas a causa de una situación ridícula, puesto que las redacciones correspondientes a este corpus se centran, sobre todo, en la descripción de lo que las niñas ven a su alrededor. Sin embargo, podemos encontrar alguna situación ridícula como en (11): 
(11) «Resulta que no necesitábamos los trajes espaciales y un alumno marciano me abrió la cápsula y yo como una tonta haciendo como si me ahogaba»

[SA9]

En este ejemplo, la niña desconoce que no necesita un traje especial para poder respirar en Marte; de ahí que, cuando se lo quitan, tenga la sensación de que se ahoga, hasta que se da cuenta de que sí puede respirar, y está haciendo el ridículo. Hemos elegido este ejemplo, para mostrar que, en ocasiones, en primaria, los niños también pueden ser el blanco de la burla, pero, además de no ser lo más habitual, ha llegado a esa situación por culpa del marciano que es el que le quita el traje.

\subsubsection{Corpus universitario}

En el corpus universitario encontramos más proporción de situaciones ridículas que en el de primaria, puesto que el tema de las redacciones de este grupo invita a describir situaciones embarazosas que posteriormente terminan convirtiéndose en anécdotas cómicas sobre una experiencia personal. El ejemplo (12) muestra una anécdota de una chica la primera vez que visitó Londres:

(12) «Cuando el taxi llegó fui a subirme por la puerta derecha del coche y como estaba tan nerviosa llegué a sentarme en el asiento y al segundo me di cuenta de que estaba sentada en el lado del volante»

[NA138]

La chica vuelve a ser el blanco de la burla, puesto que no se da cuenta de que en Inglaterra el volante está en el lado contrario. En este caso, la protagonista explica que realmente no fue desconocimiento de la cultura inglesa, sino que la confusión se creó por los nervios que tenía por ser la primera vez que visitaba la ciudad. De ahí que se vea involucrada en una situación vergonzante para ella, pero cómica para los demás.

\subsubsection{Conclusión}

Las situaciones ridículas son un recurso muy utilizado a la hora de crear humor, debido a que los errores de los demás suelen causar gracia en la sociedad española. Los ejemplos que hemos mostrado de situaciones ridículas dentro de este epígrafe, desde nuestro punto de vista, están muy relacionados con el choque cultural que veremos en el siguiente apartado, puesto que el efecto humorístico se produce debido a situaciones derivadas de diferencias culturales y no a una situación ridícula universal como puede ser un tropiezo o una caída. 


\subsubsection{El choque cultural}

Por último, en este subapartado nos centraremos en dos casos humorísticos a partir de la inferencia producida por el choque entre culturas que poseen costumbres diferentes, muy relacionada con los casos anteriores. El primero (§ 3.4.2.1) lo hemos extraído del corpus de primaria, mientras que el segundo (§ 3.4.2.2) del universitario.

\subsubsection{Corpus de primaria}

En este corpus encontramos muchos casos donde el efecto cómico se consigue a través del choque cultural, ya que las redacciones se centran en los diferentes aspectos que los niños han encontrado en el nuevo planeta que están visitando. El primer ejemplo que presentamos corresponde al corpus de primaria, (13), donde la niña explica cómo era su colegio en Marte:

(13) «Entré en mi clase y la clase era rarísima los muebles boca abajo, las mesas tenían pinchos»

[SA5]

Encontramos dicho choque cultural en la descripción que se realiza sobre el aula del colegio marciano. La discrepancia humorística se anuncia a través del superlativo «rarísimo». Se trata de un coche cultural humorístico, porque en nuestro país los muebles no se colocan de ese modo y, además, las mesas son cómodas para poder estudiar, al contrario que ocurre en el ejemplo seleccionado.

\subsubsection{Corpus universitario}

$\mathrm{Al}$ igual que ocurre con las situaciones ridículas, el choque cultural es una inferencia muy utilizada en este corpus debido al tema propuesto en la redacción. En el ejemplo (14), la chica está relatando una anécdota que le ocurrió a su abuelo hace varios años cuando vinieron a España unos amigos de Perú:

(14) «Mi abuelo hace unos años recibió la visita de unos peruanos. Un día iba paseando con ellos y pasaron por un kiosco en el que se hacen apuestas de fútbol. La hija de los peruanos gritó:

-Papá, mira ¡LA PICHA, LA PICHA!

El padre le contestó a la hija:

-No digas eso, aquí «picha» significa otra cosa»

[NA78]

En (14) encontramos el choque cultural a partir de las connotaciones diferentes que hay en el significado de una palabra entre el español de la península y 
el español de América. Concretamente, el efecto humorístico aparece a través de la palabra «picha» que en América es un término coloquial para designar a un juego de azar, mientras que en la península se trata de un eufemismo para nombrar al miembro reproductor masculino. Como ocurría en (11), hemos elegido este ejemplo, para mostrar que las universitarias también sitúan el blanco de la burla en otras personas, aunque no es lo más habitual.

\subsubsection{Conclusión}

Este tipo de inferencia es un recurso al que se recurre mucho en ambos corpus para crear el efecto hilarante, siendo más utilizado entre las universitarias que entre las niñas de primaria, posiblemente debido a que las universitarias poseen más conciencia lingüística y cultural que las niñas.

\section{Conclusiones}

Después del análisis efectuado podemos extraer una serie de conclusiones. El corpus muestra que las mujeres son capaces de crear humor desde las primeras fases de la educación. Por tanto, podemos afirmar, por una parte, que las niñas poseen las capacidades cognitivas necesarias para ello y que posteriormente las irán perfeccionando y, por otra parte, que las mujeres no se encuentran restringidas humorísticamente por la educación. No obstante, el humor en cada etapa del desarrollo humano es diferente. Existe un cierto determinismo humorístico, por un lado, el emisor crea humor del entorno, esto es, de las cosas que se conocen; y, por otro lado, se crean situaciones humorísticas por desconocimiento, ya sea cultural o verbal. También aparecen dichas situaciones humorísticas gracias a que el emisor aprecia que se trata de una situación cómica.

Como hemos visto en el análisis práctico, existen una serie de mecanismos humorísticos que se utilizan en todas las fases de la vida como, por ejemplo, los que hemos presentado en este artículo, a saber: indicadores como la fraseología y la hipérbole, la marca exclamación y las inferencias que hemos denominado situación ridícula y choque cultural.

En cuanto a la evolución del uso de estos mecanismos podemos apreciar una tendencia hacia el autohumor. En las primeras etapas de la vida se suele crear humor a partir de los demás, siendo en muy pocas ocasiones una misma el blanco de la burla. En la etapa universitaria el objetivo de la broma es el propio emisor, esto es, autohumor. Si nos centramos en cada mecanismo presentado de forma individualizada, podemos apreciar que en primaria, además de conocer algunas expresiones idiomáticas, ya distinguen entre el significado 
literal y el idiomático. Además, en esta etapa poseen conciencia lingüística, porque el hecho de no entender a los marcianos crea humor. En la etapa universitaria este indicador tiende a utilizarse para crear autohumor, para describir situaciones vergonzantes, debido a lo que los extranjeros piensan de los españoles. El indicador fraseológico se utiliza más en la etapa universitaria que en primaria. Sin embargo, el indicador hipérbole es más utilizado en primaria. En este caso se usa tanto para describir a los marcianos como para señalar la dificultad que presenta el idioma. Podemos apreciar que los enunciados humorísticos tienden a describir cómo los niños ven a los marcianos, mientras que en la etapa universitaria las anécdotas versan, en gran medida, sobre el concepto que los extranjeros tienen de los españoles.

En lo referente a la marca más utilizada en ambos corpus, la exclamación, existe un mayor uso por parte de las niñas que de las universitarias, debido, sobre todo, a que estas últimas dominan más signos gráficos. Este recurso siempre se utiliza junto con otros mecanismos, puesto que las marcas ayudan a identificar el humor, pero no son humorísticas en sí mismas. En ambos corpus destaca el uso junto al choque cultural: como la rareza de los extraterrestres y la dificultad de su idioma, en primaria; y situaciones vergonzantes para la protagonista de la historia, en la etapa universitaria. En lo que concierne a las inferencias hay una tendencia diferente de uso entre ambos corpus. Mientras que en primaria se recurre al choque cultural para crear el efecto cómico, en la etapa universitaria abusan de las situaciones ridículas. Esto puede ser debido a dos motivos fundamentales, en primer lugar, porque las situaciones ridículas es un tipo de humor que causa gracia en la sociedad española y en la infancia aún no se tiene conciencia del ridículo; y, en segundo lugar, por el tema propuesto en las redacciones, ya que en el cuento de primaria encontramos la descripción de muchos lugares distintos a la Tierra, cosa que no ocurre en las redacciones universitarias que se centran en las anécdotas vividas. Además, en las inferencias apreciamos un uso distinto al resto de los mecanismos utilizados, a pesar de no ser el más habitual: en las situaciones ridículas hemos encontrado algún caso, como el ejemplo que se ha utilizado en el análisis, donde la niña se convierte en el blanco de la burla; en el choque cultural aparece algún fragmento en el que el blanco de la burla se sitúa en otra persona. La figura 5 muestra el uso de los mecanismos presentados en este artículo. 


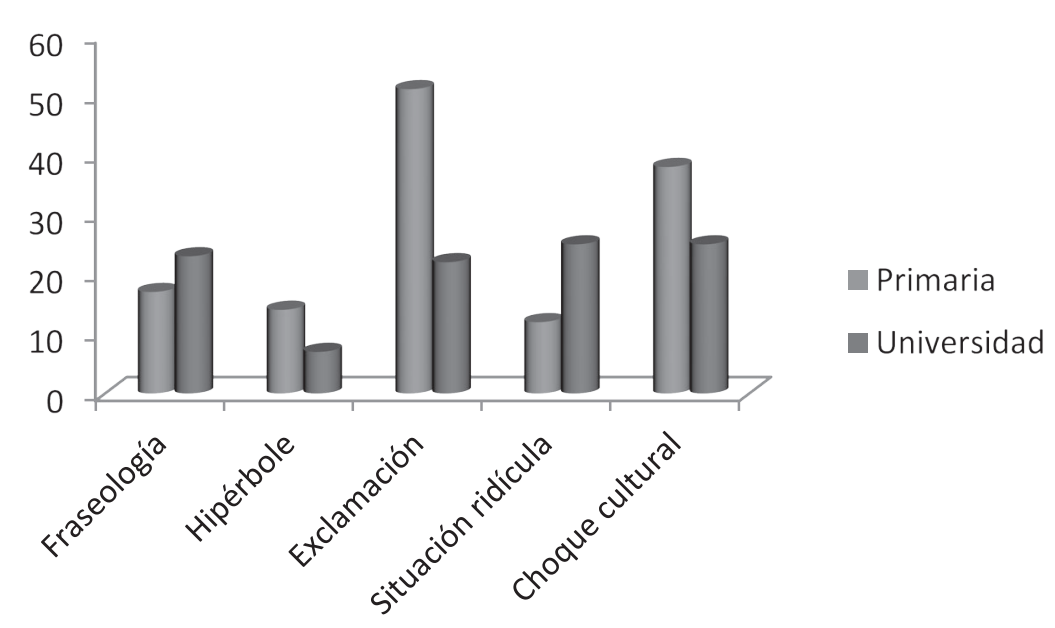

Figura 5: Mecanismos humorísticos

El trabajo aquí presentado es una primera aproximación al corpus de narraciones humorísticas de mujeres de primaria y de universidad. Se ha presentado un análisis cualitativo que cabrá ampliar en futuras investigaciones y corroborar a partir de datos cuantitativos, extendiendo el análisis a los datos obtenidos del sexo masculino.

\section{Referencias bibliográficas}

Alvarado Ortega, M. Belén y Ruiz Gurillo, Leonor (coords.). Humor, Ironía y Géneros Textuales. Alicante, Servicio de Publicaciones de la Universidad de Alicante, 2013.

Benavent Oltra, José Antonio. «Génesis de la risa infantil». Anuario de Psicología, Número 2 (1970), pp. 107-114.

Droz, Marilyn y ELLIS, Lori. Laughing While Learning: Using Humor in the Classroom. Longmont, Sopris West, 1996.

ERVIN-TRIPP, Susan and LAMPERT, Martin. «Gender differences in the construction of humorous talk» en Hall, Bucholtz and Moonwomon (eds.) Proceedings of the second Berkeley Women and Language, Berkeley, Women and Language Group, 1992, pp. 105-107.

GRICE, H. P. «Logic and Conversation» en Cole, P. and Morgan, J. L. (eds.) Speech Acts, New York, Academic Press, 1975, pp. 41-58.

HAY, Jennifer. Gender and humour: Beyond a joke. Master's thesis. Wellington, Victoria University of Wellington, 1995. 
JulE, Allyson. A Beginner's Guide to Language and Gender. Clevedon, MM Textbooks, 2008.

LAKOFF, R. Language and Woman's Place. New York, Harper and Row, 1975.

MANKE, B. «Genetic and environmental contributions to children interpersonal humor» en Ruch (ed.) The Sense of Humor Explorations of a Personality Characteristic, New York, Mounton de Gruyter, 1998, pp. 361-385.

OJEDA AlBA, Julieta. «Humour, Vocabulary and Individuality in an EFL Task», en Gendered Words: Representation and Identities, 2010, pp. 212-237.

RuIz GURILlo, Leonor. La lingüística del humor en español. Madrid, Arco Libros, 2012

Ruiz Gurillo, Leonor y Alvarado Ortega, M. Belén (eds.) Irony and Humor. From pragmatics to discourse. Ámsterdam, John Benjamins, 2013.

Ruiz Gurillo, Leonor y Padilla García, Xose. (eds.). Dime cómo ironizas y te diré quién eres. Berlín, Peter Lang, 2009. 
LITERATURA Y CULTURA 



\title{
ASPECTOS CULTURALES DE LA TRADUCCIÓN DEL HUMOR SOBRE LA MUJER
}

\author{
MOHAMED EL-MADKOURI MAATAOUI \\ Universidad Autónoma de Madrid
}

Recibido: $15 / 09 / 2014$

Aceptado: 24/11/2014

\section{Resumen}

El discurso lúdico está impregnado de referencias extralingüísticas de índole social y cultural, amén de los ya consabidos procedimientos metalingüísticos y de autorreferencia, de ahí que una traducción o interpretación del mismo que mantenga la misma carga humorística resulte complicada. Esto se debe no solamente a las distintas complejidades lingüísticas implicadas en su construcción, sino también a las atribuciones culturales que se le confieren. No estamos hablando, por tanto, de la traducibilidad lingüística, sino de la cultural. Es decir, ¿son aceptables del mismo modo los chistes sobre la mujer a ambas orillas del Mediterráneo? Partiendo de este planteamiento, el presente trabajo tiene por objeto analizar lo universal y lo particular en el trasvase del chiste sobre la mujer de una cultura a otra. Para ello, se han elegido un par de culturas aparentemente diferentes como son la árabe y la española, aunque metafóricamente se designe a ambas con el nombre de cultura mediterránea. Así, se intentará averiguar cómo se representa a la mujer en el chiste desde los siguientes parámetros: el físico, el intelectual y el moral.

Palabras clave: chiste, mujer, traducción, traductología, interculturalidad

\begin{abstract}
The playful discourse is imbued with references extralinguistic social and cultural factors, in addition to the already well known procedures and metalinguistic self-reference, hence its translation and interpretation with the same humorous load resulting complicated. Not only by the different linguistic complexities involved in its construction, but by the cultural powers conferred. Departing from this approach, this paper aims to examine the universal and the particular in the transfer of the joke about the
\end{abstract}


woman from one culture to another. For this we have selected a pair of seemingly different as Arabic and Spanish cultures, though they are both metaphorically designate the name of Mediterranean culture. Thus, try to figure out how the woman depicted in the joke from the following parameters: physical, intellectual and moral.

Keywords: Joke, Woman, translation, Translation Studies, intercultural 


\section{Introducción}

En culturas distintas no siempre se ríe de lo mismo ni de la misma manera. Los aspectos cromáticos del discurso chistoso no son simétricos entre una lengua y otra, ni entre una cultura y otra. Además, no todas las lenguas tienen colores para los chistes, y en las que los tienen, no se corresponden obligatoriamente con los de la lengua de partida. Tampoco existe necesariamente una simetría de significación (que no de significado) entre el léxico de lenguas distintas. En el marco del discurso humorístico, se ha optado por el chiste y el lenguaje humorístico en general por varias consideraciones:

1. El discurso humorístico es anónimo. No viene suscrito por ningún autor ni aparece patentado por ninguna institución.

2. Al ser despersonalizado, su autoría es asumida por toda la sociedad y cultura en que se produce y se recibe. En este sentido, podemos hablar de una autoría colectiva, que incluye a los que los escuchan y se ríen con ellos.

3. Al ser un constructo discursivo colectivo, su análisis nos permite rastrear estereotipos culturales.

4. Al estar impregnado de referencias extralingüísticas de índole social y cultural, amén de los ya consabidos procedimientos metalingüísticos y de autorreferencia, resulta complicado llevar a cabo una traducción o interpretación que mantenga la misma carga humorística. Esto se debe no solamente a las distintas complejidades lingüísticas implicadas en su construcción, sino también a las atribuciones culturales que se le confieren.

Desde este planteamiento, consideramos pertinente el estudio de la presencia y caracterización de la mujer en el chiste, entendido siempre como constructo discursivo abstracto. Cabe señalar al respecto que para la elaboración de este estudio se han tomado como ejemplo chistes en la Red. En el caso árabe, las nuevas tecnologías representan el discurso real social, un cambio generacional y conceptual. Igualmente, en el caso español se accede a chistes de todo tipo en la Red, traspasando la barrera de lo «políticamente correcto». 
En todos los casos, la caracterización discursiva de la mujer es controvertida. La mujer, en los distintos discursos, en general (novela, teatro, cine, poesía), siempre ha simbolizado a la vez la ternura y la insensibilidad, el amor y el desprecio, la ingenuidad y la astucia, la nobleza y la perfidia, la lealtad y la traición, la compasión y la crueldad. Sin embargo, en el chiste, como demostraremos en este artículo, está más presente lo negativo que lo positivo.

\section{La presencia femenina en el chiste}

Tanto en árabe como en español la presencia femenina en el chiste es notoria. El cuerpo femenino aparece reiteradamente en el chiste bajo distintas manifestaciones: como objeto de deseo, de codicia, de protección, de posesión, pero también como cuerpo desechado, repudiado, aborrecido... En esta representación, el discurso chistoso está polarizado entre el cuerpo extremadamente «bello» y el cuerpo extremadamente «feo». En ello participa reseñablemente la dimensión temporal, encontramos a la jovencita «tentadora» en oposición a la «vieja» desechada, pero que se resiste a tirar la toalla. Esta dicotomía, no obstante, no siempre es paralela a la edad real y física de la mujer, sino que encontramos la vieja y la recién conocida, la primera y la segunda. Junto con este vector temporal interviene también, en la construcción del chiste, la dimensión intelectual: la mujer es generalmente ingenua y con las facultades mentales reducidas, y cuando el chiste hace una representación contraria, la capacidad intelectual se convierte en astucia y perfidia. En cuanto a los valores morales de la mujer, quedan supeditados a sus circunstancias personales y emocionales, por lo que aparecen inconstantes. Es decir, que la mujer se presenta, por lo general, más en el chiste español que en el árabe, moralmente insolvente; de hecho, se insiste más en la infidelidad femenina en el chiste español que en el chiste árabe.

\subsection{El cuerpo femenino en el chiste}

Antes de hablar del cuerpo femenino, tema del chiste tanto en árabe como en español, cabe preguntarse qué tipo de mujer aparece en este tipo de discurso.

La mujer más representada en el discurso lúdico no es ni la madre, ni la hermana, ni la hija, sino una mujer ajena, anónima primero y esposa después, más en el chiste español que en el árabe. Es decir, la mujer más representada es la mujer-cuerpo sujeta a la posesión y al disfrute. Es la mujer como objeto. Cabe matizar, sin embargo, que, aunque la madre, la hermana y la hija están menos presentes, esto no significa que sean inexistentes, especialmente en español. De hecho, existen en la cultura española chistes sobre la hija, la 
madre y la hermana muchísimo más presentes y relevantes que en los distintos países árabes. En el mundo árabe la mujer-cuerpo que aparece en el chiste es la mujer ajena a toda relación consanguínea. Este hecho plantea una importante cuestión traductológica, ya que, salvando los demás problemas de la traducción del chiste, los árabes son traducibles al español, pero no así tanto los españoles al árabe, por las siguientes razones:

1. El chiste sobre la mujer parece de autoría masculina. Todo indica que es el hombre quien inventa estos chistes, para reírse con otro $u$ otros hombres, armando estos constructos lúdicos con cuerpos femeninos. Una encuesta informal reveló que siete mujeres de entre 27 y 40 años de edad, árabes y españolas encuestadas, creen que la autoría de estos chistes corresponde a los hombres. Por ello, lo que haría gracia a unos, no la haría necesariamente a otros, especialmente en el mundo árabe.

2. Cuando se habla de la mujer-cuerpo, en realidad se habla de la mujer como objeto sexual. Cuerpo y sexo están muy estrechamente relacionados en el chiste sobre la mujer. Sin embargo, un árabe no puede imaginarse que su hermana, madre o hija puedan ser objetos sexuales ni propios ni ajenos, aspecto irrelevante en español. Por ello, el chiste español traducido al árabe deja de ser chiste para convertirse en una broma de mal gusto.

3. La mujer-cuerpo en árabe es una mujer libre de todo compromiso matrimonial o consanguíneo. Es una mujer que no es familiar y generalmente es soltera. En otras palabras, es un cuerpo sexual anónimo. Hay pocas connotaciones sexuales sobre mujeres familiares o casadas.

4. Muy en relación con lo anterior, la mujer del chiste es más infiel en español que en árabe. Es decir, desde el punto de vista cuantitativo, la mujer infiel aparece más en el chiste español que en el chiste árabe, a pesar de que libros como Las mil y una noches están plagados de mujeres infieles. Sería interesante investigar por qué hay más presencia de mujeres infieles en la literatura árabe formal que en la popular.

\subsection{La relevancia de la mujer-cuerpo-sexo en el chiste}

El sexo es muy relevante en el chiste español sobre la mujer, además es un sexo explícito, claro y hasta pornográfico. En el caso del chiste árabe, esta presencia es más bien sutil o simbólica, y necesita de una serie de abstracciones y de operaciones interpretativas para poder ser entendido. Es más, este tipo de chistes árabes se puede contar en presencia de niños pequeños sin que estos los entiendan. De hecho, los chistes árabes no mencionan, generalmente, de 
forma explícita ningún órgano sexual, ni femenino, ni masculino. Además, el discurso sobre el sexo en español está extendido, mientras que en árabe está circunscrito a tiempos y espacios bien determinados. Es decir, en español se habla generalmente de sexo con todo el mundo, a cualquier hora y en cualquier sitio. En el caso del mundo árabe, el discurso sobre mujer-sexo aparece limitado por el tipo de interlocutor y las dimensiones espacio-temporales. Las tres variables condicionantes de la circulación del chiste árabe sobre la mujercuerpo-sexo son:

1. El receptor del chiste sexual: cuando el discurso sobre sexo es explícito en árabe su exteriorización se ve determinada por el tipo de destinatario a quien va dirigido. El cuentachistes no puede decidir por sí solo cuándo los cuenta, independientemente de a quién vayan dirigidos y del tipo de audiencia. Esto parece universal y se da igualmente en español, sin embargo, en el caso de la cultura árabe genuina, este tipo de chistes se cuenta entre iguales. Es decir, no se pueden contar cuando hay diferencias de edad. El desfase generacional limita la exteriorización del discurso sobre sexo. Uno no puede contar un chiste explícitamente sexual a otros en presencia de sus hijos o padres, por ejemplo. Del mismo modo, no es común contar un chiste sobre el cuerpo de la mujer y de connotaciones sexuales explícitas en presencia de oyentes que pudieran ser hijos o padres de quien los cuenta.

Otra variable que también debe tenerse en cuenta es el sexo del oyente. Cuando el sexo del hablante es distinto del sexo del oyente (a no ser que exista demasiada familiaridad y no parentesco consanguíneo entre ellos), el chiste sexual es mal recibido. Estamos hablando aquí de lo común y genuino, ya que muchos colectivos jóvenes, especialmente en países como Marruecos, Túnez y el Líbano están occidentalizados, por lo que se rigen por otros patrones culturales. De hecho, esta occidentalización se percibe como algo extremadamente negativo en algunos de sus aspectos. No en vano, muchos analistas de estos países atribuyen la cultura del cuerpo, la droga o la violencia juvenil en el sistema educativo a la globalización y a la occidentalización:

El mundo está experimentando grandes cambios en diferentes campos. Esto ha tenido un impacto negativo significativo en el sistema de valores y principios humanos y morales. Este comportamiento ha dado lugar a una variedad de fenómenos negativos como la violencia, el consumo de drogas... ${ }^{1}$ [Traducción propia]

1. <http://www.hibapress.com/fr/details-3138.html> consultado el 03-05-2014. 
Esta reflexión académica es corroborada con un lenguaje más directo por un responsable policial en el mismo acto discursivo:

Las escuelas son un tipo único de sociedad donde florecen muchos comportamientos irreflexivos relativos a la violencia, la agresión, la droga, la delincuencia, los asaltos, las lesiones... entre los propios alumnos y entre los alumnos y el cuerpo docente ${ }^{2}$. [Traducción propia]

Aunque estas citas no hablan explícitamente de Occidente, plantean el problema de la alteración del sistema de valores y de los principios humanos y morales. Esto se debe a que el mundo está interconectado, como si viviéramos en una pequeña aldea global. De hecho, quien pronuncia las palabras de la primera cita es un responsable académico de la región de Tadla-Azilal, en los confines de la cordillera del Atlas Medio marroquí, en el marco de un acuerdo ente las autoridades educativas y las policiales de la región para prevenir la delincuencia estudiantil, tradicionalmente insignificante en esa zona. No es de extrañar que este cambio moral afecte también a la cultura juvenil en general y a su percepción del otro sexo, en particular. En efecto, el cuerpo femenino se ha cosificado demasiado en el leguaje de este «tipo único de sociedad», especialmente en el de los países mencionados anteriormente, tema que trataremos en un futuro trabajo.

2. El espacio físico donde se desarrolla el discurso chistoso no es menos importante que el tipo de interlocutor (edad y sexo). En árabe existe el fraseologismo «a cada lugar, su discurso». Expresado de otro modo, el contexto comunicativo predetermina lo que se puede decir y cómo debe decirse. Un chiste sobre el cuerpo femenino o masculino con connotaciones sexuales no se puede contar, por ejemplo, en el hogar familiar o en un contexto discursivo en el que hay personas poco conocidas y con la cuales no existe una estrecha amistad o cordialidad. Tampoco se cuenta en voz alta, audible para los comensales de la mesa de al lado, por ejemplo. Este tipo de chistes suele contarse como si de una verdadera confidencia se tratase.

3. El momento también determina a quién y cuándo se puede contar un chiste sexual que corporeiza a la mujer. Si en el penúltimo párrafo hemos visto que la edad del oyente es determinante, también lo es el momento y la motivación con que se cuenta. El chiste sobre sexo en el mundo árabe es más nocturno que diurno, y es más frecuente en el tiempo libre (extraescolar y fuera del ambiente serio del trabajo). Sin embargo, esta es una tendencia general, cuantitativamente relevante, pero que no excluye que existan personas, hombres

2. Ibídem.

Feminismo/s 24, diciembre 2014, pp. 245-264 
generalmente, que los cuenten «fuera de tiempo» y con fines más bien provocativos, cuando parte del auditorio es femenino. Aquí ya no se cuenta el chiste para «hacer reír», sino para provocar a la mujer, especialmente cuando las relaciones entre estas personas dejan que desear. Es decir, la finalidad explícita en este caso ya no es lúdica, sino ofensiva.

Estas tres variables son, por tanto, determinantes de las circunstancias de la producción de chistes sobre la mujer con connotaciones sexuales, y son determinantes, aunque en menor grado, de la construcción de los mismos. Por ello, el problema de la traducción en estos casos no es inherente al propio discurso chistoso, sino a su divulgación y a las limitaciones culturales de su uso. Es decir, no existe simetría entre los auditorios. Si nos imaginamos, por ejemplo, una representación teatral impregnada de estos chistes que hubiera que traducir y escenificar en el mundo árabe, el teatro no tendría seguramente ni la afluencia ni el mismo tipo de espectadores que en España. Estos chistes, considerados «obscenos» y degradantes, no tendrían la misma aceptación que en la cultura origen.

En árabe, sin embargo, existen chistes sobre amoríos (no sexuales) adolescentes en las redes sociales en los cuales las adolescentes y preadolescentes son objeto de mofa, como el siguiente:

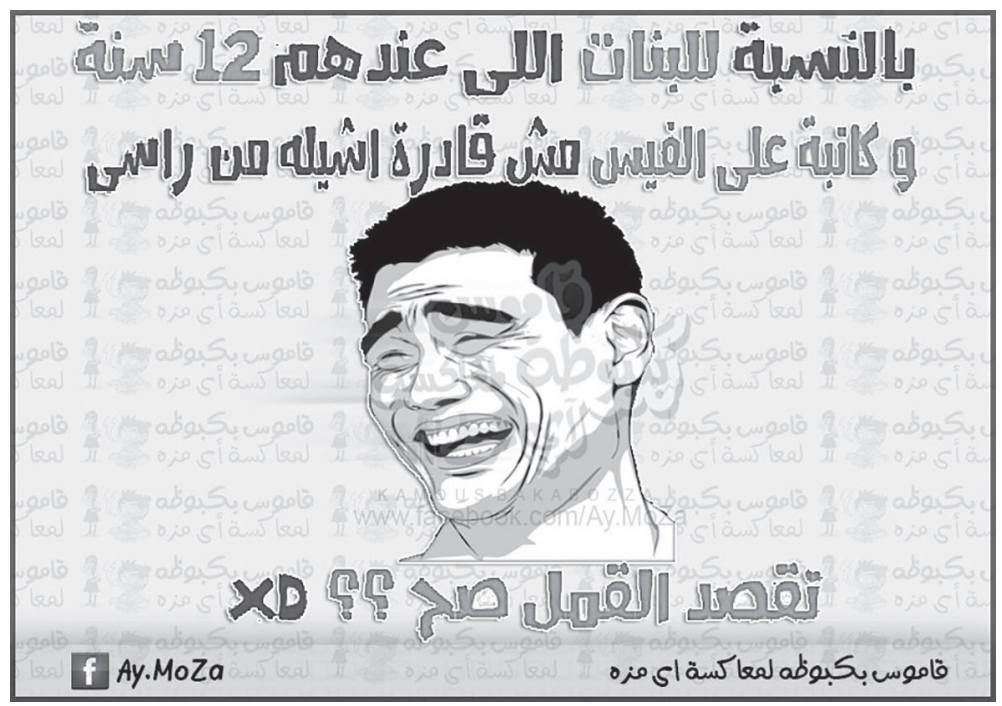

Imagen 1 
Una posible traducción de la imagen 1 podría ser la siguiente: «Las chicas de doce años que escriben en el Facebook que " No se los pueden quitar de la cabeza!"... ¿A qué se refieren? A los piojos, ¿verdad? (-)». Este tipo de chiste árabe es abundante en la Red: el objeto de la risa es siempre un niño o una niña que quiere ser mayor o pretende hacer cosas de mayores. Es decir, en el caso de las preadolescentes de «los piojos en la cabeza», el chiste es sutil y hasta educativo. En este caso, se pone de relieve la disfunción mencionada más arriba. Se supone que los doce años son una edad en la que no se debe tener nada en la cabeza que no sea, en el peor de los casos, piojos.

\subsection{El cuerpo femenino, mujer casada}

La oposición mujer-casada y mujer-independiente es más relevante en árabe que en español. La mujer en español es un cuerpo de deseo o de burla sexual con independencia de si está casada o no. En árabe se hace una diferencia entre mujer casada y mujer no casada. Los chistes sexuales sobre mujeres árabes como objeto de deseo ajeno evitan a las casadas. En español, sin embargo, el estado civil de casada de la mujer-objeto parece irrelevante para el chiste sexual. Es frecuente ver en la calle a hombres piropear a mujeres, con independencia de si están casadas o no. En el mundo árabe, en cambio, son poco frecuentes los chistes sobre mujeres casadas como objetos sexuales, es decir, como objeto de deseo o de repulsa por parte del sujeto de la enunciación. Los chistes sexuales árabes existentes sobre casadas son, al contrario, para reírse de sus disfunciones con sus maridos o de estos entre ellas. Así, desde siempre el chiste árabe de contenido sexual mayoritario ha sido sobre la mujer casada.

No obstante, existe una coincidencia entre España y muchos países árabes cuando el chiste incurre en el propio matrimonio y casamiento, más que en el cuerpo femenino. Cuando se focaliza en el matrimonio, se difumina la caracterización corporal positiva de la mujer casada y aparecen otras consideraciones relativas a la vida conyugal. En este aspecto concreto, los chistes son traducibles entre el árabe y el español. Además, tanto en árabe como en español hay abundantes chistes relativos a la mujer en la vida matrimonial. En realidad, estos chistes no focalizan en la mujer, sino en la institución matrimonial. Parece ser que la mujer es objeto de deseo hasta que se casa. Por ello, ambas culturas coinciden en los siguientes aspectos: el descuido de la casada de sí misma, su excesivo gasto, su autoritarismo, su opresión al esposo y, finalmente, su disfunción sexual (explícita en español e implícita en árabe). En este caso, podría afirmarse, a excepción del último punto, que la traducibilidad cultural de estos chistes es posible entre el árabe y el español. 


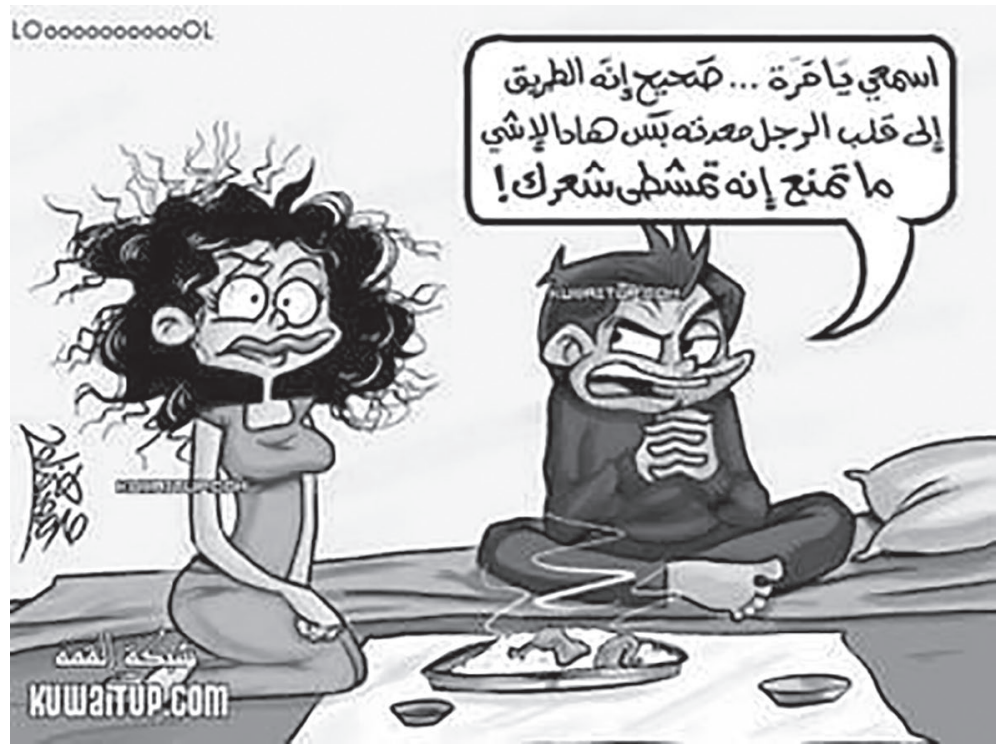

Imagen 2

Aquí se presenta la imagen de una mujer árabe descuidada. Este chiste reza:

Escucha, mujer, es verdad que a un hombre se le conquista por el estómago, pero esto no impide que te peines un poco.

La gordura está igualmente relacionada con el cuerpo de la mujer. En este sentido, el símil de la vaca es común para representar a la mujer, tanto en árabe como en español. Sin embargo, el término foca es privativo del chiste español, aunque aparece sustituido en árabe por elefanta, que no se presenta en español. De todos modos, la comparación con el animal es muy recurrente en los chistes en ambas lenguas. Sin embargo, las connotaciones propias de cada uno son distintas, aunque en este trabajo hemos hecho hincapié solo en los que califican a la mujer casada. Sirva de ejemplo este chiste árabe:

Esto es un hombre que habla con su mujer y le dice: «La vida se ha convertido en un zoo. Fíjate en mí: me levanto como un caballo, voy a trabajar como un burro, vuelvo jadeado como un perro y me acuesto ${ }^{3}$ con una vaca».

3. El verbo real en árabe es «dormir» [me duermo con], creándose una ambigüedad muy propia de la construcción de los chistes árabes, como se ha dicho anteriormente, sobre el verdadero sentido de este verbo. Haciendo uso de la característica de la explicitud propia 
Parece ser que la estética de la mujer delegada no es un lastre solo para las occidentales, sino también para la mayoría de las mujeres de los países árabes. La siguiente viñeta reproduce el mismo tópico:

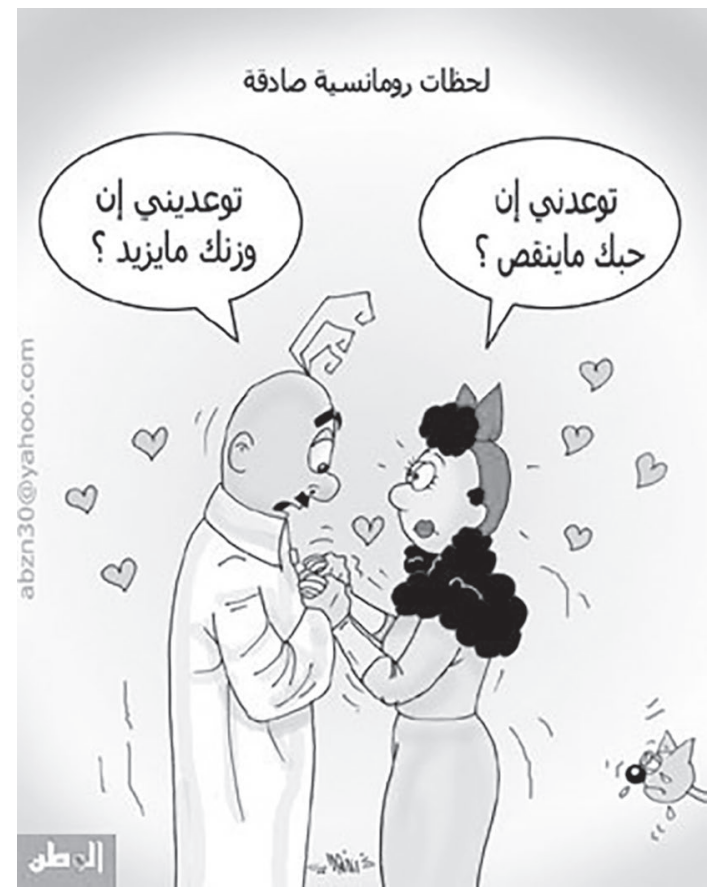

Imagen 3

El texto de esta imagen dice:

Momentos románticos de sinceridad

Ella a él: «¿Me prometes que nunca disminuirá tu amor por mí?»

Él a ella: «¿Me prometes que nunca subirás de peso?»

Tanto en español como en árabe, el tópico parece ser que la mujer es guapa, valorada y apreciada hasta que se casa. Entonces van desmejorando su amor por el marido, su estética personal y sobre todo sus relaciones maritales, como en este chiste español:

de los chistes españoles, se ha traducido por «acostarse», que es como lo entiende también un adulto árabe. 
¿Cuál es la diferencia entre una novia, una amante y una esposa?

Que la novia te dice «jay, qué dulce!», la amante dice «jay, qué vigor!», y la esposa dice «hay que pagar la luz, hay que pagar el teléfono, hay que pagar el gas...».

Esta caracterización cultural de la mujer en el matrimonio hace posible la aceptabilidad y, por tanto, la traducibilidad de los chistes y anécdotas sobre estos temas. Sin embargo, cabe señalar una excepción. Algunos chistes españoles son demasiado explícitos sobre el tema sexual -como ya se ha comentado-, mientras que sus homólogos árabes son más bien implícitos. Por ello, serían más aceptables los chistes árabes en español (aunque resultasen light), que los españoles en árabe, que perderían su gracia por pecar, a veces, de «vulgares». Los chistes árabes sobre este tema no son tan descriptivos y anatómicos como los españoles. La simbología, y consecuentemente la inferencia, parecen ser un requisito esencial en el chiste árabe sobre el sexo no solo en el matrimonio, sino en general.

Ahora bien, la disfunción sexual varonil es un tópico que se da en chistes de ambas lenguas, aunque está más naturalizada en árabe que en español. En la cultura española, parece ser que la imagen del macho queda salvaguardada, como en el siguiente ejemplo:

-Mi marido es tocólogo.

-Pues el mío es meteorólogo.

- iQué suerte tienen algunas!

Está claro que la construcción léxica de este chiste no podía ser de otro modo, pero el vigor del macho ibérico es poco cuestionado, por lo menos no del mismo modo en que aparece cuestionada la actividad sexual femenina de la española. No se ha podido encontrar ninguno parecido en árabe, en el que la mujer como sujeto del chiste no cuestione la virilidad del hombre. Ahora bien, desde el punto de vista traductológico, este tipo de chistes es traducible al árabe, aunque en esta cultura existen chistes que parecen hechos al revés, es decir, sobre mujeres que cuestionan a los hombres:

Esto es uno a quien no le gusta cómo cocina su mujer. Coge y escribe un letrero que le cuelga en la cocina: «A Dios le gusta que, cuando uno de vosotros haga algo, lo haga perfecto». La mujer coge el letrero y se lo cuelga en el dormitorio (:).

Aquí el hombre árabe no es tocólogo ni meteorólogo, sino que parece incumplir lo que pregona. La perfección no solo debe demostrarla la mujer, en este caso, cocinando, sino también el hombre en otros menesteres. Cabe mencionar que, como en casos anteriores, se precisa explicitar un dato cultural que puede pasar desapercibido a una persona con pocos conocimientos de 
la cultura islámica. La frase entrecomillada que aboga por la perfección en lo que se haga es un dicho de Mahoma, profeta del islam, que exhorta a sus seguidores a la perfección. El hombre del chiste lo aplica a su conveniencia en un sentido, y la mujer se lo devuelve, en otro.

En el mundo árabe, la mayoría de los chistes de contenido sexual versa sobre la mujer, pero esta se presenta como un ente anónimo. La casada no se presenta generalmente como diana directa del chiste sexual.

No obstante, se ha observado un cambio significativo en la profusión de los chistes sexuales que algunos atribuyen, como se ha visto anteriormente, a la cultura occidental. Con todo, cabe destacar que el chiste genuinamente árabe era el que remarcaba la torpeza del hombre en temas sexuales y en el conocimiento del cuerpo femenino, con lo que el chiste clásico participaba en cierta medida en la educación sexual de las nuevas generaciones, cuando ya son maduras para ello. Sin embargo, en la actualidad, se ha observado la irrupción de nuevos contenidos sexuales en los chistes árabes sobre la mujer. Esto es debido a varios factores:

1. El progreso de las nuevas tecnologías. Las pantallas de los ordenadores dan la impresión de cierto anonimato y previenen de la posible reacción negativa inmediata ante un auditorio real. De hecho, se codifican de forma escrita cada vez con más frecuencia, cuando su esencia es tradicionalmente una codificación oral.

2. Como consecuencia de lo anterior y por la liberación del espacio audiovisual en prácticamente todo el mundo, se asiste a un cambio sustancial en las culturas árabes, que aparecen cada vez más occidentalizadas, aunque esto no afecta a todas las generaciones ni a ambos sexos por igual.

3. La tercera causa es debida, en los mismos términos anteriores, a la globalización y al asentamiento de una gran diáspora de árabes en países occidentales con culturas que, a ojos de la cultura árabe clásica, «banalizan» el sexo. De hecho, cuando se «pesca» un chiste en la Red, como se ha hecho para la presente investigación, se sabe que es árabe porque aparece escrito en una de la variantes de la lengua árabe, por lo que se puede saber que es libanés, sirio, iraquí, marroquí, etc.; pero no se puede determinar a ciencia cierta si su autoría es interna o externa, o sea, si ha sido creado dentro del mundo árabe o por árabes asentados en países occidentales. 
Este cambio en la cultura lúdica sobre el chiste y el cuerpo, tanto el femenino como el masculino, ha sido objeto de varios artículos publicados en el mundo árabe. Sirva de ejemplo este fragmento:

«Habla para que te vea» es uno de los eslóganes más certeros para manifestar que la manera de hablar de una persona revela su cultura y educación, incluso da cuenta de su estado psicológico. El mundo de los jóvenes, el mundo de la adolescencia, distinto, convulso y siempre agitado, se entiende por medio de sus manifestaciones lingüísticas, sus expresiones, sueños y aspiraciones. El chiste como una de las fuentes de conocimiento que practicamos diariamente cumple una función paralela a las otras fuentes de cultura y demás información, y puede incluso que las supere [...].

Los chistes desempeñan un papel fundamental en la cultura sexual, pero esta vez de forma errónea, algo indudablemente muy negativo [...], una «brasa de fuego» que acabaría destruyendo su futuro y sus mentes. ¿El cabeza de familia que se yergue como guardián para que su hijo no vea una película pornográfica o adquiera una revista «sexual» podría acaso ponerle un candado en la boca o en la de sus amigos para impedirle contar chistes malsonantes? ${ }^{4}$

Este ejemplo refleja una verdadera preocupación por la trivialización y banalización del sexo por parte los jóvenes árabes, por encima de las categorías genuinas de esta cultura que rechazan el sexo fuera de una unión de pareja estable. El autor de la cita, después de excusarse por no poder reproducir una muestra de estos chistes criticados, facilita, sin embargo, el siguiente ejemplo:

Una caricatura publicada recientemente por una revista muestra a un joven que quiere pedir la mano de una chica a su padre. Como es de costumbre, existe una dote preceptiva, que se acuerda antes del matrimonio. El joven dice en la caricatura:

-Puedo entregar la mitad de la dote y llevármela solo los jueves y viernes.

Antes de comentar esta cita, cabe proporcionar las claves culturales de su interpretación. Primero, la dote la constituyen los regalos, el oro, las joyas y todo lo que el novio ofrece a la novia, y que se acuerda generalmente entre las familias de los novios. Varía entre los distintos países árabes y va de lo simbólico en algunas zonas del Magreb, hasta ingentes sumas en los países del Golfo, Siria, Jordania, Palestina... donde puede superar en ocasiones los 15000 euros, según pude comprobar en algunos certificados de matrimonio que vi en calidad de traductor jurado. Segundo, el jueves completo, o media jornada, y el viernes, son festivos en la mayoría de los países árabes. A este propósito, existen muchos chistes y caricaturas sobre la elevación de

4. <http://www.nadyelfikr.com/showthread.php?tid=33171>, consultado el 27-04-2014. 
las condiciones de contraer matrimonio en el mundo árabe. Algunos de ellos comparan los procedimientos de casarse con los de otras culturas, como en la siguiente caricatura:

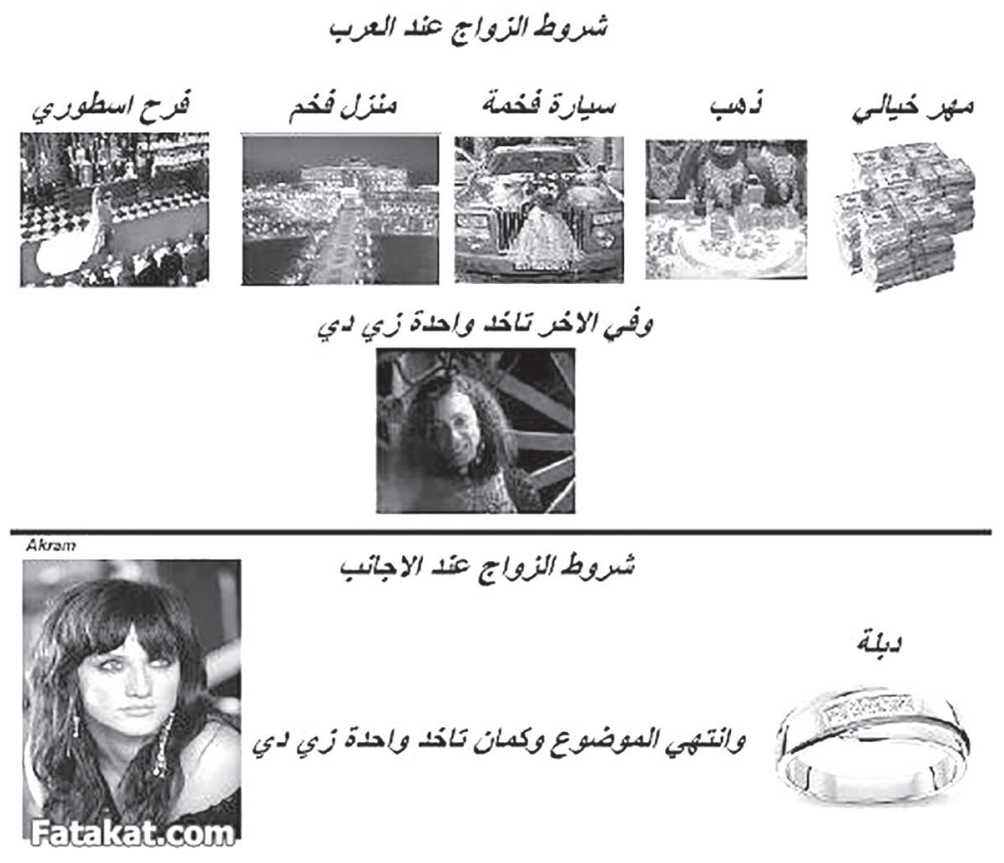

Imagen 4

Las condiciones de matrimonio de los árabes:

Una dote que roza lo imposible (entregada por el novio a la novia), oro, un vehículo y un piso de lujo, y una fiesta a lo grande... Y finalmente te casas con una como esta (la primera mujer).

Las condiciones de matrimonio de los extranjeros (se sobrentiende, occidentales):

Una alianza, y te quitas de más rollos. Finalmente te llevas una como esta (segunda mujer).

Con respecto a la caricatura sobre mujer-esposa-dote de fines de semana, lo que el crítico árabe percibe como "corruptor» en su artículo es el ataque a la estabilidad y a la convivencia de pareja, así como al cuestionamiento de la unión estable y duradera que establecen los códigos culturales árabes. Aunque la conceptualización materialista y cosificadora de la mujer es más sutil en el humor árabe que en el español, esta caricatura no deja de representar a 
la mujer como una cosa que se puede alquilar para un fin de semana. En este caso, como en otros anteriores, en realidad la mujer es una víctima colateral, siendo el objetivo principal el concepto de dote y las trabas familiares al matrimonio. La traducibilidad cultural en este caso, salvando el escollo de la dote, es plena, tanto en un sentido como en otro.

Cabe recordar, como se ha señalado anteriormente, que los chistes árabes tradicionales son menos explícitos que sus homólogos españoles, lo que hace complicado el camino inverso, es decir, traducir chistes españoles al árabe. Además, a la mujer no solo se la objetiviza (muchas veces ni siente, ni piensa), sino que, en ocasiones, se la animaliza, como en este ejemplo español, difícilmente traducible al árabe no por su contenido asociativo, sino porque el collar como gargantilla tiene un nombre y el collar para llevar animales tiene otro:

Dos amigos que se encuentran por la calle:

-Ayer a mi mujer le regalé un collar y está contentísima.

- ¡Ah! Pues yo a la mía la llevo suelta.

En el caso de la cultura árabe clásica los chistes y el humor en general tienen un fuerte calado didáctico y educador. Un adolescente entrevistado por los autores del artículo crítico con las nuevas manifestaciones de los chistes «sucios», citado anteriormente, afirma:

Estos chistes fueron la fuente de mis primeros conocimientos sexuales, primero los oía sin entender a qué se referían, pero ahora los considero un instrumento de diversión y conocimiento 5 .

Así observamos que, cuando decimos que un determinado chiste corporeiza o cosifica a la mujer considerándola un mero instrumento sexual, no hablamos de la «manera» en que se hace en árabe y en español, sino sencillamente del hecho en sí. A diferencia de lo que se podría pensar a priori, la cosificación en árabe es más sutil, más simbólica. El adolescente citado anteriormente, antes de tener conciencia sexual, no los entendía, cosa que difícilmente diría su homólogo español, porque sus chistes son demasiado explícitos y su léxico es denotativo. El aparato sexual y el acto sexual se explicitan sin tapujos en español. De hecho, es esta manera de construcción discursiva y representativa de la mujer la que complica su traducibilidad al árabe, a pesar de la irrupción de una nueva visión ajena a los patrones culturales. De hecho, en la cultura árabe no occidentalizada, el contenido sexual y corporeizador de la mujer es menos explícito que en español. La cosificación de la mujer de forma excesivamente

5. Ibídem.

Feminismo/s 24, diciembre 2014, pp. 245-264 
manifiesta es, podría afirmarse, una novedad en la cultura chistosa árabe, como se ha observado en el artículo citado anteriormente, en el cual se reproducen las palabras de un sociólogo palestino:

Abu Zanat afirma que los chistes verdes ${ }^{6}$ y su excesivo uso y reproducción en distintos contextos de nuestra vida repercuten negativamente en nuestros adolescentes, de tal forma que se pierde la veneración a la vida conyugal y al sexo. Se trivializa, por ello, la vida sexual, a pesar de su consideración como algo fundamental en la vida y el constituyente de la relación de pareja [...]. La mujer encarna en estos chistes el papel del protagonista pasivo, lo que consagra una serie de imágenes estereotipadas sobre la mujer [...]. El uso de la mujer y su representación en el chiste verde no es, sin lugar a dudas, un factor que ayude en la vida. Del mismo modo que la publicidad la presenta como si fuera una mercancía más para promocionar otra, observamos que los chistes representan a la mujer como algo negativo y «bajo» para hacer reír ${ }^{7}$.

Cabe señalar que los chistes verdes en árabe aparecen clasificados en Internet bajo el nombre de «chistes sucios», wisja o wasija. Además, el árabe tradicional considera a la mujer, en lo negativo, un contrincante o rival que pone en duda su hombría y virilidad, pero no una «cosa» inerte y objeto pasivo de acciones -a excepción de algunos chistes construidos sobre los patrones de otros valores culturales-, como en los que se critica en las citas anteriores. Como prueba de esta rivalidad entre hombre y mujer y puesta en duda de las capacidades viriles del árabe, sirva de ejemplo el chiste anteriormente mencionado sobre la perfección en la cocina y en el dormitorio.

Para concluir, diremos que la traducibilidad cultural e intercambiabilidad del chiste sobre la mujer es posible entre culturas por una serie de representaciones que parecen universales:

1. La autoría de los chistes parece masculina. Es como si todos los chistes los inventaran los hombres para reírse entre ellos de la mujer.

2. Una mujer es su cuerpo. Este cuerpo es objeto de uso o de rechazo según las circunstancias. Es más, el chiste español disecciona a la mujer nombrando sin tapujos todas las partes que el hombre desea de ella. En este sentido, la mujer está muy estrechamente relacionada con el uso que se pueda hacer de ella. Parece ser que en el chiste se sustituye el amor por la posesión utilitaria del cuerpo femenino.

3. La mujer no dispone de suficientes capacidades mentales y cognitivas, aunque el chiste árabe es ambivalente en este sentido. La mujer en

6. La expresión «chistes verdes» es la traducción al español de la expresión árabe «chistes sucios».

7. Ibídem.

Feminismo/s 24, diciembre 2014, pp. 245-264 
la cultura árabe popular, incluso en ciertas obras clásicas con buena recepción como Las mil y una noches, es menos tonta que su homóloga española y occidental en general. La árabe «asusta» más al hombre que la española. No obstante, aun así, existen chistes árabes que representan a la mujer como menos capacitada mentalmente, de ahí la paradoja árabe entre mujer «tonta» y mujer «astuta».

4. Como esposa, la mujer tiene prácticamente la misma representación en el chiste árabe y en el español. En ambas culturas chistosas se presenta el matrimonio como favorable para la mujer y desfavorable para el hombre. La mujer en el matrimonio es difícil, es exigente, es mandona, se preocupa por su propio interés más que por el del esposo... En todos los casos, la mujer es una carga en el matrimonio. Son muy reiterados, tanto en el chiste español como en el árabe, los juegos de palabras y de conceptos como el siguiente: «Es fácil morir por una mujer, lo difícil es vivir con ella». El hombre del chiste, tanto árabe como español, descubre que ha sido engañado por el matrimonio una vez que este ha sido consumado. En todos los casos, existe cierto arrepentimiento varonil con respecto a esta institución social. Muy relacionada con la imagen de la mujer casada está la de la suegra, aún más negativa si cabe. Esta representación parece común, por lo que la traducibilidad intercultural en estos casos es posible.

5. Desde el punto de vista de la moral y de los valores, la mujer del chiste parece más relajada éticamente que el hombre, aunque existen notables diferencias con respecto a la cultura árabe, como se ha señalado en el cuerpo de esta investigación. En español, es la mujer la que es infiel, generalmente. La infidelidad del hombre parece casi naturalizada en el chiste. Dicho de otro modo, la infidelidad conyugal femenina es mala, pero la del hombre español parece que no tanto. En este aspecto concreto, la traducibilidad cultural encalla, porque la cultura chistosa árabe no pone demasiado de relieve este tema. Además, es el hombre el que sale mal parado en cuanto a fidelidad conyugal. Es más, se ha observado cierta contradicción en este aspecto entre la representación de la infidelidad femenina en obras árabes clásicas como Las mil y una noches y en los chistes. Es menos frecuente el discurso de la infidelidad en la literatura popular que en el chiste.

Todos estos rasgos que toman en consideración los tres parámetros (físico, intelectual y moral) enunciados en la introducción parecen universales, lo que hace posible la traducción entre culturas. Sin embargo, existen otras particularidades que complican la tarea de la traducibilidad. 
De entre estas particularidades, el chiste español con temática femenina transciende lo lúdico, en ocasiones, para desembocar en el sarcasmo o, incluso, en el insulto, como el chiste sobre la mujer montada en un burro que se presenta como el mismo animal, pero de dos pisos. Estos chistes perderían gracia en árabe. Quizá hagan reír, pero no por lo que dicen, sino por su naturaleza. Es como si el oyente árabe dijera «vaya cómo construyen los españoles sus chistes». No tendrían buena aceptación, ya no por supuestos valores éticos y morales, sino por el mismo procedimiento constructivo de este tipo de chistes. No tiene nada de simbólico, no reta al oyente, no juega con palabras o conceptos ni implica ningún contraste llamativo. Este tipo de chiste no entraría en la categoría de chiste en árabe, sino que se tomaría como un insulto. De hecho, tiene la apariencia de insulto árabe. En árabe, igual que en muchas otras lenguas, el contrincante parece burro, hace, actúa u obra como los burros o cualquier animal que culturalmente se utiliza metafóricamente para degradar a las personas: burros, perros, cerdos, vacas, cabras (Leach, 1974). Así que el animal de dos pisos (que es la mujer) del chiste español, entraría en árabe en la categoría del insulto. Aunque existen chistes árabes sobre personas de zonas determinas (como Lepe, en España), parece ser que la cultura árabe prefiere más bien «reírse» de las situaciones que de las personas.

Es igualmente particular del chiste español el nombramiento directo e insistente de los genitales femeninos o masculinos según el caso, algo que no tendría mucha salida en la cultura árabe. Todos estos órganos tienen nombres metafóricos en árabe. Los chistes sexuales que implican actos entre padres e hijos, existentes en español y muy abundantes en la Red, por lo que se ha evitado reproducirlos en este trabajo, son intraducibles al árabe. Resultan demasiado ofensivos y demasiado inhumanos para un oído árabe. No se han podido encontrar chistes en árabe referentes a esa temática.

Cuando un chiste es sexual, la cultura árabe utiliza eufemismos polisémicos, por lo que el chiste se puede contar incluso en presencia de niños sin que estos entiendan su verdadero sentido. La traducibilidad cultural es por ello unidireccional, se podrían traducir estos chistes del árabe al español, aunque podrían resultar light, pero no se podría hacer el camino inverso. Muchos chistes españoles en los cuales la mujer es objeto sexual explícito son intraducibles e irreproducibles en árabe. Cabe recordar que el hablar de sexo en árabe viene determinado por dos coordenadas fundamentales, tiempo y espacio. Cuando hay diferencias generacionales no se habla de ello. Tampoco se habla de ello en espacios donde confluyen una «mezcla» de edades, sexos, de conocidos y desconocidos. Sin embargo, el simbolismo del chiste árabe con 
temática femenina o sexual y su abstracción permiten sortear dichas limitaciones, aunque siempre entre personas del mismo sexo. Como consecuencia de ello, existe cierta facilidad cultural para traducir del árabe al español, pero no tanto del español al árabe.

\section{Referencias bibliográficas}

Armstrong, Nigel. Translation, Linguistic, Culture: A French-English Handbook. Clevedon, Buffalo, Toronto, Multilingual Matters Ltd, 2005.

BERGSON, Henry. Ensayo sobre el significado de la comicidad. Traducido por: Rafael Blanco. Buenos Aires, Ediciones Godot, 1924 (edición de 2011). Disponible en: <http://www.edicionesgodot.com.ar/sites/default/files/ediciones-godot-larisa.pdf.>, consultado el 11-06-2014.

DE LOS REYes, Pablo. Monólogos. Disponible en <http://www.pablodelosreyes. com/blog/i/1669/65/chiste-de-mis-tetas>, consultado el 06-06-2014.

DRAGHMA, B. y ABU MUALLA, S.: «Los chistes obscenos en ropaje lúdico presentan una falsa cultura sexual». Nadi al fikr al arabi [Club del pensamiento árabe]. Disponible en <http://www.nadyelfikr.com/showthread.php?tid=33171>, consultado el 27-12-2014.

LEACH, Edmund. «Aspectos antropológicos del lenguaje: categorías humanas e injuria verbal». Revista de Occidente. Madrid, Fundación Ortega y Gasset, 1974.

Mateo Martínez-Bartolomé, Marta. La traducción del humor. Oviedo, Universidad de Oviedo, 1995.

Tolosa IGUALADA, Miguel. «De la traducibilidad del chiste: más allá de los factores perceptibles». Interlingüística 16 (2) (2005), pp. 1079-1089.

Vivero García, María Dolores (dirección). Frontières de l'humour. París, L’Harmattan, 2013.

Vivero García, María Dolores (dirección). Humour et crises sociales: Regards croisés France-Espagne. París, L’Harmattan, 2011.

ZabAlbeaesCOA, Patrick. «La traducción del humor en textos audiovisuales», en Miguel Duro (coord.): La traducción para el doblaje y la subtitulación, Madrid, Cátedra, signo e imagen número 63 (2001), pp. 251-263. 


\title{
'GIRLS WANNA HAVE FUN'?: EL VERSO SUELTO HUMORÍSTICO DE LA POESÍA DE DOROTHY PARKER EN LOS 'ALEGRES' AÑOS VEINTE
}

\author{
FrANCISCO JOSÉ CORTÉS VIECO \\ Universidad Complutense de Madrid
}

Recibido: 15/09/2014

Aceptado: 24/11/2014

\section{Resumen}

El corpus poético de Dorothy Parker trasciende el retrato de una socialite y de una época mítica: Nueva York durante los «alegres» años veinte. Debajo de ritmos de jazz, diversión nocturna y luces de neón en esta ciudad, residen malestares públicos y privados en la realidad femenina. El humor ingenioso y corrosivo del universo lírico de esta autora estadounidense actúa como una coda subversiva de modernidad hacia la invectiva social y de género, que suaviza o refuerza su trágica autobiografía de desamor y depresión, a la vez que desnuda sus pulsiones creativas, que universalizan, abrazan y rechazan paradigmas contemporáneos de feminidad. Pese a la burla del canon literario que empequeñece su legado, Parker es la última en reír porque su comedia, anfibia entre negra y diáfana, ilustra el ansiado acceso de la mujer a una poesía y un humor propios.

Palabras clave: humor, drama, mujer, hombre, sociedad, diversión, amor, infelicidad.

\begin{abstract}
Dorothy Parker's corpus of poetry transcends the portrait of a socialite and mythic times: New York in the Roaring Twenties. Underneath jazz rhythms, fun nights and the neon lights of this city, public and private female anxieties remain. The witty, but caustic, humor in this American writer's verses plays the role of a subversive, modern coda that criticizes social and gender inequalities. This does not only attenuate or strengthen her tragic biography of unrequited love, but it also universalizes, embraces and detaches its author from models of contemporary femininity. Despite the mockery of the literary canon that minimizes her legacy, Parker laughs last because her
\end{abstract}


comedy, from black to bright, illustrates women's ultimate access to their own poetry and humor.

Keywords: humor, drama, woman, man, society, amusement, love, unhappiness.

Feminismo/s 24, diciembre 2014, pp. 265-287 
«La raza humana solo tiene un arma verdaderamente efectiva, que es la risa»

Mark Twain

\section{Introducción: la mujer y su comicidad}

Es un atavismo artístico que el humor haya sido siempre catalogado como un pasatiempo sin trascendencia, una extravaganza destinada al entretenimiento del lector y denigrada, en ocasiones, por su propio creador o creadora. Con frecuencia, se ha localizado en las antípodas de la literatura «seria»-novela y teatro-, que es aquélla abocada a poder ser coronada con la solemnidad y la inmortalidad del canon literario. Sin embargo, el humor ha sido y es hoy en día un elocuente artefacto estético y/o con fines sociales, que pretende llamar la atención del público con mensajes «serios», camuflados debajo de artificios jocosos o triviales. En consonancia, corrientes historicistas entienden que la tradición de las letras en el ámbito anglonorteamericano desde los siglos XVIII y XIX, con figuras clave como Jonathan Swift, Alexander Pope, William Thackeray, Ambrose Bierce o Mark Twain, ha apelado a la sátira y la ironía como «guerrilla» escrita para combatir, o tan solo debatir, verdades absolutas, dogmas inamovibles e ideologías hegemónicas de cada periodo histórico. Sin ser necesariamente atacadas por estos y otros literatos masculinos, dichas corrientes de pensamiento se sustentan en un entramado patriarcal de desigualdad de género, desde instituciones políticas hasta esferas privadas como la familia. Frente a esta tónica generalizada, una subcultura femenina, embrionaria en la época victoriana con escritoras como Charlotte Brontë, George Eliot, Kate Chopin o Charlotte Perkins Gilman, se ha atrevido a cuestionar, rebelarse o invalidar la falacia de la inferioridad física, psíquica e intelectual de la mujer con respecto al hombre, pero no desde la comicidad subversiva, sino desde la queja, la ira, el drama personal o el activismo feminista.

Barbara Levy sostiene que, tradicionalmente, las mujeres no han podido mostrarse divertidas ni con sentido del humor por culpa de la vinculación de 
su propio ingenio con el hecho de ser «brujas o putas» ${ }^{1}$. Este axioma de la cultura occidental habría conectado su peligrosa inteligencia con su presunto poder para manipular a los hombres o desafiar los roles domésticos impuestos en su contra por voluntad humana y divina. En sintonía con la censura de su voz por parte del Establishment literario, las escritoras se han visto igualmente privadas del uso y disfrute de su agudeza mental y de juegos semánticos, intrincados y sofisticados, que son imprescindibles para crear el humor. De ahí que éstas hayan sufrido un doble hándicap: la inaccesibilidad al mismo y la falta de libertad para inventar una versión propia, alejada de su dócil mímesis de patrones masculinos de este arte «informal» y denostado. Uno de los primeros y más ilustres «versos sueltos» con novedosa autoría de una mujer es la estadounidense Dorothy Parker (1893-1967).

\section{Dorothy Parker o «el verso suelto» de su tiempo}

A continuación, pretendemos explorar las convergencias y las divergencias entre el universo lírico y otro cómico en la obra de esta escritora, o triste «mujer-chiste» de Nueva York en los «alegres» años veinte, su etapa de mayor producción literaria, durante la cual logró ser una celebridad gracias a su estilo propio, verbo fácil y desbordante hilaridad. Marion Maude afirma que tuvo un cariño especial por su padre y que, cuando era pequeña, una manera de complacerle era redactar versos para hacerle reír ${ }^{2}$. En conjunción con la tradición humorística puramente norteamericana desde Mark Twain y el gusto de Parker por el epigrama procedente de fuentes clásicas, esta génesis paterna en su creación «menor» detectaría la influencia masculina que acabamos de mencionar, la cual se canalizó durante su vida adulta a través de su ardiente deseo de satisfacer a su público fiel y sus expectativas, una vez que se consagró como paradigma de la autora cómica en la poderosa nación norteamericana. Polifacética y camaleónica, fue poetisa, narradora de relatos cortos, ensayista, guionista y crítica teatral, que trabajó y publicó en diversas revistas neoyorquinas, como Vogue, Vanity Fair, New Yorker o Lady's Home Journal. De igual manera, frecuentó los círculos literarios y periodísticos más selectos de la urbe y fue miembro de la famosa Tabla Redonda del Hotel Algoquin. Rabiosamente desenfadada y con intensidad autobiográfica, la siguiente estrofa en «Grandfather said it», detecta la problemática social y familiar de la vocación

1. LEVY, Barbara (coord.). Ladies Laughing: Wit as Control in Contemporary American Women Writers. London \& New York, Routledge, 1997, p. 1.

2. MeAdE, Marion. «Introduction». Complete Poems of Dorothy Parker. London, Penguin, 2010, p. xvii. 
artística de la mujer en los inicios del siglo XX. Bajo una cosmética de sarcasmo y burla, el abuelo de la joven prefiere para su nieta cualquier profesión, incluso si ésta es delictiva, denigrante o sin glamour, antes que la deshonra de que sea escritora en un futuro:

'Clean out ferryboats; peddle fish;

Go be chorus men if you wish;

Rob your neighbors' houses in the dark midnight;

But think of your families, and please don't write's.

Contraria al deseo de su familia, u opresora institución patriarcal, Dorothy Parker trabajó y escribió durante su vida, sin depender durante mucho tiempo de la seguridad económica de su primer marido y para compensar la ruina financiera tras una niñez en un entorno acomodado y el fallecimiento de su padre. En «Song of one of the girls», se posiciona incluso como la heredera de una pléyade -desnutrida en número- de mujeres históricas, míticas y literarias con carisma y determinación, como Eva, Dido, Safo, Lady Hamilton o Madame de Staël, que está predestinada a la gloria de la inmortalidad:

I'm one of the glamorous ladies,

At whose beckoning history shook.

But you are a man, and see only my pan,

So I stay at home with a book ${ }^{4}$.

Estas últimas líneas exaltan la profesionalización de su vocación artística y atacan las expectativas domésticas del hombre con respecto a la mujer, a la vez que dibujan una mujer indiferente al afecto, la pasión y las responsabilidades familiares, que prefiere la soledad de la lectura. Pese a ello, un surtido rastro de indicios en el corpus poético de Dorothy Parker delatan su autoengaño: no aspirar a amar y ser amada por un hombre. Proyectando una imagen pública de socialite alocada y divertida, se distrajo, flirteó y disfrutó, como mujer y artista, en un marco espaciotemporal mítico e irrepetible: la burbujeante y convulsa década de los años veinte en los Estados Unidos. Amenizada por el jazz, los clubs nocturnos, las luces de neón, el alcohol y las vanguardias, soplaron en aquellos momentos nuevos vientos de optimismo, cambio, progreso, consumismo y capitalismo; de prosperidad económica y tecnológica con el desarrollo del automóvil, el cine, la moda o las telecomunicaciones,

3. PARKer, Dorothy. Complete Poems. London, Penguin, 2010, p. 309. «Limpia barcos; vende pescado;/ Conviértete en voz del coro si lo deseas;/ Roba en la casa de tus vecinos a medianoche;/ Pero piensa en tu familia, y no escribas» (traducción propia).

4. Ibíd., p. 72. «Soy una de esas damas glamurosas/ Cuyo atractivo cautivó a la historia/ Tú tan solo eres un hombre que ve mi sartén/ Por lo que me quedaré en casa con un libro» (traducción propia). 
así como de auge de ciudades cosmopolitas con Nueva York a la cabeza. En un intento por olvidar el fracaso humano y los horrores de la Primera Guerra Mundial, el humor fue un antídoto o una terapia hacia la recuperación anímica de una sociedad y una literatura aún moribundas tras la sangre derramada. La autora perteneció a una generación «no perdida» de artistas que, frente a la libertad estética que sus errantes coetáneos Gertrude Stein, T.S. Eliot, Henry Miller o Ernest Hemingway sí lograron durante su exilio europeo, decidió permanecer en suelo patrio. James Gaines sostiene que, movidos por la necesidad económica, Parker y otros miembros de la Mesa Redonda del Algonquin entendían que la escritura era un medio más para ganarse la $v_{\text {vida }}{ }^{5}$. Este imperativo monetario, además de las presiones del mercado editorial y periodístico, estrangularían la soberanía estética de la propia escritora. En «Song for the first of the month» demuestra que el dinero no garantiza la felicidad del ser humano: «Money, spite of all its pow'r,/ Cannot purchase ruddy health $»^{6}$. Pese a ello, es honesta y prosaica al admitir, como colofón de su poema, que las constricciones de la vida cotidiana -tales como comprar comida o pagar el alquiler cada mes- impiden el adorno de esta composición con creencias ilusorias y utópicas, poco ancladas a la existencia rutinaria del individuo: «Try to tell the butcher so/ [...] Laugh the landlord off with that! $\gg^{7}$, la cual sería fuertemente hostil y vulgar. En estas últimas estrofas, se sugeriría que el chiste de Parker se asocia, intuitivamente, más a una realidad «fea» que a ideales «hermosos», o a una causalidad y narrativa en verso, en disonancia con la exploración de la belleza o de conceptos abstractos, que ha sido la materia prima par excellence de la lírica desde tiempos inmemoriales. A diferencia de corrientes humorísticas sureñas o de los suburbios acomodados en los Estados Unidos a principios del siglo XX, la comicidad en el arte de Parker es eminentemente urbana y cosmopolita, por lo que no solo rechazará, sino que abofeteará la propensión de la laureada poesía romántica por la naturaleza paisajística y su ósmosis con la psique del artista. En «Song for an April Dusk», la ensoñación y la fantasía que bañan los parajes campestres no invitan al deleite y sí al hastío: «Tell me tales of lilied pool/ Asleep beneath the sun $[\ldots]$ / And, boy, will I be bored! $»^{8}$. Mientras tanto, la estrofa inicial de

5. GAINES, James R. (coord.). Wit's End: Days and Nights of the Algonquin Round Table. New York, Harcourt Brace Jovanovich, 1977, p. 124.

6. PARKER, Dorothy. Op. cit., p. 264. «El dinero, pese a todo su poder, no compra la buena salud» (traducción propia).

7. Ibíd., p. 264-265. «Intenta contárselo al carnicero/ [... ¡ ¡El casero se lo tomará a broma! (traducción propia).

8. Ibíd., p. 344. «Cuéntame relatos de estanques llenos de nenúfares/ Adormecida bajo el sol [...] $]$ Y, chico, ¡¡cómo me aburrirás!» (traducción propia). 
«Song of the Wilderness» refleja su predilección por el asfalto y la cosmética de Nueva York, sin olvidar los cómicos versos sueltos entre corchetes de quien aclara que prefiere quedarse en casa descansando, y no sufrir las alergias $\mathrm{u}$ otras contingencias del medio natural:

We'll go out to the open spaces,

Break the web of the morning mist,

Feel the wind on our upflung faces.

[This, of course, is if you insist.]

We'll go out in the golden season,

Brave-eyed, gaze at the sun o'verhead.

[Can't you listen, my love, to reason?

Don't you know that my nose gets red?]

Where the water falls, always louder,

Deep we'll dive, in the chuckling foam.

['ll go big without rouge and powder!

Why on earth don't you leave me home? $]^{9}$

Desde el éxito de su primer volumen de poesía Enough Rope (1926), Dorothy Parker se vio obligada a no divorciarse jamás de la comedia. Este género literario simultáneamente actuaría como freno a su creatividad artística y como su única «pareja fiel», a la cual su público la casó sin su tácito consentimiento: si no estaba alegre o feliz en su interior, al menos debía fingir divertirse en su vida y poder divertir con su obra de cara a su exigente y entregada audiencia. Kevin Fitzpatrick relata anécdotas sobre cómo los neoyorquinos, que eran los principales admiradores de su verso mordaz, perseguían a Dorothy por la calle o en veladas sociales para que dijera algo gracioso; e incluso, se reían a carcajadas, sin sentido, antes de que ella pudiera articular palabra alguna ${ }^{10}$. Pese a ello, la autora ejerció su derecho a proyectar la sátira social en su corpus lírico, lanzar dardos (in)ofensivos contra hombres y mujeres, o exhibir malestares internos, dolor y traumas en su jardín secreto en verso, pero siempre con remates de humor que atenúan la beligerancia de su querella. Poemas como «Fulfilment» revelan que el glamour y la opulencia de la feria de vanidades neoyorquina no garantiza su dicha: «A life of limousined and jeweled ease/

9. Ibíd., p. 325. «Iremos al campo,/ Romperemos la tela de araña de la niebla matutina,/ Sentiremos el viento sobre nuestras caras./ [Esto haremos, por supuesto, si insistes.]/ Saldremos durante la estación dorada,/ Con ojos valientes, miraremos de cara al sol./ [Amor mío, ¿no puedes ser razonable?/ ¿No sabes que mi nariz enrojece?]/ Allí donde cae el agua, con más ruido,/ Bucearemos en sus profundidades, bajo una espuma risueña./ [¡A lo grande, sin colorete y lápiz de labios!/ ¿Por qué cielos no me dejas sola en casa?] (traducción propia).

10. FitzPATRICK, Kevin C. (coord.). A Journey into Dorothy Parker's New York. Berkeley, Roaring Forties Press, 2013, p. 9. 
Is but a round of fathomless ennui ${ }^{11}$. En contraposición, la voz de «Rhyme of an Involuntary Violet» sugiere la ausencia de sus sentimientos amorosos hacia el hombre, su carácter frívolo y práctico como mujer, o el imperativo de la seguridad económica, ya que su autofinanciación parece ser inviable:

Does my smile across a table

Win a cloak of Russian sable?

Baby, no. I'd have to kill a

Man to get a near-chinchilla ${ }^{12}$.

Estas mareas líricas a contracorriente detectarían una de las constantes del arte de Parker: la ambivalencia entre las estrecheces de una vida de bohemia y la holgura del bienestar económico junto a un caballero acaudalado. Asimismo, Rhonda Pettit enfatiza que la moda, la ropa y las joyas metaforizan su interés por posar como modelo, cambiar de identidad, adoptar personalidades ficticias o enmascarar otras muchas con su obra ${ }^{13}$.

\section{Humor y coda tragicómica: cuatro armas de mujer}

Nancy Walker ha identificado cuáles son los tres rasgos esenciales de la literatura humorística de las mujeres estadounidenses: que ésta es menos agresiva y hostil que aquella creada por el hombre, que escriben sobre lo que mejor conocen, y en torno a la incongruencia entre promesa y realidad, ya que su enfoque refleja la desigualdad de género padecida por ellas ${ }^{14}$. La poesía de Dorothy Parker no solo recoge fielmente estas características estéticas, sino que también diagnostica la polaridad entre el legendario «sueño americano», practicable únicamente en versión masculina. Asimismo, detecta la precaria coyuntura femenina, pese a los hitos sociopolíticos alcanzados por la mujer del momento gracias al esfuerzo del feminismo de inicios del siglo XX: su paulatino acceso a la educación universitaria, el mundo laboral y el derecho al

11. PARKER, Dorothy. Op. cit., p. 266. «Una vida agradable con limusinas y joyas/ No es más que un aburrimiento insondable» (traducción propia).

12. Ibíd., p. 358. «¿Puede mi sonrisa al otro lado de la mesa/ Ganarse un abrigo de piel de marta cibelina rusa?/ No, cariño. Tendría que matar a un/ Hombre para conseguir uno que pareciera de chinchilla» (traducción propia).

13. Pettit, Rhonda S. (coord.). A Gendered Collision: Sentimentality and Modernism in Dorothy Parker's Poetry and Fiction. Cranbury, Farleigh Dickinson University Press, 2000, p. 26.

14. WALKER, Nancy A. (coord.). What's so funny? Humor in American Culture. Wilmington, Scholarly Resources Inc., 1988, p. 32. 
voto $^{15}$. Sin embargo, su persistente sujeción económica y psíquica en las relaciones de pareja, no la búsqueda de su independencia profesional y emocional del hombre, es el núcleo narrativo de muchos de los poemas de Parker, en los cuales emplea dos pares de estrategias líricas de corte femenino, o corrientes antagónicas para confesar la omnipresencia del amor y el desamor en sus versos. Por un lado, la generalización de sus vivencias personales y la introspección psicológica hacia sí misma. Y por otro, su identificación con otras mujeres y su desvinculación de éstas mismas. Perteneciente a la primera categoría, «General Review of the Sex Situation» detecta cómo vierte la frustración y la amargura procedente de la experiencia propia hacia la universalización de la situación afectiva de todo el colectivo femenino, sin demarcaciones espaciotemporales, y sí producto tanto de la sabiduría popular como de su propio talento para la ácida observación sociológica:
Woman wants monogamy;
Man delights in novelty.
Love is woman's moon and sun;
Man has other forms of fun.
Woman lives but in her lord;
Count to ten, and man is bored.
With this the gist and sum of it,
What earthly good can come of it? ${ }^{16}$.

Parker sostendría que la mujer resulta ser la perdedora en la llamada «lucha entre sexos», por culpa de su inferioridad de condiciones que está provocada por estructuras sociales, y no por rasgos inherentes a su sexo ${ }^{17}$. No obstante, mostrarse crítica con su coyuntura familiar y sociopolítica no es suficiente para etiquetar a esta autora como feminista porque no proclamó cambios en las relaciones hombre-mujer, ni modeló su propia vida como ejemplo a imitar por sus conciudadanas ${ }^{18}$. Todo lo contrario, ya que, en otras composiciones, reflejaría la vulnerabilidad de quien se siente víctima indefensa, y no una

15. El Fithteenth Amendment, que fue ratificado por el Congreso de los Estados Unidos en 1919, concedía el derecho al sufragio a cualquier ciudadano norteamericano sin distinción de sexo.

16. PARKER, Dorothy. Op. cit., p. 82. «La mujer quiere monogamia;/ Al hombre le encanta la novedad./ El amor es la luna y el sol de la mujer;/ El hombre se divierte de otras maneras./ La mujer tan solo vive para su señor;/ Cuenta hasta diez, y el hombre ya se aburrió./ Este es el quid de la cuestión y se resume en,/ ¿Qué puede haber de bueno en esta situación?» (traducción propia).

17. WALKeR, Nancy A. Op. cit., p. 31.

18. Mitchell, Rebecca. «Dorothy Parker and Ambrose Bierce: A Sardonic Tradition». The ABP Journal 2, 1 (2006), <http://www.ambrosebierce.org/journal2mitchell.html>, consultado el 23-05-2014. 
empoderizada activista que reclama la emancipación de género. «Symptom recital», al igual que muchos otros versos, se adscribiría a la segunda estrategia estética en torno al amor en su corpus lírico: la introspección en su propio soma y psique. Los desórdenes nerviosos y cambios anímicos de una voz en primera persona: «I am not sick, I am not well./ My quondam dreams are shot to hell» ${ }^{19}, \mathrm{o}$ «My soul is crushed, my spirit sore;/ I do not like me any more» ${ }^{20}$, somatizarían un estado emocional deteriorado, que anuncia una conclusión ambivalente. Por un lado, su estado físico de rechazo del sentimiento amoroso al ser este pernicioso. Pero, por otro, su imperiosa ansia de enamorarse de un hombre de nuevo, lo cual diagnosticaría la naturaleza adictiva de las relaciones de pareja: «I shudder at the thought of men.../I'm due to fall in love again $»^{21}$. Este ejemplo pone de manifiesto el gusto estético de la escritora por giros lingüísticos e inversiones argumentales en sus versos, con intensidad sardónica y efectos caricaturescos, que depuró en una sofisticada ars poetica, acuñada por ella misma y que podemos denominar como drama con coda humorística. De hecho, Emily Toth defiende que la peculiar combinación entre lo cómico y lo trágico en Parker es una invención suya ${ }^{22}$. «Idyl» y «The Little Old Lady in Lavender Silk» son dos ilustraciones de una vida plagada de adversidad y desdicha durante el romance y la vida en común entre hombre y mujer, que son rematadas con ironía o humor de forma inesperada, ágil y espontánea. En la primera, sueños de calma, armonía y felicidad que podían haber colmado la vida de la pareja y evitado sufrir los pesares del mundo, son parodiados al final porque son absurdos e impracticables: «Now that you've thought of it seriously -/ Isn't it great that it never can be? $»^{23}$. En la segunda, se imagina a sí misma como una anciana, con un amplio historial de fortuna y desgracias amorosas, que lanza una mirada retrospectiva positiva a su pasado para concluir que el hombre, aquél que le causó tanto placer y ruina, es lo mejor que le pudo haber ocurrido: «Regret is not part of my plan,/ I think (if my memory's

19. PARKER, Dorothy. Op. cit., p. 77. «No estoy enferma, no estoy bien./ Mis sueños de antaño fueron destruidos por completo» (traducción propia).

20. Ibidem. «Mi alma está machacada, mi espíritu dolorido;/ Ya no me gusto más a mí misma» (traducción propia).

21. Ibidem. «Tiemblo tan solo al pensar en los hombres.../ Me toca de nuevo enamorarme» (traducción propia).

22. Тотн, Emily. «Dorothy Parker, Erica Jong, and New Feminist Humor», en Rhonda Pettit (dir.): The Critical Walz: Essays on the Work of Dorothy Parker, Cranbury, Rosemont Publishing, 2005, p. 149.

23. PARKER, Dorothy. Op. cit., p. 256. «Ahora que has pensado en ello seriamente-/ ¿No es estupendo que nunca podrá llegar a ser?» (traducción propia). 
faithful)/ There is nothing more fun than a man! $»^{24}$. Como mujer maltratada psicológicamente por hombres egoístas, el humor en su poesía supondría una terapia vomipurgante hacia la recuperación sentimental, no hacia la venganza retributiva contra sus tiranos, ni el cisma irreconciliable entre los dos sexos. Todo lo contrario. En «The New Love», su cura es la llegada de una nueva ilusión: «At my door's another lad;/ Here's his flower in my hair $»^{25}$, aunque desvele la inseguridad respecto a su físico: «If he see me pale and sad,/ Will he see me fair? $»^{26}$. Rozando la temeridad emocional, su voz en «Folk song» no solo exhibe, festiva y jovial, su modus vivendi que encadena unos amantes con otros, sino que demuestra, impasible, no aprender de sus errores pese a identificarlos con lucidez:

Robin, he is strong and sure,

Gallant, wise, and gay.

Gavin's heart is calm and pure

As the new-born day.

Steady shine young Alan's eyes,

Deep with honesty.

Jack, he tells me naught but lies, -

He's the lad for me [...]

Jack, he's wondrously untrue, -

He's my own dear love.

Casper's hair is golden brown;

Hal is straight and slim.

Martin's richest in the town -

Who'd say 'no' to him?

Rafe's a fine young gentleman;

Tom's with virtue blest.

Jack, he broke my heart and ran, -

I love him the best ${ }^{27}$.

24. Ibíd., p. 165. «Arrepentirme no es parte de mi plan,/ Opino (si mi memoria no me falla)/ Que ¡no hay nada más divertido que un hombre! (traducción propia).

25. Ibíd., p. 25. «En mi puerta, hay otro chico;/ Aquí está su flor sobre mi pelo» (traducción propia).

26. Ibidem. «Si él me viera triste y pálida,/ ¿Me verá guapa? (traducción propia).

27. Ibíd., p. 349. «Robin, es fuerte y seguro,/ Galante, sabio, y alegre./ El corazón de Gavin es tranquilo y puro/ Como un nuevo día./ Inmutables brillan los ojos del joven Alan,/ Profundos, con honestidad./ Jack, no me cuenta más que mentiras, -/ Es el chico para mí [...]/ Jack, es asombrosamente insincero, -/ Es mi querido amado./ El cabello de Casper es castaño dorado;/ Hal es serio y delgado./ Martin es el más rico de la ciudad -/ ¿Quién le diría que 'no'?/ Rafe es un caballero joven y apuesto;/ Tom está bendecido de virtudes./ Jack, me rompió el corazón y huyó, -/ Es el chico que yo más quiero» (traducción propia). 
Con cinismo y descaro, la protagonista de estos versos declara lo que parece ser irremediable en su código genético: preferir a Jack, un embaucador que le hizo sufrir y a quien ama más que a cualquier otro pretendiente sincero y galante que haya conocido. Su frivolidad y este magnetismo innato del «malo» se neutralizan en otros poemas en los que el hombre, o dicho de otro modo, el epicentro de su vida como artista y mujer, se transfigura en la diana de su resentimiento y desprecio. En ellos, se desvanece el humor inofensivo y surge otro más visceral que delata la ambivalencia casi patógena de sus emociones hacia sus parejas. En «To my dog», el perro constituye la metáfora del amado fiel, pero en lugar de reflejar las virtudes características de los canes, tales como honestidad, generosidad y empatía, se sugiere su condición de animal -poco inteligente y humano-, que hace gala de un instinto depredador e irresistible para las «hembras» de la «manada»: "You're frankly, too informal./ And mentally, I sometimes fear,/ You're slightly under normal $»^{28}$. En estos y otros poemas de amor y desamor con germen confesional se evidencia la aguda tensión psíquica y artística de la escritora. Dorothy Parker se debatiría entre la tradición de sus deseos femeninos con alta carga romántica y afectiva -noviazgo, enlace nupcial o, al menos, un compromiso emocional pleno con su «príncipe azul»-, y la modernidad de una sexualidad sin ataduras, que su entorno masculino exigiría a una mujer de su categoría. Si la llamada New Woman ${ }^{29}$ causaba ansiedad y temor en la sociedad patriarcal desde tiempos finiseculares, la flapper $^{30}$, que era su tentáculo durante los años veinte y el «traje a la medida» de Dorothy Parker, se vinculaba, con intensidad misógina, a un modus vivendi femenino caracterizado por la frivolidad, el hedonismo, la irreflexión y la disponibilidad al sexo. La biografía de la poetisa neoyorquina como celebrity y, por lo tanto, ampliamente conocida por el público estadounidense, refuerza su afiliación (in)voluntaria a la diversión, el humor y la trivialidad de este paradigma humano y estético de mujer. De hecho, la prensa rosa de su tiempo también se hizo eco de la cascada de sus amores tormentosos, fracasos matrimoniales, abortos, alcoholismo e intentos de suicidio. Nina Miller argumenta que el vanguardismo en la obra de la

28. Ibíd., p. 260. «Eres francamente demasiado informal./Y mentalmente, a veces me temo,/ Que estás ligeramente por debajo de una inteligencia normal» (traducción propia).

29. Con clara influencia de escritores del momento, este modelo femenino abogaba por un ideario feminista a favor de los derechos sociopolíticos de la mujer, y su emancipación sexual y profesional.

30. Mujeres jóvenes, rebeldes y «alegres» de los años veinte en Estados Unidos con apariencia física, vestimenta y conducta poco convencionales para los estándares de la época: pelo corto, faldas cortas, fumar, beber alcohol, bailar al ritmo del jazz, promiscuidad, o divertirse durante toda la noche. 
autora reside en el tono sofisticado de su malévola feminidad, que atacaba a otras mujeres contemporáneas, y en su osado liberalismo sexual, pese al alto precio que tuvo que pagar: que los hombres le rompieran el corazón demasiado a menudo ${ }^{31}$. En relación con este último aspecto, hemos evocado que su corpus lírico desnuda el lado oscuro del empoderamiento de la flapper: el «animal herido» muestra, al final sin humor, su miedo al cruel rechazo masculino, el duelo por el amor perdido y las secuelas del traumático abandono. En consonancia, algunos poemas, como «Triolets», desvelan un sustrato de vulnerabilidad femenina a través de la sintomática metáfora de la fragilidad de su corazón: «I send you my heart/ Marking it 'Fragile - don't break it'» ${ }^{32}$; y en su resolución, carecen del idiosincrásico verso suelto cómico: «Now you have gone and got married!/ Sweet, I have waited too long;/ Heedless and wanton, I've tarried $»^{33}$. En otros, como «Chant for dark hours», la voz poética de la creadora dramatiza constantes narrativas femeninas: la mujer que aguarda durante largas horas el regreso de su amante a sus brazos, el cual sería un hombre que seduce, pero que nunca cumple sus promesas. Incluso, clama al cielo que su futura pareja no sea otro Romeo inconstante, antes de concluir que la espera es siempre inevitable: «All your life you wait around for some damn man! $»^{34}$. La ausencia de dosis final de comicidad en ambas composiciones aproximaría a Parker más bien a las convenciones literarias en torno al drama del desamor, en manos tanto de hombres como de mujeres desde la antigüedad, por lo que el humor se manifestaría, en otros poemas, como signo inequívoco de modernidad e irreverencia con respecto a la tradición artística. La fijación autodestructiva, también en una vertiente introspectiva aunque sin especificar etiología amorosa, inunda el corpus lírico de una escritora que no sería tan feliz y que no se divertiría tanto a lo largo de los alegres años veinte como sus devotos lectores creían ciegamente. Prosaica y con vocación empírica, sintetizará en su antológico «Résumé»el porfolio de los métodos disponibles, aunque no infalibles, para suicidarse. Insinuará que todos ellos son dolorosos o antiestéticos, antes de sentenciar que la vida también es una

31. Miller, Nina. «Making Love Modern: Dorothy Parker and Her Public», en Rhonda S. Pettit (dir.): The Critical Waltz: Essays on the Work of Dorothy Parker, Cranbury, Rosemont Publishing, 2005, p. 45.

32. PARKER, Dorothy. Op. cit., p. 186. «Te envío mi corazón/ Y lo marco con la mención 'Frágil - no lo rompas'» (traducción propia).

33. Ibidem. "¡Ahora te has largado y te has casado!/ Cariño, esperé demasiado tiempo;/ Con descuido y sin sentido, me he retrasado» (traducción propia).

34. Ibíd., p. 41. «¡Toda tu vidas aguardas que llegue algún maldito hombre!» (traducción propia). 
opción plausible, lo cual equivaldría a su característica coda de imprevisibilidad, pero esta vez poco chistosa y sí muy irónica:

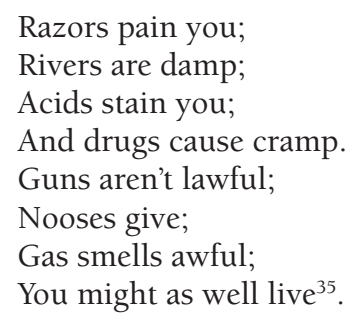

Este poema ilustraría la incursión de Dorothy Parker en la comedia negra, en la cual abordará abiertamente un tabú atemporal, como es la muerte voluntaria, aunque con el maquillaje estético de no desvelar las causas de la ideación suicida y el tono humorístico sombrío de quien, finalmente, no aboga por autodestruirse. Pero tampoco glorificaría la vida y sí somatizaría su desgana o desidia con respecto a ambas alternativas: sobrevivir o desaparecer. La ambigüedad y la mundanidad de esta estrofa, típicas de este género artístico, no es más que la «guinda» que corona un prolijo corpus lírico que no insinúa, sino que exhibe, con frontalidad expositiva y amargura, este mismo drama humano. En «Cherry white», la incongruencia es extrema al confesar, con jocosidad, lo bonito que sería ahorcarse de un cerezo en flor: «How gay 'twould be/ To hang me from a flowering tree' ${ }^{36}$, ya que convergerían en unas mismas líneas el nacimiento primaveral y la desaparición invernal. Mientras tanto, en «Epitaph» enumera cuántas veces intentó quitarse la vida: «The first time I died $[\ldots] /$ The next time I died...» $»^{37}$, con intensidad orgánica y desolación emocional, aunque sin ningún atisbo de regocijo o coda burlesca. Emplee o no el humor la «divertida» Parker para rememorar el horror o la liberación de la muerte voluntaria en sus versos, su obra supone una revolucionaria democratización de la poesía, iniciada por autores decimonónicos como Walt Whitman. Esta efeméride artística, en manos ahora de una mujer neoyorquina, se manifestaría en su extenso uso de coloquialismos y de un lenguaje vernáculo Made in USA, o en su accesibilidad para el gran público más allá de la imperante estética elitista del Modernismo angloamericano, disponible solo para una clientela selecta. Pero sobre todo, este aperturismo

35. Ibíd., p. 51. «Las cuchillas te hacen daño;/ Los ríos están húmedos;/ Los ácidos te manchan;/ Y las drogas dan calambres./ Las pistolas no son legales;/ Los nudos de la horca ceden;/ Los gases huelen fatal;/ También podrías decidir vivir» (traducción propia).

36. Ibíd., p. 158. «Qué bonito sería/ Colgarme de un árbol en flor» (traducción propia).

37. Ibíd., p. 14. «La primera vez que me morí [...]/ La siguiente vez que me morí...» (traducción propia). 
lírico se refleja en sus temáticas con cáliz femenino o infractor en torno al amor y la muerte, que verbalizan o cantan, con énfasis narrativo y confesional, experiencias prohibidas o tragicomedias difícilmente narrables por su falta de decoro.

Con independencia de esta «sobredosis» autobiográfica en su corpus lírico, la escritora neoyorquina cultivó otras dos estrategias poéticas en la aproximación a su vida y a la de sus conciudadanas: la identificación con ellas y la desvinculación de ellas. En ocasiones, su voz subjetiva e introspectiva hacia la autoconfesión se diluye. En sus reflexiones sobre las técnicas literarias de las memorias de escritoras norteamericanas, como los múltiples puntos de vista o las historias colectivas, Isabel Durán localiza su propensión a la hora de otorgar el protagonismo a las «Otras», en calidad de pilar fundacional para definir su propio «Yo» ${ }^{38}$. En sintonía, Parker no hablaría siempre en primera persona, sino que a veces, como en «Biographies», recurre a una polifonía lírica con fines caricaturescos o, tal vez, moralizantes, pero siempre buscando un alter ego divertido, que alimente su propia efigie pública de alegre flapper. En estos versos, la táctica estética de su identificación con otras mujeres surge al comparar dos chicas de familias acomodadas: Marigold Jones y Lucy Brown. La autora describe a ésta última como su antítesis, o la joven virtuosa y obediente que se comporta con decoro y respeta sus roles de hija y hermana: «She $[\ldots]$ would never play with the little boys» ${ }^{39}$. Cuando crece, previsiblemente llegará a ser la esposa perfecta conforme a las inviolables expectativas de la sociedad patriarcal: dócil, elegante e hipócritamente amantísima de su marido millonario. En contraposición, su oscura doppelgänger, Marigold, es una niña traviesa y un tomboy desde pequeña: «She [...] cut off her sister's abundant curls;/ And never would play with the little girls» ${ }^{40}$ que, en cambio, se gana la simpatía y la empatía de la autora y el lector. En edad adulta, también previsiblemente, la narrativa lírica de Parker delata su predilección por el coqueteo y el escándalo público al preferir divertirse con hombres comprometidos, antes que reproducir convencionalismos y etiquetas sociales:

38. DURÁN GIMÉNEZ-RICO, Isabel. «La Estrategia del 'Otro' en la Autobiografía Femenina Americana del Siglo XX». Revista Española de Estudios Norteamericanos 14, 5 (1992), p. 36.

39. PARKER, Dorothy. Op. cit., p. 85. «Ella [...] nunca jugaría con los muchachitos» (traducción propia).

40. Ibíd., p. 86. «Ella [...] cortó los abundantes rizos de su hermana;/Y nunca jugaría con otras muchachitas» (traducción propia). 
And once there was talk of a married man!

She sauntered in public in draperies

Affording no secrecy to her knees;

She constantly uttered what was not true;

She flirted and petted [...]

And people remarked, in sepulchral tones.

'You'll see what becomes of Marigold Jones'41.

A diferencia de la herencia victoriana aún reinante en la moralidad imperante de las primeras décadas del siglo XX, el «buen» comportamiento no se recompensaría en el universo moderno de Parker, mucho más realista que las reminiscencias decimonónicas. En esta misma línea, a la díscola Marigold, al final del poema, no le espera la desgracia, sino el mismo destino de domesticidad y respetabilidad que a Lucy, el cual no sería necesariamente afortunado, y sí estaría determinado por su estatus social privilegiado. Si bien esta coda humorística detecta la obligatoriedad de la falsedad y la duplicidad en la vida pública y privada de la mujer contemporánea, también sería el espejo de la filosofía y la biografía de la propia escritora, que recomendaría a sus conciudadanas divertirse mientras que son solteras y libres, al igual que practican sus futuros maridos sin estigmatización social. A primera vista, en «Moral Tales for the Young [I]», Dorothy Parker se identificaría con otra joven coetánea, ficticia o no, que es osada, inteligente y manipuladora, en una jungla urbana regida por el dinero y la usura sin mesura ${ }^{42}$.

Maude, the brightest of the sex,

Forged her daddy's name to checks,

Took them to the local banks,

Cashed them, with a smile of thanks.

All the money came in handy -

Maudie was so fond of candy!

Weight she gained in way affrighting,

So she's given up her writing.

Save the money, when you forge;

Little ladies do not gorge ${ }^{43}$.

41. Ibidem. «¡Una vez hubo una conversación sobre un hombre casado!/ Ella caminaba en público en paños menores/ Sin dejar lugar al secreto;/ Constantemente decía lo que no era verdad;/ Flirteaba y acariciaba [...]/ Y la gente opinaba, en tono sepulcral./ 'Ya verás qué será de Marigold Jones'» (traducción propia).

42. Este poema podría evidenciar la devoción de Dorothy Parker por su maestro, el victoriano William M. Thackeray y su famosa novela Vanity Fair (1848), con su arribista y astuta heroína Becky Sharp.

43. Ibíd., p. 278. «Maude, la más inteligente entre las chicas,/ Falsificaba la firma de su padre en los cheques, / Los llevaba a los bancos del lugar,/Los cobraba, con una sonrisa de agradecimiento./ Todo el dinero era útil -/ ¡A Maudie le encantaban las golosinas!/ 
Pese a la indeseable secuela del sobrepeso que fortalece la hilaridad del poema, la codicia de Maude simbolizaría la exaltación de su ingenio. La joven contaría con la complicidad de la autora a la hora de celebrar la habilidad femenina para gestionar su vida, pero resultaría ambiguo afirmar que el fin justifica sus medios egoístas. Asimismo, Parker recurriría a la estrategia estética de la desvinculación para distanciarse de su heroína y acusarla de materialista ante su lector masculino. Este juego de ambivalencia textual ilustraría la definición de parodia, que es un recurso humorístico clásico cultivado por la autora neoyorquina. Para Linda Hutcheon, es una noción de síntesis que incorpora un texto marco a la narración para captar una diferencia y crear, de este modo, efectos cómicos y serios, unos burlescos que vierten críticas, mientras que otros delatan confabulación ${ }^{44}$. Los quebrantamientos generados por este concepto serían, paradójicamente, autorizados por las normas oficiales que pretenden ser subvertidas para garantizar así su continuidad ${ }^{45}$. En consonancia, la autora apoyaría subrepticiamente la malicia de Maude, pero atacaría su rapacidad públicamente, en connivencia con normas sociales e intereses masculinos. Aunque la subcultura literaria femenina desde el siglo XIX se cimentaba en la solidaridad y la sororidad entre mujeres, todas bajo el mismo yugo patriarcal, el humor de Parker halla en ellas su víctima ideal. El miedo de su compatriota, actriz y colega Anita Loos a su brillante mente y afiliada pluma es una clara evidencia ${ }^{46}$. Al igual que se esmeró por agradar a su padre de niña, Dorothy ridiculizó en sus versos a otras mujeres con fines paródicos y de desafección por el género femenino en su conjunto. Su papel de distante y despiadada observadora, pretendería compensar la sobreexposición mediática de su propia vida en su obra lírica. En «On Being a Woman», ofrece argumentos misóginos que, presuntamente, apoyan aquellos clichés masculinos que, de forma ancestral, insisten en la inconsistencia e inconstancia en los sentimientos y afectos de la mujer, que sería "genéticamente» inestable y caprichosa:

Why is it, when I am in Rome

I'd give an eye to be at home,

But when on native earth I be,

My soul is sick for Italy?

And why with you, my love, my lord,

Engordó de forma pasmosa,/ Por lo que dejó de escribir./ Ahorra tu dinero, cuando falsificas;/ Las jovencitas no se atiborran» (traducción propia).

44. HutcheOn, Linda (coord.). A Theory of Parody. London, Methuen, 1985, p. 54-55.

45. Ibíd, p. 75.

46. Hammil, Faye (coord.). Women, Celebrity, and Literary Culture between the Wars. Austin, The University of Texas Press, 2007, p. 28. 
Am I spectacularly bored,

Yet do you up and leave me - then

I scream to have you back again ${ }^{47}$.

En obediencia con la tradición artística masculina, la voz de «Pagean» celebra el esplendor de la naturaleza y una felicidad, que su soma y su psique rezuman, antes de confesar en su verso suelto la banal causa de su alegría: «For I have lost a pound!» ${ }^{48}$. Pero este desprecio de Parker hacia la mujer no siempre es mundano y trivial al detectar su volubilidad y su culto al cuerpo, sino que su feroz ataque irá in crescendo en otras composiciones. En «Women: A Hate Song», la autora brinda caricaturas grotescas e hieráticas, exageradas o calcadas, de solteras y casadas sin personalidad propia. Éstas no son el reflejo de lo que ellas son en realidad como seres humanos, sino de lo que deben fingir ser o la imagen de artificio que deben proyectar, según los hegemónicos cánones estéticos e ideológicos de los «alegres» años veinte en los Estados Unidos, fuertemente arraigados al capitalismo y al consumismo. La discordia y disociación de Parker con estos modelos femeninos es evidente desde los primeros versos: «I hate Women./ They get on my Nerves» ${ }^{49}$, que podrían articular una diatriba propia, en primera persona; o ser ella misma tan solo la ventrílocua de voces masculinas a las que apoyaría: «They are pests./ They know everything on earth/ And will tell you about it gladly ${ }^{50}$. Por culpa del conflicto que crean entre iconografía e identidad femenina, Angela Weaver sostiene que la autora odió la representación genérica de las mujeres en la cultura periodística de la publicidad y las revistas de moda de aquel entonces, porque éstas dibujaban una falsa felicidad en sus rostros ${ }^{51}$. Ella misma trabajó en algunas de estas publicaciones, con el deber tácito de reverenciar los ideales domésticos de dicha conyugal y abnegación femenina, a pesar de su deseo de pisotear al déspota -el hombre- y a la víctima -su aliada, la esposa sumisa-. No obstante, sí logró materializar esta última pulsión estética en poemas cómicos, aunque cargados de violencia feminicida y caracterizados

47. PARKer, Dorothy. Op. cit., p. 124. «¿Por qué cuando estoy en Roma/ Daría lo que fuera por estar en casa,/ Pero cuando me encuentro en mi tierra,/ Mi alma añora Italia?/ $\mathrm{Y}$, ¿̇por qué contigo, mi amor, mi señor,/ Me aburro soberanamente,/ Pero entonces cuando tú te marchas-/ Grito para que regreses a mí de nuevo?» (traducción propia).

48. Ibíd., p. 333. «¡Porque he perdido una libra de peso! (traducción propia).

49. Ibíd., p. 207. «Odio a las mujeres. Me atacan los nervios» (traducción propia).

50. Ibíd., p. 208. «Ellas son una pesadas./ Saben todo de este mundo/ Y te lo dirán con gusto» (traducción propia).

51. WeAVER, Angela. «'Such a Congenial Little Circle': Dorothy Parker and the Early-Twentieth-Century Magazine Market». WSQ: Women's Studies Quarterly 38, 3 \& 4 (2010), pp. 33-34, p. 35. 
por su deliberado distanciamiento de paradigmas de género, sin importarle en apariencia la perpetuación de patrones misóginos de sometimiento de la mujer. En «Rosemary», la diana de su burla serían las técnicas de cortejo masculino y su lenguaje amoroso. La autora se travestiría en hombre para satirizar las expectativas románticas de la poesía y de la amada con la glorificación de su belleza, que solo sería un artificio con palabras huecas y embusteras:

I wear your fragant memory, like a spray of mignonette,

As I tread the winding ribbon of the years.

How clear the radiant image of your stands before me yet

In the thousand little mirrors of my tears.

And ah, my dearest love, when I forget the way to dream

I'll forget your silent nearness in the dark,

Where languorous lilies floated on a quiet woodland stream

Or were you the one I'd meet in Central Park ?52. $^{2}$.

Sin embargo, no será hasta el clímax humorístico del final cuando el lector perciba que estos versos no simbolizan una oda al amor, con imágenes sensoriales, ensoñación y profusión floral a la antigua usanza, sino que verbalizan la charlatanería sarcástica y alambicada de quien se ríe del sujeto, el objeto y el producto poético: «Your name is ever written on the pages of my heart, -l And, by the way, my dear, what was your name? $\aleph^{53}$. La parodia residiría en la convivencia en el mismo texto de la crítica velada a la seducción del hombre con fines sexuales y la ridiculización de la mujer, con el deseo de la autora de obtener la complicidad de una audiencia masculina. Pero esta ilustración de cómo el amante no se interesa por quien es o cómo se llama la amada no es más que el avant-gôut del feroz insulto y la humillación a la destinataria de los versos en «Sonnet [1]», donde Parker vuelve a demostrar la importancia del peso corporal para el público femenino:

As roses' passionate hearts, your mouth is red;

Like lilies in the wind, your long white hands.

Brighter the glance of you than summer star;

But, lady fair, how awful thick you are! $!^{54}$.

52. PARKER, Dorothy. Op. cit., p. 345. «Llevo impregnada tu memoria embriagadora, como un espray de reseda,/ Mientras piso el ondulado lazo de los años./ ¡Qué clara se posa tu radiante imagen delante de mis ojos!/ En los miles de espejitos de mis lágrimas./Y, ¡ah!, mi amor, cuando olvide cómo soñar/ Olvidaré tu silente proximidad en la oscuridad,/ Allí donde lánguidos nenúfares flotaban en un tranquilo arroyo del bosque / O ¿eres tú con quien me toparía en Central Park?» (traducción propia).

53. Ibidem. «Tu nombre está escrito en las páginas de mi corazón,-/Y, a propósito, encanto, ¿cuál era tu nombre?» (traducción propia).

54. Ibíd., p. 316. «Como los apasionados corazones de las rosas, tu boca es encarnada; Como los lirios al viento, tus largas manos son blancas./ Más brillante es una mirada 
Regina Barreca afirma que la escritora utiliza el humor para reclamar algún tipo de control y poder sobre su propia vida ${ }^{55}$. Enemistad, celos o venganza, estos versos que exaltan la lozanía del objeto poético para finalizar con una coda cómica mediante la cual se mofa de su gordura, podrían no ser ataques contra genéricos modelos femeninos promovidos en las revistas de moda, sino contra personas de carne y hueso, e identificables al pertenecer al círculo social de la autora. Más flagrante sería el humor cáustico que Dorothy Parker exhibe en «To Myrtilla, on Easter Day», donde describe la exposición pública de una grácil y perfecta dama de la alta sociedad antes de concluir «I hope she breaks her neck! » ${ }^{56}$. De igual manera, el epílogo de «To a Lady» detecta sus ansias de ver sufrir, o incluso perecer, a otra mujer porque es enemiga o antagónica: «Not a man you meet that doesn't fall for you;/ Lady, pretty lady, how I hope you choke! $\aleph^{57}$. En estas dos composiciones, se revelaría que la voz poética podría ser la de la propia escritora o, al menos, una genuinamente femenina que no experimentaría las permutaciones de género masculino observadas en otras, como «Rosemary»o «Sonnet [1]». El germen de su táctica literaria de desvinculación podría ser la rivalidad o la envidia hacia otras mujeres dibujadas en sus versos. Éstas, quizás, serían más bellas y modélicas que ella, pero siempre resultarían ser las ganadoras, porque sí se convertirían en las amadas a largo plazo o las esposas de los hombres que rompen el corazón de la graciosa -pero derrotada- Dorothy, la desprecian y, al final, la abandonan por otra. Cerrando el círculo narrativo de su poesía y bajo tupidas capas de comicidad, esta estrofa de «Frustration» vuelve a reflejar su ira y sus instintos homicidas con intensidad autobiográfica:

If I had a shiny gun

I could have a world of fun

Speeding bullets through the brains

Of the folk who give me pains ${ }^{58}$.

Mientras que el espejo del rencor en su arte es la confesión, aderezada de humor o no, en su vida real es, en cambio, el daño hacia sí misma -un largo

tuya que una estrella estival;/ Pero, bella dama, iqué terriblemente gorda estás!» (traducción propia).

55. BARRECA, Regina (coord.). Untamed and Unabashed: Essays on Women and Humor in British Literature. Detroit, Wayne State University Press, 1994, p. 12.

56. PARKER, Dorothy. Op. cit., p. 292. «iEspero que se rompa el cuello!» (traducción propia).

57. Ibíd., p. 317. «No hay ningún hombre que conozcas que no caiga rendido a tus pies;/ Dama, bella dama, ¡espero que te caigas de bruces!» (traducción propia).

58. Ibíd., p. 132. «Si tuviera una pistola brillante/ Tendría un mundo lleno de diversión/ Las balas atravesarían los sesos/ De la gente que me hace daño» (traducción propia). 
calvario del alcohol y raptos suicidas-, no el ajuste de cuentas contra la o el causante de tanto daño psíquico.

\section{Conclusión: quien ríe la última..., ríe mejor}

Dorothy Parker personifica el drama del artista que se dedica a entretener y hacer reír al público, siendo su profesión el garante de su mueca sardónica en el texto, pero no de que realmente se divierta en su vida y con su obra. El humor es el elixir de sus epigramas y codas, pero igualmente un arma de doble filo. Por un lado, es un ilimitado recurso que avala la modernidad de su corpus lírico, porque su verso suelto cómico actúa como una reflexión perspicaz, afilada y crítica, con mensajes francos que esclarecen la ambigua argumentación narrativa de sus tristes estrofas. Pero por otro, es limitador al teñir a sus poemas de tintes autobiográficos, ya que estos se transforman en números circenses, o vodevil melodramático de desamor, angustia y deseos de muerte emulando a su propia experiencia personal. La autora tuvo que pagar un alto precio por ser una chica «alegre» con escándalos sentimentales plasmados en los tabloides y que ansiaba «divertirse» con el uso del «informal» verso cómico, porque el Establishment académico de su época la condenó al estatus de figura menor de las letras estadounidenses, asociada solo a su aura de starlette sofisticada y frívola del panorama mediático de Nueva York en los míticos años veinte, no a sus méritos literarios. Sin embargo, su talento reside, primero, en su vanguardismo solvente al despreciar o parodiar antiquísimos convencionalismos estéticos del amor romántico, el silencio de la mujer, su victimismo y seriedad sin derecho a la carcajada. Y segundo, se sostiene en la atemporalidad y pluralidad interpretativa de sus poemas, regados por el equívoco de sus estrategias líricas. Principalmente, destacan dos de las cuales han sido identificadas y exploradas a lo largo de este artículo. Por un lado, el alejamiento emocional en el retrato de paradigmas femeninos -reales, abstractos o fabricados por una manufactura patriarcal-, porque los aborrece. Y por otro, la profunda introspección psicológica, ya que sus composiciones dramatizan los vaivenes de su propia vida, rebosante de luces y sombras: entre la desdicha y las ganas de amar y ser amada, distraer y distraerse.

El poder de las poetisas-humoristas es que son ellas las que «siempre ríen las últimas $»^{59}$. Tras su larga espera, así como la de sus antecesoras -tanto conocidas como olvidadas-, Dorothy Parker sí rió en vida al acceder a un humor propio, que igualmente (des)cubre injusticias de género y dramas

59. Darlington, Tenaya. «Funny Grrls: Humor and Contemporary Women Poets». Humor 22, 3 (2009), p. 340. 
sentimentales. Y, a pesar de las trabas del Establishment patriarcal y la tradición estética de la obligatoria ausencia de «gracia» en la literatura femenina, la autora ríe todavía hoy en día, porque ha conseguido arañar la inmortalidad artística, asociada a unas coordenadas espaciotemporales concretas: Nueva York durante los años veinte. Como muestra de su triunfo en «Inventory», que podría ser su propio epitafio, la mujer moderna abandona, por fin, su (in) deseado pedestal de objeto del poema -ideal, musa y modelo- para llegar a ser sujeto soberano del mismo, que vence a los traumas, los enemigos y a las malas experiencias del pasado, gracias a su sabiduría, ingenio hilarante y a una sana frivolidad femenina:

Four be the things I am wiser to know:

Idleness, sorrow, a friend, and a foe.

Four be the things I'd been better without:

Love, curiosity, freckles, and doubt.

Three be the things I shall never attain:

Envy, content, and sufficient champagne.

Three be the things I shall have till I die:

Laughter and hope and a sock in the eye ${ }^{60}$.

La mirada retrospectiva de Dorothy Parker en estos últimos versos resume, a modo de epílogo, el leitmotiv de su experiencia tragicómica, con autoridad legítima para su reconversión literaria en autobiografía y observación sociológica de género en su país y su tiempo: la prevalencia de la diversión espumosa en su propia vida, y el poder de autoconocimiento, superación y creatividad que emana de la risa y la burla, incluso hacia sí misma y sus miserias, sin caer en el desaliento, la inactividad o el hastío.

\section{Referencias bibliográficas}

BARRECA, Regina (coord.). Untamed and Unabashed: Essays on Women and Humor in British Literature. Detroit, Wayne State University Press, 1994.

DARLINGTON, Tenaya. «Funny Grrls: Humor and Contemporary Women Poets». Humor 22, 3 (2009), pp. 329-340.

DURÁN GIMÉNEZ-RICO, Isabel. «La Estrategia del 'Otro' en la Autobiografía Femenina Americana del Siglo XX». Revista Española de Estudios Norteamericanos 14, 5 (1992), pp. 36-47.

60. PARKER, Dorothy. Op. cit., p. 44. "Que sean cuatro las cosas que deba saber para ser más sabia:/ Vaguería, pena, un amigo y un enemigo./ Que sean cuatro las cosas que prefiera no tener:/ Amor, curiosidad, pecas y dudas./ Que sean tres las cosas que nunca obtenga:/ Envidia, conformidad y suficiente champán./ Que sean tres las cosas que posea hasta la muerte:/ Risa, esperanza y un golpe en el ojo» (traducción propia). 
GAINES, James R. (coord.). Wit's End: Days and Nights of the Algonquin Round Table. New York, Harcourt Brace Jovanovich, 1977.

HammiL, Faye (coord.). Women, Celebrity, and Literary Culture between the Wars. Austin, The University of Texas Press, 2007.

HutCheOn, Linda (coord.). A Theory of Parody. London, Methuen, 1985.

LEVY, Barbara (coord.). Ladies Laughing: Wit as Control in Contemporary American Women Writers. London \& New York, Routledge, 1997.

MeAdE, Marion. «Introduction». Complete Poems of Dorothy Parker. London, Penguin, 2010.

Miller, Nina. «Making Love Modern: Dorothy Parker and Her Public», en Rhonda S. Pettit (dir.): The Critical Waltz: Essays on the Work of Dorothy Parker, Cranbury, Rosemont Publishing, 2005, p. 44-61.

MitCHELl, Rebecca. «Dorothy Parker and Ambrose Bierce: A Sardonic Tradition». The ABP Journal 2, 1 (2006), <http://www.ambrosebierce.org/journal2mitchell. html>, consultado el 23-05-2014.

PARKer, Dorothy. Complete Poems. London, Penguin, 2010.

PETTIT, Rhonda S. (coord.). A Gendered Collision: Sentimentality and Modernism in Dorothy Parker's Poetry and Fiction. Cranbury, Farleigh Dickinson University Press, 2000.

Tотн, Emily. «Dorothy Parker, Erica Jong, and New Feminist Humor», en Rhonda Pettit (dir.): The Critical Walz: Essays on the Work of Dorothy Parker, Cranbury, Rosemont Publishing, 2005, pp. 137-151.

WALKer, Nancy A. (coord.). What's so funny? Humor in American Culture. Wilmington, Scholarly Resources Inc., 1988.

Weaver, Angela. "Such a Congenial Little Circle': Dorothy Parker and the Early-Twentieth-Century Magazine Market». WSQ: Women's Studies Quarterly 38, $3 \& 4$ (2010), pp. 25-41. 



\section{RESEÑA BIO-BIBLIOGRÁFICA}

\section{A. Virginia Acuña Ferreira}

Es Doctora en Filología Hispánica por la Universidad de Vigo desde 2007. En 2010 obtuvo el Premio Extraordinario de Doctorado por su actividad investigadora, que se ha centrado principalmente en el análisis de la conversación coloquial desde una perspectiva de género. Es autora de los libros Género y discurso. Las mujeres y los hombres en la interacción conversacional (Lincom 2009) y La realización de quejas en la conversación femenina y masculina (Lincom 2011). Ha publicado artículos en revistas nacionales e internacionales de Sociolingüística y Análisis del discurso sobre las identidades de género, las narrativas conversacionales, el humor, el cotilleo y las alternancias de código gallego/español en la conversación. Actualmente trabaja como profesora interina en la Universidad de Vigo.

\section{Laura M. Aliaga Aguza}

Es doctoranda de la Universidad de Alicante en el área de Lengua Española. En un principio centró su investigación en aspectos de fraseología española, concretamente en enunciados de valor específico, presentando el DEA bajo el título Una aproximación a los enunciados de valor específico en español en junio de 2010, tutelado por la doctora Leonor Ruiz Gurillo. A continuación, su investigación se ha centrado en aspectos relacionados con el humor. Actualmente, realiza la tesis titulada Análisis lingüístico del humor: aplicaciones a la clase de español como lengua extranjera, bajo la tutela de las doctoras Leonor Ruiz Gurillo y M. ${ }^{a}$ Belén Alvarado Ortega. Forma parte del grupo GRIALE (grupo de investigación sobre la ironía y el humor en español), coordinado por Leonor Ruiz Gurillo. 


\section{María Belén Alvarado Ortega}

Es Doctora en Lengua Española y Profesora Titular del Área de Lengua Española de la Universidad de Alicante. Ha trabajado como profesora visitante en la Universidad de Rutgers (EEUU), Cork (Irlanda), Roethampton (Reino Unido), París III (Francia), Lisboa (Portugal), Viterbo (Italia) y Bruselas (Bélgica). María Belén Alvarado Ortega imparte «Español del Turismo» en el Máster de Español e Inglés para fines específicos que oferta el IULMA. Además, trabaja en el grupo de investigación GRIALE, que cuenta con numerosas publicaciones entre las que se encuentra L.Ruiz/X.Padilla (eds.) (2009): Dime cómo ironizas y te diré quién eres: una aproximación pragmática a la ironía. Frankfurt, Peter Lang, trabajo que pretende convertirse en un manual sobre la ironía en español. Asimismo, ha publicado junto a Leonor Ruiz Gurillo (eds.) (2013): Irony and Humor: From Pragmatics to Discourse. Amsterdam, John Benjamins.

\section{Amaia Alvarez Uria}

Es profesora del departamento de Didáctica de la Lengua y la Literatura en la Escuela de Magisterio de Vitoria-Gasteiz de la Universidad del País Vasco. Desde 2011 es doctora en literatura con la tesis Genero eta nazio identitateak Katalina Eleizegiren antzezlanetan (Identidades de género y nación en las obras teatrales de Katalina Eleizegi). Suele impartir cursos monográficos y talleres sobre el uso no sexista del euskera y sobre teatro para la infancia. Es una de las integrantes del grupo feminista-literario Sareinak (Las rederas) -sareinak.nety crítica literaria de la revista Argia. Sus líneas de investigación son la perspectiva de género en la literatura vasca y el análisis multimodal del discurso.

\section{Francisco José Cortés Vieco}

Es Profesor Asociado de Literatura Inglesa y Norteamericana en la Universidad Complutense de Madrid (UCM), y ha sido Profesor Asociado de Inglés en la Universidad Autónoma de Madrid. Es Doctor en Estudios Literarios (UCM), tiene el Máster en Estudios Literarios (UCM), realizó una estancia en la Universidad de Oxford, y es licenciado en Filología Inglesa (UNED). Asimismo, es miembro del Grupo de Investigación «Estudios de la Mujer en el ámbito de los países de habla inglesa» (UCM), y su publicación más reciente sobre poesía femenina lleva por título: El romancero de Emily Brontë: Antología épica y lírica (Sevilla, Arcibel, 2014). 


\section{Mohamed El-Madkouri Maataoui}

Es profesor titular de Universidad, especialista en Lingüística Aplicada a la Traducción y Traductología, traductor Jurado y autor de varias investigaciones sobre Traductología y Análisis Crítico del Discurso.

\section{Ana Mancera Rueda}

Es profesora en el Departamento de Lengua Española de la Universidad de Sevilla, donde desarrolla sus investigaciones sobre el español coloquial, el lenguaje de los medios de comunicación y el discurso mediado por ordenador. Es autora de las siguientes monografías: 'Oralización' de la prensa española: la columna periodística (Peter Lang, 2009), Una aproximación al estudio de los marcadores discursivos en textos periodísticos españoles (Proquest, 2009), ¿Cómo se "habla» en los cibermedios? (Peter Lang, 2011), El discurso político en Twitter (Anthropos, 2013) y El español coloquial en las redes sociales (Arco/ Libros, 2014) -estas dos últimas en coautoría con Ana Pano Alamán-.

\section{José Joaquín Martínez Egido}

Es Profesor titular del Área de Lengua Española del Departamento de Filología Española de la Universidad de Alicante, en donde desarrolla su labor docente en diferentes asignaturas de grado y de másteres (Máster en Inglés y español para fines específicos y empresariales y Máster en español e inglés como L2/LE. Su labor investigadora abarca el análisis y el estudio del léxico desde la perspectiva diacrónica del español y los lenguajes de especialidad en su vertiente de enseñanza y de aprendizaje de ELE. Es miembro del IULMA y de AELex y de los grupos de investigación GRIALE, EPA-IULMA, de la Universidad de Alicante y de LiCEI, de la Universidad de Bolonia.

\section{Meritxell Maza Farran}

És llicenciada en Filologia Catalana per la Universitat de Lleida i Màster de Recerca en Didàctica de la Llengua i la Literatura per la Universitat de Barcelona.

Actualment està finalitzant la seva tesi doctoral que gira a l'entorn de la funció de les reformulacions en la gestió de l'humor que es produeix a l'aula i que s'emmarca dins el mètode etnogràfic. Des de l'any 2012 col-labora amb el grup de recerca consolidat Plurilingüismes Escolars i Aprenentatge de Llengües (PLURAL) de la Universitat de Barcelona, coordinat pel Dr. Juli Palou Sangrà i des de l'any 2008 és professora de català en un Institut de secundària del Vallès Oriental. 


\section{G. Angela Mura}

Es profesora de Lengua Italiana en el Centro Superior de Idiomas de la Universidad de Alicante. Es Doctora en Lengua Española por la Universidad Complutense de Madrid, Máster en Enseñanza de Español e Inglés como Segundas Lenguas/Lenguas Extranjeras por la Universidad de Alicante y Licenciada en Lingue e Letterature Straniere por la Università degli Studi di Sassari (Italia).

Su línea de investigación principal es la fraseología del español -en clave contrastiva español/italiano- y se extiende a otros ámbitos como la enseñanza de las unidades fraseológicas en clase de lengua extranjera y el lenguaje juvenil.

Forma parte del grupo de investigación GRIALE (Grupo de Investigación para la Pragmática y la Ironía del Español), dirigido por la Dra. Leonor Ruiz Gurillo; es miembro del Proyecto COLA (Corpus Oral de Lenguaje Adolescente) de la Universidad de Bergen, coordinado por la Dra. Annette Myre Jørgensen; y colabora con el grupo de investigación FRASYTRAM (Fraseología y Traducción Multilingüe) de la Universidad de Alicante, dirigido por el Dr. Pedro Mogorrón Huerta.

\section{Raquel (Lucas) Platero}

Es doctor en Sociología, docente universitario y en intervención socio-comunitaria, es miembro de la Cátedra de Género de la URJC. También ejerce la docencia en el Programa de Estudios Avanzados del Museo Nacional Centro de Arte Reina Sofía, en el programa del Centro de Estudios Somateca, dirigido por Beatriz Preciado. En la actualidad está realizando una residencia de investigación sobre el Archivo Queer en el Museo Nacional Centro de Arte Reina Sofía y forma parte del i+d «Colectivos en los márgenes: su exclusión por el derecho en tiempos de crisis» (2013-2015), dirigido por Patricia Laurenzo Copello de la Universidad de Málaga. En 2014 ha publicado el libro Trans*exualidades. Acompañamiento, factores de salud y recursos educativos (Ed. Bellaterra).

\section{Magdalena Romera}

Es Profesora Titular de Universidad de Lengua Española en la Universitat de les Illes Balears. Se doctoró en Lingüística por la Universidad del Sur de California en Los Ángeles (USA), con una tesis sobre las Unidades Funcionales del discurso. Sus áreas de investigación son el Análisis del discurso, la Sociolinguistica y todos los aspectos relativos a la identidad de género a través de la interacción. Ha publicado en revistas nacionales e internacionales como 
Oralia, Linguistics o International Journal of the Sociology of Language. En este momento se encuentra de Profesora Visitante en la Universidad Pública de Navarra.

\section{María Rosón}

Es doctora en Historia del Arte por la Universidad Autónoma de Madrid. Forma parte del grupo de investigación «Estudios de cultura visual contemporánea» y es investigadora del Proyecto I+D «La historia del arte en España: devenir, discursos y propuestas» (HAR 2012-32609). Ha desarrollado estancias de investigación en University of Southampton, New York University, University of Oxford y Leeds University. Además, ha comisariado la exposición «José Ortiz Echagüe: representando mujeres, tipos y estereotipos» (2010, CAM, Red Itiner) y ha co-comisariado junto a Raquel Osborne la exposición «Mujeres bajo sospecha» (2013, UNED). Sus líneas de investigación se centran en la cultura visual, principalmente del siglo XX español, en los estudios de género y construcción de la historia, la memoria cultural e imaginario visual.

\section{Leonor Ruiz Gurillo}

Es catedrática de Lengua Española en la Universidad de Alicante. Ha centrado su investigación en diversos temas de fraseología española, español coloquial, pragmática, ironía y humor. Miembro fundacional del grupo Val.Es.Co. y directora del grupo GRIALE que se encarga del análisis pragmático de la ironía y el humor y de su aplicación didáctica a la enseñanza del español como lengua extranjera Cuenta con más de 100 publicaciones, de las que destacan sus libros Hechos pragmáticos del español (Alicante, Universidad, 2006) y La lingüistica del humor en español (Madrid, Arco/Libros, 2012). Es coeditora de los volúmenes Dime cómo ironizas y te diré quién eres: una aproximación pragmática a la ironía (Frankfurt, Peter Lang, 2009), Irony and Humor: From Pragmatics to Discourse (Ámsterdam, John Benjamins, 2013) y Humor, ironía $y$ géneros textuales (Alicante, Universidad, 2013). Prepara como editora el volumen Metapragmatics of Humor: Current Research Trends (Ámsterdam, John Benjamins, 2016).

\section{Larissa Timofeeva}

Es Licenciada en Filología Hispánica y Doctora en Lingüística por la Universitat d'Alacant. En la actualidad, es profesora de Lingüística en el Departamento de Filología Española de la misma universidad. Sus intereses investigadores giran en torno a la fraseología, la pragmática, los estudios de la ironía y el 
humor, la lingüística aplicada. Es autora de Acerca de los aspectos traductológicos de la fraseología española (UA, 2008), El significado fraseológico. En torno a un modelo explicativo y aplicado (Liceus, 2012), coautora de Un pollastre amb quatre potes (Bromera, 2004), ¿Estás de broma? 20 actividades para practicar la ironía en clase de ELE (Edinumen, 2011). Sus artículos han aparecido en revistas como ELUA, RLA, Onomázein, CFG y otras. 
La revista Feminismo/s se publica semestralmente. Está abierta a las aportaciones del personal investigador que compone el Instituto Universitario de Estudios de Género de la Universidad de Alicante, así como a toda la comunidad académica. La organización editorial se realiza a través de números monográficos, estando prevista en su caso, la publicación de algunos números en los que se presente una miscelánea de artículos. El carácter de la publicación, al igual que la del Instituto Universitario de Estudios de Género, es multidisciplinar.

\section{NORMAS EDITORIALES DE LA REVISTA FEMINISMO/S}

1. Los trabajos, que necesariamente deberán ser producto de investigación original, se presentarán en soporte magnético utilizando el procesador de textos Word, y además impresos en la forma habitual.

2. Los artículos serán redactados con letra Times New Roman de 12 puntos y con un interlineado de un espacio y medio.

3. El título del artículo irá centrado y en letra mayúscula de 12 puntos. El nombre del autor del trabajo se pondrá unas líneas debajo del título, a la derecha, en letra de 10 puntos y mayúscula. Justo debajo se escribirá el nombre de la Universidad o, en su defecto, la ciudad a la que el autor/a pertenece, en letra minúscula de 10 puntos.

Un ejemplo sería:

SEXISMO Y VIOLENCIA: LA SOCIALIZACIÓN A TRAVÉS DE LOS VIDEOJUEGOS

ENRIQUE J. DÍEZ GUTIÉRREZ

Universidad de León 
4. La extensión de los artículos será entre 15 y 18 páginas.

5. La primera línea de cada párrafo irá sangrada.

6. Las citas en el texto con una extensión superior a tres líneas irán sangradas, sin entrecomillar y en letra de 10 puntos. Las citas de menor extensión se integrarán en el texto, entrecomilladas y con letra de 12 puntos.

7. Los títulos de libros y de revistas citados irán en letra cursiva. Los títulos de artículos o capítulos de libros se consignarán entre comillas.

8. Las notas serán a pie de página, con letra de 10 puntos e interlineado sencillo.

9. Las referencias bibliográficas se harán siempre en nota a pie de página y no en el texto. El modelo para las citas de libros será el siguiente:

ARRÁEZ, José Luis (coord.). No te di mis ojos, me los arrebataste. Ensayo sobre la discriminación, misoginia y violencia contra las mujeres desde la literatura. Alicante, Colección Lilith, 2010.

10. Las citas de artículos o capítulos de libros se realizarán según el siguiente modelo:

GoRDANO, Cecilia. "Construyendo sentido sobre internet en el espacio de la diáspora: mujeres latinas inmigrantes en Granada». Feminismo/s 14 (2009), pp. 143-162.

CRAMPE-CASNABET, Michelle: «Las mujeres en las obras filosóficas del siglo XVIII», en Georges Duby y Michelle Perrot (dirs.): Historia de las Mujeres, vol. 3, Madrid, Taurus, 2000, pp. 344-384.

11. Si una obra ya ha sido citada con anterioridad, en la referencia bibliográfica se omitirá el título y se citará de la siguiente manera:

Berenguer, Elisa. Op.cit., p. 345.

Si se citan a lo largo del trabajo diferentes obras de un/a mismo/a autor/a, se identificará el título del trabajo al que se hace referencia en cada ocasión:

BERENGUER, Elisa. La investigación feminista... Op.cit., p. 345.

Si se cita varias veces seguidas la misma obra, se omitirán el título y el nombre del/de la autor/a y se seguirá el siguiente modelo de citación:

BERENGUER, Elisa. La investigación feminista... Op.cit., p. 345.

Ibíd., p. 22.

Ibíd., p. 35.

Para citar mismo autor/a, misma obra, misma página: Ibidem. 
12. Las webs se citarán de acuerdo con el siguiente modelo:

<http://www.cis.es/cis/opencms/ES/2_barometros>, consultado el 19-06-2008.

13. Los diferentes apartados del texto se ordenarán siguiendo la numeración arábiga $(1,2,3, \ldots)$ y el título de cada uno de ellos irá en letra minúscula y en negrita. Los subapartados se numerarán de la siguiente manera: 1.1, $1.2,1.3$, etc. y sus títulos irán en minúscula y en cursiva.

14. Al final de cada texto se incluirán unas «Referencias bibliográficas». El sangrado de la bibliografía irá en Francesa.

15. Los artículos irán acompañados de un resumen de 10 líneas en español y en inglés, de unas palabras clave en español y en inglés, así como de un breve currículum del autor/ de la autora (8 líneas).

16. Las fotografías e imágenes deben entregarse en formato digital, separadas del texto, en formato tif, con una calidad de 300 puntos por pulgada. Deben ir identificadas convenientemente según sean citadas en el texto.

17. Todos los trabajos serán sometidos a informes anónimos de especialistas de reconocido prestigio externos al Consejo Editorial y a la Universidad de Alicante. Los informes son la base de la toma de decisiones sobre la publicación de los artículos, que corresponde en última instancia al Consejo Editorial.

18. Se ruega acompañar los originales con la dirección postal de la autora o autor, así como su correo electrónico.

19. Los trabajos no aceptados para su publicación serán devueltos a petición de la autora o autor.

Remitir los trabajos a:

Redacción de Feminismo/s

Instituto Universitario de Estudios de Género

Universidad de Alicante

Apdo. 99 - 03080 Alicante

e-mail: revistafeminismos@ua.es; iuieg@ua.es 

La revista Feminismo/s es publica semestralment. Està oberta a les aportacions del personal investigador que compon el Institut Universitari d'Investigació d'Estudis de Gènere de la Universitat d'Alacant, i també a tota la comunitat acadèmica. L'organització editorial es porta a terme a través de números monogràfics, i també està prevista, si és el cas, la publicació d'alguns números en què es presenta una miscel-lània d'articles. El caràcter de la publicació, igual que la del Institut Universitari d'Investigació d'Estudis de Gènere, és multidisciplinari.

\section{NORMES EDITORIALS DE LA REVISTA FEMINISMO/S}

1. Els treballs, que necessàriament hauran de ser producte d'investigació original, es presentaran en suport magnètic utilitzant el processador de textos Word i, a més, impresos en la forma habitual.

2. Els articles seran redactats amb lletra Times New Roman de 12 punts i amb un interlineat d'un espai i mig.

3. El títol de l'article estarà centrat i en lletra majúscula de 12 punts. El nom de l'autor del treball es posarà unes quantes línies davall del títol, a la dreta, en lletra de 10 punts i majúscula. Justament a sota s'escriurà el nom de la Universitat o, en defecte d'això, la ciutat a la qual pertany l'autor/a, en lletra minúscula de 10 punts.

Un exemple seria:

SEXISMO Y VIOLENCIA: LA SOCIALIZACIÓN A TRAVÉS DE LOS VIDEOJUEGOS

ENRIQUE J. DÍEZ GUTIÉRREZ Universidad de León 
4. L'extensió dels articles serà entre 15 i 18 pàgines.

5. La primera línia de cada paràgraf estarà sagnada.

6. Les citacions en el text amb una extensió superior a tres línies estaran sagnades, sense posar entre cometes, i en lletra de 10 punts. Les citacions de menys extensió s'integraran en el text, entre cometes i amb lletra de 12 punts.

7. Els títols de llibres i de revistes esmentats estaran en lletra cursiva. Els títols d'articles o capítols de llibres es consignaran entre cometes.

8. Les notes seran a peu de pàgina, amb lletra de 10 punts i interlineat senzill.

9. Les referències bibliogràfiques es faran sempre en nota a peu de pàgina i no en el text. El model per a les citacions de llibres serà el següent:

ARRÁEZ, José Luis (coord.). No te di mis ojos, me los arrebataste. Ensayo sobre la discriminación, misoginia y violencia contra las mujeres desde la literatura. Alicante, Colección Lilith, 2010.

10. Les citacions d'articles o capítols de llibres es faran segons el model següent:

GORDANO, Cecilia. «Construyendo sentido sobre internet en el espacio de la diáspora: mujeres latinas inmigrantes en Granada». Feminismo/s 14 (2009), pp. 143-162.

CRAMPE-CASNABET, Michelle: «Las mujeres en las obras filosóficas del siglo XVIII», en Georges Duby y Michelle Perrot (dirs.): Historia de las Mujeres, vol. 3, Madrid, Taurus, 2000, pp. 344-384.

11. Si una obra ja ha estat esmentada abans, en la referència bibliogràfica s'ometrà el títol i se citarà de la manera següent:

BERENGUER, Elisa. Op.cit., p. 345.

Si se citen al llarg del treball diferents obres d'un/a mateix/a autor/a, s'identificarà el títol del treball a què es fa referència en cada ocasió:

BERENGUER, Elisa. La investigación feminista... Op.cit., p. 345.

Si se citen diverses vegades seguides la mateixa obra, s'ometran el títol i el nom de l'autor o l'autora i se seguirà el següent model de citació:

BERENGUER, Elisa. La investigación feminista... Op.cit., p. 345.

Ibíd., p. 22.

Ibíd., p. 35.

Per a citar mateix autor/a, mateixa obra, mateixa pàgina: Ibidem. 
12. Les webs se citaran d'acord amb el model següent:

<http://www.cis.es/cis/opencms/ES/2_barometros/>, consultat el 19-06-2008.

13. Els diferents apartats del text s'ordenaran seguint la numeració aràbiga $(1,2,3, \ldots)$ i el títol de cada un d'aquests estarà en lletra minúscula i en negreta. Els subapartats es numeraran de la manera següent: 1.1, 1.2, 1.3, etc. i els seus títols estaran en minúscula i en cursiva.

14. Al final de cada text s'inclouran unes «Referències bibliogràfiques». El sagnat de la bibliografia serà en francesa.

15. Els articles estaran acompanyats d'un resum de 10 línies en espanyol i en anglès, d'unes paraules clau en espanyol i en anglès, i també d'un breu currículum de l'autor o 1 'autora (8 línies).

16. Les fotografies i imatges han de lliurar-se en format digital, separades del text, en format tif, amb una qualitat de 300 punts per polzada. Han d'estar identificades convenientment segons siguen esmentades en el text.

17. Tots el treballs seran sotmesos a informes anònims d'especialistes de reconegut prestigi externs al Consell Editorial i a la Universitat d 'Alacant. Els informes són la base de la presa de decisions sobre la publicació dels articles, que correspon en última instància al Consell Editorial.

18. Es demana acompanyar els originals amb l'adreça postal de l'autora o autor, i també la seua adreça electrònica.

19. Els treballs no acceptats per a publicar-los seran tornats a petició de l'autora o autor.

S'han de remetre els treballs a:

Redacció de Feminismo/s

Institut Universitari d'Investigació d'Estudis de Gènere

Universitat d'Alacant

Apt. 99 - 03080 Alacant

A/e: revistafeminismos@ua.es; iuieg@ua.es 

Feminismo/s is published on a biannual basis, and encourages contributions from researchers at the University Institute of gender studies research of the University of Alicante, as well as from the academic community as a whole. The journal is generally published in issues devoted to a single subject, although occasional issues containing articles on a range of subjects may also be published. Both the journal and the University Institute of gender studies research are multidisciplinary in nature.

\section{FEMINISMO/S: EDITORIAL POLICY AND GUIDELINES}

1. All works should be original, and should be submitted both on a CD-ROM or floppy disk containing a Microsoft Word file, and in printed form. The name of the file and its author should be written on the disk label.

2. Articles should be written in 12 point Times New Roman letter font and with 1.5 line spacing.

3. The title of the article should be centred on the page and written in 12 point upper-case letters. The name of the author should appear a few lines below the title and also on the right, in 10 point upper-case letters. The name of the university or city should come just below this and in 10 point lowercase letters.

See the following example:

SEXISMO Y VIOLENCIA: LA SOCIALIZACIÓN A TRAVÉS DE LOS VIDEOJUEGOS

ENRIQUE J. DÍEZ GUTIÉRREZ 
Universidad de León

4. Articles should be between 15 and 18 pages in length.

5. The first line of each paragraph should be indented.

6. Quotations in the text of over three lines in length should be indented, without quotation marks, and in 10 point letter size. Shorter quotations should be run on, in quotation marks, as part of the body of the text, and in 12 point letter size.

7. Titles of cited books and journals should be written in italics. Titles of articles and chapters of books should be enclosed in quotation marks.

8. Footnotes should appear at the bottom of the page, in 10 point letter size and with single line spacing.

9. Bibliographical references should always appear as footnotes and not in the body of the text. See the following model for citing books:

ArráEz, José Luis (coord.). No te di mis ojos, me los arrebataste. Ensayo sobre la discriminación, misoginia y violencia contra las mujeres desde la literatura. Alicante, Colección Lilith, 2010.

10. Articles and chapters of books should be cited as in the following example:

GORDANO, Cecilia. «Construyendo sentido sobre internet en el espacio de la diáspora: mujeres latinas inmigrantes en Granada». Feminismo/s 14 (2009), pp. 143-162.

CRAMPE-CASNABET, Michelle: «Las mujeres en las obras filosóficas del siglo XVIII», en Georges Duby y Michelle Perrot (dirs.): Historia de las Mujeres, vol. 3, Madrid, Taurus, 2000, pp. 344-384.

11) If a work has already been cited, its title is omitted in subsequent references, as follows:

BERENGUer, Elisa. Op.cit., p. 345.

If different works by the same author are cited, then the title should be given in each reference:

BERENGUER, Elisa. La investigación feminista... Op.cit., p. 345.

If the same work is cited several times in succession, both the title and author's name should be omitted and the following model adopted:

BERENGUER, Elisa. La investigación feminista... Op.cit., p. 345.

Ibíd., p. 22.

Ibíd., p. 35. 
To quote same autor, same work, same page: Ibidem.

12. Web references should be given as follows:

$<$ http://www.cis.es/cis/opencms/ES/2_barometros/>, consulted on 19-06-2008.

13. Different sections of the text should be ordered using Arabic numerals $(1,2,3$, etc.) and section headings should be written in lower-case letters and bold type. Sub-sections should be numbered as follows: 1.1, 1.2, 1.3, etc.; sub-section headings should be written in lower-case letters and italics.

14. A «Bibliographical references» section will appear at the end of each text. This should be indented in French style.

15. Articles should be accompanied by an abstract of about 10 lines in Spanish and English, with keywords in Spanish and English, and a short CV of the author (8 lines).

16. Photographs and graphic items should be submitted on a CD-ROM or floppy disk, separate from the text, in TIF format and with an image quality of 300 dots per inch. They should be clearly labelled according to their position in the text.

17. All contributions are evaluated anonymously by specialists of recognised prestige external to the Editorial Board and the University of Alicante. The reports sent in by these specialists form the basis for decisions concerning the publication of articles, which are ultimately made by the Editorial Board.

18. Contributions should be submitted with the author's postal and e-mail addresses.

19. Works not accepted for publication may be returned to the author on request.

Please send contributions to:

Redacción de Feminismo/s

Instituto Universitario de Estudios de Género

Universidad de Alicante

Apdo. 99 - 03080 Alicante

e-mail: revistafeminismos@ua.es; iuieg@ua.es 



\section{Números anteriores publicados}

Feminismo/s 1. Feminismo y multidisciplinariedad. Helena Establier (coord.)

Feminismo/s 2. Imagin/ando a la mujer. Pilar Amador Carretero (coord.) y Mónica Moreno Seco (ed.)

Feminismo/s 3. Mujer y participación política. Mónica Moreno Seco y Clarisa Ramos Feijóo (coords.)

Feminismo/s 4. Writing, memoirs, autobiography and history. Silvia Caporale Bizzini (coord.)

Feminismo/s 5. Habitar / escribir / conquistar el espacio. Teresa Gómez Reus (ed.)

Feminismo/s 6. Violencia estructural y directa: mujeres y visibilidad. Carmen Mañas Viejo (coord.)

Feminismo/s 7. Hèléne Cixous: Huellas de intertextos. Maribel Peñalver Vicea y Rosa María Rodríguez Magda (eds.)

Feminismo/s 8. Mujeres y derecho. Nieves Montesinos Sánchez y $\mathrm{M}^{\mathrm{a}}$ del Mar Esquembre Valdés (coords.). Nieves Montesinos Sánchez (ed.)

Feminismo/s 9. Género, conflicto y construcción de la paz. Reflexiones y propuestas. Eva Espinar Ruiz y Eloisa Nos Aldás (coords.)

Feminismo/s 10. Medicines i Gènere. El torsimany necessari. Elizabeth Mora Torres, Albert Gras i Martí (coords.)

Feminismo/s 11. La representación/presencia de la mujer en los Medios de Comunicación. Sonia Núñez Puente (coords.) y Helena Establier Pérez (ed.)

Feminismo/s 12. Mujeres en democracia. Nieves Montesinos Sánchez y $\mathrm{M}^{\mathrm{a}} \mathrm{del}$ Mar Esquembre Valdes (coords. y eds.)

Feminismo/s 13. Mujeres y diversidad funcional (discapacidad): construyendo un nuevo discurso. Carmen Mañas (coord.)

Feminismo/s 14. Género y nuevas tecnologías de la información y la comunicación. Eva Espinar Ruiz (Coord.)

Feminismo/s 15. ¿Feminismo de la igualdad y feminismo de la diferencia? Elena Nájera (Coord.)

Feminismo/s 16. Género e imagen del poder en la historia contemporánea. Mónica Moreno Seco y Alicia Mira Abad (Coords.) 
Feminismo/s 17. La arquitectura y el urbanismo con perspectiva de género. María Elia Gutiérrez Mozo (Coord.)

Feminismo/s 18. Salud pública desde la perspectiva de género: Hitos e innovación. María Teresa Ruiz Cantero (Coord.)

Feminismo/s 19. Mirada/s trans/identitarias. Ángel Amaro (Coord.)

Feminismo/s 20. La Diosa y el poder de las mujeres. Reflexiones sobre la espiritualidad femenina en el siglo XXI. Angie Simonis (Coord.)

Feminismo/s 21. Mujeres, actividad física, deporte y ocio. Juan Tortosa Martínez y Lilyan Vega Ramírez (Coords.)

Feminismo/s 22. Ecofeminismo/s: Mujeres y Naturaleza. Lorraine Kerslake y Terry Gifford (Coords.)

Feminismo/s 23. Todo sobre mi familia. Perspectivas de género. Adrián GrasVelázquez (Coord.) 



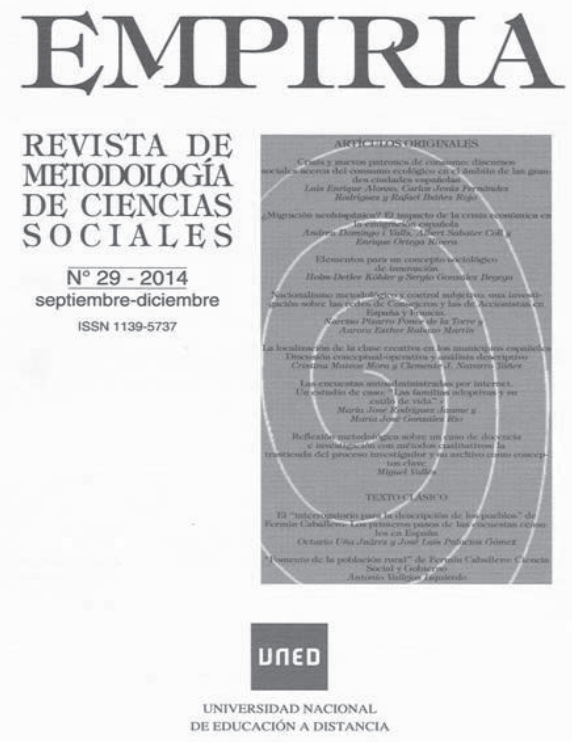

\section{REVISTA DE METODOLOGÍA DE CIENCIAS SOCIALES}

No $29-2014$

Septiembre-Diciembre

DIRECTOR: JOSÉ MARÍA ARRIBAS MACHO (UNED)

Consejo de redacción:

Alejandro Almazán, Luis Enrique Alonso, Michel Armatte, Michel Bourdeau, Javier Callejo, Luis Camarero, Ignacio Duque, Iñaki Garcia Borrego, Jesús Gutiérrez, Marie Jaisson, Carlos Lozares, Emilio M. Martínez, Jesús Oliva, Julio A. del Pino, Ted. Porter, Raquel Osborne, Miguel Requena,

Secretaría: Beatriz Mañas, Antonio Vallejos.

Secretaría Técnica: Lola Velázquez

Web http:// www.uned.es/dpto-sociologia-I/empiria/

Correo electrónico: empiria@poli.uned.es

Correo postal: Secretaría de la Revista EMPIRIA

Facultad de CC. PP. y Sociología, UNED.

Obispo Trejo, s/n.

28040, Madrid

\section{ARTÍCULOS ORIGINALES}

luis Enrique Alonso, Carlos Jesús fernández Rodríguez y Rafael ibáñez Rojo: Crisis y nuevos patrones de consumo: discursos sociales acerca del consumo ecológico en el ámbito de las grandes ciudades españolas.

Andreu Domingo i Valls; Albert Sabater Coll; enrique Ortega Rivera: ¿migración neohispánica? El impacto de la crisis económica en la emigración española

Holm-Detlev Köhler; Sergio González Begega: Elementos para un concepto sociológico de innovación

Narciso Pizarro ponce de la torre, Aurora esther Rabazo Martín: Nacionalismo metodológico y control subjetivo: una investigación sobre las redes de Consejeros y las de Accionistas en España y Francia.

Cristina Mateos Mora y Clemente J. Navarro Yáñez: la localización de la clase creativa en los municipios españoles Discusión conceptual-operativa y análisis descriptivo

María Jose Rodríguez Jaume y MARÍA José González Río: Las encuestas autoadministradas por internet. Un estudio de caso: "Las familias adoptivas y su estilo de vida"

Miguel Valles: Reflexión metodológica sobre un caso de docencia e investigación con métodos cualitativos: la trastienda del proceso investigador y su archivo como conceptos clave

\section{Texto Clásico:}

Octavio Uña JuÁRez y José Luis Palacios Gómez: El "interrogatorio para la descripción de los pueblos" de Fermín Caballero: Los primeros pasos de las encuestas censales en España Antonio Vallejos IzQuierdo: "Fomento de la población rural" de Fermín Caballero: Ciencia Social y Gobierno.

\section{LIBROS}

UNIVERSIDAD NACIONAL DE EDUCACIÓN A DISTANCIA - Madrid, 2014

Reservados los derechos y prohibida su reproducción total o parcial

ISSN: 1139-5737

Depósito legal: M. 31.469-1998

Impreso en España - Printed in Spain.

Versión electrónica/Electronic edition:

http://e-spacio.uned.es/revistasuned/index.php/empiria/

http://www.uned.es

Dialnet.unirioja.es

SUSCRIPCIONES: UNED, DIFUSIÓN Y VENTAS, C/ BRAVO MURILLO, 38(28015 MADRID-ESPAÑA)

FAX: 913987527

Precio suscripción:(4 números) 50 C IVA incluido.

(Números sueltos) $18 \mathrm{C}$ IVA Incluido. 
